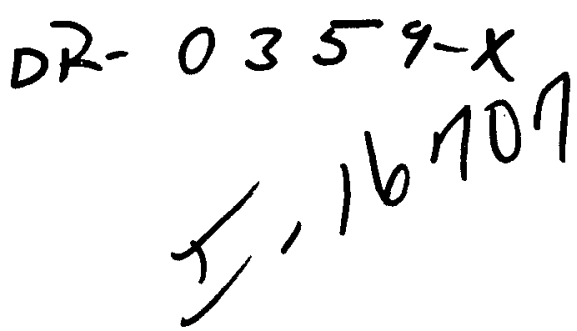

SAND84 - 7102

Unlimited Release

$\mathrm{UC}-66 \mathrm{c}$

\title{
Phase 1 User Instruction Manual \\ A Geological Formation - \\ Drill String Dynamic \\ Interaction Finite Element \\ Program (GEODYN)
}

Mark A. Tinianow, Richard L. Rotelli, Jr., Jerold A. Baird Jordan, Apostal, Ritter Associates, Inc.

Administration Building 7

Davisville, Rhode Island 02854

Prepared by Sandia National Laboratories Albuquerque, New Mexico 87185

and Livermore, California 94550 for the United States Department of Energy

under Contract DE-AC04-76DP00789

Printed June 1984

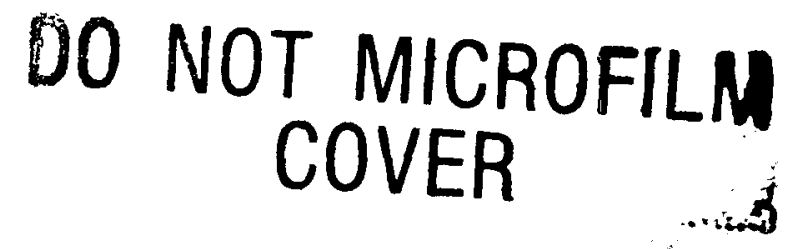




\section{DISCLAIMER}

This report was prepared as an account of work sponsored by an agency of the United States Government. Neither the United States Government nor any agency Thereof, nor any of their employees, makes any warranty, express or implied, or assumes any legal liability or responsibility for the accuracy, completeness, or usefulness of any information, apparatus, product, or process disclosed, or represents that its use would not infringe privately owned rights. Reference herein to any specific commercial product, process, or service by trade name, trademark, manufacturer, or otherwise does not necessarily constitute or imply its endorsement, recommendation, or favoring by the United States Government or any agency thereof. The views and opinions of authors expressed herein do not necessarily state or reflect those of the United States Government or any agency thereof. 


\section{DISCLAIMER}

Portions of this document may be illegible in electronic image products. Images are produced from the best available original document. 


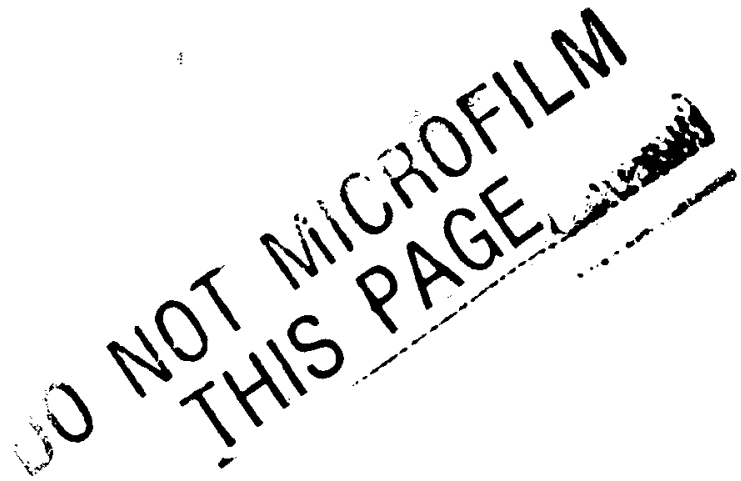

Issued by Sandia National Laboratories, operated for the United States Department of Energy by Sandia Corporation.

NOTICE: This report was prepared as an account of work sponsored by an agency of the United States Government. Neither the United States Govern ment nor any agency thereof, nor any of their employees, nor any of their contractors, subcontractors, or their employees, makes any warranty, express or implied, or assumes any legal liability or responsibility for the accuracy, completeness, or usefulness of any information, apparatus, prodtict, or process disclosed, or represents that its use would not infringe privately owned rights. Reference herein to any specific commercial product, process, or service by trade name, trademark, manufacturer, or otherwise, does not necessarily constitute or imply its endorsement, recommendation, or favoring by the United States Government, any agency thereof or any of their contractors or subcontractors. The views and opinions expressed here in do not necessarily state or reflect those of the United States Government, any agency thereof or any of their contractors or subcontractors.

Printed in the United States of America Available from

National Technical Information Service

U.S. Department of Commerce

5285 Port Royal Road

Springfield, VA 22161

NTIS price codes

Printed copy: A16

Microfiche copy: A01 


\title{
DISCLAIMER
}

This report was prepared as an account of work sponsored by an agency of the United States Government. Neither the United States Government nor any agency thereof, nor any of their employees, makes any warranty, express or implied, or assumes any legal liability or responsibility for the accuracy, completeness, or usefulness of any information, apparatus, product, or process disclosed, or represents that its use would not infringe privately owned rights. Reference herein to any specific commercial product, process, or service by trade name, trademark, manufacturer, or otherwise does not necessarily constitute or imply its endorsement, recommendation, or favoring by the United States Government or any agency thereof. The views and opinions of authors expressed herein do not necessarily state or reflect those of the United States Government or any agency thereof.

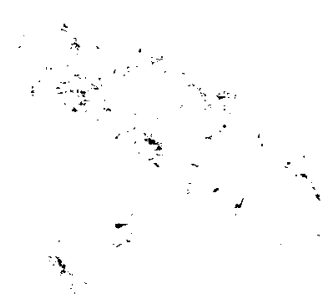

PHASE I USER INSTRUCTION MANUAL

A GEOLOGICAL FORMATION - DRILL STRING DYNAMIC

INTERACTION FINITE ELEMENT PROGRAM (GEODYN)

Sandia Laboratories Contract Number 68-3061

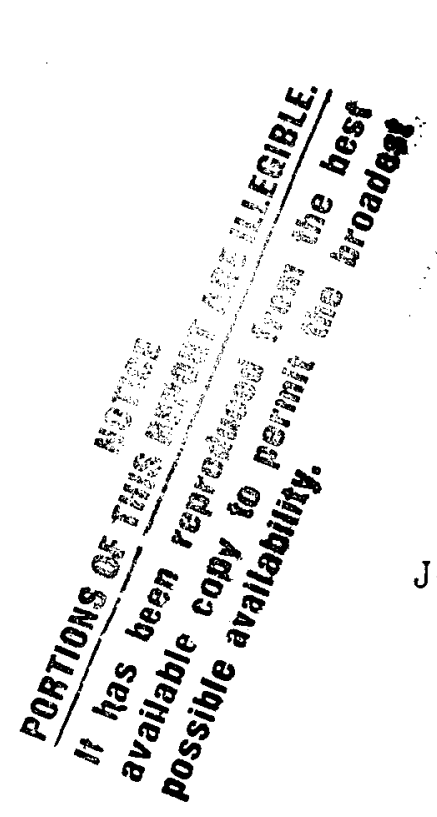

\author{
SAND $84-7102$ \\ Prepared By: \\ Mark A. Tinianow \\ Richard L. Rotelli, Jr. \\ and \\ Jerold A. Baird
}

SAND $-84-7102$

DE84. 016955

JORDAN, APOSTAL, RITTER ASSOCIATES, INC. Administration Building 7 Davisville, Rhode Island 02854

February, 1984

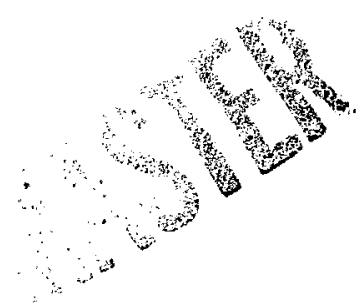

\section{ABSTRACT}

User instructions for the GEODYN Interactive Finite Element Computer Program are presented. The program is capable of performing the analysis of the three-dimensional transient dynamic response of a Pollycrystalline Diamond Compact Bit - Bit Sub arising from the intermittent contact of the bit with the downhole rock formations. The program accommodates non-linear, time dependent, loading and boundary conditions. 
I A B L E OF C ON TEN T S

Section

Title

$\underline{\text { Page }}$

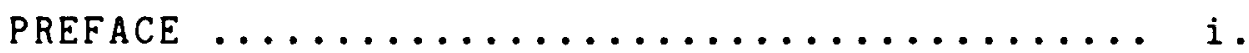

EXECUTIVE SUMMARY $\ldots \ldots \ldots \ldots \ldots \ldots \ldots \ldots \ldots \ldots \ldots$ ii.

$1.0 \quad$ INTRODUCTION $\ldots \ldots \ldots \ldots \ldots \ldots \ldots \ldots \ldots \ldots \ldots \ldots \ldots \ldots \ldots \ldots$

2.0 MODEL OVERVIEW $\ldots \ldots \ldots \ldots \ldots \ldots \ldots \ldots \ldots \ldots \ldots \ldots \ldots \ldots \ldots \ldots$

2.1 Element Descriptions $\ldots \ldots \ldots \ldots \ldots \ldots \ldots \ldots \ldots \ldots \ldots \ldots \ldots$

2.1.1 Eight-Node 3-D Isoparametric Brick Element ... 2.4

2.1.2 3-D Linear Beam Element $\ldots \ldots \ldots \ldots \ldots \ldots \ldots 2.7$

2.1.3 Twenty-Node 3-D Isoparametric Brick Element .. 2.10

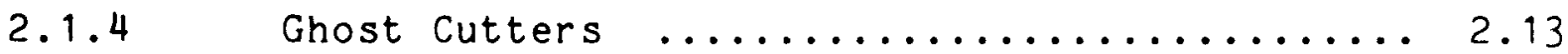

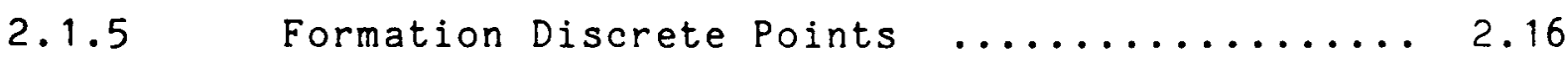

2.2 Characteristic Planes and Element Surface

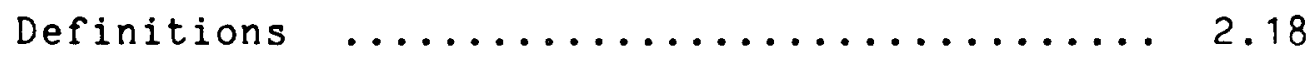

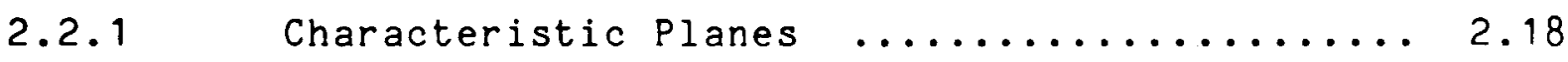

2.2.2 Element Surface Definitions $\ldots \ldots \ldots \ldots \ldots 2.23$

2.3 Drill String Nodal Numbering Conventions .... 2.26

2.3.1 General Model Numbering $\ldots \ldots \ldots \ldots \ldots \ldots \ldots .26$

2.3.2 External Node Definition $\ldots \ldots \ldots \ldots \ldots \ldots \ldots \ldots \ldots \ldots$

2.3.3 Internal Node Definition $\ldots \ldots \ldots \ldots \ldots \ldots \ldots \ldots \ldots \ldots$

2.3.4 Tied Bit Nodes (Constraint Tying) ........ 2.29

2.4 Element Constraint Tying And Boundary

Constraints .............................. 30

2.4.1 Element Constraint Tying $\ldots \ldots \ldots \ldots \ldots \ldots .30$

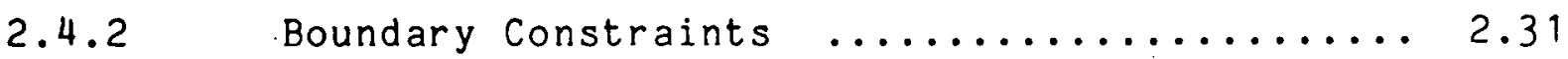

2.5 Solution of Eigenvalues And Eigenvectors .... 2.37 


\section{TA B L E O F C O N I ENT \\ (Continued)}

Section

Title

Page

2.6

Modal Reduction

2.38

2.7

Formation

Discrete

Point Idealization

2.39

2.8

Solution Algorithm

2.45

2.8 .1

Incremental Control

2.45

2.8 .2

Iterative Control

2.45

2.8 .3

Convergence Criteria

2.46

2.8 .4

Output Control

2.46

3.0

GEODYN FEATURES

3.1

3.1

Types And Control of Analysis

3.2

3.2

Coordinate Systems

3.13

3.2 .1

The Drill String Rotational Coordinate

System

3.2 .2

The Global Coordinate System

$3.2 \cdot 3$

Ghost Cutter Local Coordinate System

3.16

3.2 .4

Formation Local Coordinates

3.18

3.3

Sign Conventions

3.4

Forces

3.4 .1

External Forces

3.4 .2

Body Forces

3.22

$3.4 \cdot 3$

Interactive Forces

$3 \cdot 4 \cdot 3 \cdot 1$

Penetration Forces

3.23 
$\underline{\text { (Continued) }}$

Section

$\underline{\text { Title }}$

$\underline{\text { Page }}$

3.4.3.2 Frictional Forces $\ldots \ldots \ldots \ldots \ldots \ldots \ldots \ldots \ldots .24$

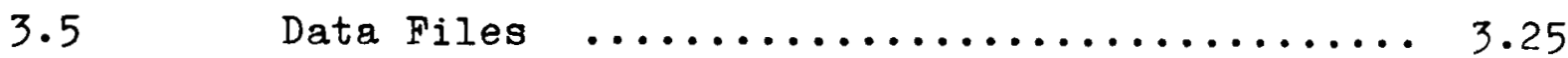

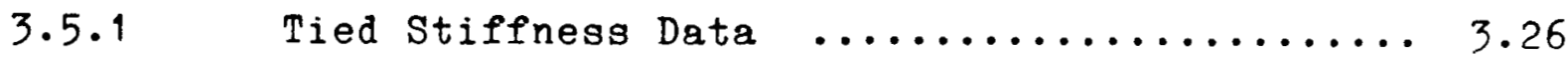

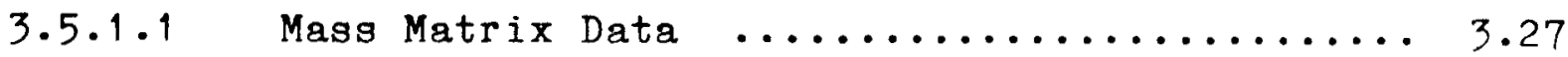

3.5 .2 Natural Frequency Data $\ldots \ldots \ldots \ldots \ldots \ldots \ldots .28$

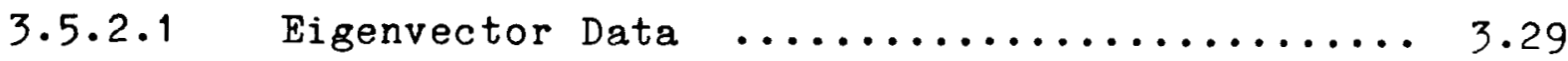

3.5.3 Common Block Data .....................30

3.5.4 Model Data (ACORE and MCORE) .......... 3.31

3.5.5 Double Precision Data $\ldots \ldots \ldots \ldots \ldots \ldots \ldots \ldots \ldots \ldots \ldots \ldots$

3.5 .6 Modal System Data $\ldots \ldots \ldots \ldots \ldots \ldots \ldots \ldots \ldots . . \ldots \ldots$

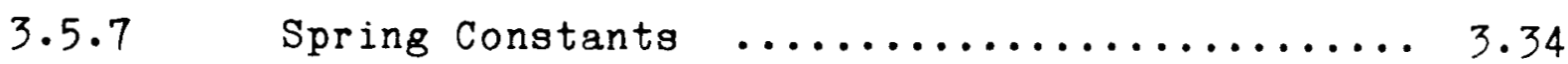

3.5.8 Formation Discrete Point Data ......... 3.36

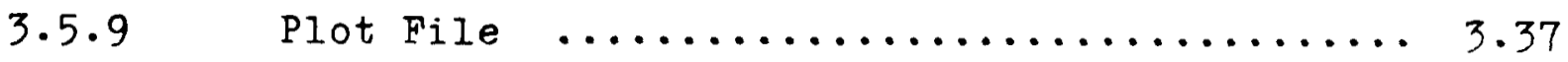

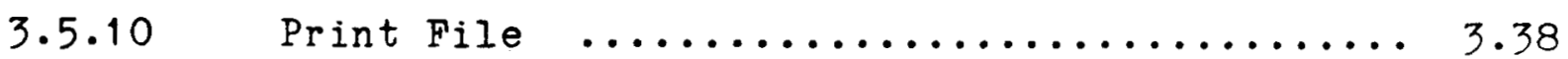

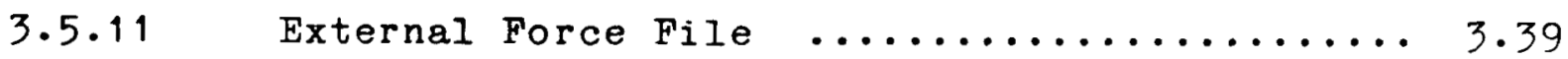

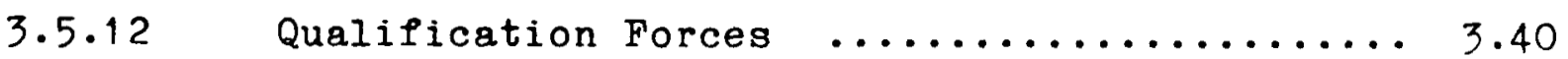

3.6 Formation Mesh and Property Generator ..... 3.41

3.6.1 Generation of Point Number Arrays ....... 3.42

3.6.2 Specification of Penetration Coordinates .... 3.46

3.6.2.1 Default Penetration Coordinates $\ldots \ldots \ldots \ldots 3.46$

3.6.2.2 Penetration Coordinate Modifications ...... 3.47 
(Continued)

Section

Title

$\underline{\text { Page }}$

3.6 .3

Assigning Formation Material Properties .....

3.50

3.7

Input Features

3.59

3.7 .1

Free Format Input

3.59

3.7 .2

Input File Option

3.59

3.7 .3

Save/Restore Feature

3.60

3.8

Output

3.61

3.8 .1

Model Description And Natural Frequency

Summary (GENDYN)

3.8 .1

Debug Output File (GENDYN)

3.8 .2

Dynamic Solution Summary (RUNDYN) -

Print And Plot File

4.0

EXAMPLE OF A TRANSIENT DYNAMIC ANALYSIS

WITH FORMATION INTERACTION

$4 \cdot 1$

4.1

Input For Running The

$4 \cdot 1 \cdot 1$

Output

4.2

Input

Fro

Running

he G

NDYN Sub-Program

$4 \cdot 1$

4.2 .1

Force Files For Running The RUNDYN

Sub-Program

$4 \cdot 2 \cdot 2$

Output Fro

Running

$\mathrm{g}$ Th

RUNDYN Sub-Program

4.77

5.0

EXAMPLE OF A QUALIFICATION - TYPE ANALYSIS

(NO FORMATION)

5.1

5.1

Input For Running The GENDYN Sub-Program .... 5.1

5.1 .1

Output From Running The GENDYN Sub-Program ... 5.39

5.2

Input For Running The RUNDYN Sub-Program .... 5.54 
IA B L E OF CONTENTS

(Continued)

Section

Title

$\underline{\text { Page }}$

5.2.1 Force Files For Running The RUNDYN

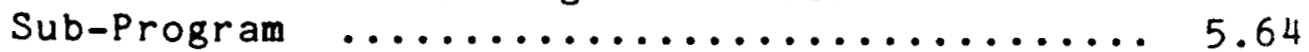

5.2.2 Output From Running The RUNDYN Sub-Program ... 5.72

6.0 OVERVIEW OF INPUT DATA $\ldots \ldots \ldots \ldots \ldots \ldots \ldots .6 .1$

6.1 Overview of GENDYN Input $\ldots \ldots \ldots \ldots \ldots \ldots .6 .1$

6.2 Overview of RUNDYN Input $\ldots \ldots \ldots \ldots \ldots \ldots 6.4$

7.0 UTILITY PROGRAMS AND THEIR UTILIZATION $\ldots \ldots .7 .1$

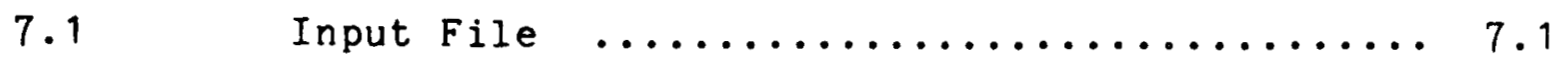

7.1.1 Files Associated With Input File Generation .. 7.2

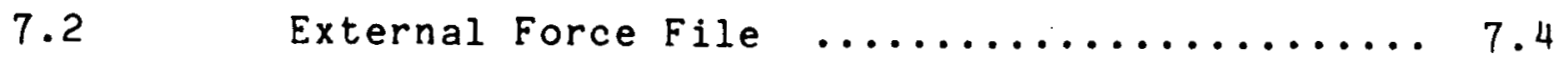

7.2.1 Files Associated With External Force File

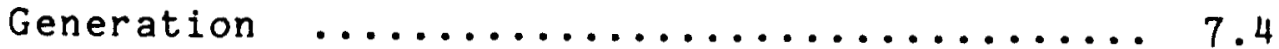

8.0

DISTRIBUTION $\ldots \ldots \ldots \ldots \ldots \ldots \ldots \ldots \ldots \ldots \ldots \ldots \ldots \ldots \ldots$ 
Figure Number

Title

Page

$2 \cdot 1 \cdot 1 \cdot 1$

$2 \cdot 1 \cdot 1 \cdot 2$

$2 \cdot 1 \cdot 2 \cdot 1$

$2 \cdot 1 \cdot 3 \cdot 1$

$2.1 \cdot 3.2$

$2 \cdot 1 \cdot 4 \cdot 1$

$2 \cdot 2 \cdot 1 \cdot 1$

$2 \cdot 2 \cdot 2 \cdot 1$

$2 \cdot 3 \cdot 1 \cdot 1$

$2 \cdot 4 \cdot 1 \cdot 1$

$2 \cdot 4 \cdot 1 \cdot 2$

$2 \cdot 4 \cdot 1 \cdot 3$

$2 \cdot 4 \cdot 2 \cdot 1$

$2 \cdot 7 \cdot 1$

2.7 .2

$2 \cdot 7 \cdot 3$

$2 \cdot 7 \cdot 4$

3.1
The Undistorted 8-Node Brick Element -

Nodal Numbering Scheme $\ldots \ldots \ldots \ldots \ldots \ldots . . .5$

Nodal Numbering Scheme of The

Distorted 8-Node Brick Element ........ 2.6

Beam Element Connectivity ........... 2.9

The Undistorted 20-Node Brick

Element - Nodal Numbering Scheme ...... 2.11

Nodal Numbering Scheme of The

Distorted 20-Wode Brick Element ....... 2.12

Ghost Cutter Definition Data ........ 2.15

Characteristic Plane Definition Data .... 2.19

Element Surface Definition Data ....... 2.24

Drill String Node Numbering ......... 2.27

Tied Degrees-of-Freedom ............ 2.32

Top Surface of Bit Remains Plane ....... 2.33

Tied Bit Nodes .................. 2.34

Boundary Constraints ............. 2.36

Penetration Directions For The Three

Formation Sub-Models ............... 2.41

The Bottom surface Formation Sub-Model .. 2.42

The Side-Wall Surface Formation

Sub-Model (Opened Up) $\ldots \ldots \ldots \ldots \ldots \ldots .2 .43$

The Incline Surface Formation

Sub-Model ..................... 2.44

Execution of GEODYN Code $\ldots \ldots \ldots \ldots \ldots 3.4$ 


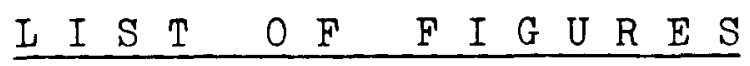

$\underline{\text { (Continued) }}$

Figure Number

Title

Page

3.2

Generation of Drill String Model $\ldots \ldots .3 .5$

3.3

Execution of Drill String - Formation

Dynamic Interaction Analysis $\ldots \ldots \ldots \ldots .7$

3.2 .1

Definition of Coordinate Systems ...... 3.14

$3.2 \cdot 3 \cdot 1$

Ghost Cutter Local Coordinate System .... 3.17

$3 \cdot 2 \cdot 4 \cdot 1$

Definition of Local Formation Coordinates

For The Incline Surface $\ldots \ldots \ldots \ldots \ldots .3 .20$

$3 \cdot 6 \cdot 1 \cdot 1$

Required Geometric Parameters For

Formation Mesh Generation ........... 3.43

3.6.2.2.1 Effect of Penetration Coordinate

Modifications On Hole Cross-Section .... 3.48

3.6.2.2.2 Example of Penetration Coordinate

Modifications For Bottom Surface ...... 3.49

$3 \cdot 6 \cdot 3 \cdot 1$

Example of Material ID Assignment For

The Bottom Surface ............... 3.52

$3.6 \cdot 3.2$

Determining The Appropriate Formation

Sub-Model $\ldots \ldots \ldots \ldots \ldots \ldots \ldots \ldots \ldots \ldots \ldots \ldots . .58$

$3 \cdot 8 \cdot 1.1$

Format Usage For GENDYN Output ........ 3.69

3.8 .2 .1

BFNPRT File Structure ............. 3.84

3.8 .2 .2

BFNPLT File Structure ............ 3.85

3.8 .2 .3

GENDYN Output Summary ........... 3.92

3.8 .2 .4

Formation Model Output ............ 3.92

$3.8 \cdot 2 \cdot 5$

Solution Control Parameters .......... 3.93

3.8 .2 .6

Dynamic Solution Quantities .......... 3.94

$3.8 \cdot 2 \cdot 7$

Ghost Cutter Interaction Summary ...... 3.95 


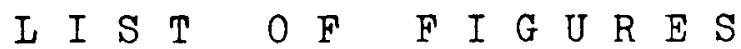

$\underline{\text { (Continued) }}$

Figure Number

$\underline{\text { Title }}$

Page

3.8 .2 .8

Dynamic Solution Summar

3.97

3.8 .2 .9

Format Usage For Formation Model Output.

3.101

3.8 .2 .10

Format Usage For Solution Control

Parameters Output ................... 3.109

3.8 .2 .11

Format Usage For Dynamic Solution

Output

3.8 .2 .12

Format Usage For Ghost Cutter

Interaction Summary Output

3.8 .2 .13

Format Usage For Dynamic Solution

Output Summary

$4 \cdot 1 \cdot 1$

The Formation Interaction Test

Case Model

4.2

$4 \cdot 1 \cdot 2$

Characteristic Planes For Formation

Interaction Case ................ 4.3

$4 \cdot 2 \cdot 2 \cdot 1$

Selected RUNDYN Output - Formation

Interaction

5.1 .1

The Model For The Qualification - Type

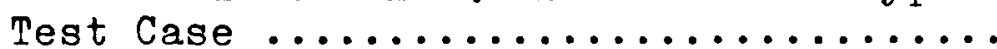

5.2

5.1 .2

Characteristic Planes For Qualification -

Type Test Case ................... 5.3

$5 \cdot 2 \cdot 2 \cdot 1$

Selected RUNDYN Output - Qualification -

Type Test Case ....................

5.73 
GENDYN Output Summary $\ldots \ldots \ldots \ldots \ldots \ldots .63 .64$

3.8 .1 .2

GENOUT Formats Corresponding To

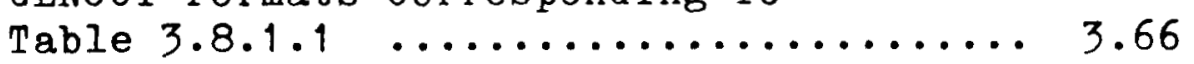

3.8 .2 .1

Formation Model Output Summary ....... 3.98

$3.8 \cdot 2 \cdot 2$

FRMOUT Formats Corresponding to

$3 \cdot 8 \cdot 2 \cdot 3$

Table 3.8.2.1

Solution Control Parameters Output

$3.8 \cdot 2 \cdot 4$

Summar

3.107

CNTOUT Formats Corresponding TO

Table $3.8 .2 .3 \ldots \ldots \ldots \ldots \ldots \ldots \ldots \ldots . . . \ldots .108$

$3.8 .2 \cdot 5$

Dynamic Solution Output Summary ....... 3.110

3.8 .2 .6

RUNOUT Formats Corresponding To

Table $3.8 .2 .5 \ldots \ldots \ldots \ldots \ldots \ldots \ldots \ldots . \ldots \ldots \ldots .112$

$3.8 \cdot 2 \cdot 7$

Ghost Cutter Interaction Output Summary • 3.120

3.8 .2 .8

INTSUM Formats Corresponding To

Table $3.8 .2 .7 \ldots \ldots \ldots \ldots \ldots \ldots \ldots \ldots \ldots \ldots \ldots .121$

3.8 .2 .9

RUNDYN Output Summary $\ldots \ldots \ldots \ldots \ldots \ldots .3 .126$

$3 \cdot 8 \cdot 2 \cdot 10$

Summary Formats Corresponding To 
PREFACE

The work presented in this document was performed for Sandia National Laboratories, P.O. Box 5800, Albuquerque, New Mexico, 87185, under Phase 1 of Contact No. 68-3061, during the period March 15, 1982 through October 15, 1983. The project was sponsored by the Geothermal Technology Development Division 6241, Sandia National Laboratories; NL MWD R\&D/NL Industries, Inc., P.O. Box 60087, Houston, Texas 77205; and Superior 0il Company, P.O. Box 51108 OCS, Lafayette, Louisiana 70505. The Sandia Technical Project Manager for the project was Mr. Bill C. Caskey, with Don Wesenberg, Ph.D. for NL MWD R\&D and Dr. R.E. Martin for Superior $0 i l$ Company functioning in a similar capacity for their respective companies. The Sandia Division Manager for the duration of the Phase 1 Project was Dr. James R. Kelsey. The work was performed by Jordan, Apostal, Ritter Associates, Inc., Administration Building 7, Davisville, Rhode Island 02854, with Dr. Jerold A. Baird serving as Program Manager and Technical Director.

The authors wish to acknowledge the support and numerous constructive technical comments received from the above cited individuals. This report would be incomplete without the additional acknowledgement of the technical support and comments provided, specifically, by Mr. Charles M. Stone, Mr. John T. Finger, and Dr. Thomas G. Carne, in addition to many of their colleagues at Sandia National Laboratories. 
EXECUTIVE SUMMARY

This User Instruction Manual details the use of the GEODYN Phase 1 Program developed by Jordan, Apostal, Ritter Associates, Inc., for Sandia National Laboratories under the first phase of Contract Number 68-3061. The program was developed during the period March 15, 1982 through October 15, 1983. The program is capable of performing the analysis of the three-dimensional transient dynamic response of a PDC Bit-Bit Sub arising from the intermittent contact of the bit with downhole rock formations. This analysis accounts for non-linear, time dependent, loading and boundary conditions.

Input required by the program serves the function of: (1) describing the overall PDC Bit-Bit Sub finite element model idealization (i.e. number and type of elements, nodal coordinates, material properties, etc.); (2) identifying the utilization of rigid body elements, hereafter generally referred to as "ghost cutters"; (3) characterizing the wellbore formation properties and geometry via the specification of discrete formation points; and (4) defining the dynamic loadings and solution parameters utilized in the analysis. Attention is directed toward how individual components are assembled within the program to provide the full analysis capability. Note that input to the program is interactive in nature. 
In addition to describing the input of element, nodal, and control information, the manual provides a brief description of how the program is structured and the types of analysis which can be performed. A review of the two coordinate systems utilized within the program is presented, along with the appropriate sign conventions employed. The need for two such coordinate systems is, however, described in a separate theoretical description (see Sandia National Laboratories Contractor Report SAND84-7101).

A detailed description of a number of data files employed within the program, both formatted and unformatted, is provided. The function of these data files should be well understood by the user prior to initiating a series of analyses. Information contained in these data files includes: (1) the PDC Bit-Bit Sub assembled constrained system stiffness and mass matrices, (2) the PDC Bit-Bit Sub Eigenvector and Eigenvalue solution results, (3) numerous control parameters (i.e. number elements, ghost cutters, nodes, etc.) as well as element ghost cutter and node point properties (i.e. element connectivity, material properties, node point coordinates, etc.), (4) the system stiffness, mass, and damping matrices formed as a result of modal superposition, (5) properties associated with the formation discrete point idealization, (6) required external or qualification force data, and (7) various input and output data files. 
The manual concludes by providing examples of the use of the GEODYN Phase 1 Program. These examples demonstrate the interactive nature of the Program's input, while providing the user the opportunity to become familiar with the various conventions used to define the models (i.e. connectivity, coordinate systems, ghost cutter characteristic planes, etc.). Illustrative results for these example problems, obtained on a VAX 11/780, have also been provided. These results should assist the user in assessing his understanding of how to utilize the GEODYN Phase 1 Program. 
I. INTRODUCTION

This User Instruction Manual has been prepared to facilitate the use of the GEODYN Phase 1 Program for the analysis of the three-dimensional transient dynamic response of a PDC Bit-Bit Sub. Such an analysis can account for the non-linear, time dependent, loading and boundary condition response arising from the intermittent contact of the bit with the downhole rock formations modeled.

This introduction will highlight many of the analytical techniques employed by the Program. The GEODYN Phase 1 Theoretical Description, Sandia National Laboratories, Contractor Report SAND84-7101, should be consulted for an in-depth description of these analytical techniques.

Chapter 2 of this manual has been structured to provide the user with a general overview of what analytical modeling techniques are available, and the required information needed for their utilization. Section 2.1 details the finite elements utilized for the PDC Bit-Bit Sub idealization, in addition to describing both the "ghost cutter" and formation discrete point specification (also see Sections 2.7 and 3.6 ). Although described in the manual, use of the 3-D twenty node isoparametric brick element for formation description is not currently supported by the Program. Section 2.2 of the manual describes the specification of the requisite characteristic plane and 
element surface definition associated with the ghost cutter idealization. Sections 2.3 and 2.4 describe all nodal numbering conventions and constraint tying and boundary condition specifications. Section 2.5 describes the need for and the solution of Eigenvalues and Eigenvectors, while Section 2.6 outlines their use in performing the modal reduction procedures employed by the Program. The formation discrete point idealization is defined in Section 2.7. The utilization of the "Formation Mesh and Property Generator", a GEODYN feature, is reviewed in Section 3.6. The concluding section in Chapter 2 (i.e. Section 2.8) describes the aspects of the solution algorithm controlled by the user.

Chapter 3 of this manual provides a review of various features and conventions in the GEODYN Phase 1 Program. The first section of the Chapter provides an overview, complete with a conceptual flow chart, of the capabilities and control of the GEODYN Phase 1 Program. The existence of a GENDYN Sub-program and RUNDYN Sub-program is noted. The various coordinate systems (i.e. drill string rotational or rotating, global, ghost cutter local, and formation local) are described in some detail in Section 3.2. The sign conventions associated with the above mentioned coordinate systems are presented in section 3.3 . Section 3.4 describes the various force components (external, gravity, centrifugal and formation interaction) which are either prescribed as input or computed by the Program during execution. 
Section 3.5 provides the necessary information for understanding the various data files utilized by the Program. Section 3.8 provides information on the format of such output data files. The previously mentioned Formation Mesh and Property Generator is described in Section 3.6. Illustrative examples of its use and capabilities are provided. Finally, certain noteworthy input features are briefly highlighted in Section 3.7 .

The next two chapters of the manual have been included to illustrate the use of the GEODYN Phase 1 Program. It should be noted that the analyses chosen are for illustrative purposes only, and are not intended to depict an analysis situation likely to be modeled by the user. Chapter 4 details the analysis of a rotating bit (i.e. one 8 node brick) interacting with the wellbore formation. The interactive input as well as the associated output summary file for the execution of the GENDYN Sub-program are included in Section 4.1. The execution of the RUNDYN Sub-program for the formation interaction case, and selected output is presented in Section 4.2 . Chapter 5, on the other hand, illustrates the execution of a simple benchmark verification analysis used to qualify the GEODYN Phase 1 Program. Section 5.1 includes the input for, and the output summary file from the GENDYN Sub-program execution. The input for, and selected output from the RUNDYN Sub-program analysis is provided in Section 5.2. The user should understand the execution of these two analyses before attempting to utilize the GEODYN Phase 1 Program to study a more pertinent problem. 
Chapter 6 presents a summary of how the various input parameters are grouped. Although brief, the user should be familiar with this material as it provides a handy reference for determining: (1) what input data is required to perform an analysis; (2) how this data is grouped (i.e. coordinates, material properties, solution control, etc.); (3) what data is required for executing the GENDYN Sub-program versus the RUNDYN Sub-program; and (4) the general order in which the data will be input.

The final chapter included in the manual provides a discussion of two utility programs which were developed to facilitate the execution of the GEODYN Phase 1 Program. The first utility program, GEOIN, is described in Section 7.1. During the development and verification of the GEODYN Program it became apparent that the utilization of an input data file rather than repeated interactive input into the program would be a desirable feature. This input file concept not only saves time spent inputing data, but also permits the GEODYN program to be run in a batch environment. The GEOIN Program was developed to provide this capability. The GEOIN Program requires the user to input data interactively in the exact manner as GEODYN, while storing such data in a user defined input data file. This resultant input file may be utilized numerous times, and with judicious care, may be edited to modify the analysis being performed. Section 7.2 describes a small driver program which 
has been provided to facilitate the creation of an external force file. The external force file so created serves as input to the RUNDYN Sub-program during the solution analysis. Similarily, this file may be used many times and edited with judicious care to simulate alternate external loading situations. 


\subsection{MODEL OVERVIEW}

This chapter describes many of the key components of both the drill string and formation models. These components are treated as follows:

Section 2.1 defines element type and position codes, element connectivity, and general descriptions of the drill string and formation models.

Section 2.2 deals with components of the drill string model that are associated with providing an accurate description of ghost cutter behavior. Specifically, characteristic planes and bit surfaces are defined, as is the input required for these planes and surfaces.

Nodal considerations are detailed in Section 2.3. The nodal numbering convention for the drill string model is given, along with definitions of external, internal, and tied nodes.

In Section 2.4, descriptions are given of the constraint tying procedure and the method of applying boundary conditions. The input required for these descriptions is also given. The use of modal solution techniques is dealt with in Sections 2.5 and 2.6. Section 2.5 discusses the use of Eigenvalues and Eigenvectors, and how they are obtained. Section 2.6 discusses the input required for performing a modal analysis. 
A description of the formation model and the formation mesh is given in Section 2.7. The input associated with the description of the formation model is also detailed.

Section 2.8 describes the input required for performing a dynamic solution. This description includes input for incremental and iterative control of the solution algorithm, as well as how to control output.

\subsection{ELEMENT DESCRIPTIONS}

Currently, the GEOPYN program models the drill string using 8-node brick elements, 3-D linear beam elements, and ghost cutter sub-elements. The 8-node brick elements are used to model the bit, the linear beams are used to model the drill collar and drill pipe, and the ghost cutters are used to model the teeth on the bit.

An element type code and position code is associated with each of these elements. The element type codes are as follows:

Element

8-Node Brick 20-Node Brick 3-D Linear Beam Ghost Cutter Sub-Element Infinite Brick 3-D Non-Linear Beam

\section{Element Type Code}

1

2

3

4

5 
The element position codes are as follows: .

Description

Brick element used in drill string

Brick element used in formation

Beam element used in drill string

Ghost cutter sub-element on bit surface

Infinite element used in formation

\section{Element Position Code}

1

2

3

4

5

GEODYN currently cannot completely model 20-node bricks, infinite bricks, and non-linear beams. However, these have been included because they are likely to be used in the future, as the scope of the program increases. 


\subsubsection{EIGHT-NODE 3-D ISOPARAMETRIC BRICK ELEMENT}

ELEMENT TYPE: 8-node, 3-D Isoparametric Brick

TYPE CODE: 1

POSITION CODE: 1

DEGREES OF FREEDOM: 3 per node $-X, Y$ and $Z$ translational

NUMBER OF NODES: 8

PHYSICAL PROPERTIES: Elastic Modulus

Poisson's Ratio

Material Unit Weight (converted to mass)

LOADING: 1 . Concentrated Nodal Forces

2. Distributed Nodal Forces From Ghost Cutters

3. Body Forces - Centrifugal (angular velocity based) Gravity

Force Directions Consistent with Rotating Coordinate System.

OUTPUT: Displacements]

Velocities $\} \quad$ Rotating, Absolute, Global

Accelerations

CONNECTIVITY: 8-Node Brick definition is composed of the following information (please refer to

Figure 2.1.1.1):

- Element number

- 8-node numbers, in the order shown in Figure 2.1.1.1

GENERAL REMARKS: 8 integration points are used to generate this element. 


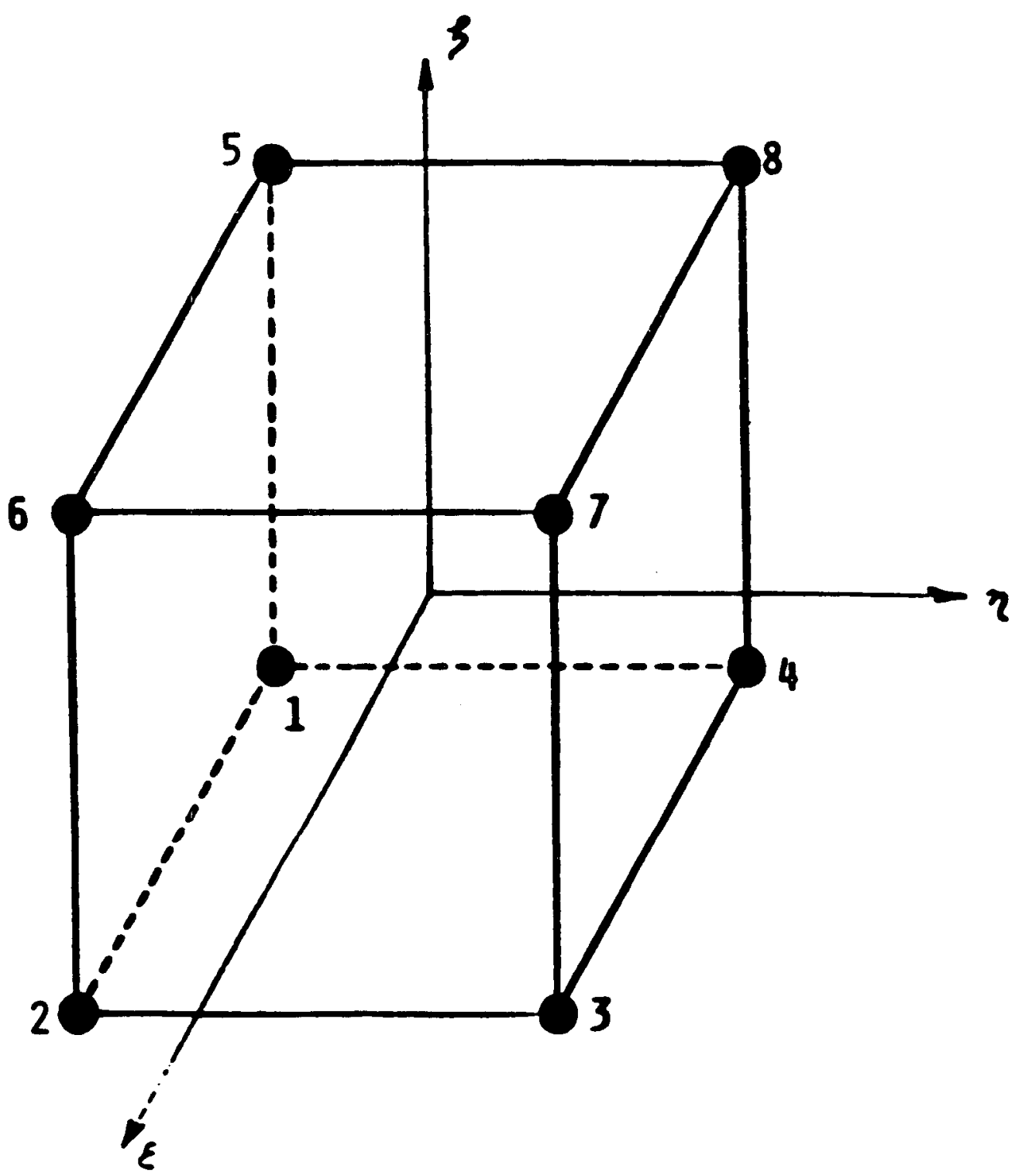

FIGURE 2.1.1.1: The Undistorted 8-Node Brick Element Nodal Numbering Scheme 


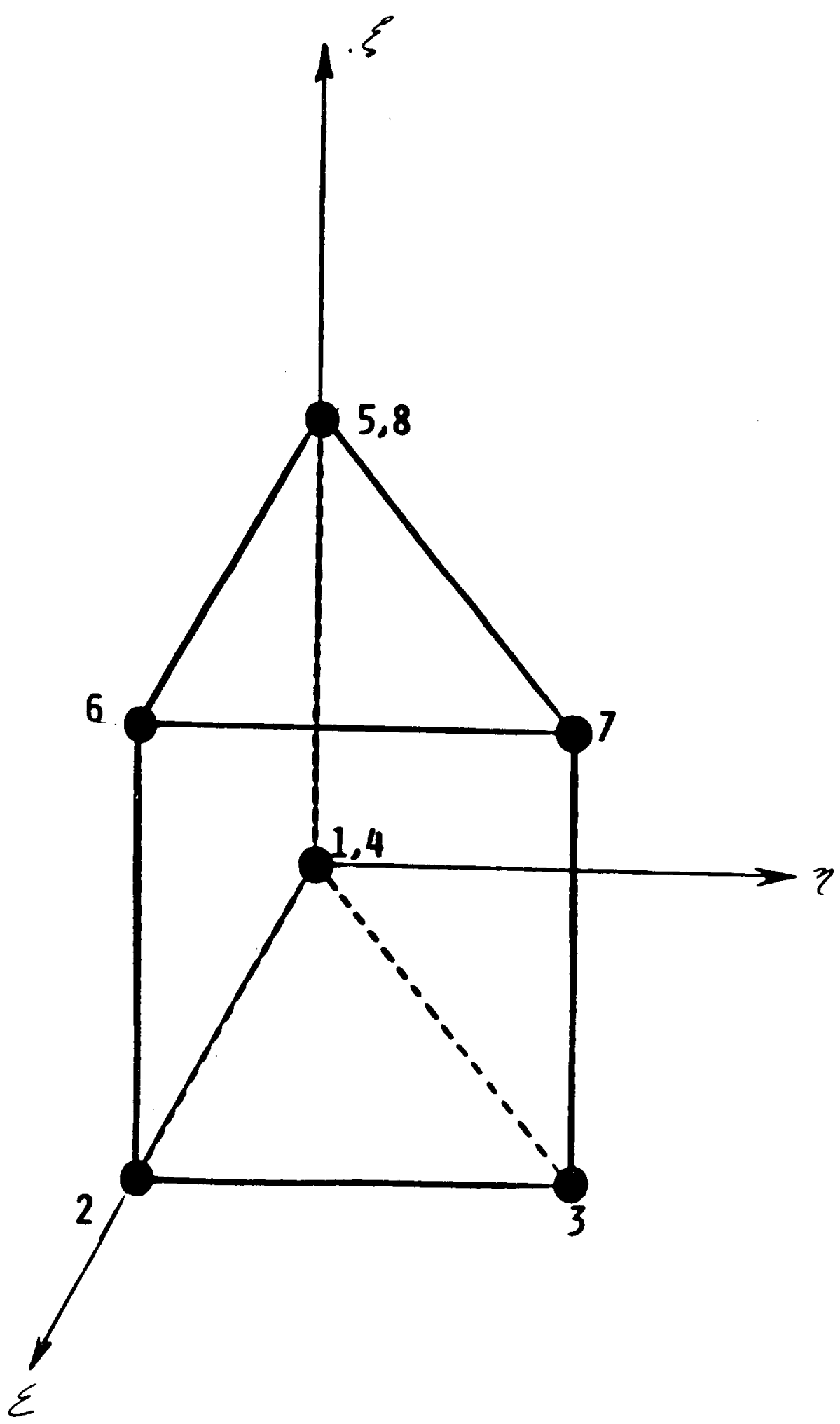

Figure 2.1.1.2: Nodal Numbering Scheme of The Distorted 8-Node Brick Element 


\section{1 .2 3-D IINEAR BEAM ELEMENT}

ELEMENT TYPE: 3-D Linear Beam

TYPE CODE: $\quad 3$

POSITION CODE: 3

DEGREES OF FREEDOM: Six per node - $X, Y$ and $Z$

NUMBER OF NODES: 2

Translational, $X, Y$ and $Z$ Rotational

PHYSICAL PROPERTIES: Length

$$
\begin{aligned}
& \text { Outside Diameter } \\
& \text { Inside Diameter } \\
& \text { Elastic Modulus } \\
& \text { Poisson's Ratio } \\
& \text { Material Unit Weight } \\
& \text { (converted to mass) }
\end{aligned}
$$

LOADING: 1. Concentrated Nodal Forces And Moments

$$
\text { 2. Body Forces - Centrifugal (Angular Velocity Based) }
$$

Force Directions Consistent With Rotating Coordinate System

OUTPUT: Displacements $\left.\begin{array}{l}\text { Velocities } \\ \text { Accelerations }\end{array}\right\}$

Rotating, Absolute, and Global 
CONNECTIVITY: 3-D linear beam definition is composed of the following information (please refer to

Figure 2.1.2.1):

- Element number

- Node number having lower elevation in model

- Node number having higher elevation in model

GENERAL REMARKS: Note that the cross-section of the beam must be either circular or square. 


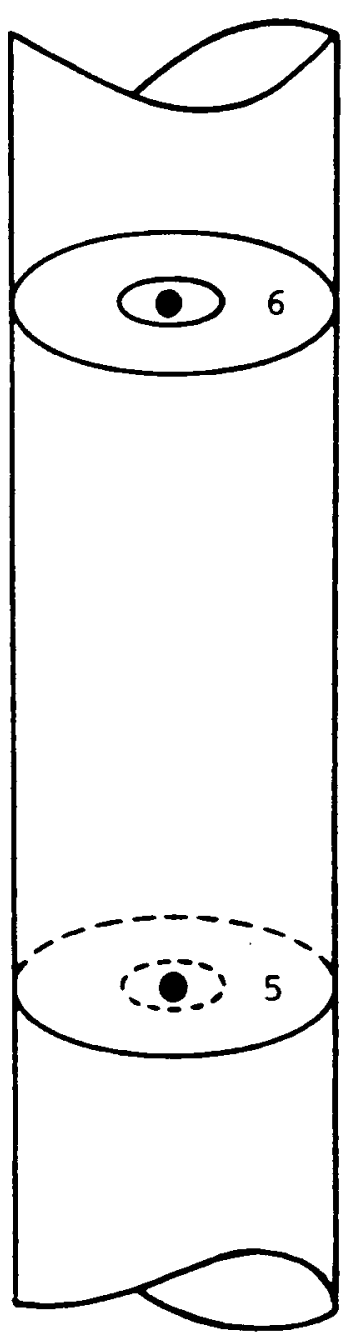

Element \#4

Connectivity: $\quad 5,6$

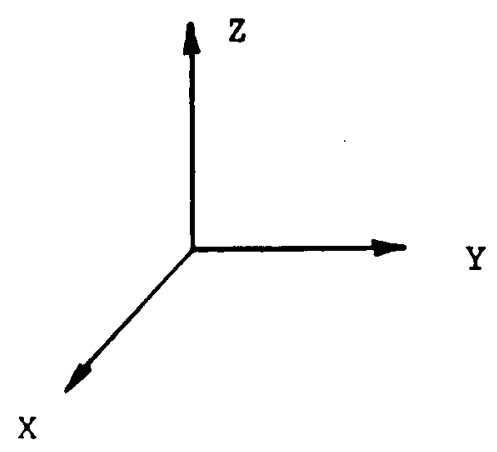




\subsubsection{TWENTY-NODE 3-D ISOPARAMETRIC BRICK ELEMENT}

ELEMENT TYPE: 20-Node, 3-D Isoparametric Brick Element TYPE CODE: $\quad 2$

POSITION CODE: 2

DEGREES OF FREEDOM: 3 per node $-X, Y$ and $Z$ Translational

NUMBER OF NODES: 20

PHYSICAL PROPERTIES: Elastic Modulus

$$
\text { Poisson's Ratio }
$$

Material Unit Weight

(Converted to mass)

LOADING: 1. Concentrated Nodal Forces

2. Distributed Nodal Forces From Ghost Cutters

Force Directions Consistent With Global Coordinate System

OUTPUT: Displacements imposed by Ghost Cutters (?) Global Coordinate System

CONNECTIVITY: 20-Node Brick definition is composed of the following information (please refer to Figure 2.1.3.1)

- Element number

- 20 node numbers, in the order shown in Figure 2.1.3.1

GENERAL REMARKS: As of November 1, 1983 this element has not been implemented in the formation model. 


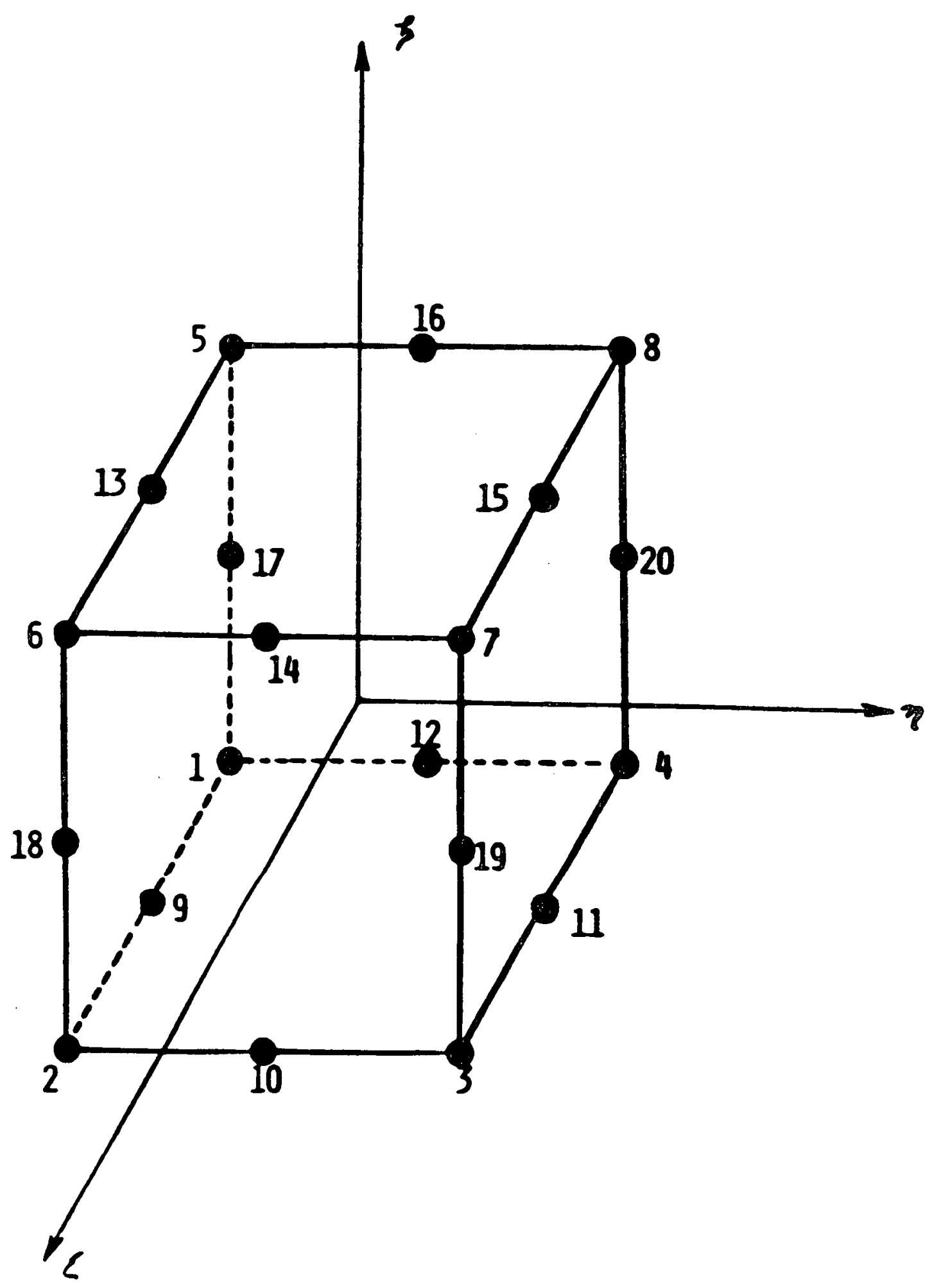

FIGURE 2.1.3.1: The Undistorted 20-Node Brick Element Nodal Numbering Scheme 


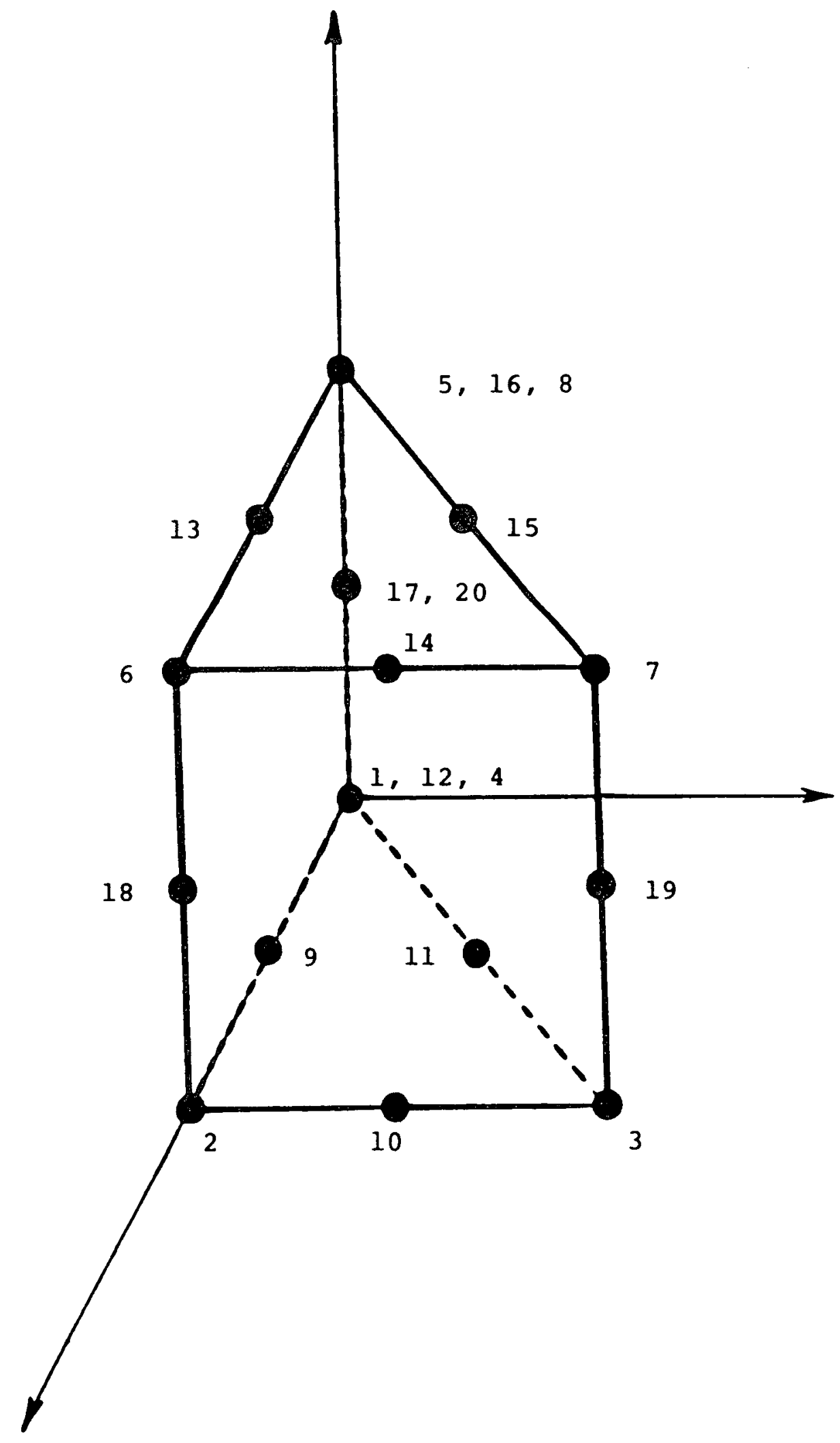

Figure 2.1.3.2: Nodal Numbering Scheme of The Distorted 20-Node Brick Element 
2.1 .4 GHOST CUTTERS

- To keep track of the positions of the cutters, "geometric sub-elements" are used which are essentially rigid body elements whose motions depend on the motions of the nodes to which they are attached. The geometric sub-elements are also called "ghost-cutters".

- Each ghost-cutter (sub-element) has three geometric sub-nodes attached to it (see Figure 2.1.4.1). The global locations of these sub-nodes will be the basis for determining the forces which the formation exerts on the bit. 
ELEMENT TYPE: Ghost Cutter Sub-Element

TYPE CODE: $\quad 4$

POSITION CODE: 4

DEGREES OF FREEDOM: 3 per sub-node $-x, y$ and $z$ translational

NUMBER OF SUB-NODES : 3

PHYSICAL PROPERTIES: Length (zero for a gauge cutter) Area

Moment of Inertia, I Polar Moment of Inertia, J Elastic Modulus Poisson's Ratio

Max. Allowable Shear Force, $F_{y}$

LOADING: Loaded by the formation, only at sub-node 2. Loads vary during the iterative cycle and are proportional to the distance to which the cutter has penetrated the formation.

OUTPUT: Position (Global and Rotating) Absolute Velocity (Global) Relative Velocity (w.r.t. steady-state rotation) (Global)

For a definition of cutter velocity and the details of its computation, see the Theoretical Manual.

CONNECTIVITY: The ghost cutter definition is composed of the following information (refer to Figure 2.1.4.1):

a) The ghost-cutter sub-element number.

b) The number of the nearest finite element node.

c) The three sub-nodes for the cutter (see

Figure 2.1.4.1 for numbering scheme).

\section{GENERAL REMARKS :}

- No sub-node number may appear on more than one cutter.

- Sub-nodes 1, 2, and 3 are sometimes referred to as cutter points $A, B$, and $C$ respectively. 


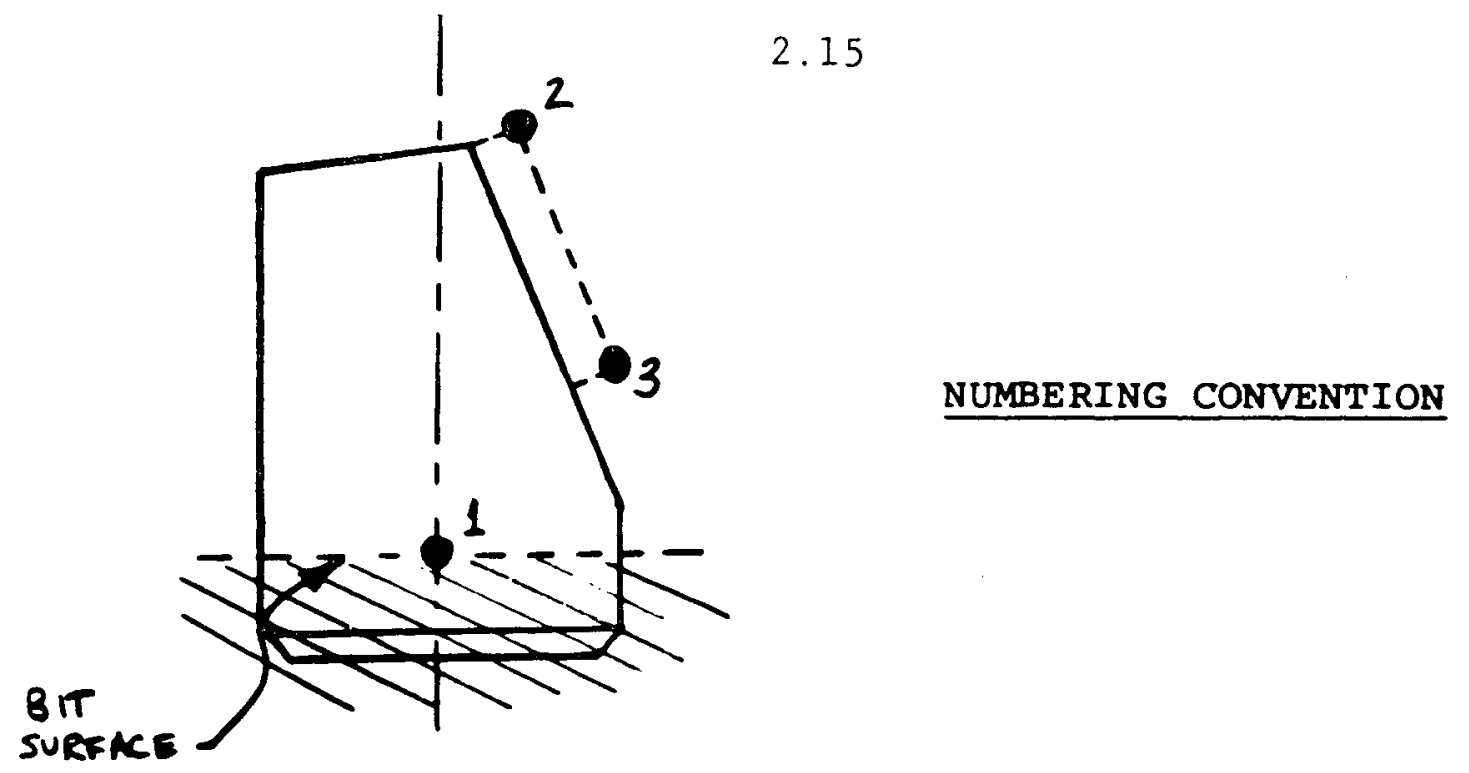

\section{EXAMPLE:}

INPUT DATA:
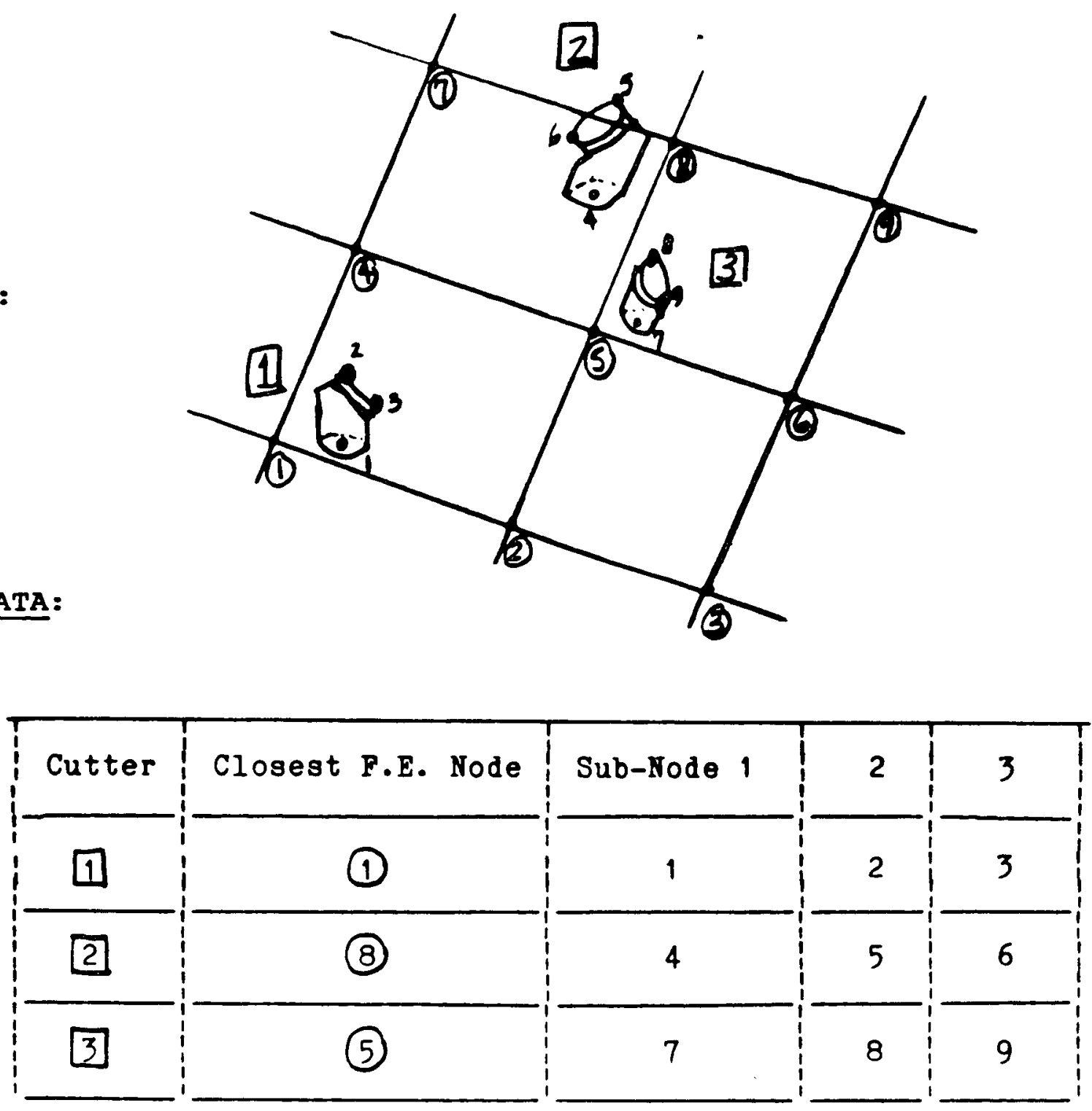

FIGURE 2.1.4.1: Ghost Cutter Definition Data 


\section{1 .5 FORMATION DISCRETE POINTS}

A collection of discrete points (called "formation points") is used to model the formation surfaces with which the bit may come in contact. Formation properties are assigned to each of these points. Once it is determined that a cutter is closest to a specific formation point, all geometric and material properties of the formation at the true point of contact are said to be equal to those at that formation point. (The process of determining the formation point closest to the cutter is discussed in the theoretical manual.)

At every formation point, a coordinate is stored which is used to determine the penetration distance. This is called the "penetration coordinate". (The penetration directions for the various portions of the formation sub-model are discussed in Section 2.7.)

The following material properties are stored at every formation point:

$$
\begin{aligned}
\text { Kpen - } & \text { A linear stiffness (analogous to a spring) } \\
& \text { resisting penetration. It is used to } \\
& \text { calculate the penetration force. }
\end{aligned}
$$

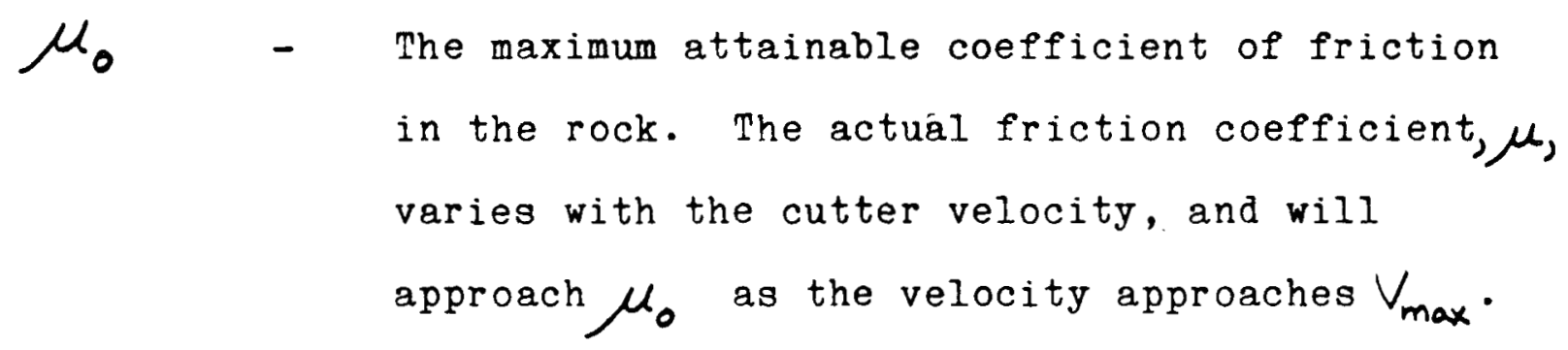


2.17

$V_{\max }$ - The velocity at which the rock's coefficient of friction is equal to $\mu_{0}$.

The actual friction coefficient, $\mu$, is computed as:

$$
\mu=\mu_{0} \tanh \left(\frac{|\vec{v}|}{v_{\text {max }}}\right)
$$

This $\mu$ is used to calculate the velocity dependent friction forces.

The details of the penetration distance and force calculations are discussed in the theoretical manual.

The method of specifying the penetration coordinates and material properties at each formation point will be discussed under the heading of "The Formation Mesh and Property Generator" later in this manual. 


\subsection{CHARACTERISTIC PLANES AND ELEMENT SURFACE}

\section{DEFINITIONS}

This section defines characteristic planes and element surfaces, which are used to accurately represent the behavior of ghost cutters.

\subsubsection{CHARACTERISTIC PLANES}

- The movements of the ghost-cutter sub-nodes are tied to the nodal translations of a nearby node (called the "primary node"), with the qualification that the ghost-cutter must also move according to the rotation of a plane defined by the primary node and two other nearby nodes. This plane is termed the "characteristic plane".

The input data required for each characteristic plane is:

a) The plane number.

b) The three finite element nodes defining the plane. (The first node specified is called the primary node.)

c) A list of ghost-cutter sub-element numbers which are attached to that plane (maximum number of cutters on any one plane $=20$ ).

See Figure 2.2.1.1 for an example of characteristic plane definition data. 


\section{EXAMPLE :}

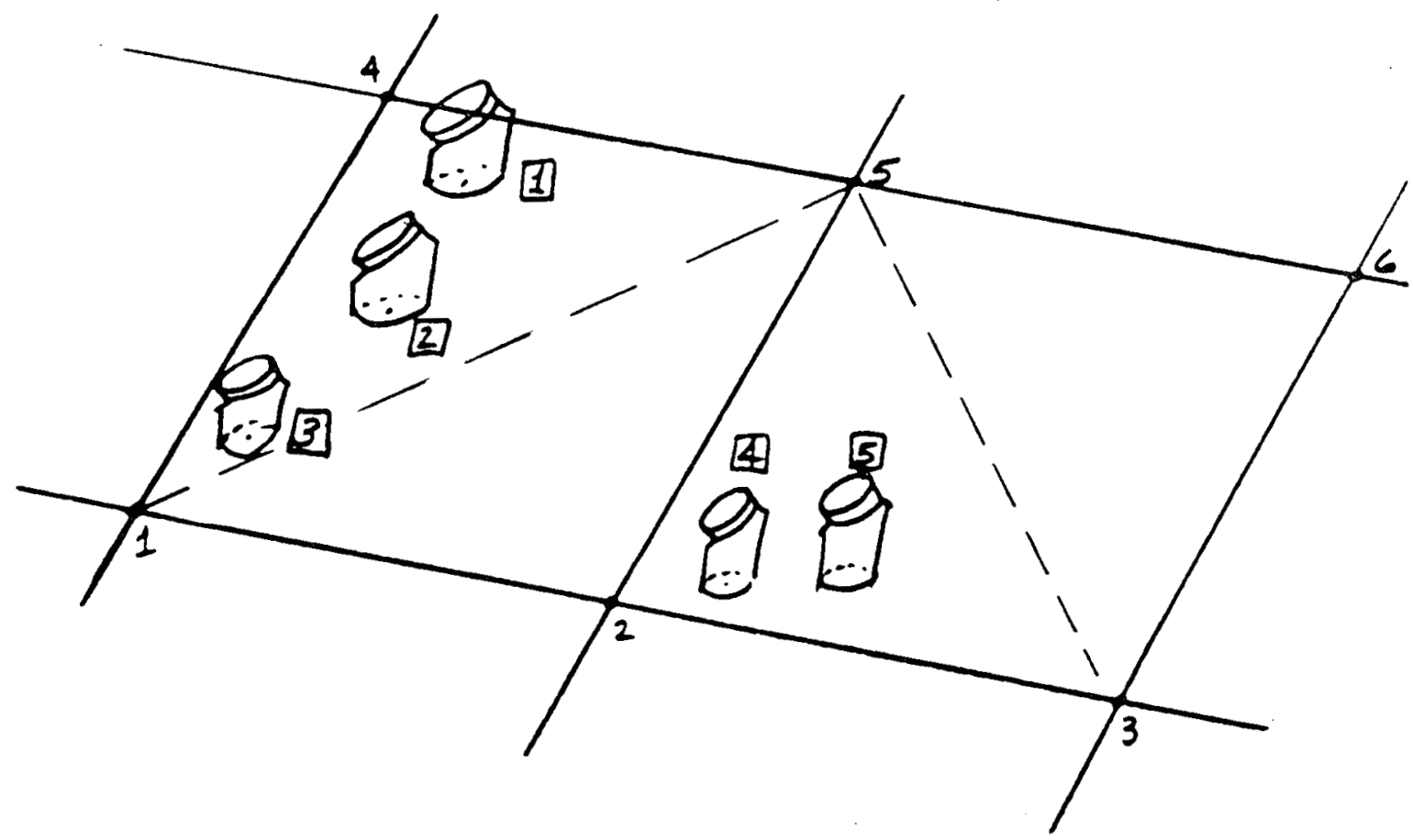

INPUT DATA:

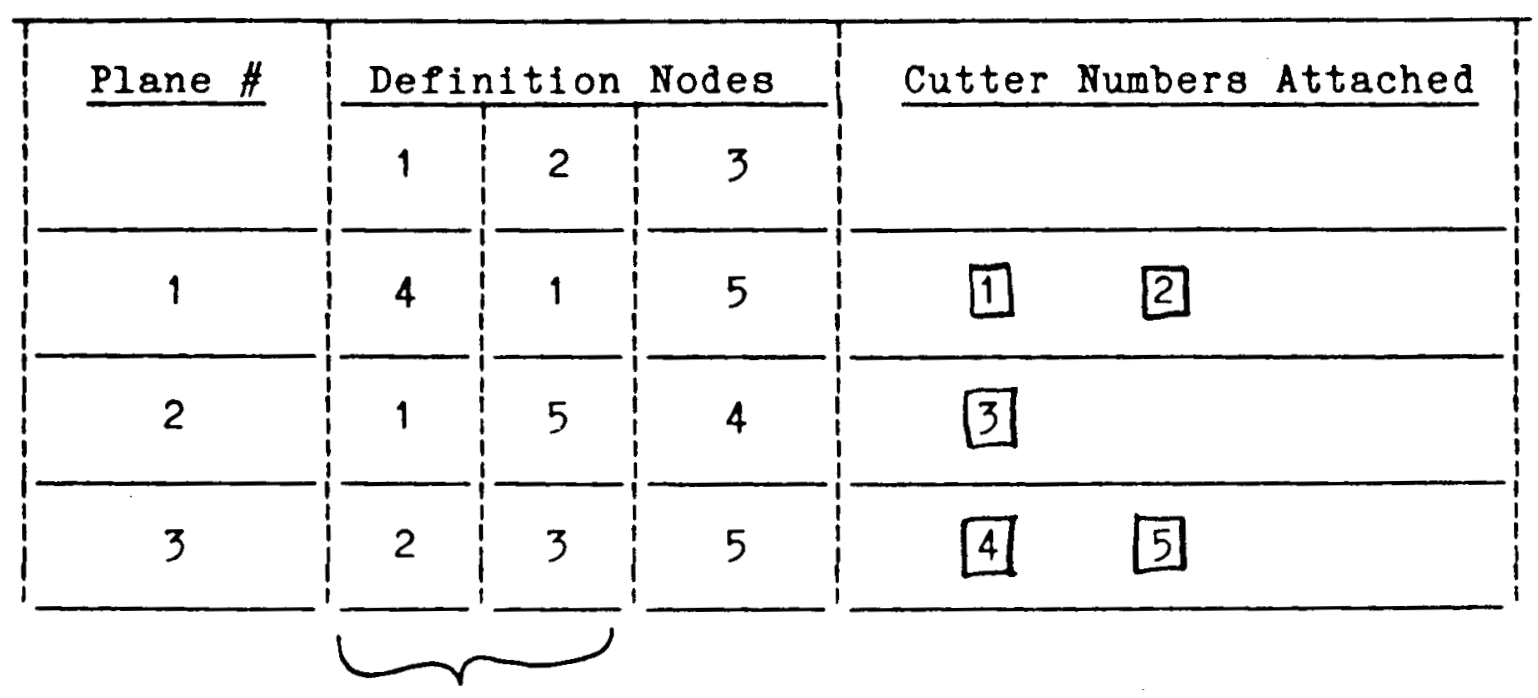

Called Side 1-2

FIGURE 2.2.1.1: Characteristic Plane Definition Data 
GENERAL REMARKS:

- Characteristic planes should be numbered such that when the right hand rule is applied, the resulting surface normal is outward.

- Notice that in the example, plane 1 and plane 2 are not the same. Although they use the same finite element node numbers, the order is different.

- When specifying characteristic planes keep this in mind:

a) The primary node (first in definition) is by far the most important since the translations of the primary node are applied directly to the cutters.

b) The second node in the definition should also be picked carefully, because the ghost-cutters are rigidly attached to Side 1-2.

c) The third point in the definition is only used to determine how much to rotate the cutters about Side 1-2. 
- No cutter may be attached to more than 1 characteristic plane.

- User should insure that every cutter is assigned to a plane.

\section{SPECIAL CASE: THE "BYPASS" METHOD}

- In the special case in which the characteristic plane experiences no appreciable rotation in the rotating $X Y Z$ system, the deformed coordinates of the geometric sub-node may be more simply calculated. For this case the nodal translations experienced at the closest node (see cutter definition) are simply added to the undeformed $X Y Z$ coordinates of the sub-node to obtain the new position of the sub-node in the rotating $X Y Z$ system. This is called the "Bypass" Method.

- The user is asked to specify what is to be considered "appreciable rotation" of the characteristic plane. The user inputs tolerances for the $X, Y$, and $Z$ components respectively. The 
displacement vector at each plane node ( $X, Y$, Z) is compared to the displacements at the other two nodes. If the difference between the two displacement values is greater than the specified tolerance for that component, the "General Transformation Method" is used to calculated the deformed ghost-cutter positions. Otherwise, the "Bypass Method" is used.

By entering very large or very small values of the tolerances, the user may force the program to always use one particular method:

If a very large tolerance is set, (i.e. 100), the program will always utilize the "Bypass Method".

If a negative tolerance is input, (i.e. -1), the program will always utilize the "General Transformation Method".

For more details regarding the "Bypass" and "General Transformation" methods of calculating the deformed cutter positions, see the Theoretical Manual. 


\subsubsection{ELEMENT SURFACE DEFINITIONS}

In order to distribute a cutter's force to the finite element nodes of the bit, and to investigate the cutter for possible failure, the program requires input defining the element surface to which the cutter is attached. The element surface definition is simply a list of 3 or 4 node numbers defining the exposed surface of a solid element to which a cutter is attached. (If the solid element is a "brick" element, the surface is defined by four nodes, while three node numbers are used to define the three-sided surfaces of "wedge" elements.)

The input data required for each element surface is

a) Four node numbers defining the surface. (For a three-sided surface, the fourth entry will be zero).

b) A list of ghost-cutter sub-element numbers which are attached to the surface. (Maximum number of cutters on any one surface $=10)$.

See Figure 2.2.2.1 for an example of element surface definition data. 

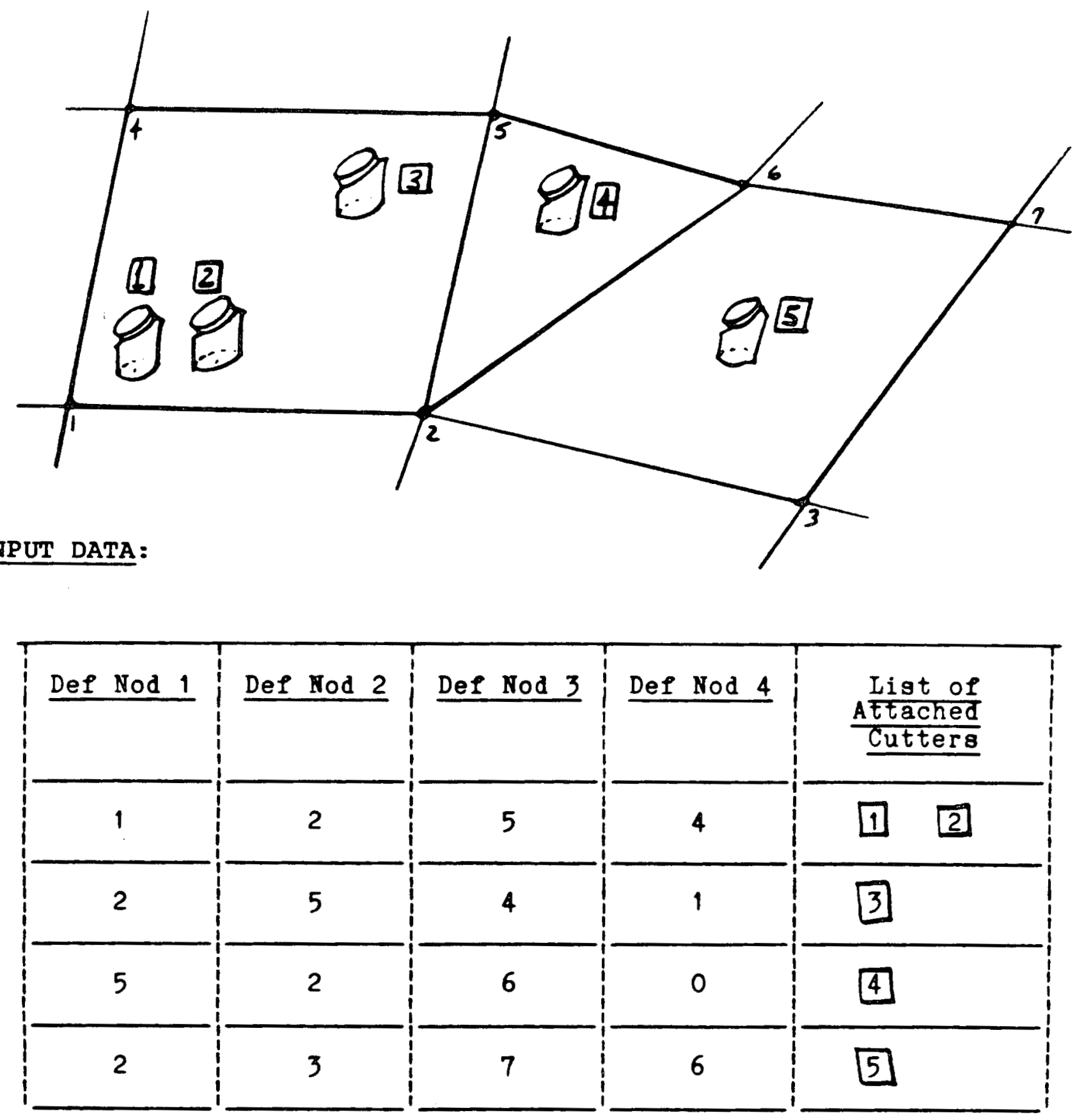

Notice that Surface 2-5-4-1 is not the same as

Surface 1-2-5-4. The first 3 nodes are used to

define the orientation of the failure plane.

(Plane 2-5-4 might not be parallel with

Plane 1-2-5.)

FIGURE 2.2.2.1: Element Surface Definition Data 
GENERAL REMARKS:

- No cutter may be attached to more than one element surface.

- The user should insure that every cutter is attached to an element surface.

- The element surfaces will not normally be equivalent to the characteristic planes. (The characteristic planes may, if desired, be defined with complete disregard for the element boundaries.) 
2.3 DRILL STRING NODAL NUMBERING CONVENTIONS

This section describes the nodal numbering convention which must be used for the drill string model.

\section{3 .1 GENERAL MODEL NUMBERING}

- 3-D, 8-node brick nodes must be numbered beginning with node number 1 and ending with the number of 8-node brick nodes. 8-node brick nodes on the top surface of the bit must be numbered consecutively, and be the highest node numbers in the bit. (Please see Figure 2.3.1.1.)

- Linear beam node numbers must begin with the next node number after the highest numbered 8-node brick node. They must then be numbered consecutively moving upwards towards the top of the drill string. (Please see Figure 2.3.1.1.)

- Ghost Cutter sub-node numbers must start at 1 and be numbered consecutively. 


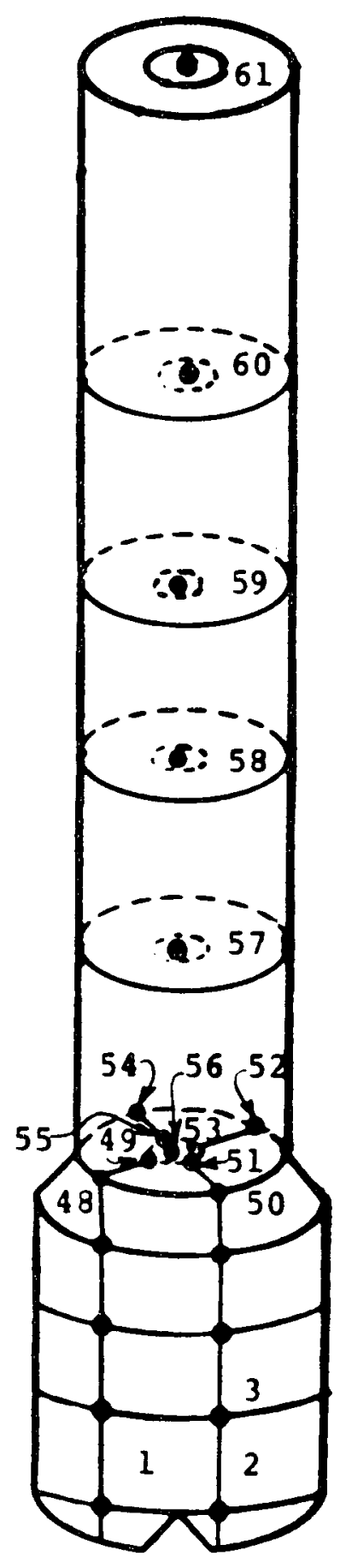

Total Brick Nodes: 55

Brick Node Begin With: 1 End With: 55

Highest Numbered Brick Nodes on Top Surface of Bit.

Beam Nodeg Begin With: 56 Numbered Consecutively Moving Up.

$$
\text { Moving Up. }
$$


2.3.2 EXTERNAL NODE DEFINITION

- Any node which enters into the ghost cutter characteristic plane or element surface definitions must be defined as an external node.

All linear beam nodes must be defined as external nodes.

- Note that all drill string nodes with the exception of those on the top surface of the bit (which are tied to the beam) could be defined as external nodes.

\section{3 .3 INTERNAL NODE DEFINITION}

Any 3-D brick node which does not enter into the definitions of characteristic planes or element surfaces and is not on the top surface of the bit (tied to the beam) may be defined as an internal node. Again, note that all beam nodes must be defined as external. 


\section{3 .4 TIED BIT NODES (CONSTRAINT TYING)}

- All 8-node brick nodes which are located on the top surface of the bit will be tied to the lowest beam node, and are all tied bit nodes. 


\subsection{ELEMENT CONSTRAINT TYING AND BOUNDARY CONSTRAINTS}

The drill string model can be thought of as being composed of two parts - the bit and the drill pipe. Because the bit and the drill pipe are physically connected such that the drill pipe and bit rotate as an integral unit, so too must the bit model be mathematically connected to the drill pipe model (beams). It is this mathematical connection of the drill pipe to the bit that is termed element constraint tying. In addition to the physical bit - drill pipe connection, the physical drill string is confined by the rotary table used in laboratory verification of the Phase 1 model. The corresponding confinement of the drill string in the model is accomplished by applying boundary constraints.

\subsubsection{ELEMENT CONSTRAINT TYING}

In modeling the connection of the bit portion of the model to the drill pipe portion of the model, it is assumed that the entire top surface of the bit (the surface of the bit at the bit - drill pipe interface) remains planar. Therefore, it is the objective of element constraint tying to relate (tie) the displacements, velocities, and accelerations of the degrees-offreedom on the top surface of the bit to the displacements, velocities, and accelerations of the degrees-of-freedom at the beam (drill pipe) node which is to be connected to the bit. It 
should be noted that bit nodes each have three degrees-offreedom, while beam nodes have six degrees-of-freedom. Please refer to Figure 2.4.1.1 and 2.4.1.2 for further clarification of the preceding discussion.

The nodal numbering convention, discussed in Section 2.3, stipulates that node numbers on the top surface of the bit must be the highest numbered bit nodes. The tying of the bit to the beam is accomplished internally. The user need only specify each node number that is on the top surface of the bit. Please refer to Figure 2.4.1.3 for an illustrative example.

\section{4 .2 BOUNDARY CONSTRAINTS}

The confinement of the drill string by the rotary table is currently modeled by restraining the degrees-of-freedom at the very top of the drill string. These degrees-of-freedom are restrained by attaching springs to each of the six degrees-offreedom at this beam node. The other end of these springs goes to ground. This is illustrated in Figure 2.4.2.1. As this figure shows, there are three translational springs, and three rotational springs. The user must supply values of stiffness of these springs. These values should be chosen to accurately simulate the manner in which the drill pipe is physically constrained. 
Figure 2.4.1.1: Tied Degrees-Of-Freedom
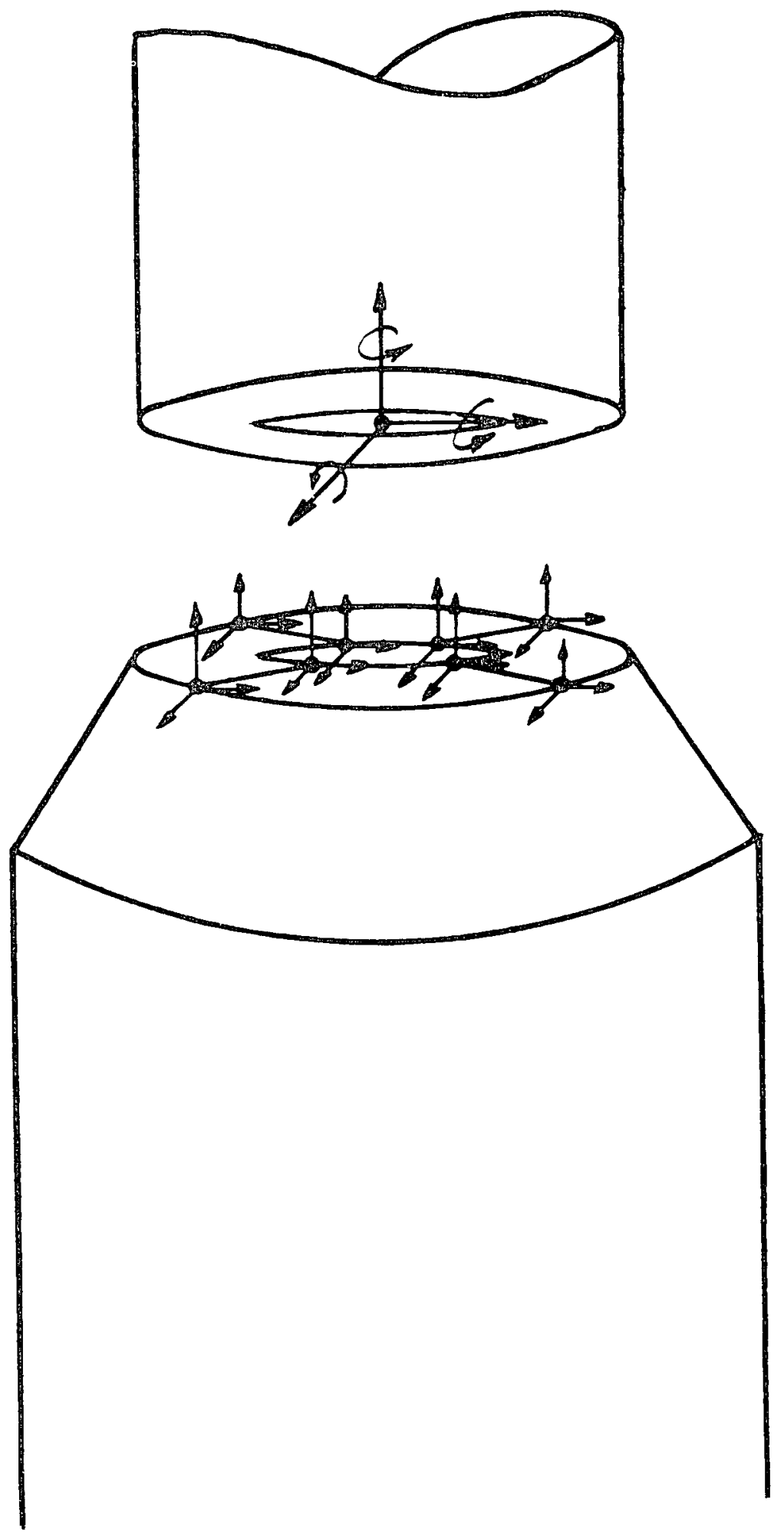
FIGURE 2.4.1.2: Top Surface of Bit Remains Plane
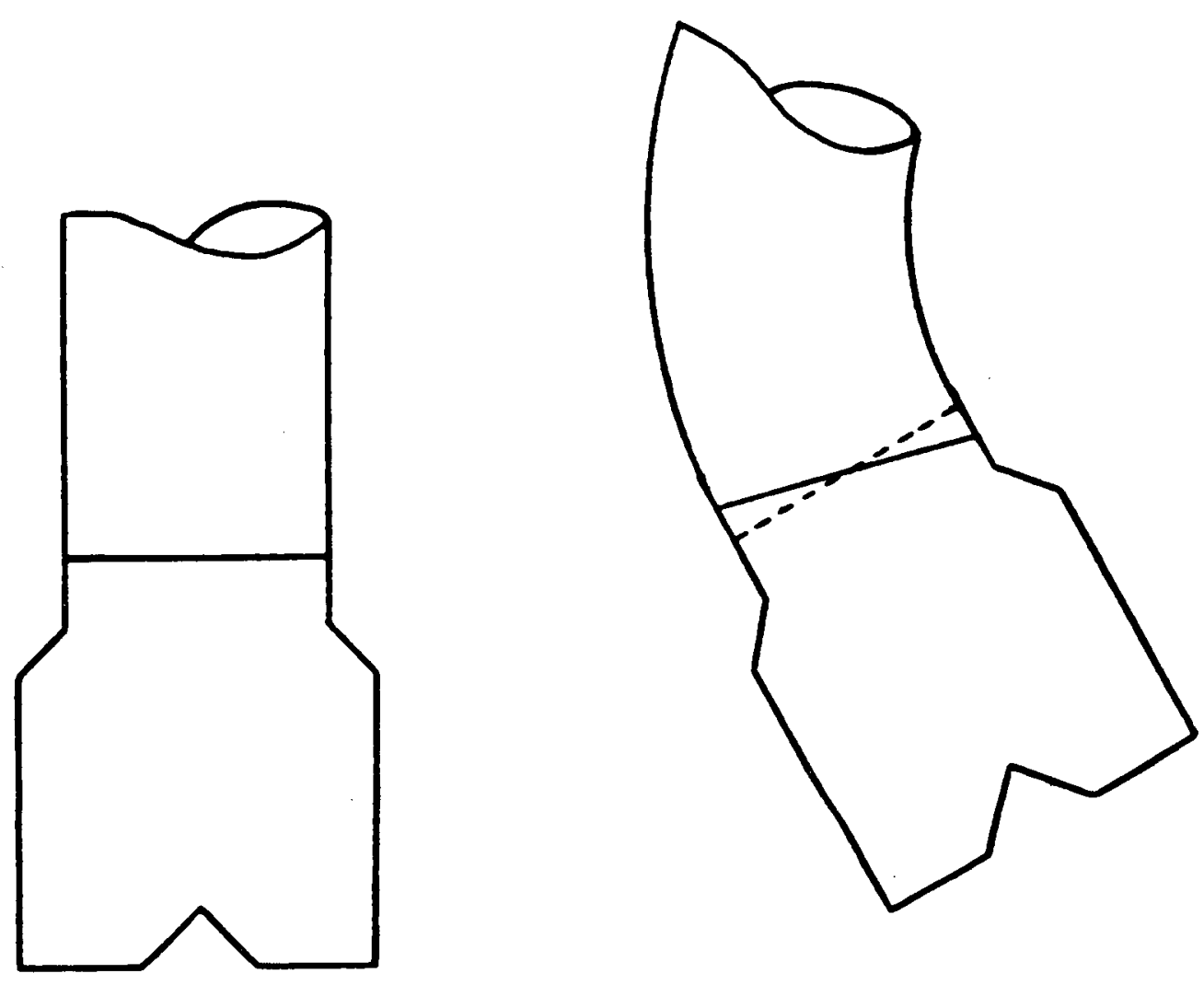

Undeformed - Top surface of bit is plane

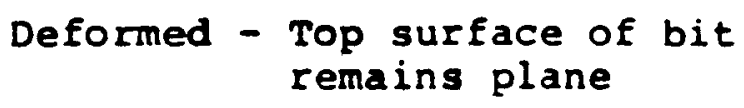


FIGURE 2.4.1.3: Tied Bit Nodes

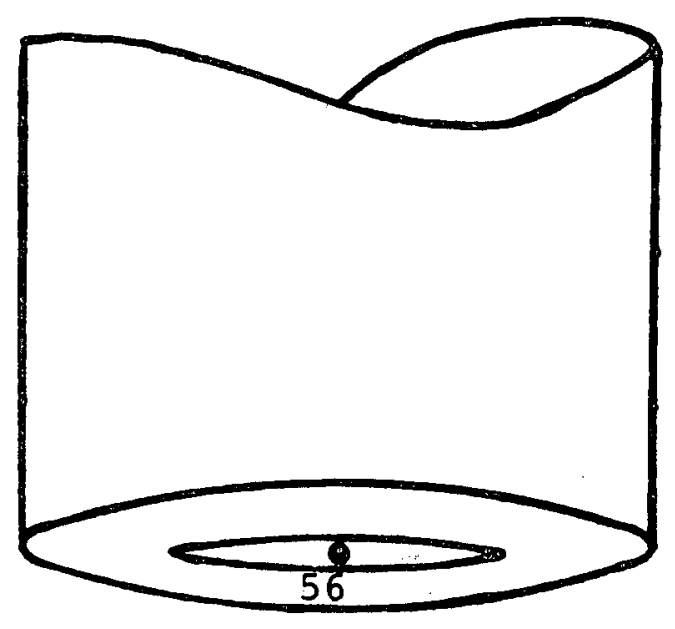

Tied Beam Node: 56

List of Tied Bit Nodes:

48

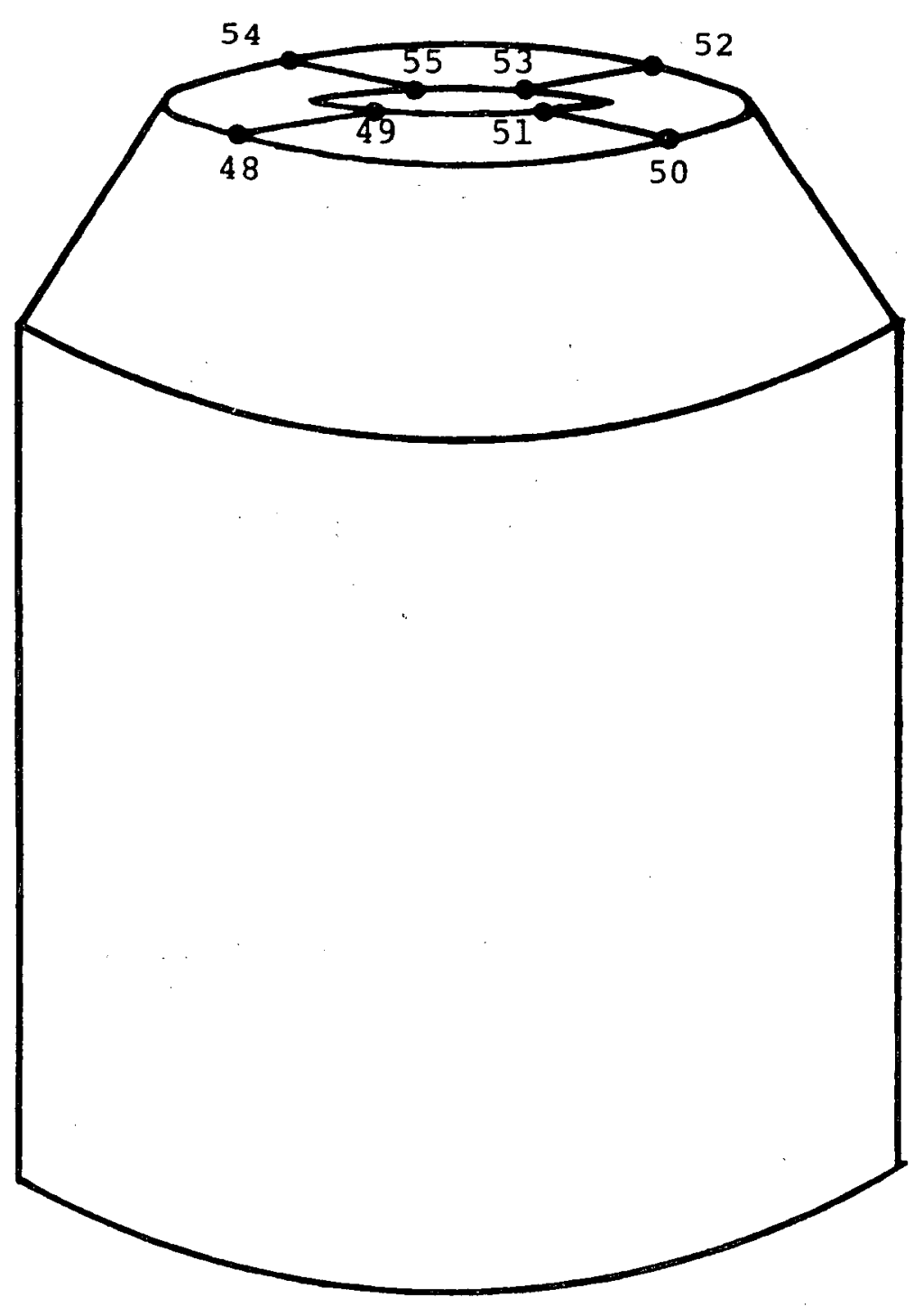

49
50

51

52

53

54

55

(A1l on top surface of bit) 
Once these spring stiffnesses have been determined, external forces may be applied to the six degrees-of-freedom having springs associated with them. These may take the form of forcing functions which may be applied to any or all of these restraining springs in order to model a certain condition. Once a condition has been modeled, a new restraining condition may be modeled by changing the forcing function rather than the spring constants. This has the advantage of not having to recalculate drill string Eigenvalues and Eigenvectors, since the drill string stiffness is unchanged. However, if it is desired to change these spring constants, only the six degrees-of-freedom in the stiffness matrix corresponding to the springs are altered. The remainder of the drill string stiffness matrix is not recalculated. However, new Eigenvalues and Eigenvectors will be computed, as will new modal stiffness (and mass) matrices. 


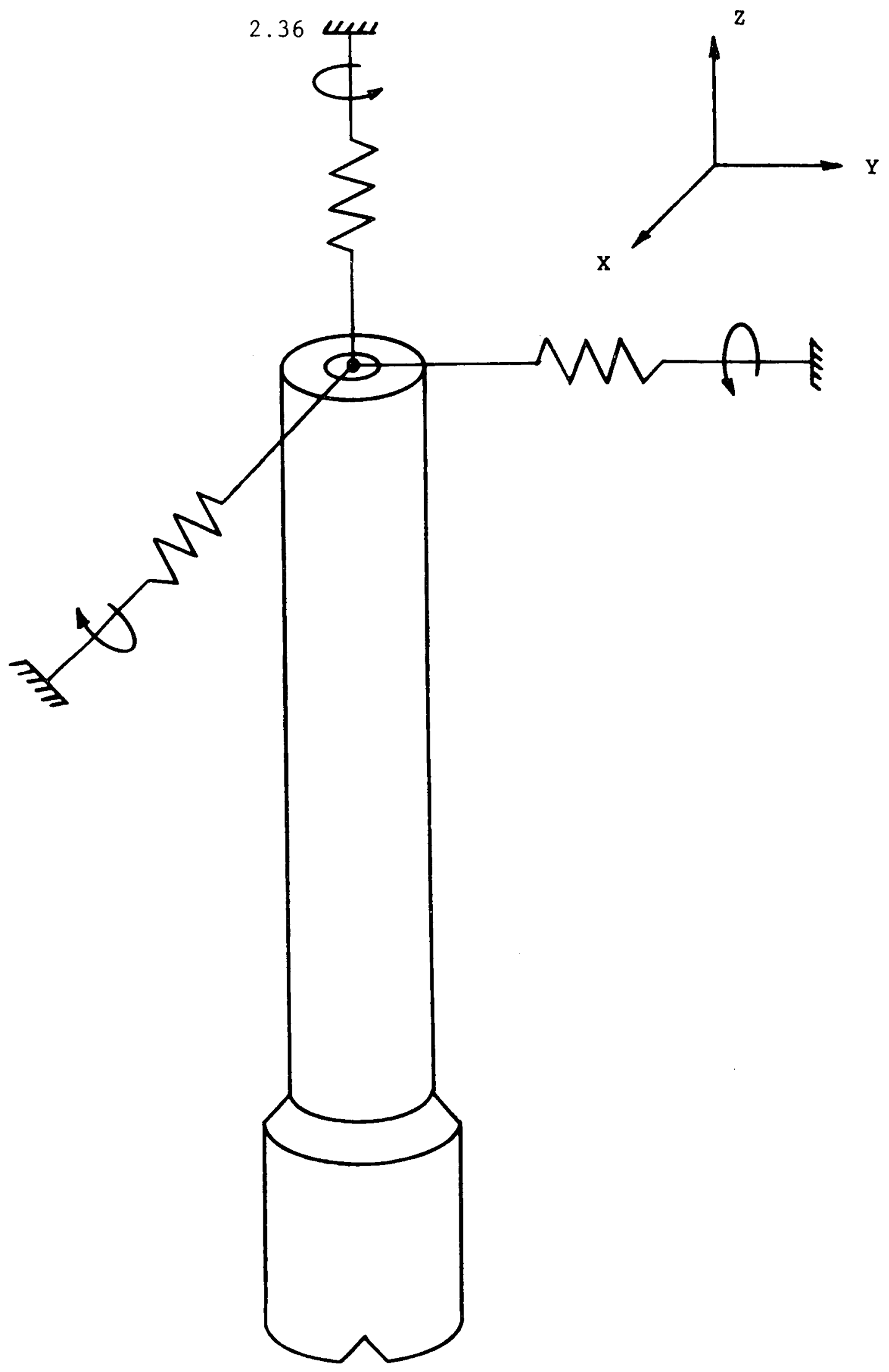

• 
2.5 SOLUTION OF EIGENVALUES AND EIGENVECTORS

In order to perform a dynamic solution, both Eigenvalues and Eigenvectors of the drill string system are required. The Eigenvalues are used to calculate the natural frequencies of the drill string. The natural frequencies are used to determine an appropriate time step size, as well as the frequency range to consider in the modal analysis. The Eigenvectors are used to transform various matrices and vectors from the rotating coordinate system to the modal coordinate system.

Eigenvalues and Eigenvectors are calculated by subroutines TRED2 and TQL2, which are part of the EISPACK subroutine library. For numerical conditioning of the input to these routines, each term of the drill string stiffness matrix is divided by a "normalization" factor. This factor is requested in the interactive input section of the program. A value of 1000.0 has been found to be effective for this quantity when the program is run on a VAX. This value may be different if the program is ran on a different computer system. Numerical accuracy of the Eigenvalue/Eigenvector solution is greatly improved by using this normalization factor . 


\subsection{MODAL REDUCTION}

Prior to the equations of motion being transformed from the rotating coordinate system (see Section 3.2.1) to the modal coordinate system (Modal Reduction), the user must supply two pieces of information. The first piece of information is the number of modes that are to be considered in the analysis. If desired, all modes of the drill string may be considered in the analysis. However, if the influence of the higher frequency modes may be neglected, the user may specify that fewer modes should be considered. To assist the user in making this decision, the list of drill string natural frequencies is printed. If only frequencies below a certain value are to be considered in the analysis, find this frequency in the list, and which natural frequency it is (20th, 30th, etc.). Then simply input that this many modes are to be considered in the analysis.

The second piece of information pertains to insuring that the modal reduction has been done correctly. Once the drill string stiffness and mass matrices have been transformed to the modal coordinate system, the resultant modal matrices should be diagonal. The user must define the criteria for deciding if these matrices are diagonal or not. The criteria for deciding that a matrix is diagonal is that within each row, the diagonal term of the matrix must be a certain many times larger than the largest off-diagonal term. The user must input this number. When GEODYN has been run on a VAX, a value of up to 1000 has been acceptable. 
The formation model has three separate portions (or sub-models) for which the direction of penetration varies: There is the "Bottom" surface, the "Side-wall" surface, and the "Incline" surface (see Figure 2.7.1). The direction of penetration for the bottom surface is always the negative $Z$ direction (regardless of whether the bottom is flat), and the penetration directions for the side-wall and incline surface are always perpendicular to the formation surface in question.

The formation points are arranged in a way which simplifies retrieving the point numbers. The two most important aspects of this approach are discussed below.

1. Uniform grid patterns are employed within each of the three portions of the formation model.

Bottom

An $X-Y$ grid is employed with $\Delta X$ constant and $\Delta Y$ constant (see Figure 2.7.2). 
Side-Wall

A $\theta-Z$ grid is employed with $\Delta \theta$ constant and $\Delta z$ constant (see Figure 2.7.3).

\section{Incline}

An "S"- $\ominus$ grid is employed, where $S$ is a measurement of distance up the incline as shown in Figure 2.7.4. $\Delta S$ is constant and $\Delta \theta$ is constant.

2. The formation point numbers for each of the formation sub-models are stored in arrays such that a point's row and column location is directly analogous to its position on the formation surface. The generation of the "formation mesh", therefore, amounts to the generation of the formation point number arrays. Although the formation point number arrays may be very large, the user need only specify minimal geometric information regarding the desired configuration, and the program internally generates the point number arrays. This step is called "Formation Mesh Generation" and is discussed in detail later in this manual. 

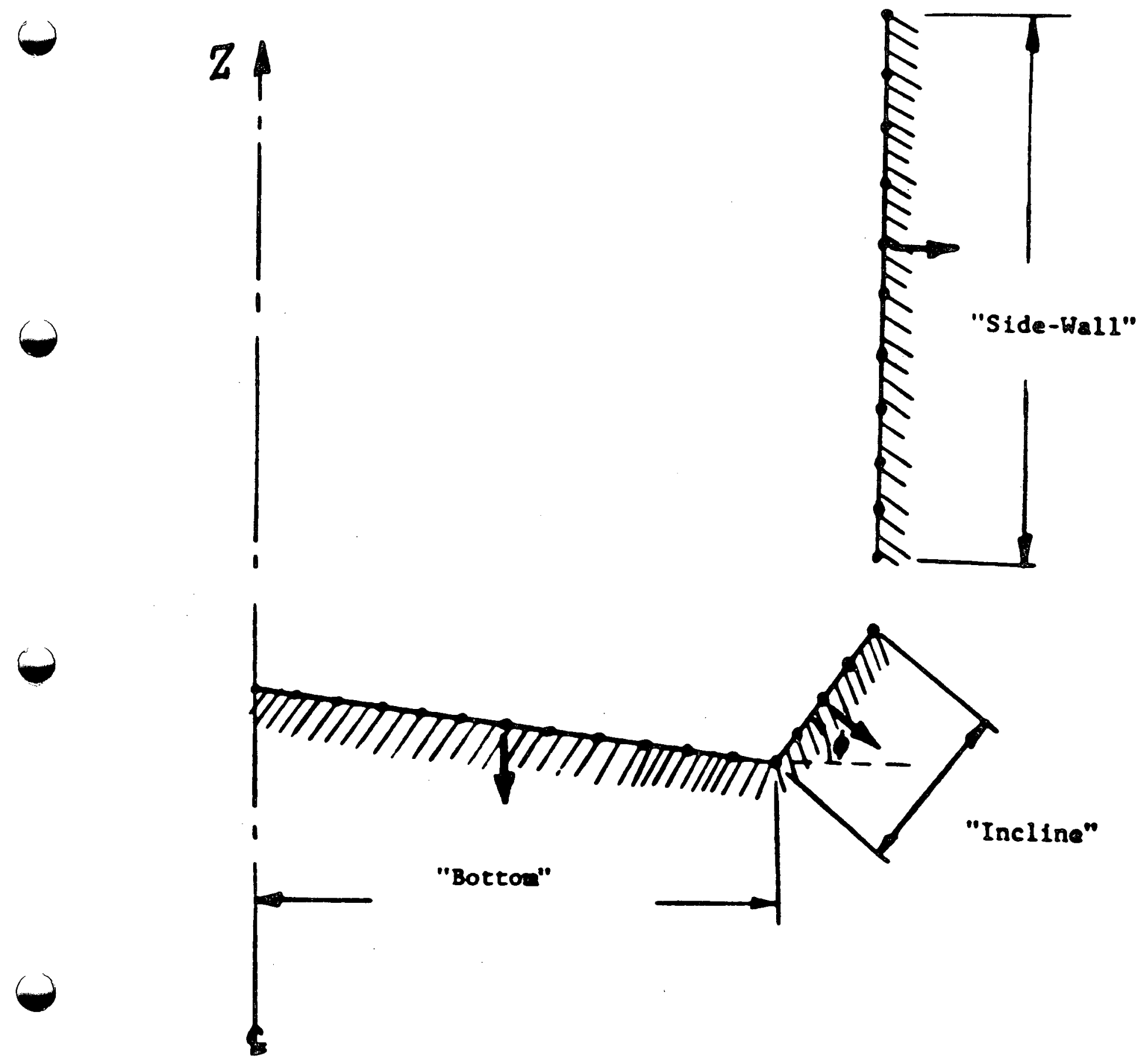

Hole Centerline

$\longrightarrow=$ Penecration Direction

FIGURE 2.7.1: Penetration Directions For The Three Formation Sub-Models 


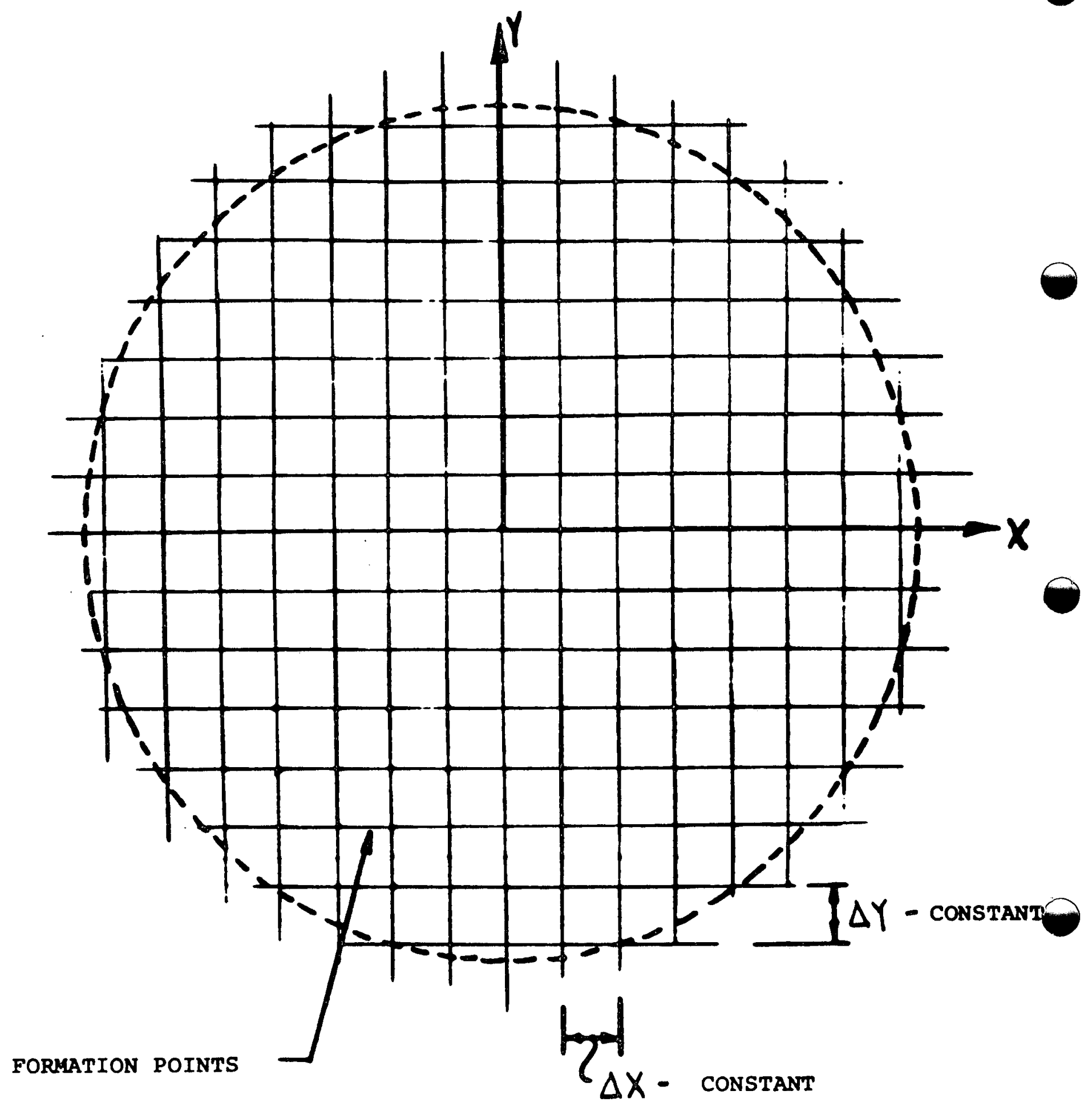

FIGURE 2.7.2: The Bottom surface Formation Sub-Model 


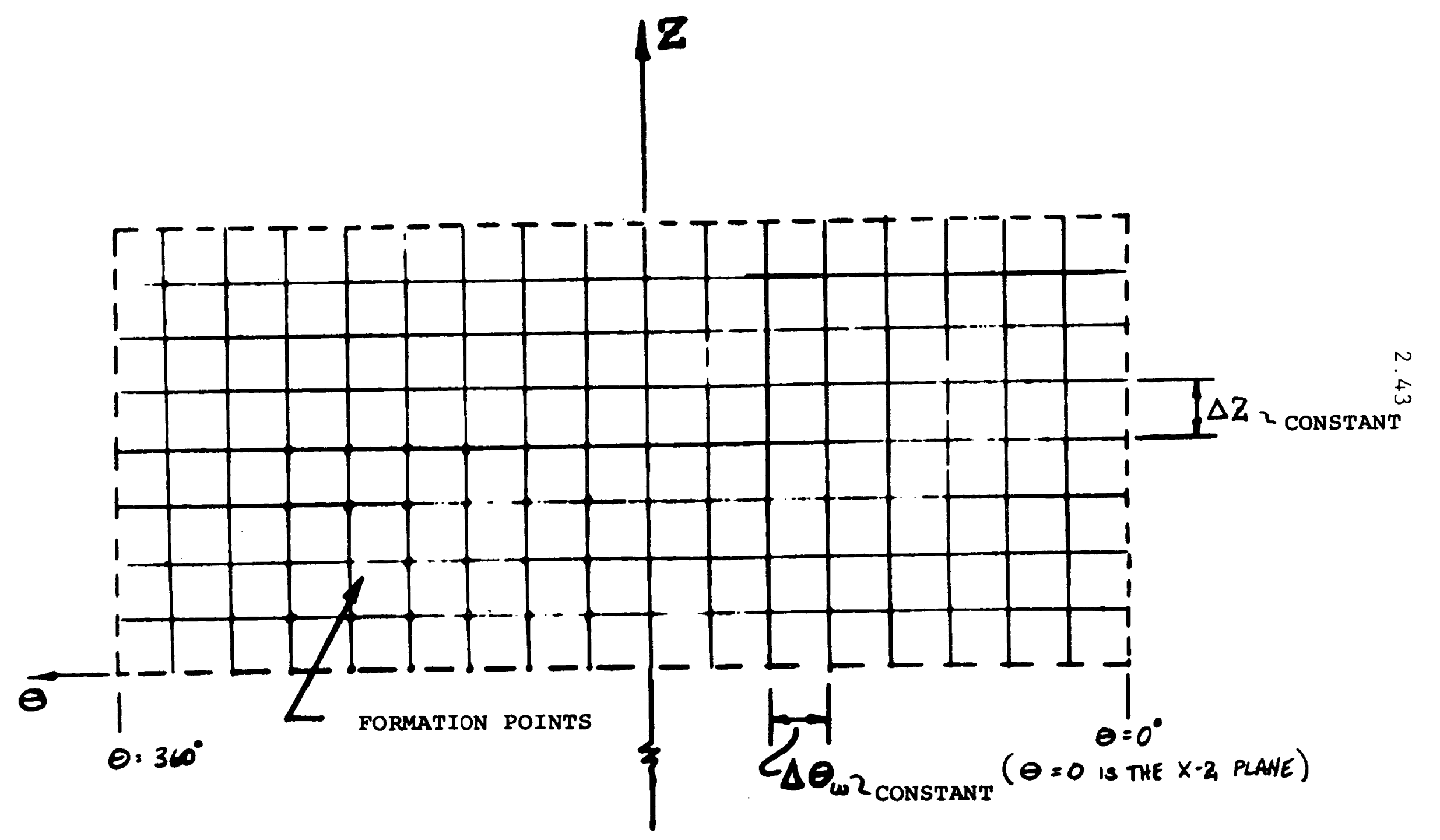

FIGURE 2.7.3: The Side-Wall Surface Formation Sub-Model (Opened Up) 

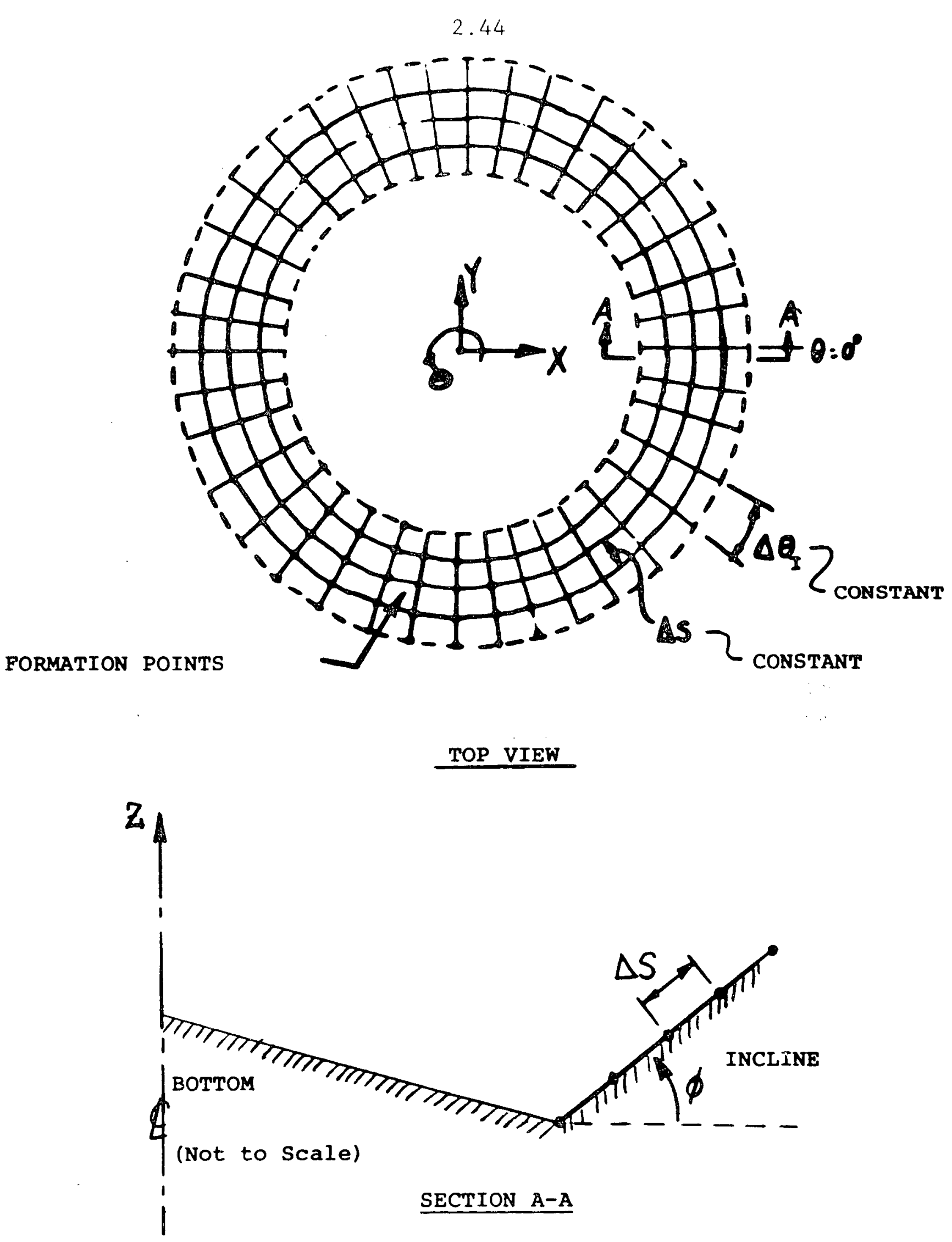

FIGURE 2.7.4: The Incline Surface Formation Sub-Model 


\subsection{SOLUTION ALGORITHM}

The user is given a substantial amount of control over the execution of the solution algorithm. This section describes the aspects of the solution algorithm which the user can control by the choice of input parameters.

\subsubsection{INCREMENTAL CONTROL}

For incremental control of the solution algorithm, the user must specify the following:

- The time step size, in seconds.

- The number of time steps to take for the complete analysis.

- (The number of time steps to take to accomplish the start-up procedure - Future.)

\subsubsection{ITERATIVE CONTROL}

For iterative control of the solution algorithm, the user must specify the following:

- The maximum number of iterations which should be allowed to obtain a converged solution for any time step. 


\section{8 .3 CONVERGENCE CRITERIA}

For control of the convergence criteria used in the solution algorithm, the user must specify the convergence tolerance, expressed as a percentage of successive displacement approximations. That is, if the difference between approximations of the displacement at the previous time step minus the displacement at the current time step between successive iterations is less than this input convergence tolerance, then the solution has converged.

\section{8 .4 OJTPUT CONTROL}

For output control of data generated by the solution algorithm, the user must specify the following:

The number of time steps to be taken between print stations. At each print station, the information shown in Figures 3.8.2.6 and 3.8.2.7

is written to the print file.

- The number of time steps to be taken between plot stations. At each plot station, the information shown in Figure 3.8.2.6 is written to the plot file.

- (The number of time steps to be taken between restart stations - Future). 
3.0 GEODYN FEATURES

The following chapter will provide the user with an overview of the basic capabilities of the GEODYN Program and how to exercise these capabilities. To facilitate this overview the structure and computational flow of the program will be presented in Figures 3.1 through 3.3. A section describing the coordinate systems utilized in the solution of the interaction processes which the program was developed to model will then be presented. A good understanding of not only the coordinate systems employed but the sign conventions consistent with these coordinate systems is essential. The results of the analytical problem solution will be output consistent with several of the coordinate system idealizations. This output will include finite element displacements, positions, velocities, accelerations, and force components in addition to ghost cutter sub-node point positions, velocities, accelerations, and forces.

Following this introductory material, Section 3.5 will detail the user's control of the generation of numerous external files utilized by the program. These external files will be utilized to store such information as the tied-system stiffness and mass matrices, the eigenvalues (natural frequencies actually stored) and eigenvectors, the contents of control common blocks and arrays contained in core (i.e. coordinates, connectivity, etc.), the modal stiffness, mass, and damping matrices, the formation's discrete point idealization and output files. External force and 
cutter-force qualification files are also utilized. In addition, future portals for the utilization of input data bases (i.e. coordinate and connectivity information) and a restart file have also been accounted for.

Subsequent to the discussion on external file control a section on the utilization of the bit (bit-sub) formation discrete point mesh generator will be included. Note that this capability will not be exercised when in the qualification solution mode. The final two sections contained in this chapter will detail the input and output features of the current Phase 1 GEODYN Program.

\subsection{TYPES AND CONMROL OF ANALYSIS}

The GEODYN Program can currentIy accomplish two major tasks. The first of these tasks is the generation of a finite element drill string model and the solution of the model's Eigenvalues and Eigenvectors. The second task (which cannot be performed until the first task has been completed) is the solution of the response of the model to dynamic loading. The program must be run each time one of these tasks is to be accomplished. This is clearly illustrated in Figure 3.1.

The choice of which of these two major tasks the program will perform is easily made by the user. When GEODYN is run, the Pirst interactive question asked of the user is which of these 
two options is to be performed. The interactive questions which then follow correspond to the user's response to the first question. Certain data entered by the user is checked internally for validity, regardless of which of the two options is being performed.

When solving for the response of the model to dynamic loading, GEODYN can currently solve two classes of problems. The first class of problems is when there is no formation present in the model. Because this was the nature of the various qualification tests which were made, this class of problem is termed a qualification problem. The second class of problems is when there is a formation present in the model. This class of problem is termed a formation interaction problem.

To solve a qualification problem, the user simply responds, when asked, that there is to be no formation used in the model. Note that forces can still be applied to ghost cutters by means of a cutter force file (see Section 3.5.12). Similarly, to solve a formation interaction problem, the user simply responds, when asked, that a formation is to be included in the model. 
FIGURE 3.1: EXECUTION OF GEODYN CODE

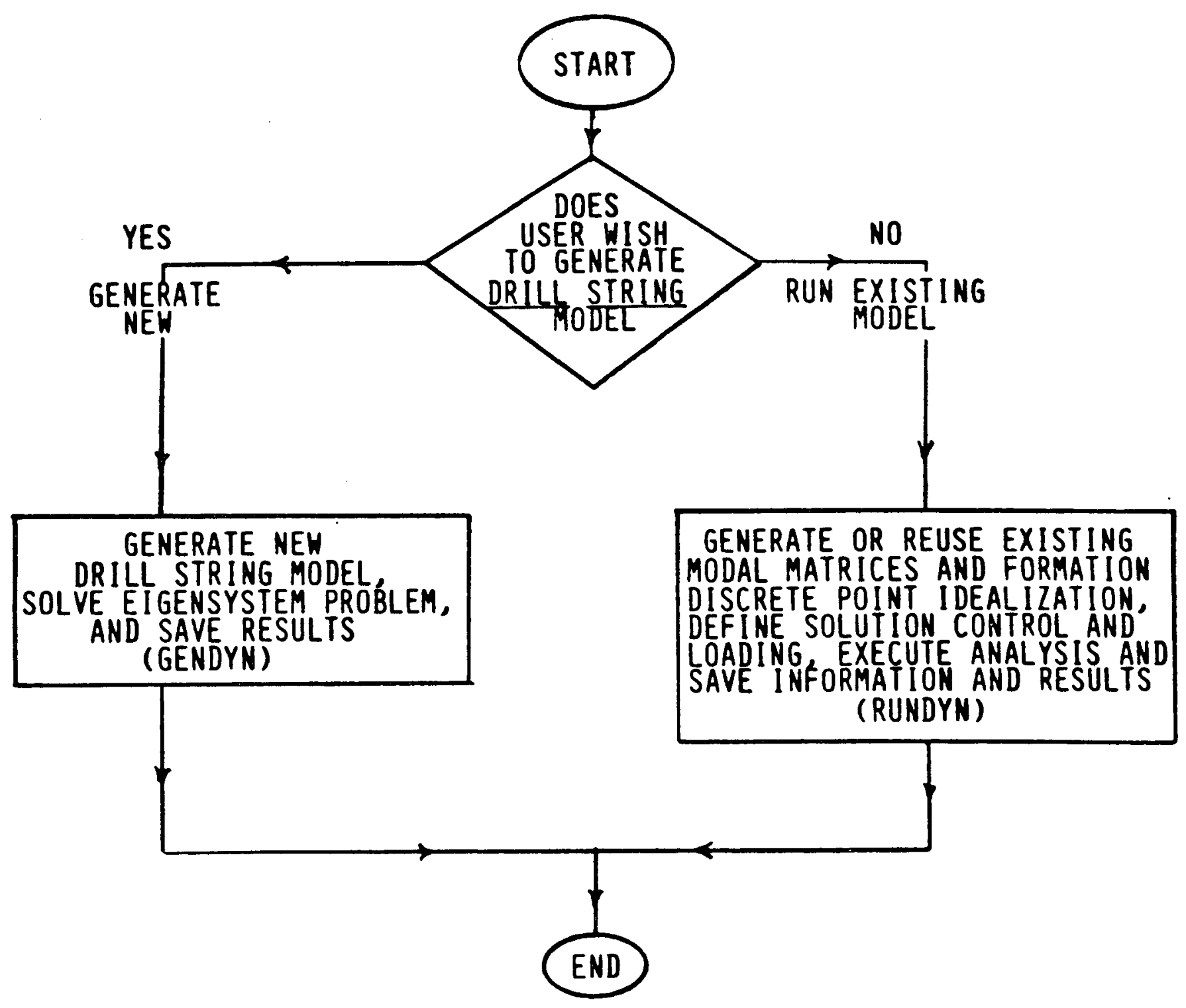


FIGURE 3.2: GENERATION OF DRILL STRING MODEL

(GENDYN)
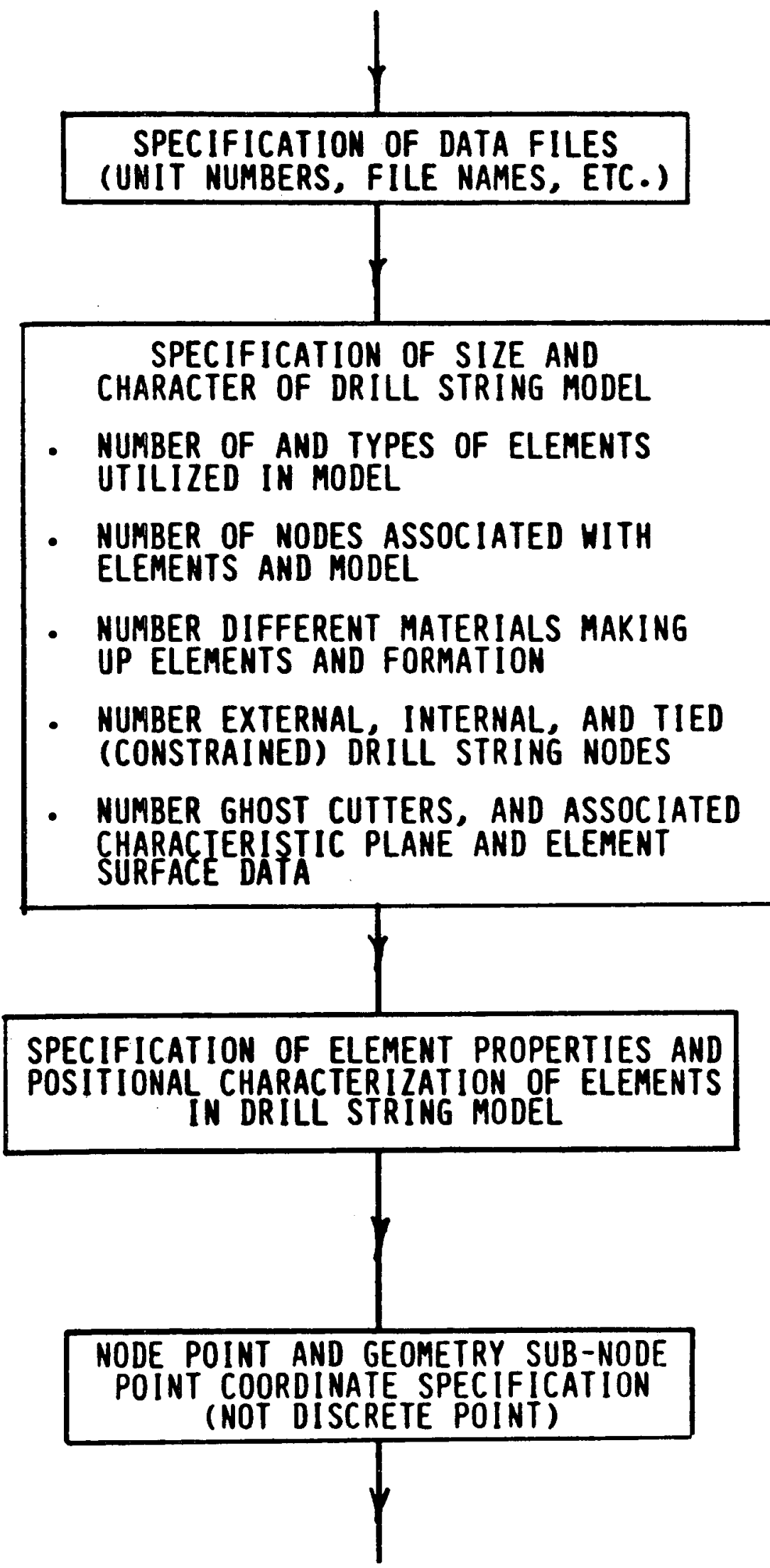
3.6

FIGURE 3.2 - CONTINUED

(GENDYN - CONTINUED)

INPUT ELEMENT CONNECTIVITY, AND GHOST CUTTER CHARACTERISTIC PLANE AND ELEMENT SURFACE DEFINITION DATA

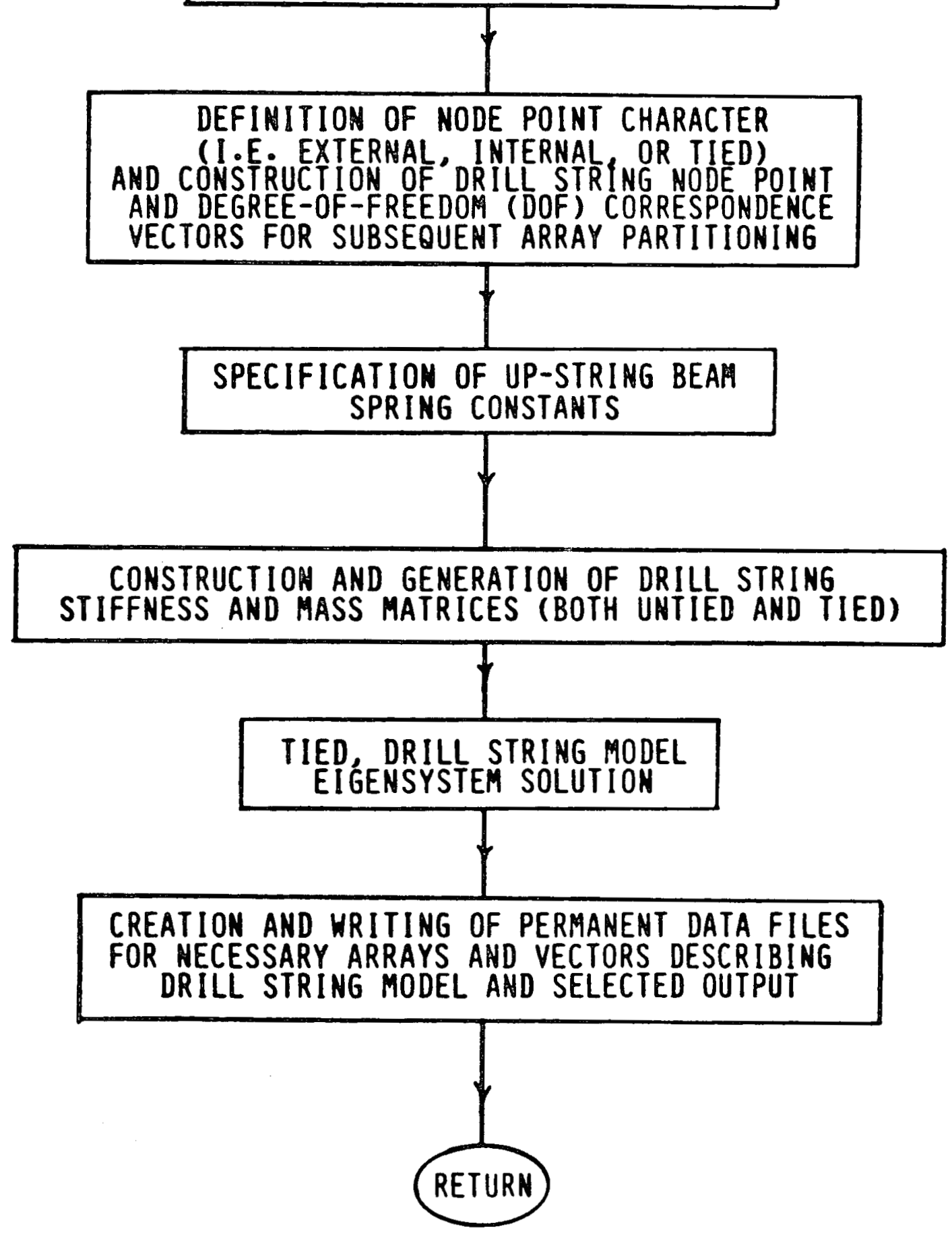


FIGURE 3.3: EXECUTION OF DRILL STRING - FORMATION DYNAMIC INTERACTION ANALYSIS

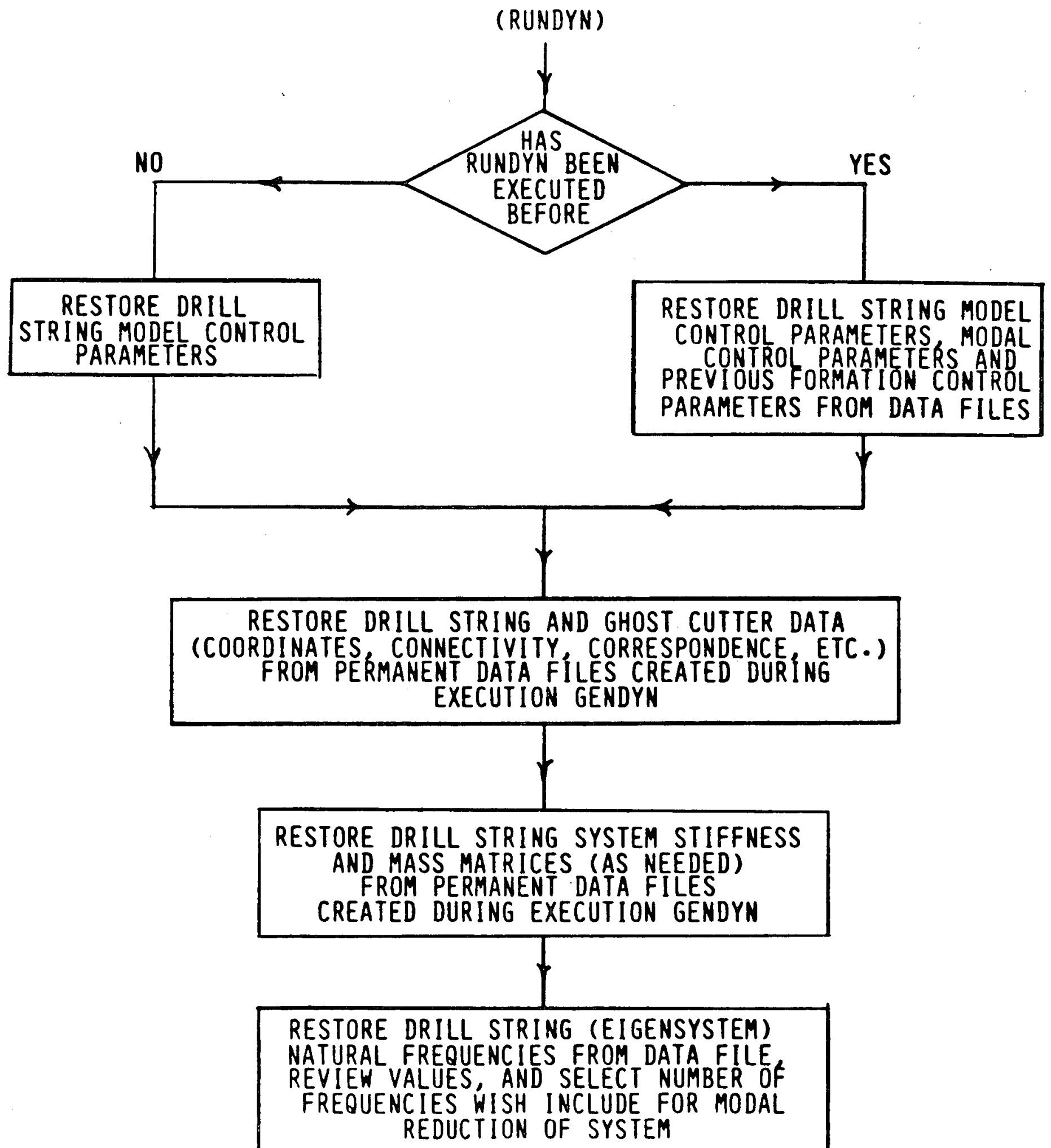


(IF A PREVIOUS

EXECUTION OF RUNDYN PERFORMED NUMBER FREQ.>0)
3.8

FIGURE 3.3 - CONTINUED

(RUNDYN - CONTINUED)
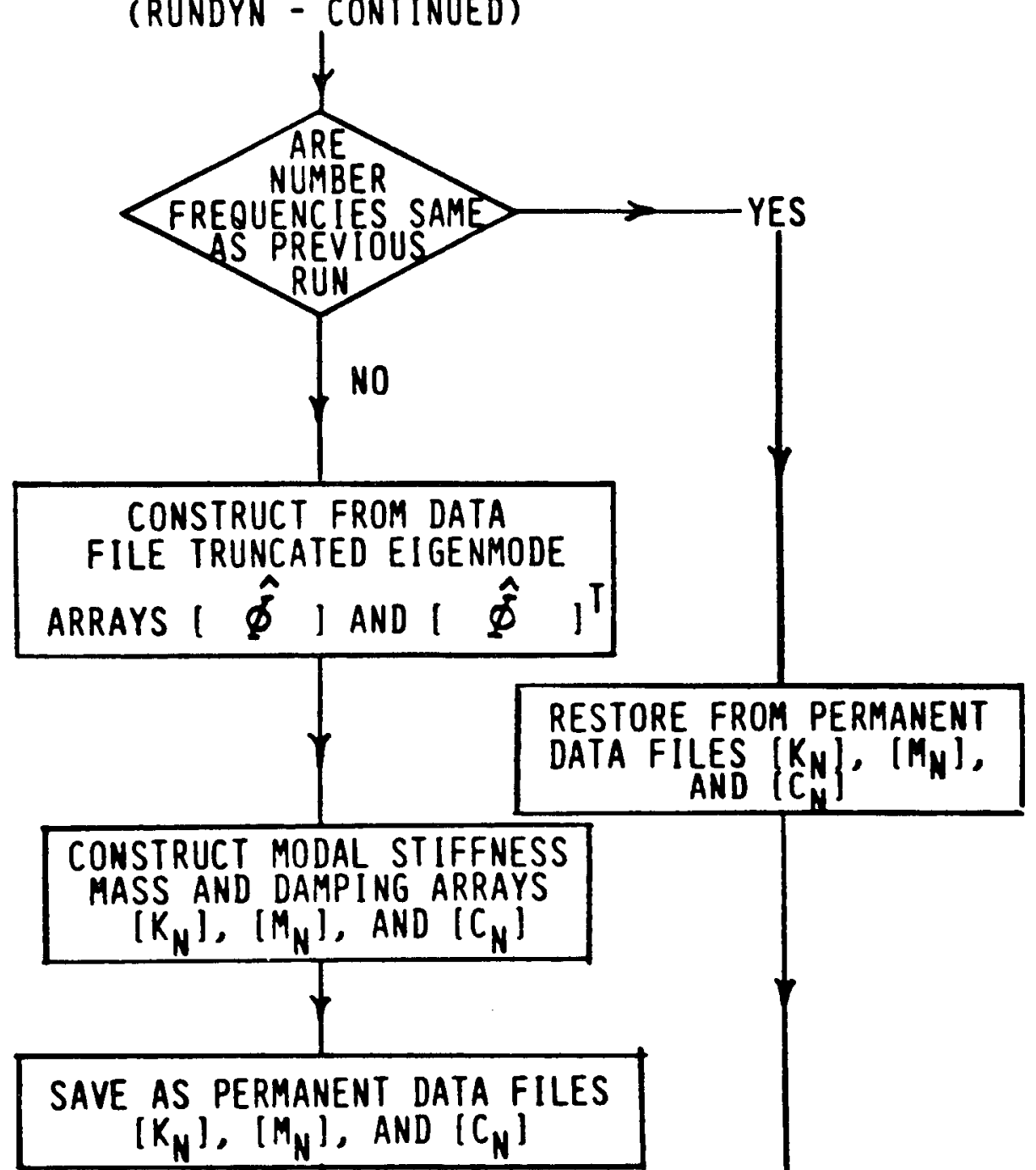

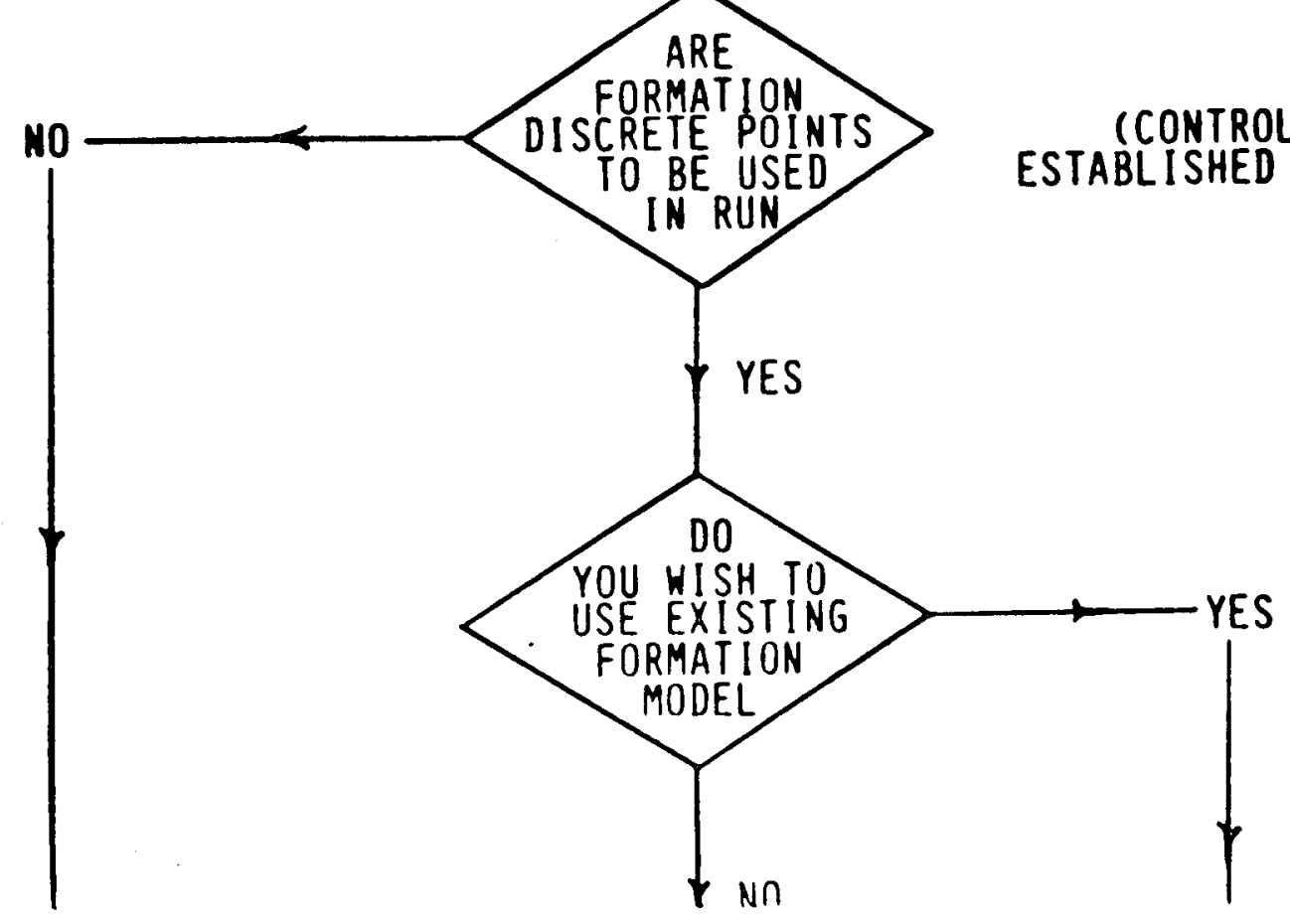

YES 
FIGURE $3.3^{3.9}-$ CONTINUED

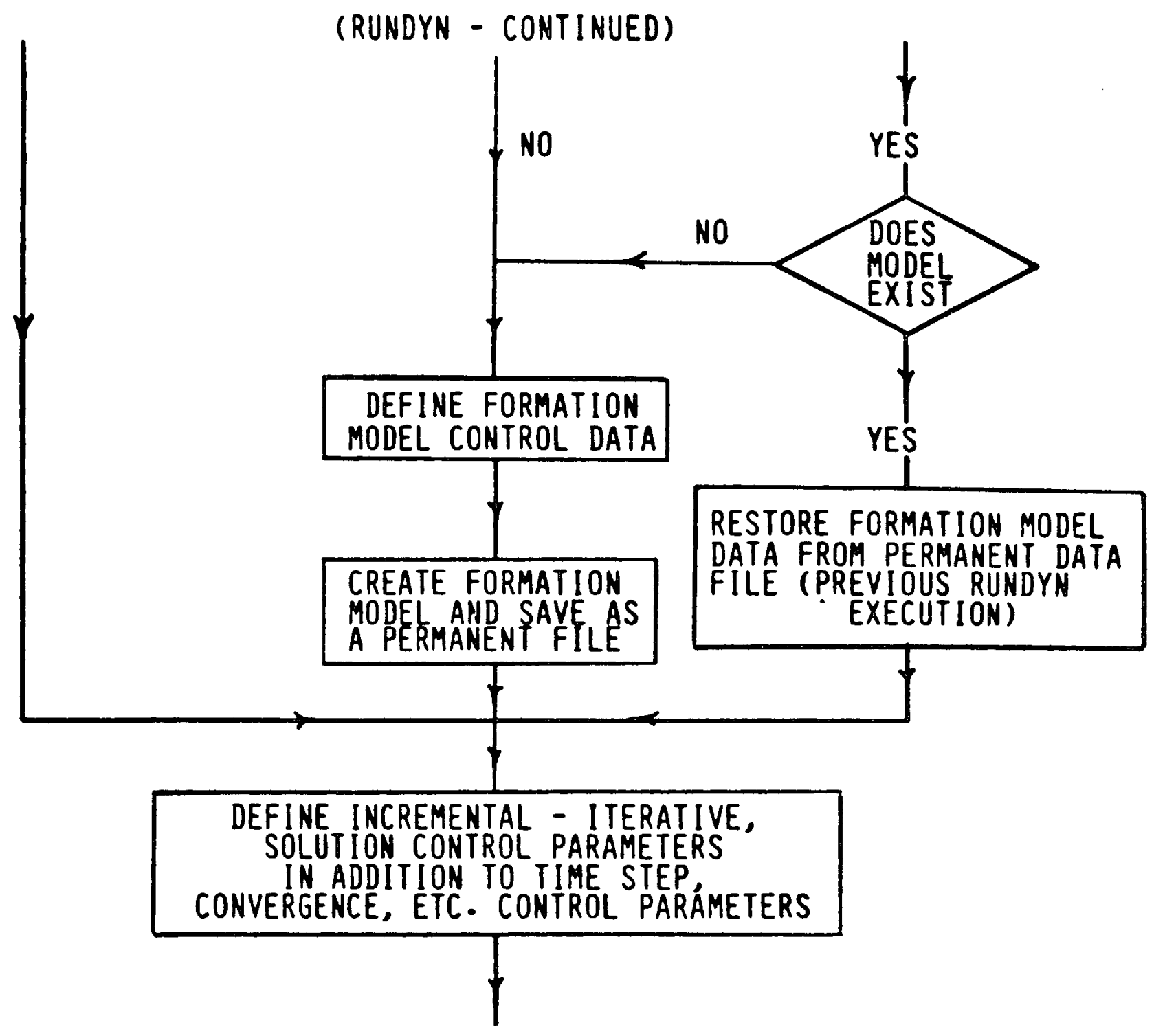

(INITIATE SOLUTION PROCESS)

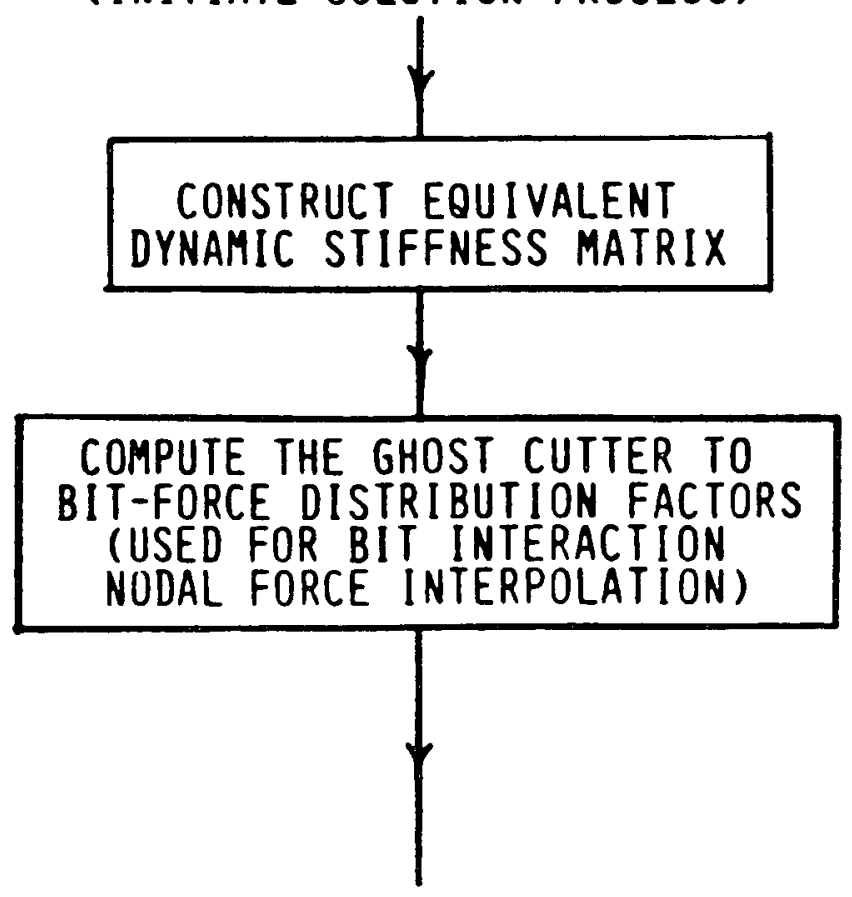




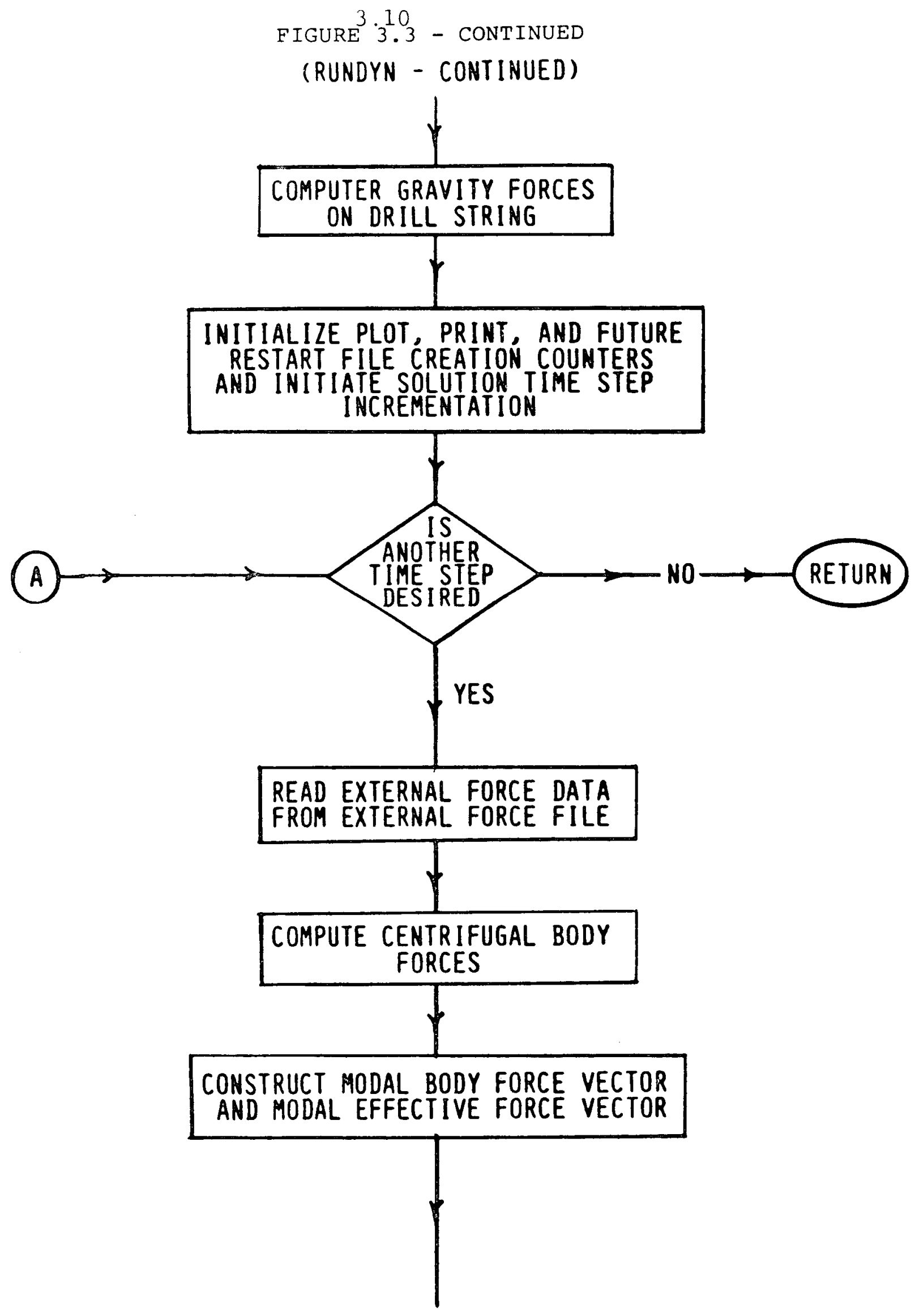


3.11

FIGURE $3.3-$ CONTINUED

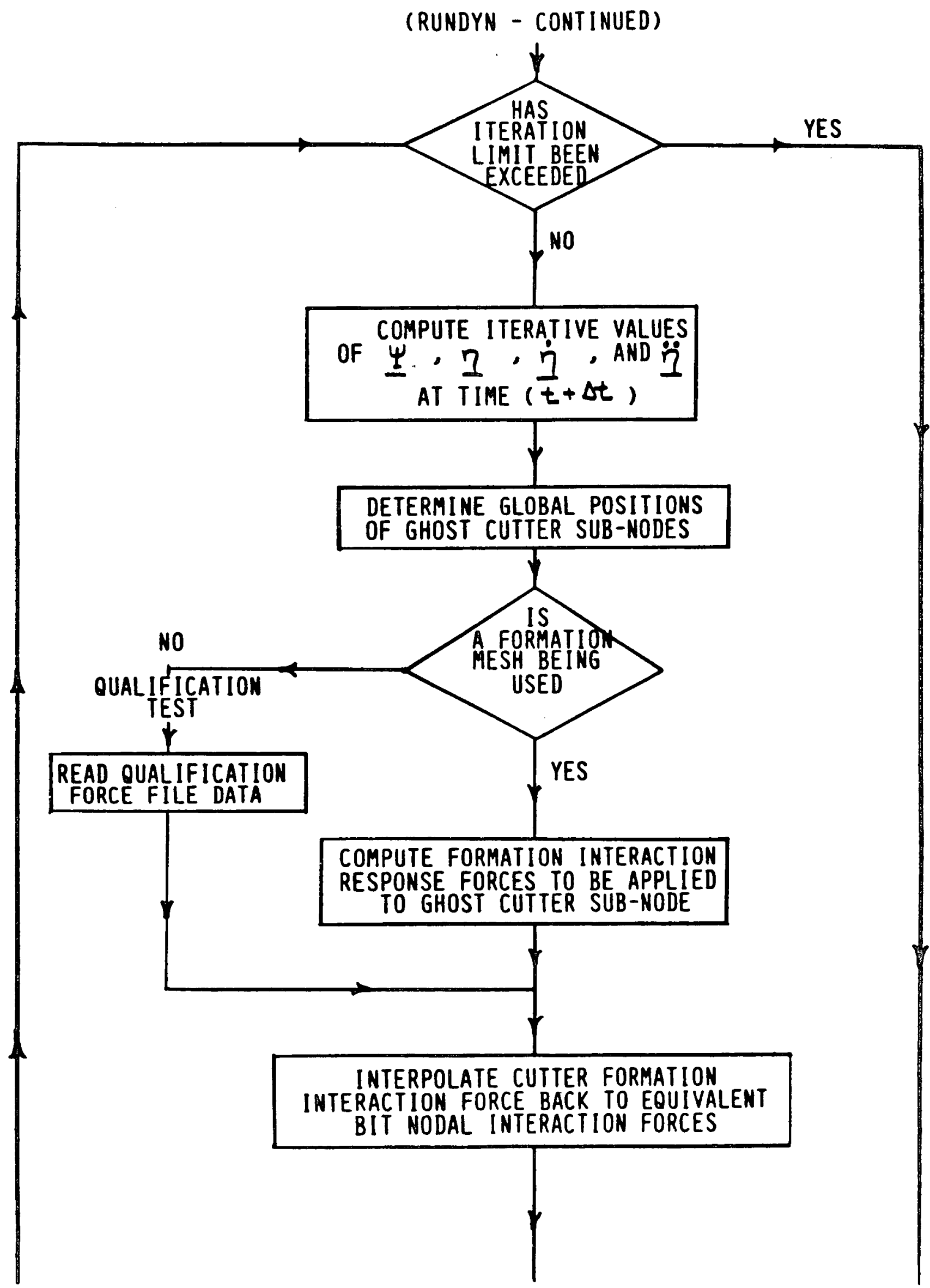


3.12

FIGURE 3.3 - CONTINUED
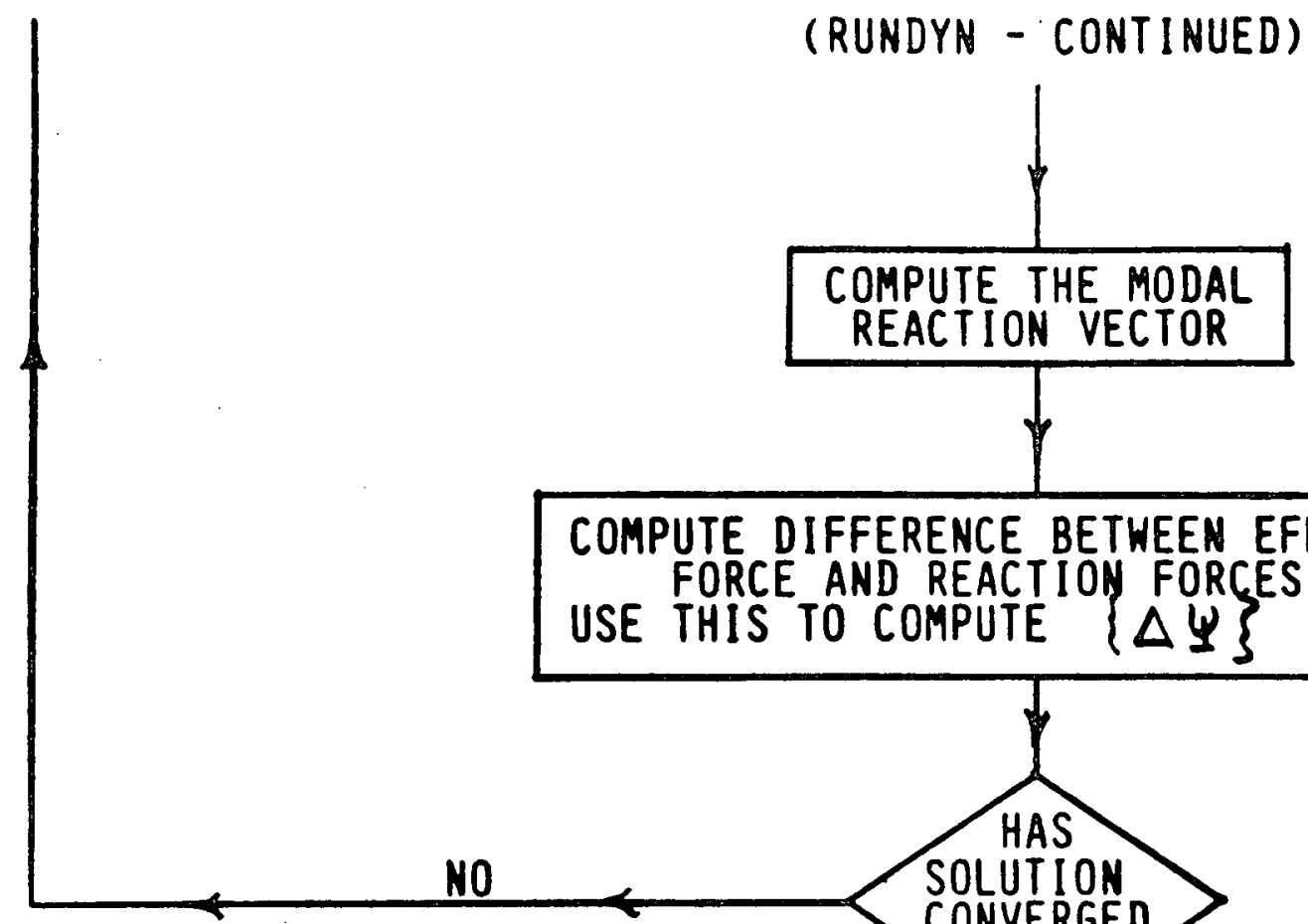

\section{COMPUTE DIFFERENCE BETWEEN EFFECTIVE} FORCE AND REACTION FORCES AND USE THIS TO COMPUTE $\{\Delta \Psi\}$ VECTOR

NO

YES

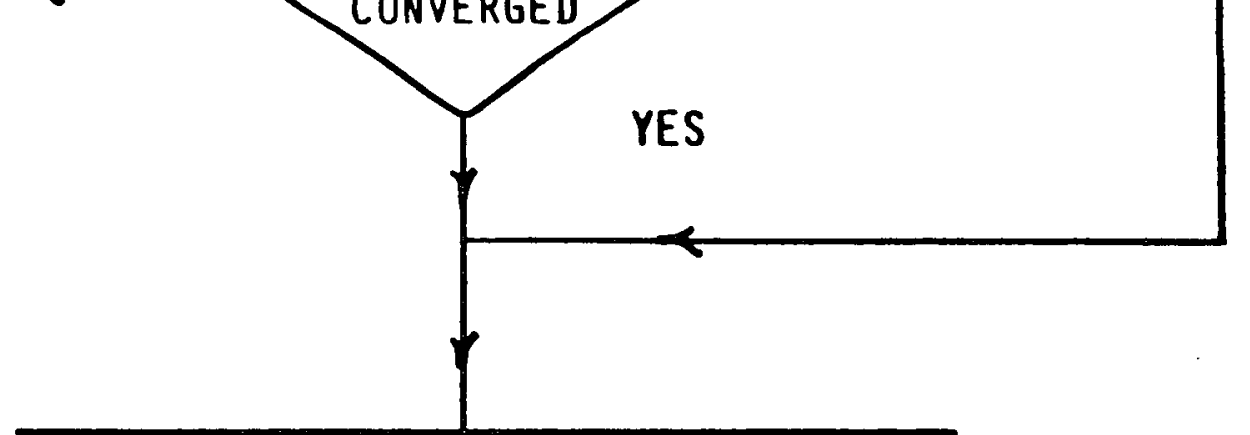

UPDATE VARIOUS DISPLACEMENT

AND LOAD VECTORS FOR NEXT

TIME STEP AND WRITE PERTINENT DATA

TO PLOT OR PRINT FILES

(FUTURE RESTART) IF SPECIFIED

BY USER 
3.2 COORDINATE SYSTEMS

Two coordinate systems are primarily used to solve and report system forces, displacements, velocities, and accelerations. These are the drill string rotational coordinate system and the global coordinate system. The z-axes of these two coordinate systems are always coincident. The $x$ and $y$ axes may also line up at time $t=0$, but they do not have to. Please refer to Figure 3.2.1 for a sketch of these coordinate systems.

\subsubsection{THE DRILL STRING ROTATIONAL COORDINATE SYSTEM}

The rotational coordinate system is a right-handed rectangular Cartesian coordinate system which rotates in a positive sense about its z-axis. This coordinate system rotates at the same angular velocity $(\omega)$ as the drill string. The drill string and the rotational coordinate system rotate at a constant angular velocity ( $\omega$ is constant). This coordinate system is used to represent drill string finite element forces, displacements, velocities, and accelerations. Displacements, velocities, and accelerations expressed in terms of this coordinate system are essentially relative only to those quantities at other degreesof-freedom which are also rotating with the coordinate system. In other words, a displacement in the rotating coordinate system 


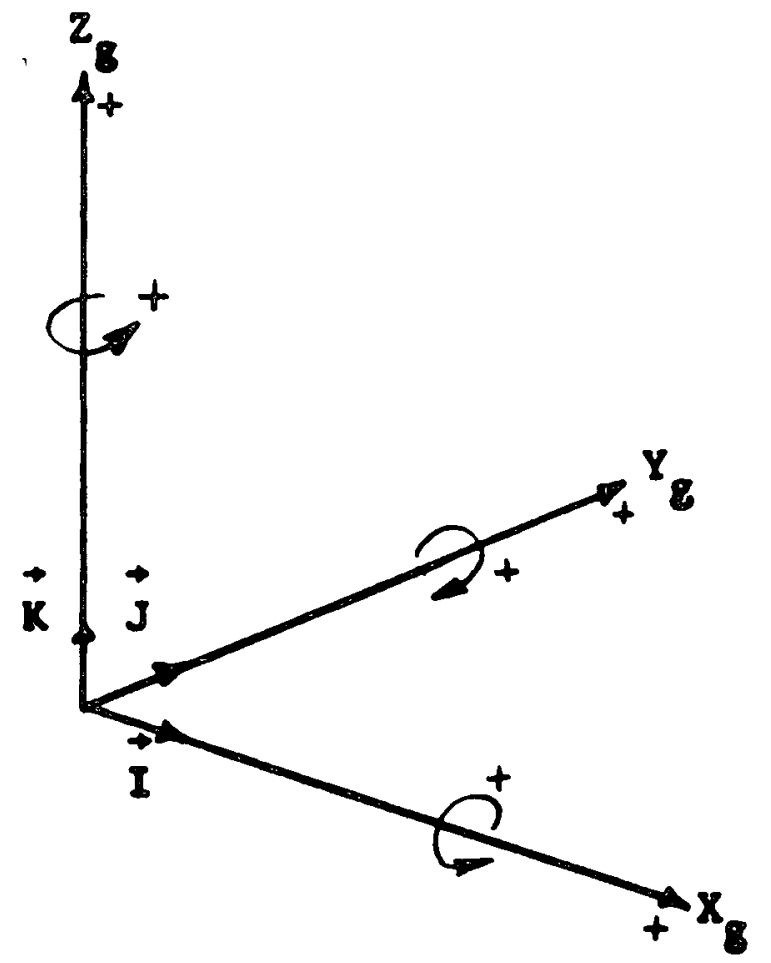

a) The Globsl Flxed Inertial $X_{g}, Y_{g}, Z_{g}$ Coordinate System Used for Defining the Hellbore Geometry and the Bormation Mater1 1 Propert1es

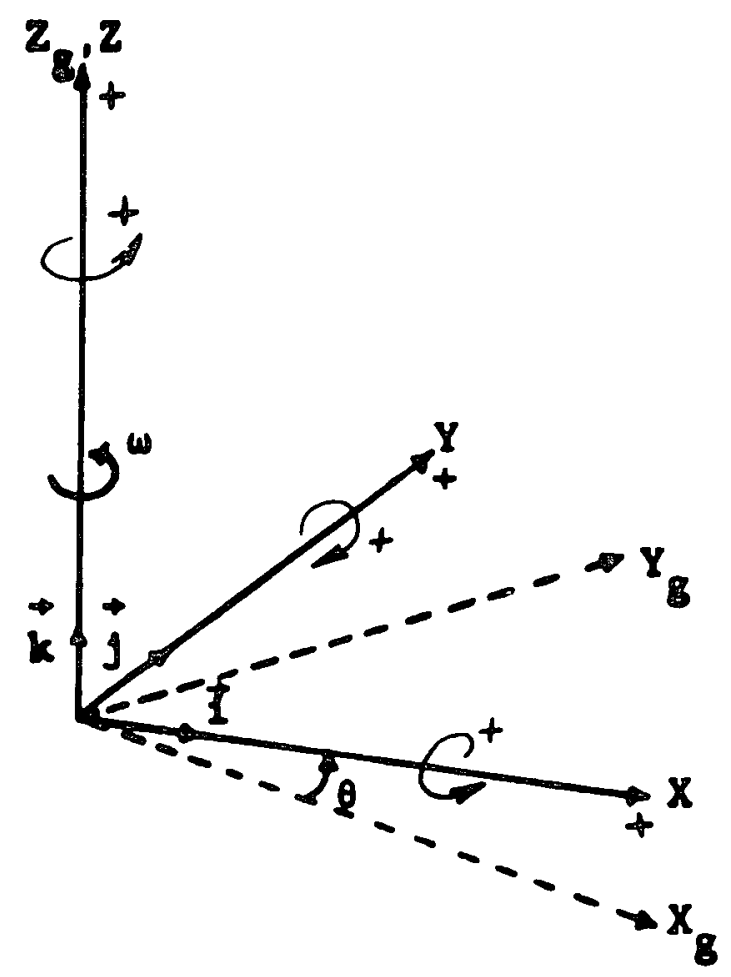

b) The Locsl Rotating $X, Y, Z$ Coordinate Systen Used for Defining the Finite I l Model of the Bit-Bit Sub System

FIGURE 3.2.1: Definition of the Two Governing Right Hand Rectangular Cartesian Coordinate Systems of the Global Computational Algorithm for Modelilng the BDC Bit-Bit Sub./Formation Interaction 
does not include the displacement of the degree-of-freedom due to the rotation of the drill string. It is strictly a finite element displacement. Note that at present, the z-axis of the drill string must line up with the z-axis of the rotational coordinate system.

\subsubsection{THE GLOBAL COORDINATE SYSTEM}

The global coordinate system is a fixed right-handed rectangular Cartesian coordinate system. It is used to define the wellbore geometry. Displacements, velocities, and accelerations of drill string degrees-of-freedom expressed in terms of this coordinate system do account for the rotation of the drill string. A displacement or velocity expressed in terms of this coordinate system includes both the finite element displacement or velocity, and the displacement or velocity associated with the rotation of the drill string. As is the case with the rotational coordinate system, the z-axis of the global coordinate system must line up with the z-axis of the drill string. Therefore, as previously stated, the z-axis of the global coordinate system must be the same as the $z$-axis of the rotating coordinate system. However, the $x$ and $y$ axes need not line up with each other at time $t=0$. The user has the option of lining up these $x$ and $y$ axes. 


\subsubsection{GHOST CUTTER LOCAL COORDINATE SYSTEM}

In order to determine the deformed positions of the sub-nodes in the rotating XYZ system, a ghost-cutter local coordinate system is employed as depicted in Figure $3 \cdot 2 \cdot 3 \cdot 1$. This system is also called the rst coordinate system.

The ghost cutter geometric sub-node in the figure has local rst coordinates of $\left(d_{1}, d_{2}, d_{3}\right)$. The lengths $d_{1}, d_{2}$, and $d_{3}$ may be interpreted physically as rigid links which do not change length or relative angles. For a given geometric sub-node, its rst coordinates $\left(r=d_{1}, s=d_{2}, t=d_{3}\right)$ never change. (Except in the case of cutter break-off.)

Prior to the solution sequence, the local rst coordinates of all the sub-nodes are generated automatically by the program based on their undeformed XYZ coordinates and the definition of the characteristic plane to which they are attached. (This is done by Subroutine BCKWRD.) For more information regarding the local rst coordinates, how they are generated, and how they are used to compute the deformed sub-node positions, the reader should consult the Theoretical Manual.

The local rst coordinates of the sub-nodes are useful when checking the ghost-cutter input data. A large value for any local coordinate might indicate one of the following conditions:
a) Error in the sub-node's $X Y Z$ coordinates
b) Error in the cutter's characteristic plane data
c) Error in the cutter's connectivity information 
Another useful aspect of the local coordinates concerns the physical significance of the $t$ coordinate:

a) The $t$ coordinate of any sub-node gives the perpendicular distance from characteristic plane to sub-node.

b) For the special case in which the characteristic plane coincides with the actual bit surface, the $t$ coordinate of a sub-node tells how far above the actual bit surface that sub-node is.

\subsubsection{FORMATION LOCAL COORDINATES}

Internal to the Formation Response Module, the position of any formation point is described by two "search" coordinates and one "penetration" coordinate. These three coordinates and how they are defined differ for the three portions of the formation model (Bottom, Sidewall, Incline). The first two coordinates are called "search" coordinates because they are the coordinates which are used to determine which formation point is closest to a given cutter. The "penetration" coordinates get their name from the fact that they are used when calculating the distance to which a cutter has penetrated the formation surface.

The three internal coordinates for each portion of the formation are: 


\begin{tabular}{|c|c|c|}
\hline BOTTOM: & $\begin{array}{l}\text { Search Coordinates } \\
\text { Penetration Coordinate }\end{array}$ & $\begin{array}{l}\text { Global } X \text { and } Y \\
\text { Global } Z\end{array}$ \\
\hline \multirow[t]{2}{*}{ SIDE-WAII: } & Search Coordinates & $\Theta$ and Global $Z$ \\
\hline & Penetration Coordinate & $\mathrm{R}$ \\
\hline \multirow[t]{2}{*}{ INCLINE: } & Search Coordinates & "S" and $\theta$ \\
\hline & Penetration Coordinate & $" P^{n}$ \\
\hline
\end{tabular}

where:

$$
\begin{aligned}
& \theta=\text { Angle (in degrees) around } Z \text { axis from the } \\
& \quad X-Z \text { plane } \\
& R=\text { Radial distance to point }\left(\sqrt{\mathrm{X}^{2}+\mathrm{Y}^{2}}\right) \\
& \text { "S" and "P" are as defined in Figure } 3.2 \cdot 4 \cdot 1 .
\end{aligned}
$$

\subsection{SIGN CONVENTIONS}

In both coordinate systems, the sign conventions follow the right-hand rule. The positive senses of quantities expressed in terms of these coordinate systems is illustrated in Figure 3.2.1. Note that forces follow this same sign convention. 


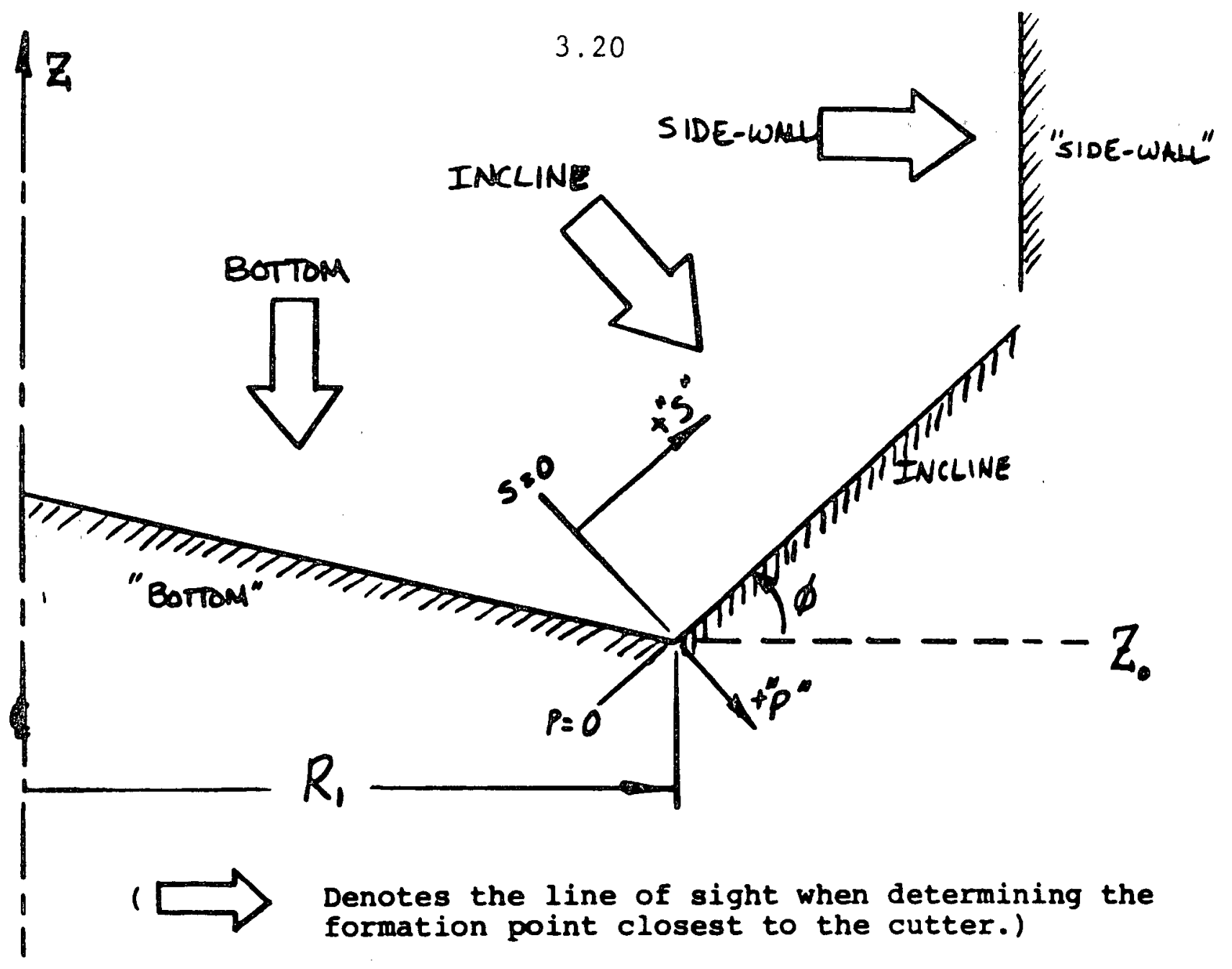

The " $S$ " coordinate of any point in space is the distance, parallel to the incline surface, from the inner edge of the incline to the point.

The " $P$ " coordinate of any point in space is the perpendicular distance from the incline to the point.

Given an arbitrary point in space given by $R=R_{c}, Z=Z_{c}$ )

the $\mathbf{S}$ and $\mathbf{P}$ coordinates are calculated as:

$$
\begin{aligned}
& S_{c}=\frac{\left(R_{c}-R_{2}\right)}{\cos \phi}+\left[\left(z_{c}-z_{0}\right)-\left(R_{c}-R_{1}\right) \tan \phi\right] \sin \phi \\
& P_{c}=\left[\left(R_{c}-R_{1}\right) \tan \phi-\left(z_{c}-z_{0}\right)\right] \cos \phi
\end{aligned}
$$

FIGURE 3.2.4.1: Definition of Local Formation Coordinates For the Incline Surface 


\subsection{FORCES}

There are various forces which act on the drill string during a dynamic solution. These forces may be thought of as being of three types:

- External forces

- Body forces

- Interaction forces

The external forces and body forces are linear forces. The interaction forces are non-linear forces. This section gives a brief description of the nature of these forces.

\section{4 .1 EXTERNAI FORCES}

External forces are linear forces which are applied to the top of the drill string model; that is, at the top beam node. They consist of a total of six forces, corresponding to the six degrees-of-freedom at the top beam node. Specifically, there are $X, Y$ and $Z$ direction translational forces, and $X, Y$ and $Z$ rotational forces (moments about the $X, Y$ and $Z$ axes). These forces are included in the model in order to model physical conditions at the top of the drill string. These six forces must be specified for each time step in the dynamic solution process. 
These external forces are made available to the solution algorithm by means of an external file. When the program needs values of these external forces, they are read in from a file. Therefore, prior to a dynamic solution, the user must decide what these forces should be, and then create an external file which contains the values of these forces at each time step. The direction of these forces corresponds to the right handed system adopted for the drill string (Section 3.2.1). A separate program is available which enables the user to interactively generate this external force file. The use of this program is discussed in Section 7.2. The characteristics of the external force file created by running this separate program are detailed in Section $3 \cdot 5 \cdot 11$

\subsubsection{BODY FORCES}

Body forces are linear forces which act over the volume of the drill string model. Consequently, they are forces which act at each node of the tied drill string system. These forces are included in the model in order to represent the force of gravity acting on the drill string, and the radial centrifugal force which acts on the drill string due to the fact that it is rotating. The gravity forces are calculated once, because they remain unchanged throughout the dynamic solution process. The centrifugal force vector is calculated at each time step. 
These body forces are calculated internally by the program. The magnitude of the angular velocity of the drill string, which is an input quantity, affects the magnitude of the centrifugal body force. The gravity force vector and the centrifugal force vector are added together and printed out in the dynamic solution print file.

\subsubsection{INTERACTIVE FORCES}

The "interactive" forces denote the forces exerted by the formation on the ghost-cutters. (These cutter forces are then distributed to the finite element nodes of the bit to be used in the iterative solution algorithm.) The total interactive force on a given cutter is composed of a penetration force and a velocity dependent friction force.

\subsubsection{PENETRATION FORCES}

The "penetration force" is the force exerted on the cutter by the formation as computed solely on the penetration distance and the formation's penetration stiffness at the point of contact. The penetration force always acts in the direction opposite to the penetration direction. (Refer to Figure 2.7.1.)

$$
F_{p}=K_{\text {pen }} \times \Delta_{\text {pen }}
$$




\section{4 .3 .2 FRICTIONAL FORCES}

The frictional force on the cutter is computed on the basis of the magnitude of the penetration force and the coefficient of friction at the point of contact. These friction forces are velocity dependent in that the friction coefficient is a function of the cutter's absolute velocity:

$$
\mu=\mu_{0} \tanh \left(\frac{|\vec{v}|}{V_{\text {max }}}\right)
$$

where $\mu_{0}$ is the maximum attainable friction coefficient and $V_{\max }$ is the velocity at which $\mu$ reaches $\mu_{0}$. Material properties are assigned to the formation points using the Formation Mesh and Property Generator (described later in this manual).

The friction forces are applied in the direction opposite to the cutter's absolute velocity. 


\title{
3.5 DATA FILES
}

Execution of the GEODYN program creates various data files. These files are required for successful execution of future GEODYN runs. The following sections describe the files created by executing GEODYN. This description includes the following:

\author{
- File Name \\ - Access Method \\ - Form \\ - Where File is Created \\ - Error Status \\ - Delete Status \\ - File Contents \\ - Purpose of File \\ - Additional Remarks
}




\subsubsection{TIED STIFFNESS DATA}

FILE NAME:

ACCESS :

FORM :

WHERE CREATED:

ERROR STATUS:

DELETE STATUS:

CONTENTS:

PURPOSE:

REMARKS :
AFNTYK(.DAT)

Sequential

Unformatted

Subroutine GENDYN

Execution terminated if error occurs opening file. (No error condition in open statement.)

Previous version of file will automatically be over-written if it exists and attempt to write same size matrix to file. User must delete previous file if a different size matrix will be written to this file.

(NOTE: On a VAX, the over-written file will contain the new data, but will not have a new version number or creation date.)

The Tied Drill String Stiffness Matrix.

Used in dynamic solution algorithm (RUNDYN) to generate modal stiffness matrix.

This file need not be deleted by the user if the new tied drill string matrix is the same size as the previous one, because it will automatically be over-written. This file must be available in RUNDYN if a new modal stiffness matrix is being generated.

NOTE: This file is opened with a specified record length. If a new tied drill string stiffness matrix is to be generated which is a different size than the existing one, an attempt to open an existing file with a different record length than it was originally created with will be made, thus causing an error on opening. If this is the case, the previous file must first be deleted by the user, to avoid the record length error. 
3.5.1.1. MASS MATRIX DATA

FILE NAME:

ACCESS :

FORM :

WHERE CREATED:

ERROR STATUS:

DELETE STATUS:

CONTENTS:

PURPOSE :

REMARKS :
AFNTYM ( . DAT )

Sequential

Unformatted

Subroutine GENDYN

Execution terminated if error occurs opening file. (No error condition in open statement.)

Previous version of file will automatically be over-written if it exists and attempt to write same size matrix to file. User must delete previous file if a different size matrix will be written to this file. (NOTE: On a VAX, the over-written file will contain the new data, but will not have a new version number or creation date.)

The Tied Drill String Mass Matrix.

Used in dynamic solution algorithm (RUNDYN) to generate modal mass matrix.

This file need not be deleted by the user if the new tied drill string matrix is the same size as the previous one, because it will automatically be over-written. This file must be available in RUNDYN if a new modal mass matrix is being generated.

NOTE: This file is opened with a specified record length. If a new tied drill string mass matrix is to be generated which is a different size than the existing one, an attempt to open an existing file with a different record length than it was originally created with will be made, thus causing an error on opening. If this is the case, the previous file must first be deleted by the user, to avoid the record length error. 


\section{5 .2 NATURAL FREQUENCY DATA}

FILE NAME:

ACCESS :

FORM :

WHERE CREATED:

ERROR STATUS:

DELETE STATUS:

CONTENTS:

PURPOSE :

REMARKS :
AFNLAM ( . DAT)

Sequential

Unformatted

Subroutine DPEIGL (DPEIGV - for consistent mass idealization) (From GENDYN)

File closed and execution continued. However, natural frequencies are not saved.

Previous version of file will automatically be over-written if it exists and attempt to write new natural frequencies. User may delete if sure new natural frequencies will be calculated by GENDYN. (NOTE: On a VAX, the over-written file will contain the new data, but will not have a new version number or creation date.)

The natural frequencies (in HEP:Z) of the Drill String System.

Used in Dynamic Solution Algorithm (RUNDYN) to chose number of frequencies/modes to consider in the analysis, as well as the size of the time step to use.

This file need not be deleted ky the user if new natural frequencies are calculated in GENDYN. It will automatically be over-written. This file must be available to perform a dynamic solution. 


\subsubsection{EIGENVECTOR DATA}

FILE NAME:

ACCESS :

FORM :

WHERE CREATED:

ERROR STATUS:

DELETE STATUS:

CONTENTS:

PURPOSE :

REMARKS :
AFNPHI(.DAT)

Sequential

Unformatted

Subroutine DPEIGL (DPEIGV - for consistent mass idealization)

(From GENDYN)

File closed and execution continues. However, eigenvectors are not saved.

Previous version of file will automatically be over-written if it exists and attempt to write same number of new eignevectors. User must delete if new number of eigenvectors will be calculated by GENDYN.

(NOTE: On a VAX, the over-written file will contain the new data, but will not have a new version number or creation date.)

The eigenvectors of the drill string system.

Used in Dynamic Solution Algorithm (RUNDYN) to transform matrices to the modal system.

This file need not be deleted by the user if the same number of new eigenvectors are calculated in GENDYN. It will automatically be over-written. This file must be available to perform a dynamic solution.

NOTE: This file is opened with a specified record length. If a new eigenvector matrix is to be generated which contains a different number of eigenvectors, an attempt to open an existing file with a different record length than it was originally created with will be made, thus causing an error on opening. If the new file is to contain a different number of eigenvectors than the previous file, the previous file must first be deleted by the user, to avoid the record length error. 


\section{5 .3 COMMON BLOCK DATA}

FILE NAME:

ACCESS :

FORM :

WHERE CREATED:

ERROR STATUS:

DELETE STATUS:

CONTENTS:

PURPOSE:

REMARKS :
AFNCOM(.DAT)

Sequential

Unformatted

Subroutines CMSARE and RNSARE (From GENDYN)

File closed and execution terminated if error occurs opening file.

If reading data from file (in RUNDYN), file is not deleted. If writing data to file (in GENDYN) existing file is automatically deleted prior to writing any new data (user need not delete).

The contents of all common blocks.

Used for running RUNDYN (performing a dynamic solution). Makes common block data (generated by GENDYN) available to RUNDYN.

It is never necessary for the user to delete this file. If new data is to be written to this file, the old version is automatically deleted. This file must be available to perform a dynamic solution. 
3.5 .4 MODEL DATA (ACORE AND MCORE)

FILE NAME:

ACCESS :

FORM :

WHERE CREATED:

ERROR STATUS:

DELETE STATUS:

CONTENTS:

PURPOSE :

REMARKS :
$\operatorname{AFNARM(.DAT)~}$

Sequential

Unformatted

Subroutine AMSARE (From GENDYN)

File closed and execution terminated if error occurs opening file (stop code = 0764 ).

If reading data from file (in RUNDYN), file is not deleted. If writing data to file (in GENDYN), existing file is automatically deleted prior to writing any new data (user need not delete).

The contents of vectors ACORE and MCORE. This is primarily model data.

Used for running RUNDYN (performing a dynamic solution). Makes model data (generated by GENDYN) available to RUNDYN.

It is never necessary for the user to delete this file. If new data is to be written to this file, the old version is automatically deleted. This file must be available to perform a dynamic solution. 
3.5 .5 DOUBLE PRECISION DATA

FILE NAME:

ACCESS :

FORM:

WHERE CREATED:

ERROR STATUS:

DELETE STATUS:

CONTENTS:

PURPOSE:

REMARKS :
AFNDPC (.DAT)

Sequential

Unformatted

Subroutine DPSARE (from GENDYN)

File closed and execution terminated if error occurs opening file (stop code = 0765).

If reading data from file (in RUNDYN), file is not deleted. If writing data to file (in GENDYN), existing file is automatically deleted prior to writing any new data (user need not delete).

Double Precision Variables - a beam local to global transformation matrix, and the bit-to-beam tjing transformation matrix.

Used for running RUNDYN (performing a dynamic solution). Makes data (zenerated by GENDYN) available to RUNDYN.

It is never necessary for the user to delete this file. If new data is being written to this file, the old version is automatically deleted. This file must be available to perform a dynamic solution. 
3.5 .6 MODAL SYSTEM DATA

FILE NAME:

ACCESS :

FORM :

WHERE CREATED:

ERROR STATUS :

DELETE STATUS:

CONTENTS :

PURPOSE:

REMARKS :
AFNMOD (.DAT)

Sequential

Unformatted

Subroutine MDSARE (From RUNDYN)

File closed and execution terminated if error occurs opening file (stop code = 0766).

If reading data from file, file is not deleted. If writing new data to file, existing file is automatically deleted prior to writing any new data (user need. not delete).

Matrix of truncated eigenvectors, transpose of matrix of truncated eigenvectors, modal stiffness matrix, modal mass matrix, and modal damping matrix, all double precision values.

Used to solve modal displacements, velocities, accelerations, and modal forces. If the current dynamic solution considers the same number of modes as the previous run, the data in this file is read back in, rather than re-generated.

It is never necessary for the user to delete this file. If accidentally deleted by the user, will have to re-run RUNDYN. If new data is being written to this file, the old version is automatically deleted. If in the current analysis the same number of modes are considered as in the previous analysis, this file should be available in RUNDYN. It will save re-calculating several matrices. 
3.5 .7 SPRING CONSTANTS

FILE NAME:

ACCESS :

FORM :

WHERE CREATED:

ERROR STATUS:

DELETE STATUS:

CONTENTS:

PURPOSE :
OLDBSPG (.DAT)

Sequential

Formatted

Subroutines BMSPRG or ASMSPG (From GENDYN)

Execution terminated if error occurs opening file (no error condition in open statement)

Previous version of file will automatically be over-written if it exists and new spring constants are input. (NOTE: On a VAX, the over-written file will contain the new data, but will not have a new version number or creation date.)

The stiffnesses of the six restraining springs at the top of the drill string, for the previous run. If it is the first time GENDYN has been run, there will be 6 zeros in this file.

Used to add effect of current springs into the over-all tied drill string stiffness matrix. This file serves to "remember" previous values of spring constants, so that when they are changed, the affected terms in the system

stiffness matrix can be re-calculated as:

$$
K_{\text {new }}=k_{\text {current }}-k_{\text {old }}+k_{\text {new }}
$$

where $k_{\text {current }}-k+d$ is the original stiffness matrix term, without the effects of any springs. kold are the values of previous spring constants stored in this file (OLDBSPG). After all 6 Knew have been calculated, the current spring constants, knew, are wrjtten to this file, so that they become k.ld for the next time these constants are changed. 
REMARKS :

This file need not be deleted by the user. It will always contain the appropriate spring stiffnesses. If the user tells the program that this is not the first GENDYN run for the current model, yet the spring constants have not changed, no changes are made in the system stiffness matrix, and this file is unaffected. 
3.5.8 FORMATION DISCRETE POINT DATA

FILE NAME:

ACCESS :

FORM :

WHERE CREATED:

ERROR STATUS:

DELETE STATUS:

CONTENTS :

PURPOSE :

REMARKS :
AFNFRM(.DAT)

Sequential

Unformatted

Subroutine FRSARE (From GENDYN)

File closed and execution terminated if error occurs opening file (stop code = 0767).

If reading data from file (in RONDYN), file is not deleted. If writing data to file (in GENDYN), existing file is automatically deleted prior to writing any new data (user need not delete).

Formation point data for all formation points. Describes the formation mesh.

To store the formation point mesh data.

It is never necessary for the user to delete this file. If new data is to be written to this file, the old version is automatically deleted. This file must be available to perform a dynamic solution when a formation is included in the model. 


\section{5 .9 PLOT FILE}

FIIE NAME:

ACCESS :

FORM :

WHERE CREATED:

ERROR STATUS:

DELETE STATUS:

CONTENTS:

PURPOSE:

REMARKS :

$$
\text { BFNPLT (.DAT) }
$$

\section{Sequential}

Formatted

Subroutine RUNOUT (From RUNDYN)

Execution terminted if error occurs opening file (stop code $=2468$ ).

If a previous version of this file exists, it will automatically be deleted before the new data is written to the file.

Positions, velocities, and accelerations of drill string degrees-of-freedom to be used as input to an external plotting program.

To make data available for plotting purposes.

Please refer to Section 3.8 .2 for a detailed discussion of this file. This file need not be deleted by the user to allow for a new version. This file is created only if the user wishes to have a plot file. 
3.5.10 PRINT FILE

FILE NAME:

ACCESS :

FORM :

WHERE CREATED:

ERROR STATUS:

DELETE STATUS:

CONTENTS:

PURPOSE :

REMARKS :
BFNPRT (.DAT)

Sequential

Formatted

Subroutine RUNOUT (From RUNDYN)

Execution terminated if error occurs opening file (stop code $=2468$.)

If a previous version of this file exists, it will automatically be deleted before the new data is written to the file.

Displacements, positions, velocities, accelerations, and forces in a formatted output form.

To make data available for printing purposes.

Please refer to Section 3.8 .2 for a detailed discussion of this file. This file need not be deleted by the user to allow for a new version. 
3.5.11 EXTERNAL FORCE FILE

FILE NAME:

ACCESS :

FORM :

WHERE CREATED:

ERROR STATUS:

DELETE STATUS:

CONTENTS:

PURPOSE:

REMARKS :
$\operatorname{EXTFRC~(.DAT)~}$

Sequential

Formatted

Program EXTFRC

Execution terminated if error occurs opening file (stop code $=2468$ )

If a previous version of this file exists, it will be over-written if a new file is created.

(NOTE: On a VAX, the over-written file will contain the new data, but will not have a new version number or creation date.)

The 6 external forces applied to the 6 degrees-of-freedom at the top of the drill string. Contains 6 forces for each time step.

All external forces applied to the drill string are supplied by this file.

Please refer to Section 7.2 for a detailed discussion of this file. This file need not be deleted by the user to allow for a new version. This file must be available to perform a dynamic solution. 
3.5 .12 QUALIFICATION FORCES

FILE NAME:

ACCESS :

FORM :

WHERE CREATED:

ERROR STATUS:

DELETE STATUS:

CONTENTS:

PURPOSE :

REMARKS :
$\operatorname{EXTCFF(.DAT)~}$

Sequential

Formatted

Standard user file creation.

Execution terminated if error occurs opening file (stop code $=2468$ ).

Since this file is created entirely by the user, the user is responsible for insuring that the correct version of this file is available at execution time.

Forces applied to ghost cutters. At each time step, there is an $X, Y$, and $Z$ force for every cutter.

To simulate forces applied to the cutters by the formation. Used only for qualification purposes.

This file is used only for GEODYN qualification purposes. It must be available to perform a dynamic qualification run. 
3.6 FORMATION MESH AND PROPERTY GENERATOR

As previously discussed in Section 2.7, the Formation Response Module requires:

1. A set of formation point number arrays in which a point number's row and column position in the array is analogous to that point number's location in the formation model. These point number arrays constitute the "formation mesh." (Formation point number arrays may be thought of as coordinate and connectivity data rolled into one.)

2. The penetration coordinate of each formation point. The penetration coordinate specifies a point's location in the penetration direction.

3. The formation material properties for each point. Specifically, a property ID number is stored for each formation point. A property ID number corresponds to a set of formation material values set in a previous execution of GENDYN.

As part of the program, a Formation Mesh and Property Generator is supplied which is automatically invoked during a RUNDYN execution, prior to entering the solution algorithm. The purpose of the Formation Mesh and Property Generator is to:

1. Automatically generate and store the required formation point numbers in the point number arrays based on minimal geometric information from the user.

2. Set the penetration coordinates of all the formation points, allowing the user to create arbitrarily "bumpy" surfaces. 
3. Assign property ID numbers to all the formation points, allowing the user to account for arbitrarily sized and spaced property regions.

These three aspects of the Formation Mesh and Property Generator are discussed in the remainder of this section.

\subsubsection{GENERATION OF POINT NUMBER ARRAYS}

The input parameters required for the program to correctly generate the formation point number arrays are: (Refer to Figure 3.6 .1 .1$.

BOTTOM SURFACE:

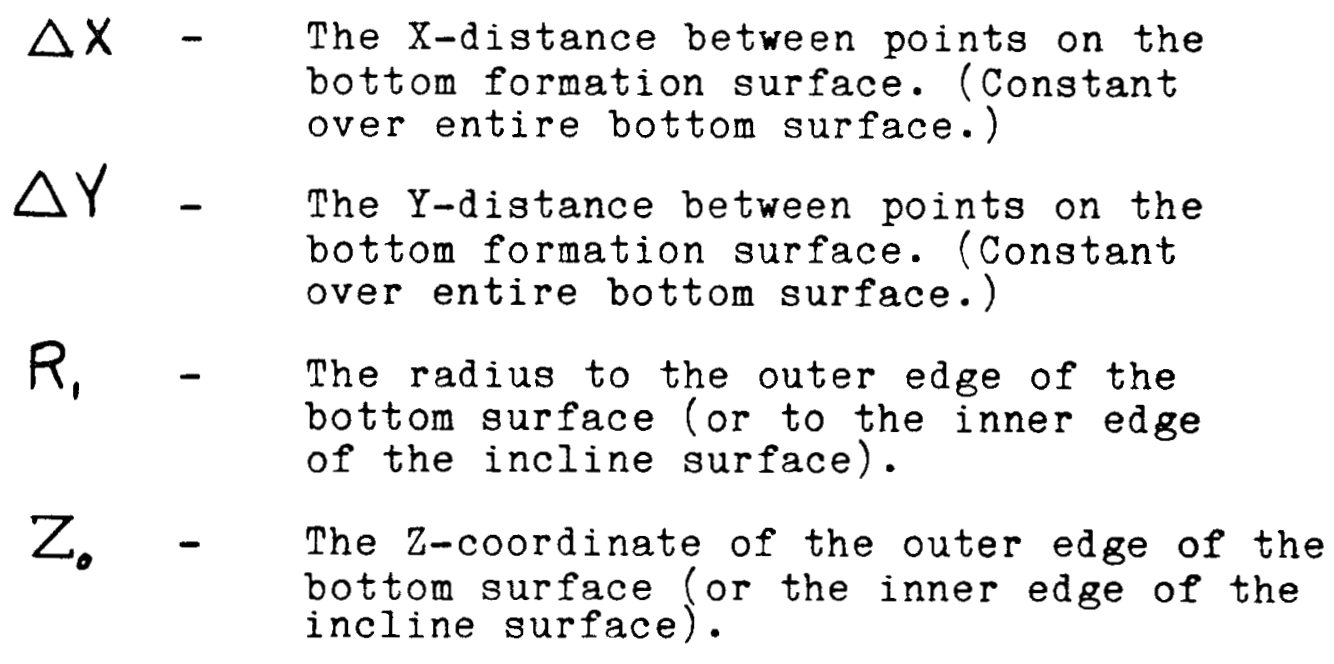 bottom surface (or the inner edge of the incline surface).




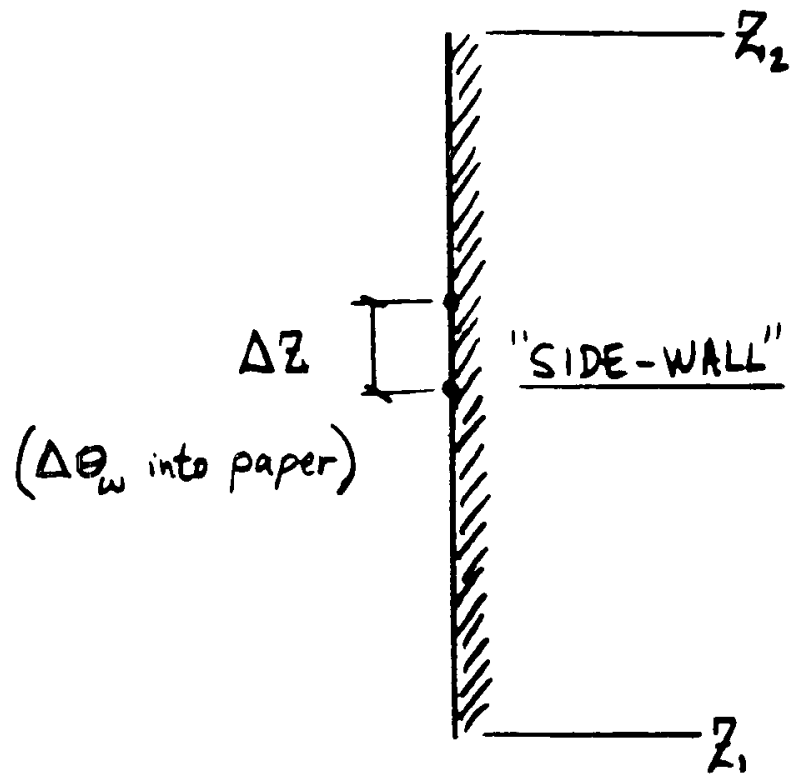

( $\Delta Y$ into paper) $\quad\left(\Delta \theta_{I}\right.$ into paper)

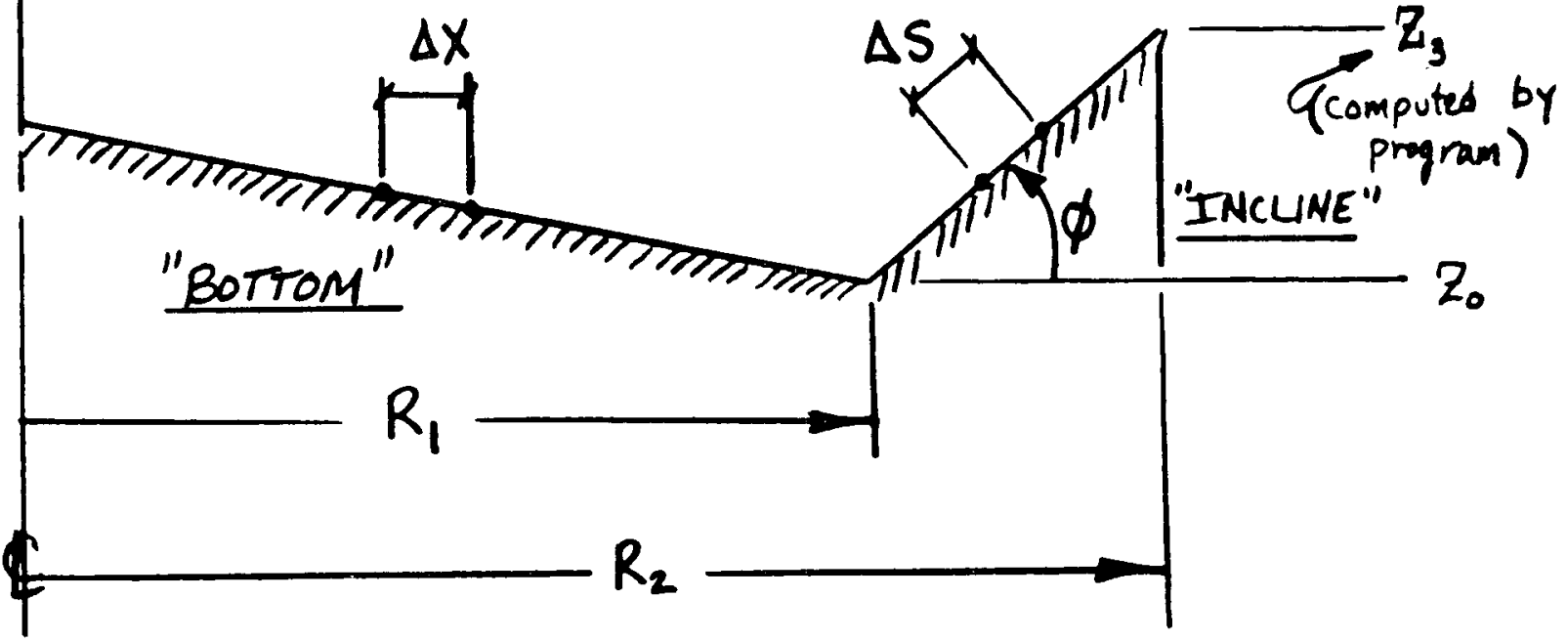

FIGURE 3.6.1.1: Required Geometric Parameters For Formation Mesh Generation 
Note that the bottom does not have to be flat. The parameter which sets the slope of the bottom surface will be discussed later as part of the penetration coordinate information. (Remember the $Z$ coordinate of the bottom is the penetration coordinate.)

SIDE-WALI SURFACE:

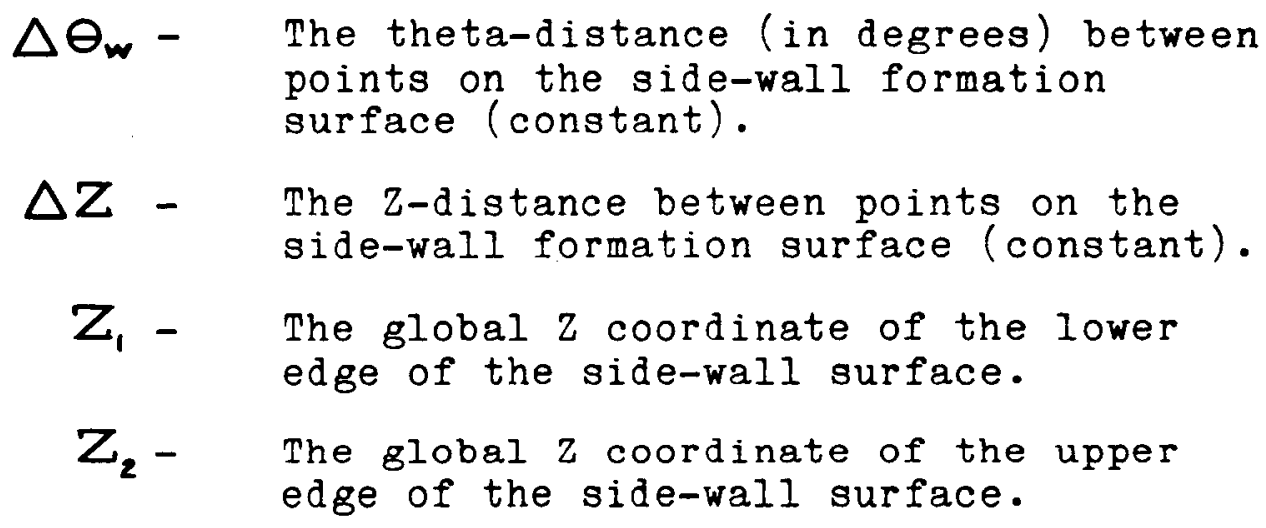

INCLINE SURFACE:

\begin{tabular}{|c|c|c|}
\hline$\Delta S$ & - & $\begin{array}{l}\text { The "S"-distance between points on the } \\
\text { incline formation surface (constant). } \\
\text { See Section } 3.2 .4 \text { for definition of "S" } \\
\text { coordinate on the incline. }\end{array}$ \\
\hline & - & $\begin{array}{l}\text { The theta-distance (in degrees) between } \\
\text { points on the incline formation surface } \\
\text { (constant). }\end{array}$ \\
\hline & - & $\begin{array}{l}\text { The radius to the outer edge of the incline } \\
\text { surface. (Note that this is also the nominal } \\
\text { radius to the side-wall surface.) }\end{array}$ \\
\hline 1 & - & $\begin{array}{l}\text { The angle (in degrees) from horizontal to } \\
\text { the nominal incline surface (must be positive } \\
\text { ( } 90 \text { ). }\end{array}$ \\
\hline
\end{tabular}


REMARKS :

1. Notice that $\mathbf{R}_{\mathbf{1}}, \mathbf{R}_{\mathbf{2}}, \mathbf{Z}_{\mathbf{0}}$, and $\varnothing$ are sufficient to compute the 2 -coordinate of the upper edge of the incline surface $\left(Z_{3}\right.$ in Figure 3.6.1.1). If the $Z_{3}$ calculated by the program is greater than $\mathbf{Z}_{\mathbf{1}}$, (the bottom of the side-wall) an error message is printed and the user must re-enter the geometric parameters.

2. The word "Nominal" is used to describe the positions of the formation surfaces because arbitrary deviations from these positions may be incorporated by the specification of penetration coordinates which will be discussed in the next section. 


\subsubsection{SPECIFICATION OF PENETRATION COORDINATES}

When specifying the penetration coordinates, each of the three formation sub-models are treated separately; first the Bottom, then the Side-wall, and finally the Incline. For each sub-model there are specific default values which may be used, or the default values may be modified.

\subsubsection{DEFAULT PENETRATION COORDINATES}

BOTTOM SURFACE:

By default, the penetration coordinates of all the bottom surface formation points are such that all the points will lie on a uniform slope between the origin and the outer edge of the bottom surface. In order to set these default values, the user must input one parameter: the $\mathrm{z}$-coordinate of the formation at $X=0$ and $Y=0$.

SIDE-WALI SURFACE:

By default, the penetration coordinates for all of the side-wall surface formation points are set equal to the nominal wall radius as previously input $\left(R_{2}\right.$ in Figure 3.6.1.1). 
INCLINE SURFACE:

By default, the penetration coordinates for all the incline surface formation points are set to zero. (The incline surface will by default be smooth, with all points lying on a surface making an angle $\varnothing$ with the horizontal. (See Figure 3.6.1.1.)

\subsubsection{PENETRATION COORDINATE MODIFICATIONS}

In the event that the default penetration coordinates do not correctly specify the formation surface, (i.e. local bumps or indentations) the user has the ability to modify the default values. For each sub-model the user has the choice of two methods for modifying the default penetration coordinates.

The two methods available are discussed below. (In the following discussion: "Sub-model" denotes either Bottom, Side-wall, or Incline; "Delta" denotes either $\Delta Z, \Delta R$, or $\triangle P$; and "coordinate" denotes either $X$ and $Y$, theta and $Z$, or $S$ and theta, respectively.)

\section{Method 1 - Range Method:}

The user specifies a "Delta" value and the "coordinate" ranges for which it applies. The "Delta" value will be added to the penetration coordinate of all the "Sub-model" formation points within the specified range. 


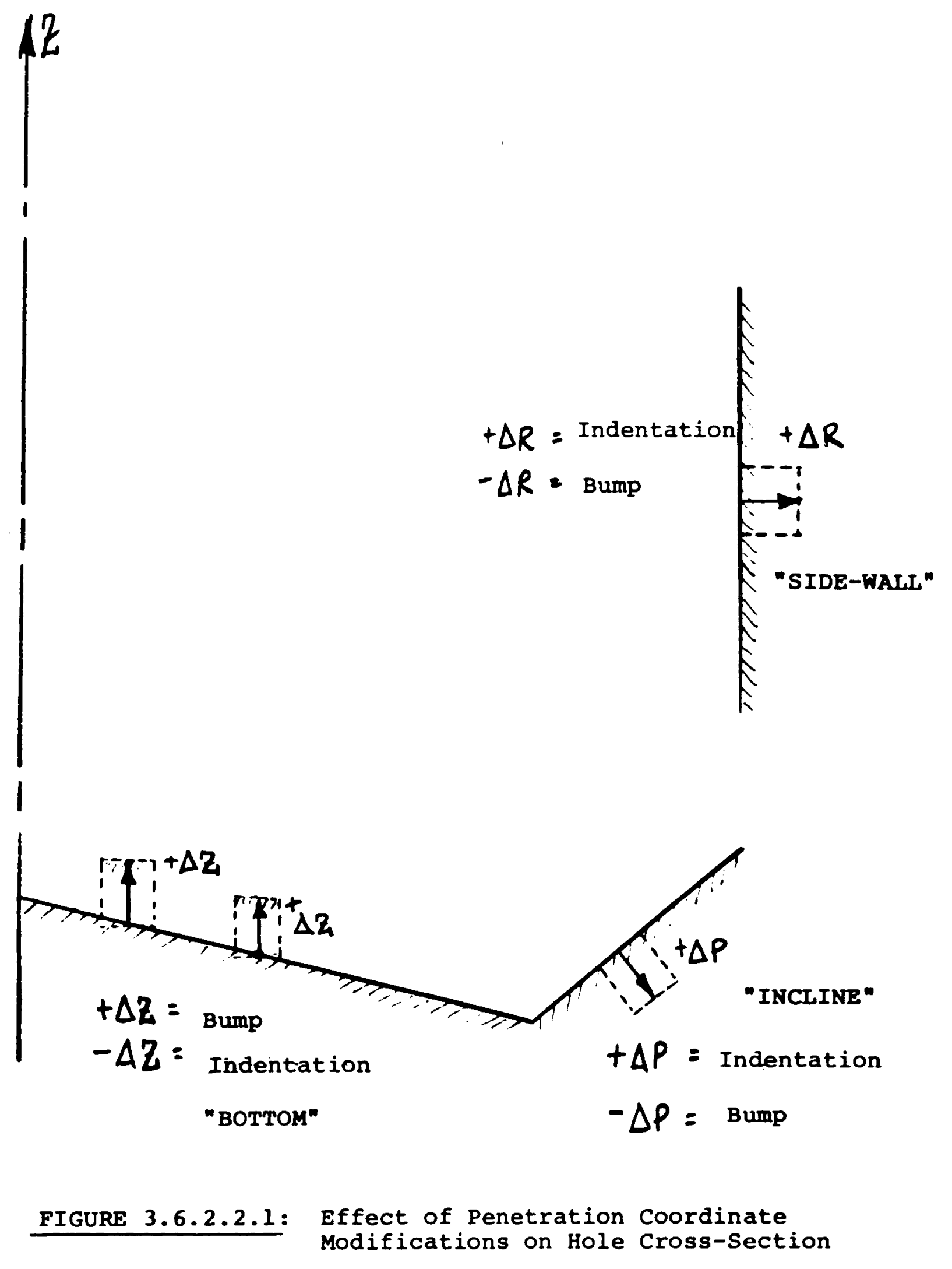


- Assume Flat Bottom Profile at $z=0$ to start

Penetration Coordinate Modifications:

\section{First Pass - Range Method:}

$$
\begin{aligned}
& \Delta Z=+0.5 \text { for } \\
& X \text { range of } 0 . \text { to }+10 . \\
& Y \text { range of } 0 \text {. to }+10 .
\end{aligned}
$$

(This sets entire first quadrant to $z=0.5$ )

\section{Second Pass - Radius Method:}

At $X=-0.60, Y=0.0$, Radius $=1.2, \Delta Z=-.25$

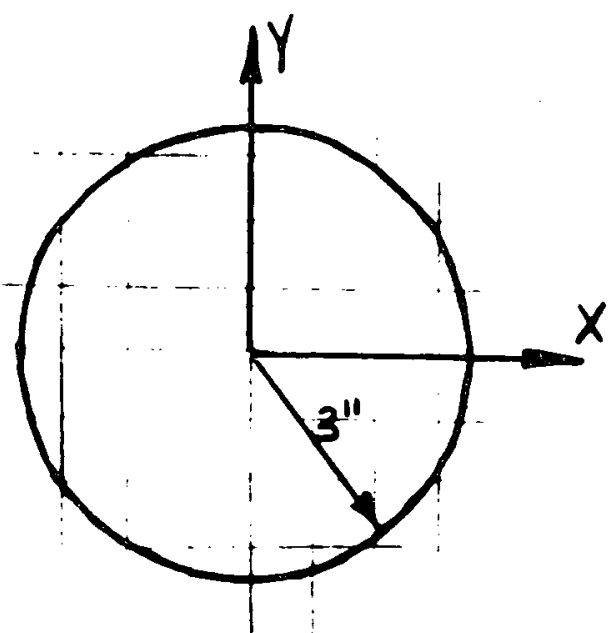

Originally all $\mathrm{z}=0$ (Default)

\section{Third Pass - Range Method:}

$$
\begin{aligned}
& \Delta z=1.0 \\
& X \text { range of } .65 \text { to } 1.8 \\
& Y \text { range of } .65 \text { to } 1.8
\end{aligned}
$$

\section{FINAL BOTTOM PROFILE :}
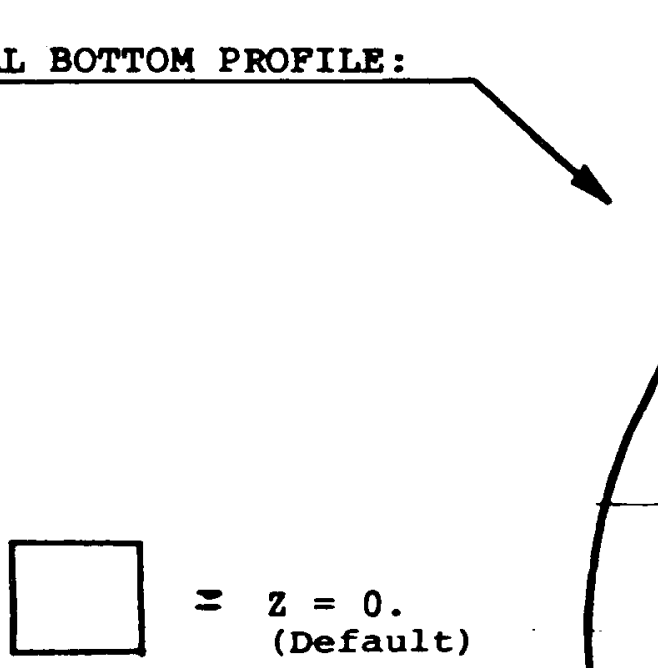

6

$$
\begin{aligned}
& M==-.25 \\
& \square==2=+0.5
\end{aligned}
$$
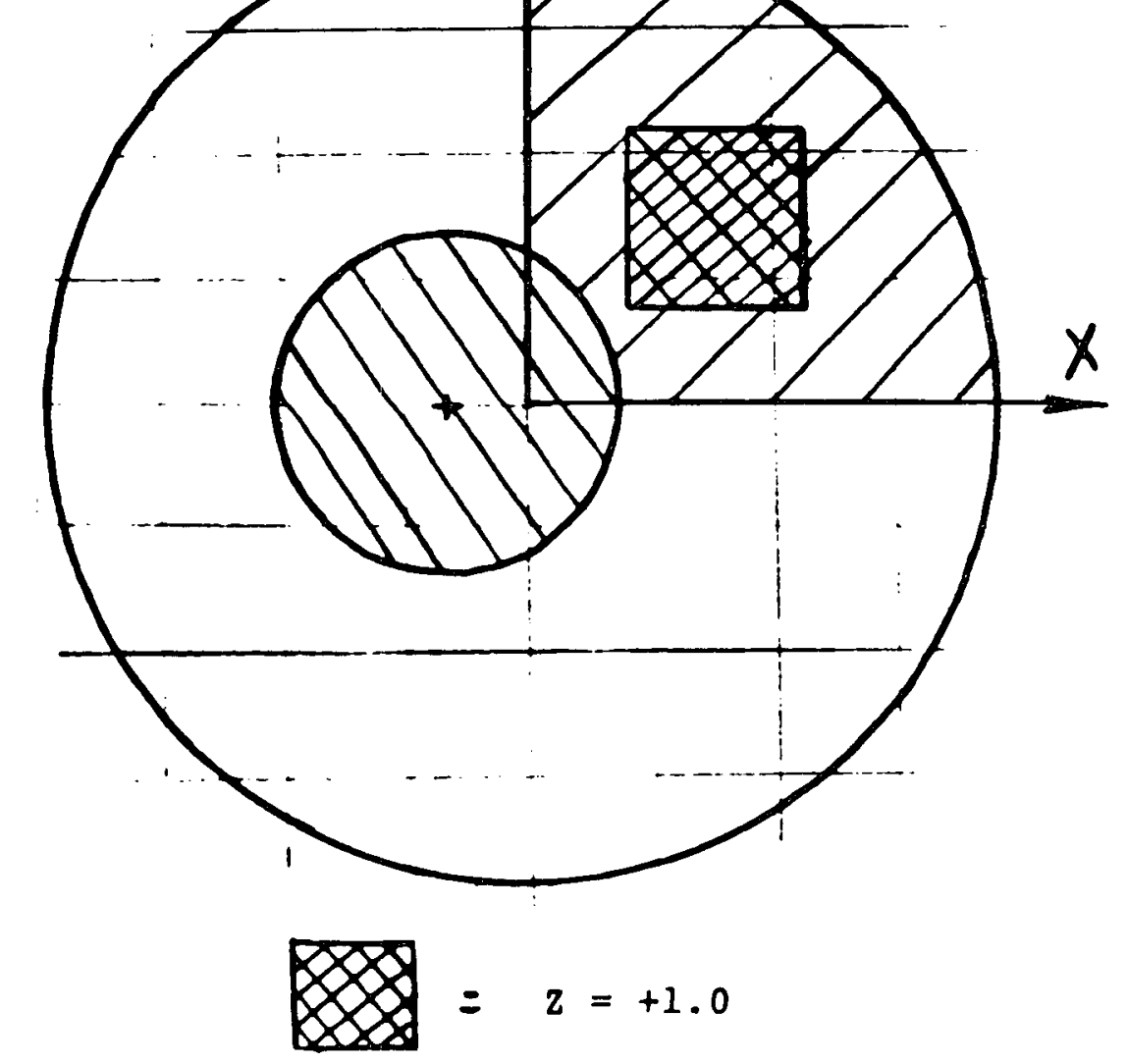

FIGURE 3.6.2.2.2: Example of Penetration Coordinate Modifications for Bottom Surface 
Method 2 - Radius Method:

The user enters a "coordinate" location, a radius, and a "Delta" value. The "Delta" value will be added to the penetration coordinate of every

"sub-model" formation point within the specified radius from the given "coordinate" location.

Figure 3.6.2.2.1 shows the effects of penetration coordinate modifications on the formation cross-section.

For a given sub-model, the user may use many combinations of the Range and/or Radius methods. (An entry of 99 for the modification method tells the program that the user has completed the penetration coordinate modifications for that sub-model.) In the case of any overlap in the modified regions, the last "Delta" value entered for a given formation point is utilized and all previous "Delta" values at that point are ignored.

Figure 3.6.2.2.2 is an illustrative example of penetration coordinate modifications on the bottom formation surface.

\subsubsection{ASSIGNING FORMATION MATERIAL PROPERTIES}

When assigning material properties, each of the three formation sub-models are treated separately; first the Bottom, then the Side-wall, and finally the Incline. For each sub-model, the objective is to assign a material property ID number to each formation point. The actual material property values $\left(K_{\text {pen, }}, \mu_{0}, V_{\text {max }}\right)$ must be set in a GENDYN run. (The property ID's selected by the Formation Mesh and Property Generator must have had values specified for them in the GENDYN run.) 
In each formation sub-model, the user has the choice of two methods for assigning material ID's to the formation points. The two methods are described below. (In this explanation, "Sub-model" denotes either Bottom, Side-wall, or Incline; and "Coordinate" denotes either $X$ and $Y$, theta and $Z$, or $S$ and theta, respectively.)

METHOD 1 - Range Method:

The user specifies a material ID and the "Coordinate" ranges for which it applies. The property values previously set for this material ID will be assigned to all the "Sub-model" formation points within the specified range.

METHOD 2 - Radius Method:

The user enters a "Coordinate" location, a radius, and a material ID. The property values previously set for this material ID will be assigned to all the "Sub-model" formation points within the specified radius from the given "Coordinate" location.

For a given formation sub-model, the user may use many combinations of the Range and/or Radius Methods. (An entry of 99 for the assignment method instead of 1 or 2 tells the program that the user has finished assigning material ID's to that sub-model.) In the case of any overlap in the material assignment regions, the last material ID assigned to a given formation point is used, and all previous ID's at that point are ignored.

Figure $3 \cdot 6 \cdot 3.1$ is an illustrative example of material ID assignment for the bottom formation surface. 
FORMATION MATERIAL ID ASSIGNMENT:

First Pass - Radius Method:

At $X=0, Y=0$, Radius $=10.0$, Mat. ID $=100$

(This effectively sets material group 100 as the default for all Bottom Surface Formation Points.)

Second Pass - Range Method:

Mat. ID $=200$

$X$ Range of 0 . to +10 .

$Y$ Range of 0 . to +10 .

Third Pass - Radius Method:

At $X=-0.6, Y=0.0$, Radius $=1.2$, Mat. ID $=300$

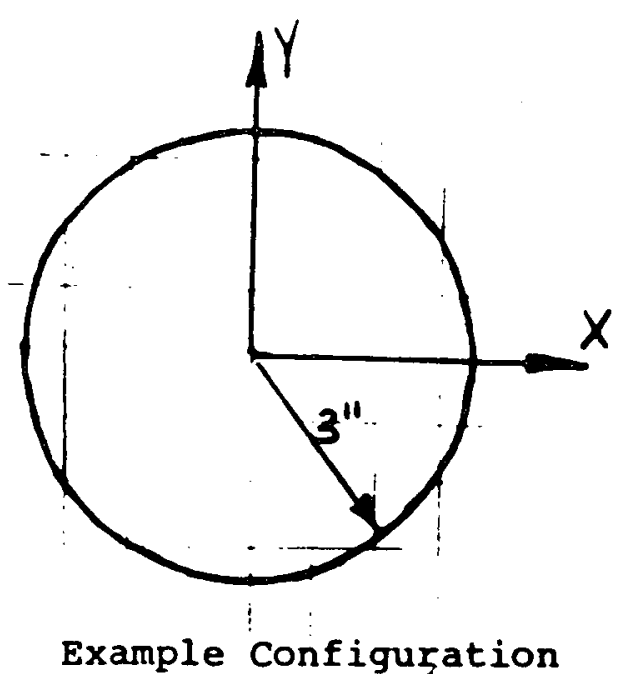

Fourth Pass - Range Method:

Mat. ID $=400$

$X$ Range of .65 to 1.8

$Y$ Range of .65 to 1.8

\section{FINAL MATERIAL ID ASSIGNMENT:}

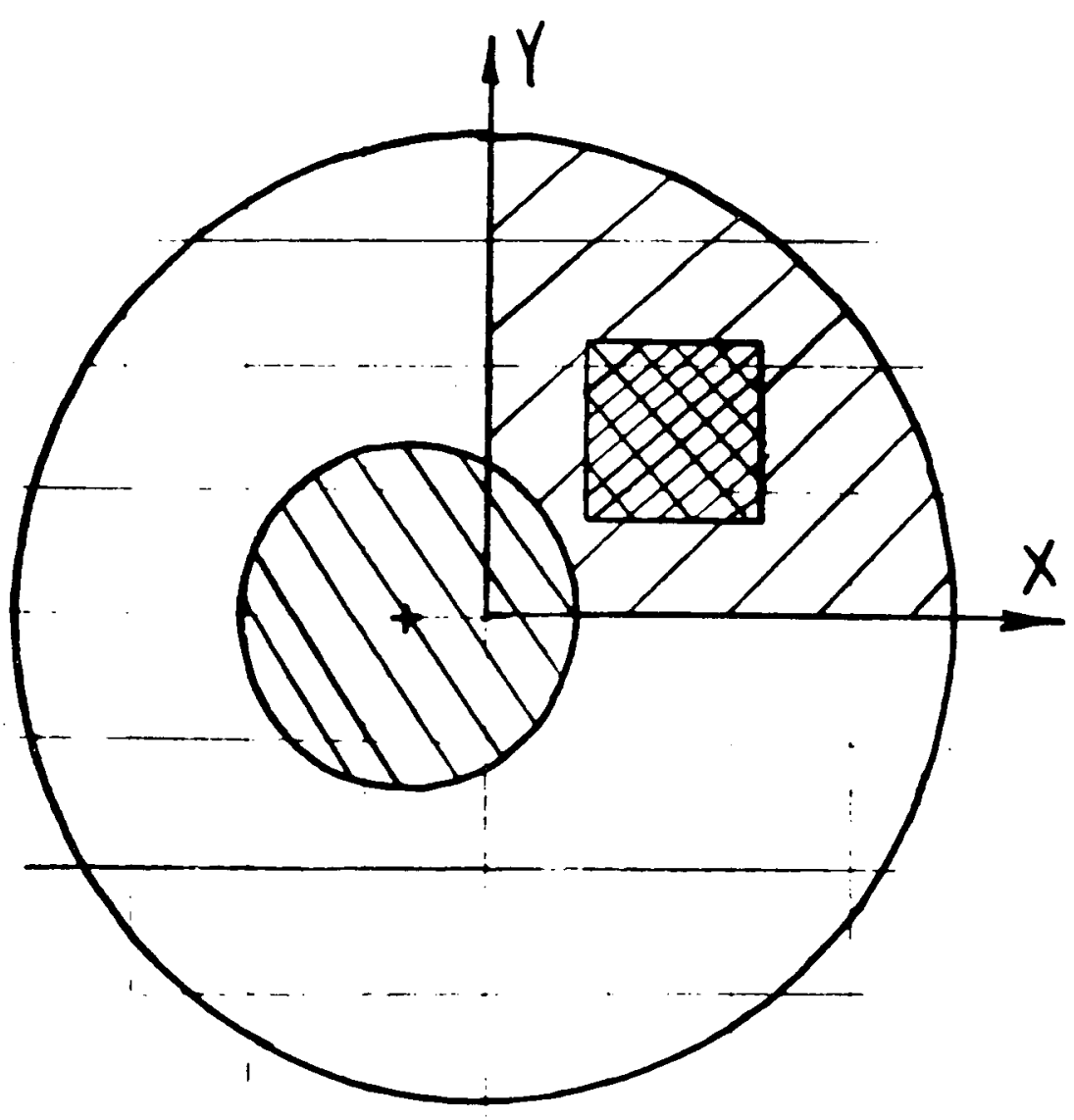

$\Rightarrow=200$

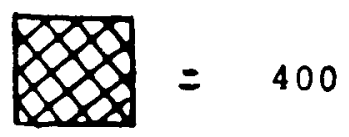

FIGURE 3.6.3.1: Example of Material ID Assignment For The Bottom Surface 


\section{REMARKS :}

1. Once the R-coordinate and Z-coordinate of a cutter are determined (during solution algorithm), the closest portion of the formation surface (bottom, side-wall or incline) is determined as follows:

First, if $R_{c}<R_{1} \Longrightarrow$ Bottom Surface Else, if $R_{c}=R_{1}$, and $Z_{c} \leq Z_{0} \Longrightarrow$ Bottom surface Else, if $Z_{c}>Z_{3} \Longrightarrow$ Side-wall Surface Otherwige,

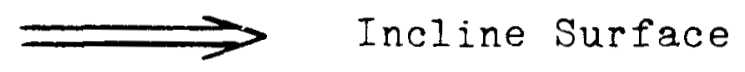

The above logic for determining the appropriate portion of the formation is depicted in Figure 3.6.3.2.

2. Regardless of the geometric parameters entered, there will always be a bottom surface, a side-wall surface, and an incline surface. Even if the geometric parameters are entered such that the logic of remark 1 will insure that a certain sub-model will never be used, there will always be point number arrays corresponding to each of the three formation sub-models. At such 
time, if any, that the current three sub-models are insufficient to accurately model the formation surface, (i.e. radically different bit design) a new development effort must be undertaken to modify the program accordingly.

3. As a consequence of remark 2 above, the user is always required to specify penetration coordinate and material property data for all three formation sub-models (Bottom, Side-wall, Incline).

4. Even on the side-wall and incline, the radius entered is always a length measurement. (Never an angle measurement.) Using the radius method on the side-wall and incline is analogous to pressing a flexible disc against the formation surface and operating only on the formation points which are covered.

5. If a ghost-cutter is found to be beyond the range of a defined formation surface, (i.e. above the top edge of the side-wall surface). The appropriate formation point on the nearest edge of that surface will be used to evaluate the penetration coordinate and material properties at the actual point of contact. This fact may be used to the advantage of the analyst to reduce 
the number of formation points required to accurately model the formation surface. (This is especially true for the side-wall surface.)

6. When modifying penetration coordinates or assigning material properties, only the formation points of the current sub-model (i.e. Bottom, Side-wall, Incline) are considered. For instance, no matter how large a radius is specified when operating on the Bottom surface, the formation points of the Side-wall and Incline will never be affected.

7. In light of remark 6 above, it is legal (and actually recommended) to use an extremely large range or radius for the first pass when assigning material ID's for each sub-model. In this way the user can essentially set default material ID's for that entire sub-model which he may then change to obtain local hard or soft spots.

8. When modifying penetration coordinates or assigning material properties on the Incline, the user must remember that the coordinate location (required for the radius method) and the coordinate ranges (required for the range method) are in terms of "S" and theta coordinates. The "S" coordinate is a measure of 
distance up the incline and, by definition, $S=0$ denotes the lowest ring of points on the Incline. (Refer to Figure 3.2.4.1.)

The theta coordinate is measured in degrees, and ranges from zero (at the global $X-Z$ plane) to 360 . To assign one material ID to the entire Incline, it is best to use the range method with $S$ ranging from zero to some large number, and theta ranging from zero to 360.

9. When modifying penetration coordinates or assigning material properties on the Sidewall, the user must remember that the coordinate location (required for the radius method) and the coordinate ranges (required for the range method) are in terms of theta and $z$ coordinates. The theta coordinate is measured in degrees, and ranges from zero (at the global X-Z plane) to 360 . The $Z$ coordinate is a measure of linear distance and ranges from $z_{1}$ to $z_{2}$ as previously specified by the user (See Figure 3.6.1.1). To assign one material ID to the entire Sidewall, it is best to use the Range method with theta ranging from zero to 360 , and $Z$ ranging from $z_{1}$ to $z_{2}$.

10. All formation points in a given sub-model must have material ID's assigned to them before the user may go on. 
11. The Radius and Range methods are used to set penetration coordinates and assign material ID's because the user will not uslally know the location of specific formation points (or even how many exist) until after executing the program. Remember, the formation points are generated, numbered, and stored by the Formation Mesh and Property Generator.

12. If desired, the user may define (in GENDYN) a formation material group to represent air $\left(K_{\text {pen }}=0\right)$. By assigning "Air" properties to a formation point, the user is saying that regardless of the penetration distance calculated, there will never be a force exerted on the bit by the formation at that point. 

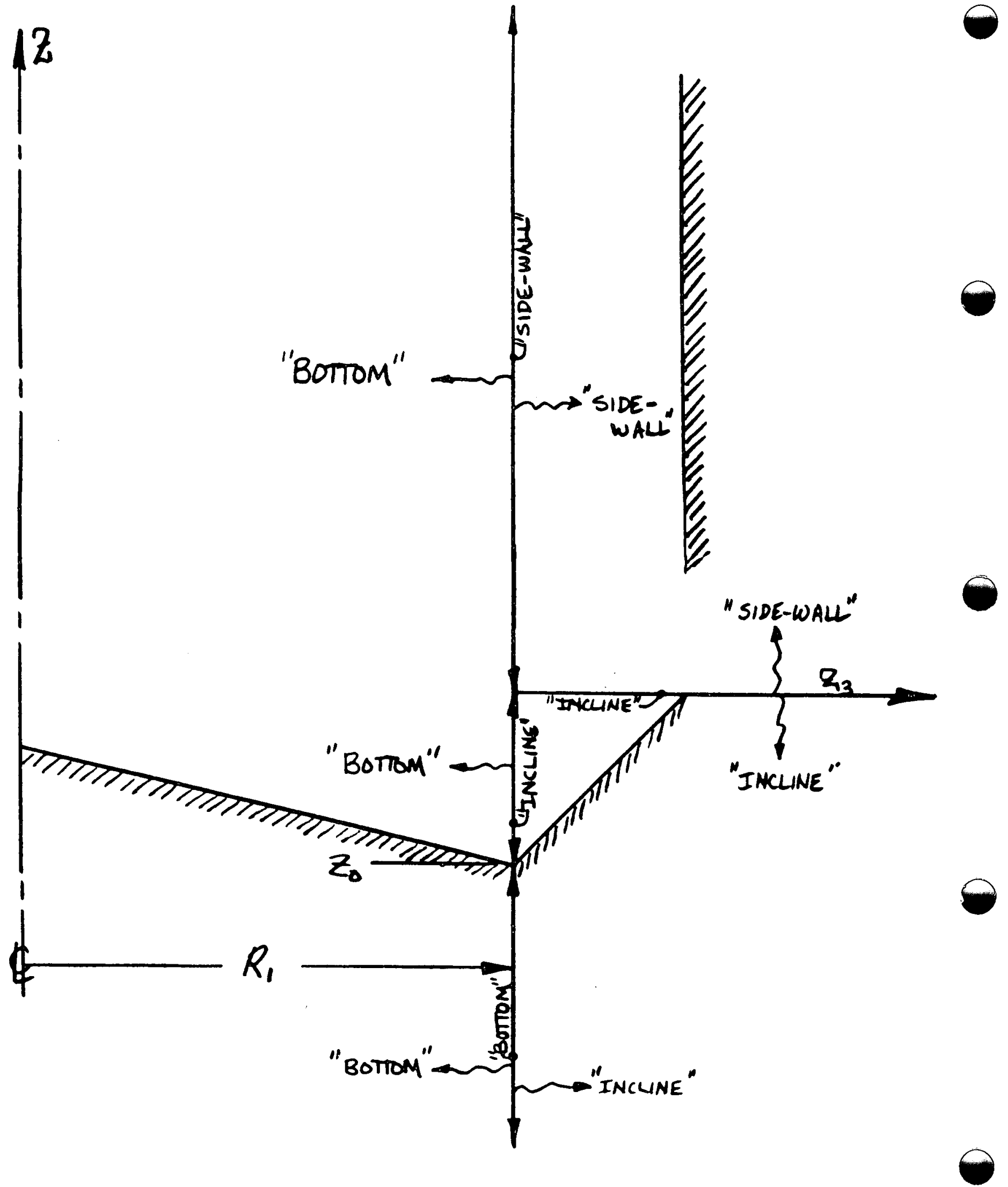


\subsection{INPUT FEATURES}

This section describes some of the input features of the GEODYN program.

\subsubsection{FREE FORMAT INPUT}

All input to the GEODYN program is in free format. That is, input data does not need to be typed in certain columns, but can start in any column, and be separated by spaces or commas. If character data is to be entered, character data must be typed in. Entering numerical data will result in an error. Also, if numerical data is required, numerical data must be entered. Entering character data will result in an error.

\section{7 .2 INPUT FILE OPTION}

In all cases, ths user has the option of having the input data read in from an input file rather than typing the data in as the program executes. Please refer to Sections 7.0 and 7.1 for a complete description of this option. 


\subsubsection{SAVE/RESTORE FEATURE}

The separation of model generation from the dynamic solution of the model and the desire for improved program efficiency necessitated that a save/restore feature be included in GEODYN. This save/restore feature is simply a method of saving selected data in files until this data is needed. At this point, the data is restored by reading the file, this making the data available for use.

Typical applications of the save/restore feature are as follows. As mentioned in section 3.1, the response of the model to dynamic loading cannot be obtained until the model has first been generated and its Eigenvalues and Eigenvectors have been solved. To perform a dynamic solution (RUNDYN), all of the model data must be available to the program. This data is made available by way of the save/restore feature. After generating the finite element model and solving for system Eigenvalues and Eigenvectors (GENDYN), the save feature is exercised by writing this data to various files described in section 3.5. When the dynamic solution begins (RUNDYN), this data is made available by using the restore feature. The files containing the stored data are opened and the data is read in, thus restoring the required data for a dynamic solution. When the dynamic solution has been completed, the save feature is exercised again, and updated data is written to the various data files. 
The save/restore feature is also employed when making successive dynamic solutions of similar models. Program efficiency is improved by restoring model data and modal matrices rather than regenerating them.

3.8 OUTPUT

Successful execution of the GEODYN program will produce up to five formatted output files. If a model is being generated and its natural frequencies are being calculated (GENDYN), then a summary file will automatically be generated. For a dynamic solution (RUNDYN), "print" files or "plot" files may be generated. In this case, the user specifies whether print files or plot files are desired, or both. The data reported in these files cannot be specified by the user. However, how often in simulated time this data is reported must be specified by the user. This specification is included in the interactive input to the program. In either case (GENDYN or RUNDYN), debug output files may be created as well. This section covers the names of all five of these output files, their contents, the format that the data is written in, and how to selectively read data from the files. 


\subsubsection{MODEL DESCRI PTION AND NATURAL FREQUENCY SUMMARY (GENDYN)}

If a drill string model is being generated and its natural frequencies are being calculated (running the GENDYN sub-program), than a summary file is automatically created. The following is a brief summary of the data reported in this file (please refer to Figure 3.8.2.3).

FILE NAME: User specified output file name, with a .GEN extension.

FILE TYPE: Formatted, sequential access.

DATA REPORTED: (Also see Figure 3.8.2.3)

A. GENDYN Run Title

B. Model Size Summary

1. Number of each element type used

2. Number of nodes for each element type

3. Number of degrees-of-freedom in model

4. List of tied bit nodes

C. Element definition (connectivity)

D. Material Type And Properties Summary

E. Model Geometry Summary

1. Drill string nodal coordinates

2. Ghost cutter sub-node coordinates

F. Ghost Cutter Definitions

1. Ghost cutter lengths

2. Cutter definition (connectivity)

3. Characteristic plane definitions

4. Bit surface definitions

G. Drill String Natural Frequency Summary 
All of the output contained in this file is written in subroutine GENOUT. Please note that all of the information contained in this file is also included in both a dynamic solution print file and plot file. Tables 3.8.1.1 and 3.8.1.2 and Figure 3.8.1.1 contain various character strings one can search for to locate specific data, as well as how to read this data. These are intended to be sufficient to assist the user in retrieving data pertaining to the drill string model.

\section{8 .1 .1 DEBUG OUTPUT FILE (GENDYN)}

In addition to the file just described, a debug output file may be created by running the non-interactive version of the GENDYN sub-program of GEODYN. The contents of this file are quite varied. Anything written to unit IOUT is included in this file. This includes an echo of the interactive input phase of the program, as well as any data which is conditionally printed if internal logical debug variables have been set to true. Typically, these items include vectors and arrays which are calculated by the various subroutines. They may be intermediate quantities, or they may be in their final form. Various error messages are likely to be printed here as well, such as those occurring during file manipulations, or those causing execution of the program to be terminated. Consequently, although this may 


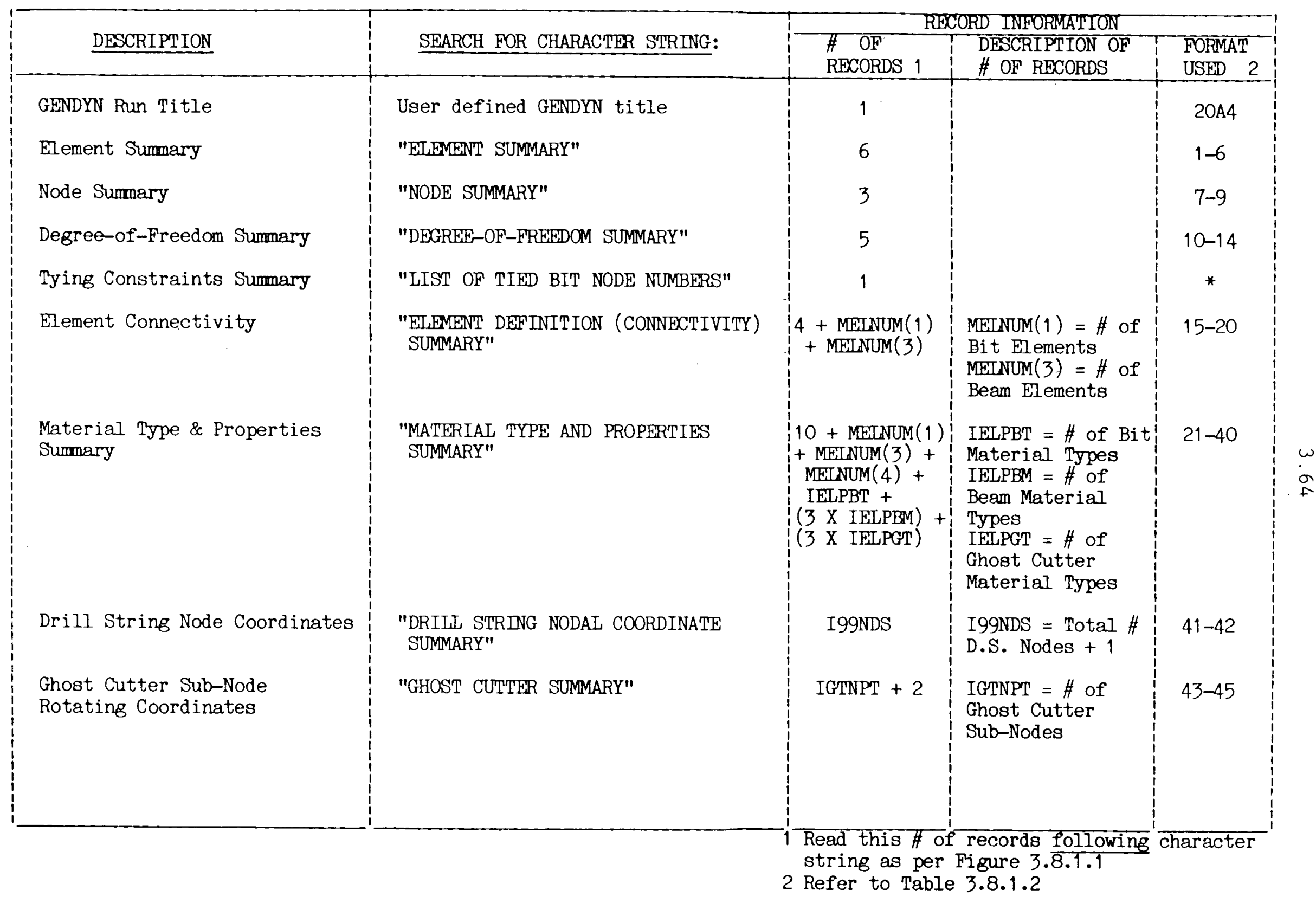

TABLE 3.8.1.1: GENDYN OUTPUT SUMMARY 


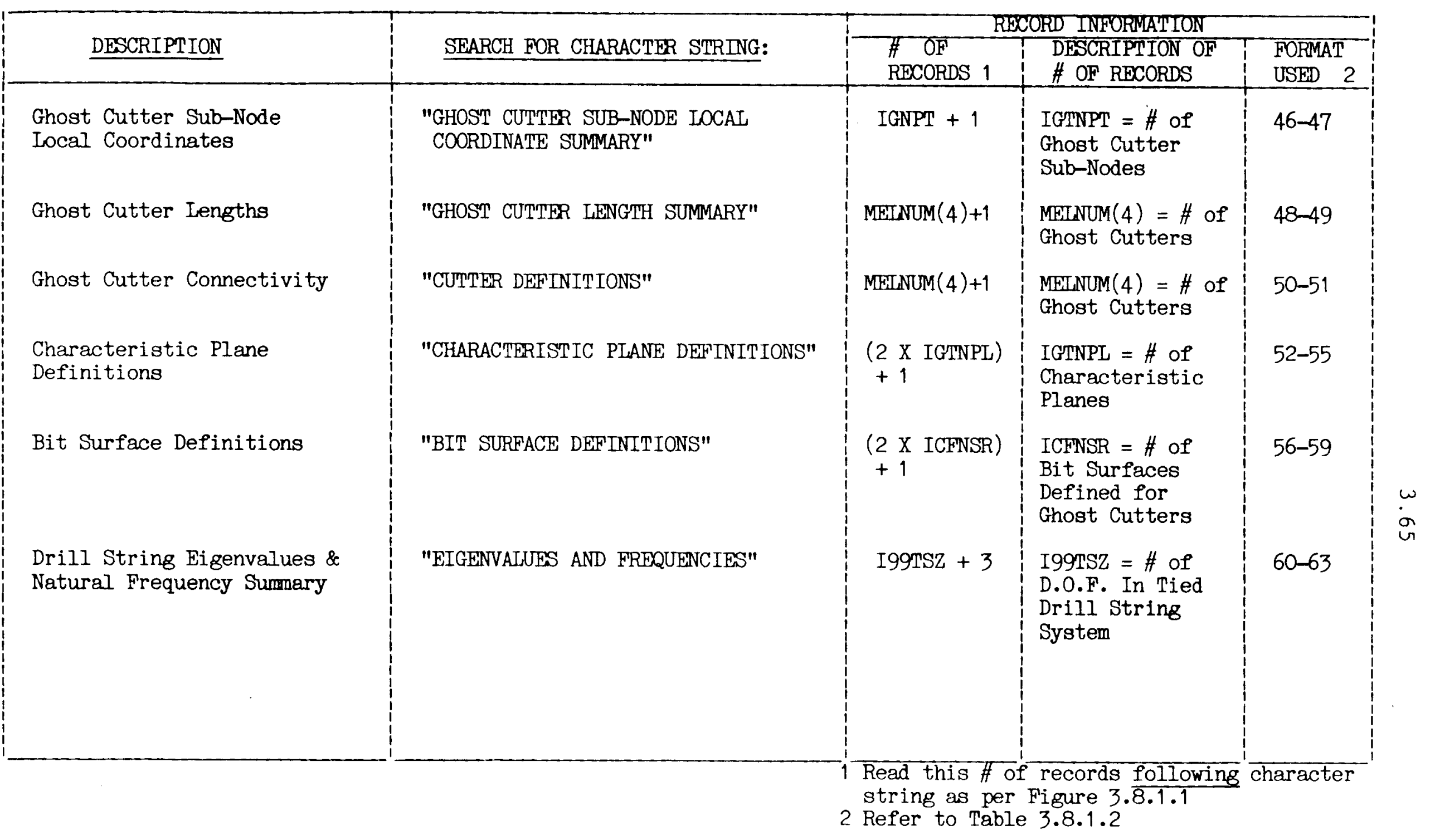

TABLE 3.8.1.1: GENDYN OUTPUT SUMMARY (CONTINUED) 
1. 1600 FORMAT $(1,5 X, 39$ HTOTAL NUMEER OF 8-NODE BRICK ELEMENTS : , $16 X$, I5)

2. 1700 FORMAT $(1,5 x, 4$ OHTOTAL NUMBER OF 20 -NODE BRICK ELEMENTS $:, 15 X, 15)$ I

3. 1900 FORMAT $(/, 5 X, 38 H T O T A L$ NUMBER OF LINEAR BEAM ELEMENTS $:, 17 X, 15)$ 1 ( 1000 FORMAT $/, 5 X, 53 H T O T A L$ NUMBER OF GHOST CUTTER GEOMETRIC SUB ELEME

4. 2000 FORMAT $(/, 5 x, 53 H T O T A L$ NUMBER OF GHOST CUTTER GEOMETRIC SUB-ELEMENT is $:, 2 x,(5)$

5. 2100 FUFIMAT $(1,5 \times, 51$ HTOTAL NUMEER OF INFINITE CONTINIUUM BRICK ELEMENTS $1:, 4 \times, 15$ )

6. 2200 FORMAT $(1,5 x, 42$ HTOTAL NUMBER OF NON-LINEAR BEAM ELEMENTS $:, 13 x, 1$

7. 2400 FOFMAT $(/, 5 x, 43 H T O T A L$ NUMBER OF BIT NOLIES $(\varepsilon-N D E E$ BRICKS) $:, 2 x, 15)$

8. 2500 FORMAT $(/, 5 x, 35$ HTOTAL NUMBER OF LINEAR BEAM NODES $:, 10 X, 15)$

9. 2600 FORMAT $(/, 5 X, 40 H T O T A L$ MUBER OF GHOST CUTTER SUB-NODES $:, 5 X, 15)$ 1

10. 2800 FORMAT( $/, 5 X, 44 H T O T A L$ MMEER OF BIT D.O.F. (8-NODE BRICKS) :, 10X, (15)

11. 2900 FORMAT $/, 5 X, 36$ HTOTAL NUMBER OF LINEAR BEAM D.O.F. :, 18X, I5)

12. 3000 FORMAT $(/, 5 x, 52 H T O T A R$ NUMBER OF DRILL STRING D.O.F. PRIOR TO TYIN $1:, 2 x,(5)$

13. 3100 FORMAT $/, 5 x, 49 H T O T A L$ NUMBER OF DRILL STRING D.O.F. AFTER TYING :, $15 x,(5)$

14. 3200 FORMAT $(/, 5 \times, 51$ HTOTAL MUMBER OF FORMATION D.O.F. (2O-NODE BRICKS) $18,3 x, 15)$

15. 3700 FORMAT (5X, 15H8-NODE BRICKS $:, 1,3 \mathrm{X}, 17(1 \mathrm{H}-), 1 /)$

$16,193800^{-}$FORMAT $(10 X, 9$ HELEMENT $*, 6 x, 19$ HCONSISTS OF NODES $:, 1,9 x, 11(1 H-), 4 X$, $121(1 H-), / 1$

17. 3900 FORMAT $(1,12 x, 14,9 x, 8(14,1 x))$

1

18. 4000 FORMAT $(/ / 1,5 x, 14$ HLINEAR BEAMS $:, 1,3 x, 16(1 \mathrm{H}-), 1 / 1)$

20. 4100 FORMAT $(1,12 x, 14,9 x, 14,6 x, 14)$

21. 4300 FORMAT $(5 x, 32 H B-N I D E$ BRICK MATERIAL FRCIPERTIES, $/, 4 X, 34(1 H-), / 1)$

22. 4400 FDRMAT(5X, 15HMATEFIAL TYPE $, 5 X, 1$ EHYTIUNG'S MOD. (PSI), 5X, 13HPOISS ION RATIO, 4X, 14HUINIT WT. (PCF))

23. 4500 FORMAT $(1,10 X, 14,13 X, E 13.7,8 X, E 13.7,4 X, E 13,7)$

4600 FORMAT $(5(1), 5 X, 27 H 8-N O D E$ BRICK MATERIAL TYFES, $1,4 X, 29(1 H-), 1 /)$

24. 4600 FIIRMAT $(5(1), 5 X, 27 H 8-N O D E$ BRICK: MATERIAL TYFES, $1,4 X, 29(1 H-), 1 /)$

25. 4700 FIJRMAT $/, 5 X$, GHELEMENT \#, $, X, 1$ IHMATEFIAL TYFE, $/$ ) 


\section{TABLE $3 \cdot 3 \cdot 67.1 .2$ : Continued}

\section{4800 FDRMAT $(1,7 x, 14,13 x, 14)$}

27. 4900 FORMAT $(1 / 1,5 X, 31 H L$ INEAR BEAM MATERIAL FROPERTIES, $1,4 x, 33(1 \mathrm{H}-1), 1 / 1)$

28. 5000 FIRMAT $(5 X, 7 H T Y P E=, 14,9 X, 10 H E(F S I)=, E 13.7,5 X, 5 H N U=, E 13.7)$

29. 5025 FORMAT $(/, 25 X, 10 H W T(P C F)=, E 13.7,5 X, 9 H L(F T)=, E 13.7)$

30. 5050 FORMAT (/,25X,10HO.D. = E13.7,5X,9HI.D. = E13.7, $/ / 1 /)$

31. 5200 FORMAT $(5(1), 5 X, 26 H L I N E A R$ BEAM MATERIAL TYPES, $1,4 X, 28(1 H-1,11)$

32. 5300 FORMAT $(/, 5 x$, SHELEMENT *3X, 13HMATERIAL TYPE, $/$,

33. 5400 FORMAT $(1,7 \times, 14,10 \times, 14)$

34. 5500 FORMAT $(5(1), 5 X, 32$ HGHOST CUTTER MATERIAL PROPERTIES, $1,4 X, 34(1 \mathrm{H})$, $1 / / 1$

35. 5600 FORMAT $(5 X, 7 H T Y P E=, I 4,4 X, 10 H A(I N-2)=, E 13,7,7 X, 10 H E(P S I)=$, (E13.7)

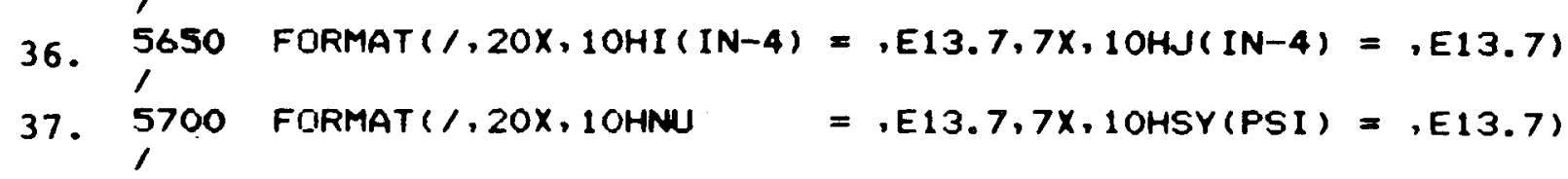

38. 5800 FORMAT $(5(1), 5 X, 27 H G H O S T$ CUTTER MATERIAL TYPES, $1,4 X, 29(1 H-1,1 / 1)$

39. 5900 FORMAT $/, 5 X, 8$ HCUTTER $* 5 X, 13$ HMATERIAL TYPE, $/)$

40. 6000 FORMAT $(1,7 X, 14,11 \times, 14)$

41. 6300 FORMAT( $/, 10 X, 6 H N O D E$, 9X, 8HX-COORD., 9X, 8HY-COORD. , 9X, 8HZ-COORD. . $1 /, 9 X, 8(1 H-), 7 X, 10(1 H-), 7 X, 10(1 H-), 7 X, 10(1 H), 1)$

42. 6400 FORMAT (/, 10X, I4, 10X,F10.5,7X,F10.5,7X,F10.5)

43. 65OS FORMAT $(5 X, 40 H G H O S T$ CUTTER SUB-NODE COORDINATE SUMMARY,, $4 X$, $142(1 H=), / /)$

44. 6506 FDRMAT(/,8X,1OHSUB-NODE *,9X, 8HX-COORD., 9X, 8HY-COORD., $9 X$, 1 BHZ-COORD., $,, 9 X, 10(1 \mathrm{H}-), 7 X, 10(1 \mathrm{H}-), 7 \mathrm{X}, 10(1 \mathrm{H}-), 7 \mathrm{X}, 10(1 \mathrm{H}-), 1)$ 1.45 .47

45,476508 FDRMAT $(1,12 x, 14,10 x, F 10.5,7 x, F 10.5,7 x, F 10.5)$

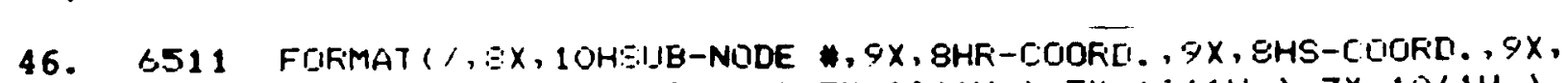

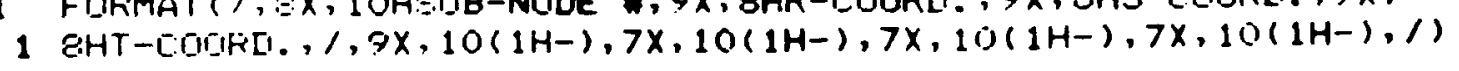

48. 6515 FORMAT (, $5 X$, SHCITTER $*, 7 X, 11$ HLENGTH $(I N), /, 4 X, 10(1 H-), 5 X, 13(1 H-)$, 111

49. ¿517 FORMAT $(1,7 \times, 14,10 \times, F 10.5)$ 


\section{TABLE 3.8.1.2: Continued}

50. 6540 FORMAT $(/, 5 X$, BHCUTTER $\$, 3 X, 12$ HFRIMAFY NODE, 3X,21HSUB-NODES : BIT S IURF., $3 X, 9 H T O P$ BLANK, 3X, 1OHBOT. BLANK, /1)

51. 6560 FDRMAT $(1,6 x, 14,10 X, 14,21 X, 14,9 x, 14,8 X, 14)$

52. 6600 FORMAT $(/, 5 x, 7$ HPLANE * $8 x, 6$ HNODE $1,10 x, 6$ HNODE $2,10 x, 6$ HNODE $3, / 1)$

53. 6620 FORMAT $(1,6 x, 14,11 x, 14,12 x, 14,12 x, 14)$

54. 6640 FORMAT $(10(1), 5 X, 7$ HPLANE $, 1 x, 14,1 X, 18 H C O N T A I N S$ CUTTERS $:, 1,4 X$. $133(1 \mathrm{H}-), / / 1)$

55* FREE FORMAT

56. 6680 FORMAT $(1,5 x, 9$ 9HSURFACE $* 6 x, 6$ HNODE $1,8 x$, 6HNODE $2,8 x$, 6HNODE $3,8 x$. 1 GHNOIDE 4,1$)$

57. 6700 FORMAT $(1,7 x, 14,10 x, 14,10 x, 14,10 x, 14,10 x, 14)$

58. 6720 FORMAT $(10(1), 5 x, 9 H S U R F A C E *, 1 x, 14,1 x, 18 H C O N T A I N S$ CUTTERS $:, 1,4 x$,
135(1H-), $1 /)$

7. 59* FREE FORMAT

60. 1300 FORMAT $(1 x, 1 H *, 77 x, 1 H *, 1,1 x, 1 H *, 77 x, 1 H *, 1,1 x, 79(1 H *), 10(1))$

61. 6760 FGIRMAT (5X,27HEIGENUALIJES AND FREQUENCIES, $1,4 x, 29(1 \mathrm{H}-1,1 / 1)$

62. 6780 FORMAT (6X, 17HE IGENUALUE NUMEER, 10X, 5HVALUE, 15X, OHFREQUENCY, 1 )

63. 6800 FIRRMAT(/,13X,13,14X,D11.5,11X,D11.5) 
FIGURE 3.8.1.1: FORMAT USAGE FOR GENDYN OUTPUT

GENDYN RUN TITLE

\section{READ FORMAT (20A4)}

\section{ELEMENT SUMMARY}
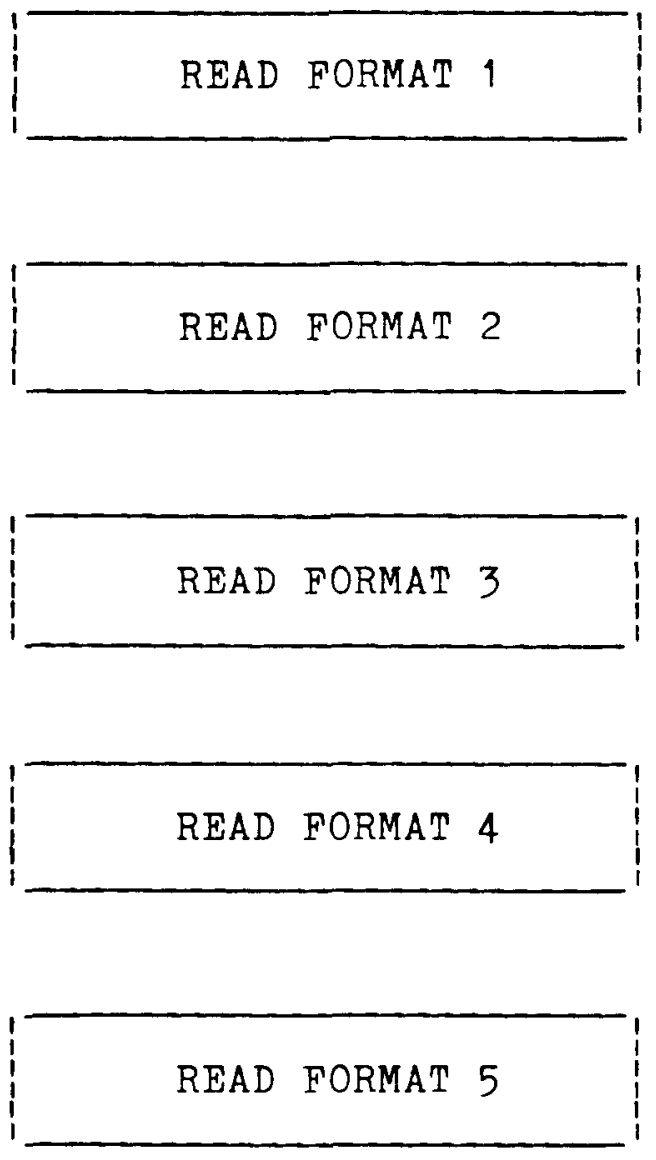

READ FORMAT 6 
FIGURE 3.8.1.1: FORMAT USAGE FOR GENDYN OUTPUT (CONTINUED)

NODE SUMMARY
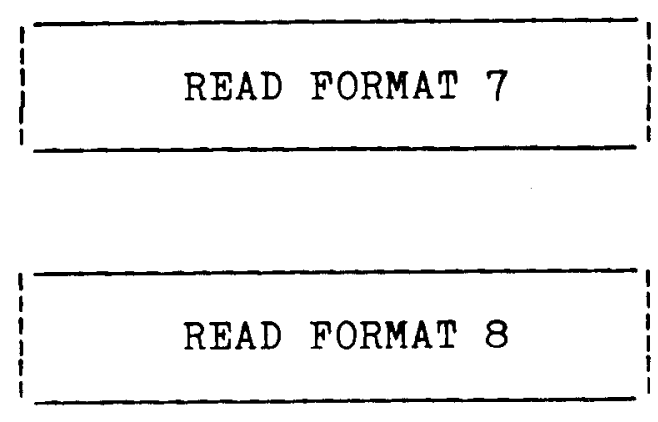

\section{READ FORMAT 9}

DEGREE-OF-FREEDOM SUMMARY

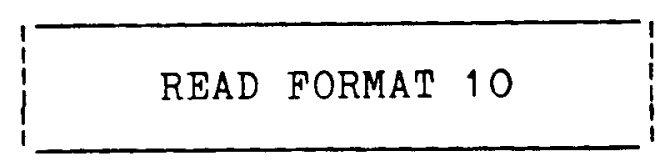

READ FORMAT 11

READ FORMAT 12

READ FORMAT 13 
FIGURE 3.8.1.1: FORMAT USAGE FOR GENDYN OUTPUT (CONTINUED)

READ FORMAT 14

LIST OF TIED BIT NODE NUMBERS

READ FREE FORMAT (*)

ELEMENT DEFINITION (CONNECTIVITY) SUMMARY

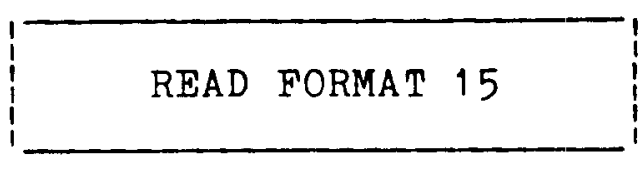

READ FORMAT 16

DO $I=1$, \# OF BIT ELEMENTS

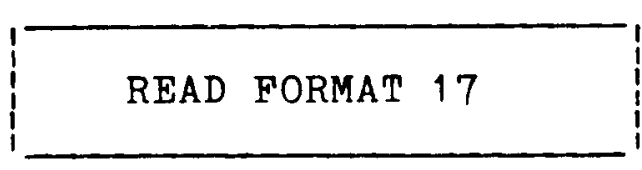

CONTINUE I

READ FORMAT 18 
FIGURE 3.8.1.1: FORMAT USAGE FOR GENDYN OUTPUT (CONTINUED)

READ FORMAT 19

DO $I=1$, \# OF BEAM ELEMENTS

READ FORMAT 20

CONTINUE I

MATERIAL TYPE AND PROPERTIES SUMMARY

READ FORMAT 21

READ FORMAT 22

DO I $=1$, \# OF BIT PROPERTIES (IELPBT)

READ FORMAT 23

CONTINUE I 
FIGURE 3.8.1.1: FORMAT USAGE FOR GENDYN OUTPUT (CONTINUED)

\section{READ FORMAT 24}

\section{READ FORMAT 25}

DO $I=1$, \# OF BIT ELEMENTS (I99BM-1)

\section{READ FORMAT 26}

CONTINUE I

READ FORMAT 27

DO $I=1$, \# BEAM PROPERTY TYPES

READ FORMAT 28

READ FORMAT 29

READ FORMAT 30

CONTINUE I 
FIGURE 3.8.1.1: FORMAT USAGE FOR GENDYN OUTPUT (CONTINUED)

\section{READ FORMAT 31}

READ FORMAT 32

DP $I=1$, \# OF BEAM ELEMENTS (I99GT - I99BM - 1)

READ FORMAT 33

CONTINUE I

READ FORMAT 34

DO I $=1$, \# GHOST CUTTER PROPERTY TYPES

$$
\text { READ FORMAT } 35
$$

READ FORMAT 36 
FIGURE 3.8.1.1: FORMAT USAGE FOR GENDYN OUTPUT (CONTINUED)

READ FORMAT 37

CONTINUE I

READ FORMAT 38

READ FORMAT 39

DO I $=1$, \# OF GHOST CUTTERS (I99GT - I99FR-1)

READ FORMAT 40

CONTINUE I

DRILL STRING NODAL COORDINATE SUMMARY

READ FORMAT 41

DO I $=1$, \# OF DRILL STRING NODES (I99NDS - 1) 
FIGURE 3.8.1.1: FORMAT USAGE FOR GENDYN OUTPUT (CONTINUED)

READ FORMAT 42

CONTINUE I

GHOST CUTTER SUMMARY

READ FORMAT 43

READ FORMAT 44

DO I - 1, \# OF GHOST CUTTERS (IGTNPT)

READ FORMAT 45

CONTINUE I

GHOST CUTTER SUB-NODE LOCAL COORDINATE SUMMARY

READ FORMAT 46 
FIGURE 3.8.1.1: FORMAT USAGE FOR GENDYN OUTPUT (CONTINUED)

DO I $=1, \#$ OF GHOST CUTTERS (IGTNPT)

\section{READ FORMAT 47}

CONTINUE I

GHOST CUTTER LENGTH SUMMARY

READ FORMAT 48

DO I $=1$, \# OF GHOST CUTTERS (MELNUM (4))

READ FORMAT 49

CONTINUE I

CUTTER DEFINITIONS

READ FORMAT 50 
FIGURE 3.8.1.1: FORMAT USAGE FOR GENDYN OUTPUT (CONTINUED)

DO I $=1$, \# OF GHOST CUTTERS (MELNUM (4))

READ FORMAT 51

CONTINUE I

CHARACTERISTIC PLANE DEFINITIONS

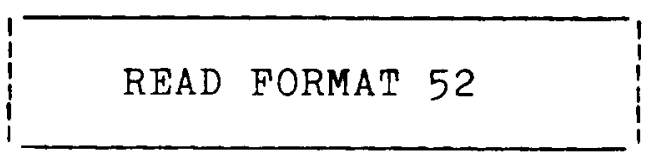

DO $I=1$, \# OF CHARACTERISTIC PIANES (IGTNPL)

READ FORMAT 53

CONTINUE I

DO $I=1$, \# OF CHARACTERISTIC PLANES (IGTNPL)

READ FORMAT 54 
FIGURE 3.8.1.1: FORMAT USAGE FOR GENDYN OUTPUT (CONTINUED)

READ FORMAT 55

CONTINUE I

BIT SURFACE DEFINITIONS

READ FORMAT 56

DO I $=1$, \# OF BIT SURFACES (ICFNSR)

READ FORMAT 57

CONTINUE I

DO $I=1$, \# OF BIT SURFACES (ICFNSR)

READ FORMAT 58

READ FREE FORMAT, 59 
FIGURE 3.8.1.1: FORMAT USAGE FOR GENDYN OUTPUT (CONTINUED)

EIGENVALUES AND FREQUENCIES
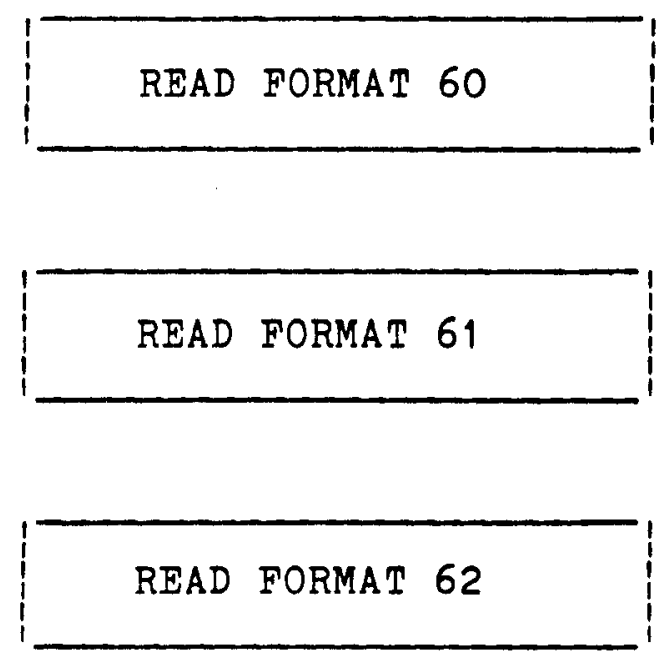

DO $I=1$, \#D.O.F. IN TIED SYSTEM (I99TSZ)

READ FORMAT 63

CONTINUE I 
be an extremely large file, it may contain important data pertaining to why a run failed to execute properly. The following is a brief summary of the data reported in this file:

FILE NAME: User specified output file name, with a -DAT extension.

FILE TYPE: Formatted, sequential access. CHARACTERISTICS: Typically a large file if a great deal of debug output is desired. May occupy large amounts of storage space.

DATA REPORTED: A. Any data written to unit IOUT, including but not limited to:

1. Echo of interactive input questions.

2. Various vectors and arrays - those which the user desires to see.

3. Various error messages of any type, including system errors and internal program errors.

NOTE: If execution of a run is terminated, the error responsible for program termination is frequently the last entry in this file. This error can be found by editing the file and going to the bottom. 


\subsubsection{DYNAMIC SOLUTION SUMMARY (RUNDYN) - PRINT FILE} AND PLOT FILE

When a dynamic solution is performed by the GEODYN program (running the RUNDYN sub-program), up to three output files may be created. These files include a "print" file, a "plot" file, and a debug output file. Figures 3.8.2.1 through 3.8.2.8 illustrate the data which is reported in the print and plot files. The debug output file is similar to the debug output file produced by GENDYN. Please refer to Section 3.8.1.1. for a description of the data in the debug output file.

The print and plot files both contain the same data, with the exception of a summary which appears at the end of the print file, but does not appear in the plot file, and a ghost cutter interaction summary which appears in the print file but not the plot file. The user specifies how often in simulated time data is to be written to the print and plot files. Data is written independently to these two files. That is, data may be written to the print file every $n$ seconds, and written to the plot file every $m$ seconds. A detailed breakdown of the data contained in the print and plot files follows, including information pertaining to how to locate and read this formatted data. 


\section{PRINT AND PLOT FILES}

FILE NAMES: BFNPRT.DAT - Print file

BFNPLT.DAT - Plot file

FILE TYPE: Formatted, sequential access.

DATA REPORTED: See Figures 3.8.2.1 and 3.8.2.2 and refer to the following detailed break-down:

A. GENDYN output - Figure 3.8.2.3

1. Please refer to Section 3.8 .1

B. Formation Model Output - Figure 3.8.2.4

1. Scalar Mesh Parameters -

- Describes the geometry of the formation mesh

2. Organization of the Formation Points -

- Describes the formation point numbers located along the coordinate axes and in each quadrant on the bottom surface

- The formation point numbers on the sidewall surface and incline surface

- The available material properties of these points 
BFNPRT FILE STRUCTURE

GENDYN OUTPUT SUMMARY $\mid$ (See F1 gure 3.8.2.3)

FORMATION MODEI OUTPUT

(See Pigure 3.8 .2 .4 )

\section{SOLUTION CONTROL PARAMETERS}

(See Figure 3.8.2.5)

DO $I=1$, \# OF SPECIPIED PRINT STATIORS

\section{DYNAMIC SOLUTIOH QUANTITIES}

(See Figure 3.8.2.6)

GHOST COTTER INTERACTIOR SUMAAR

(See Pigure 3.8.2.7)

CONTIRUE I

DYNAMIC SOLUTION SUMMARY

(See Figure 3.8.2.8)

FIGURE 3.8 .2 .1 : BFNPRT FILE STRUCTURE 
3.85

BFNPLT FILE STRUCTURE

GENDYN OUTPUT SUMMARY

(See Figure $3 \cdot 8 \cdot 2 \cdot 3$ )

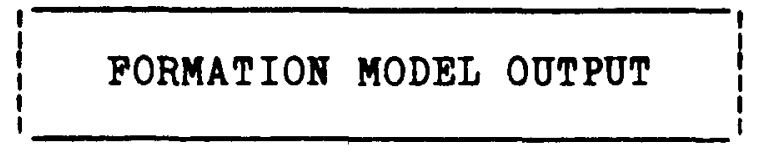

(See Figure 3.8.2.4)

SOLUTION CONTROL PARAMETERS

(See Figure 3.8.2.5)

DO $I=1$, \# OF SPECIPIED PLOT STATIONS

\section{DYNAMIC SOLUTION QUANTITIES}

(See Figure 3.8.2.6)

CONTINUE I 
3. Global Formation Point Locations and Property ID's

- For each point number, gives its location (bottom, side, or incline), $X, Y, Z$ coordinates, and material type I.D.

Tables 3.8.2.1 and 3.8.2.2 and Figure 3.8.2.9 contain information pertaining to how to locate and read various data in the Formation Model Output section of a print or plot file.

C. Solution Control Parameters - Figure 3.8.2.5

1. Solution Control Parameters - Includes:

- Total number of revolutions during the analysis

- Total number of degrees rotated during the analysis

- The angular velocity of the drill string

- The size of the time step used for the analysis

- The total number of time steps to complete the analysis

- The total time simulated during the analysis

2. Print Station Summary - Includes:

- The total number of print stations for the analysis output

- The number of degrees the drill string rotates between print stations for output

- The simulated time between print stations

- The total number of time steps between print stations 
3. Plot Station Summary - Includes:

- The total number of plot stations for the analysis output

- The number of degrees the drill string rotates between plot stations for output

- The simulated time between plot stations

- The total number of time steps between plot stations

4. Restart Station Summary - Includes:

- Total number of restart stations for the analysis output

- The number of degrees the drill string rotates between restart stations

- The simulated time between restart stations

- The total number of time steps between restart stations.

5. Start-Up Summary - Includes:

- The total number of time steps taken to ramp on the external loads.

6. Solution Algorithm Summary - Includes:

- Maximum number of iterations allowed per time step

- The convergence criteria (\$) for acceptable solution

- Numerical integration constants - Alpha, Gamma, $\mathrm{A} 0, \mathrm{~A} 1, \mathrm{A2}, \mathrm{A3}, \mathrm{A} 4, \mathrm{~A} 5$ 
Tables $3 \cdot 8 \cdot 2.3$ and $3 \cdot 8 \cdot 2.4$ and Figure $3 \cdot 8 \cdot 2.10$ contain information pertaining to how to locate and read various data in the Solution Control Parameters Output summary section of a print or plot file.

D. Dynamic Solution Quantities - Figure 3.8.2.6

1. Status Summary - Includes:

- Heading - Print Summary for Print Station Number _ or Plot Station Number _

- Elapsed simulated time since start-up

- Total degrees drill string rotated since start-up

- Elapsed simulated time since the last print or plot station

- Number of degrees drill string rotated since the last print or plot station

- Number of time steps since the last print or plot station

2. Finite Element Displacements, Velocities, and Accelerations

3. Absolute Positions, Velocities, and Accelerations

4. Global Positions, Velocities, and Accelerations

5. Finite Element Forces - Includes:

- External forces

- Body forces

- Formation forces 
6. Global Forces - Includes:

- External forces

- Body forces

- Formation forces

7. Ghost Cutter Absolute Positions, Velocities, and Accelerations

8. Ghost Cutter Global Positions, Velocities, and Accelerations

9. Ghost Cutter forces - Includes:

- Force in rotating coordinate system

- Force in global coordinate system

Tables 3.8.2.5 and 3.8.2.6, and Figure 3.8.2.11 contain information pertaining to how to locate and read various data in the Dynamic Solution Output Summary section of a print or plot file.

E. Ghost Cutter Interaction Summary - Figure 3.8.2.7 (Print File Only!)

1. Number of cutters in contact with formation

2. For each cutter in contact with formation:

- Penetration distance

- Global coordinates of the cutter

- Nearest formation point to the cutter

- Global coordinates of the nearest formation point

- Internal coordinates of the nearest formation point 
- Formation properties at the point of cutter contact

- Cutter velocity in global coordinates

- Absolute velocity magnitude

- Global components of the interaction forces on the cutter

- Resultant shear and normal force on the cutter

- Cutter properties

- Cutter status - failed or intact

Tables 3.8 .2 .7 and 3.8 .2 .8 , and Figure 3.8 .2 .12 contain information pertaining to how to locate and read various data in the Ghost Cutter Interaction Summary portion of a print file.

F. Dynamic Solution Summary (Print File Only) - Figure 3.8.2.8

1. RUNDYN title

2. Number of degrees the drill string has rotated during the analysis

3. Simulated time elapsed during the analysis

4. The applied angular velocity (degrees/second) of the drill string

5. Number and size of time steps used in solution algorithm

6. Number of modes considered in the analysis, and highest frequency considered

7. The maximum number of iterations allowed per time step for a converged solution 
8. The specified convergence criteria

9. The number of time steps which failed to converge within the maximum number of iterations allowed per time step

10. The dynamic integration constants (alpha and gamma) used in the analysis

11. The status of all ghost cutters at the end of the run - intact, not intact, or gauge.

Tables 3.8.2.9 and 3.8.2.10 and Figure 3.8.2.13 contain information pertaining to how to locate and read various data in the Dynamic Solution Summary portion of the print file.

NOTE: The debug output files must be re-named between successive runs if the same file names are desired, and the previous output data is to be retained. This is because if data is to be written to a debug output file which already exists, the data in this existing file will be over-written, and thus lost.

The GENDYN summary file and the print and plot files have a similar problem, because they always have the same name. They are automatically deleted if they already exist at the beginning of a run. Therefore, if these files are to be saved, they must also be re-named prior to another execution! 
FIGURE 3.8.2.3: GENDYN OUTPUT SUMMARY

GENDYN TITLE

MODEL SIZE SUMMARY

MODEL GEOMETRY SUMMARY

DRILI STRING EIGENVALUE \& NATURAL PREQUENCY SUMMARY

FIGURE 3.8.2.4: PORMATION MODEL OUTPUT

SCALAR MESH PARAMETERS

ORGANIZATION OF PORMATION POINTS

GLOBAL FORMATION POINT LOCATION AND PROPERTY ID'S 
FIGURE 3.8.2.5: SOLUTION CONTROL PARAMETERS

SOLUTION CONTROL PARAMETERS

PRINT STATION SUMMARY

PLOT STATION SUMMARY

RESTART STATION SUMMARY

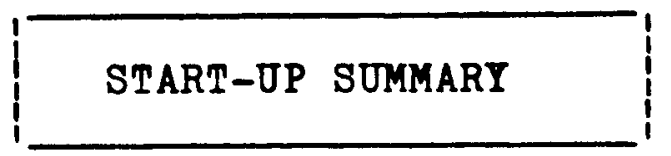

SOLUTION ALGORITHM SUMMARY 
FIGURE 3.8.2.6: DYNAMIC SOLUTION QUANTITIES

\section{STATOS SUMMARY}

FINITE ELEMENT DISPLACEMENTS, VELOCITIES, AND ACCELERATIONS

ABSOLUTE POSITIONS, VELOCITIES, \& ACCELERATIONS

GLOBAL POSITIONS, VELOCITIES AND ACCELERATIONS

FINITE ELEMENT FORCES

GLOBAL FORCES

GHOST CUTTER ABSOLUTE POSITIONS, VELOCITIES AND ACCELERATIONS

GHOST CUTTER GLOBAL POSITIONS, VELOCITIES AND ACCELERATIONS

GHOST CUTTER ROTATIONAL AND GLOBAL FORCES 
FIGURE 3.8.2.7: GHOST CUTTER INTERACTION SUMMARY

NUMBER OF CUTTERS IN CONTACT WITH FORMATION

DO $I=1, \#$ OF CUTTERS IN CONTACT

PENETRATION DISTANCE

GLOBAL COORDINATES OF CUTTER

NEAREST FORMATION POINT TO CUTTER

GLOBAL COORDINATES OF NEAREST FORMATIONS POINT

INTERNAL COORDINATES OF NEAREST FORMATION POINT

FORMATION PROPERTIES AT POINT OF CONTACT

CUTTER VELOCITY IN GLOBAL COORDINATES

ABSOLUTE VELOCITY MAGNITUDE 
FIGURE 3.8.2.7: GHOST CUTTER INTERACTION SUMMARY (CONTINUED)

INTERACTION FORCES ON THE CUTTER

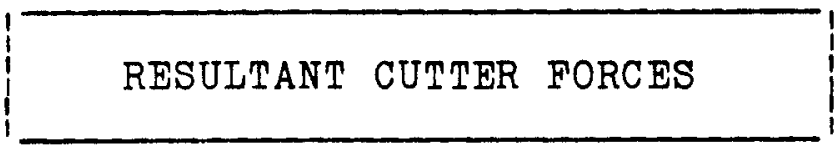

CONTINUE I 
FIGURE 3.8.2.8: DYNAMIC SOLUTION SUMMARY

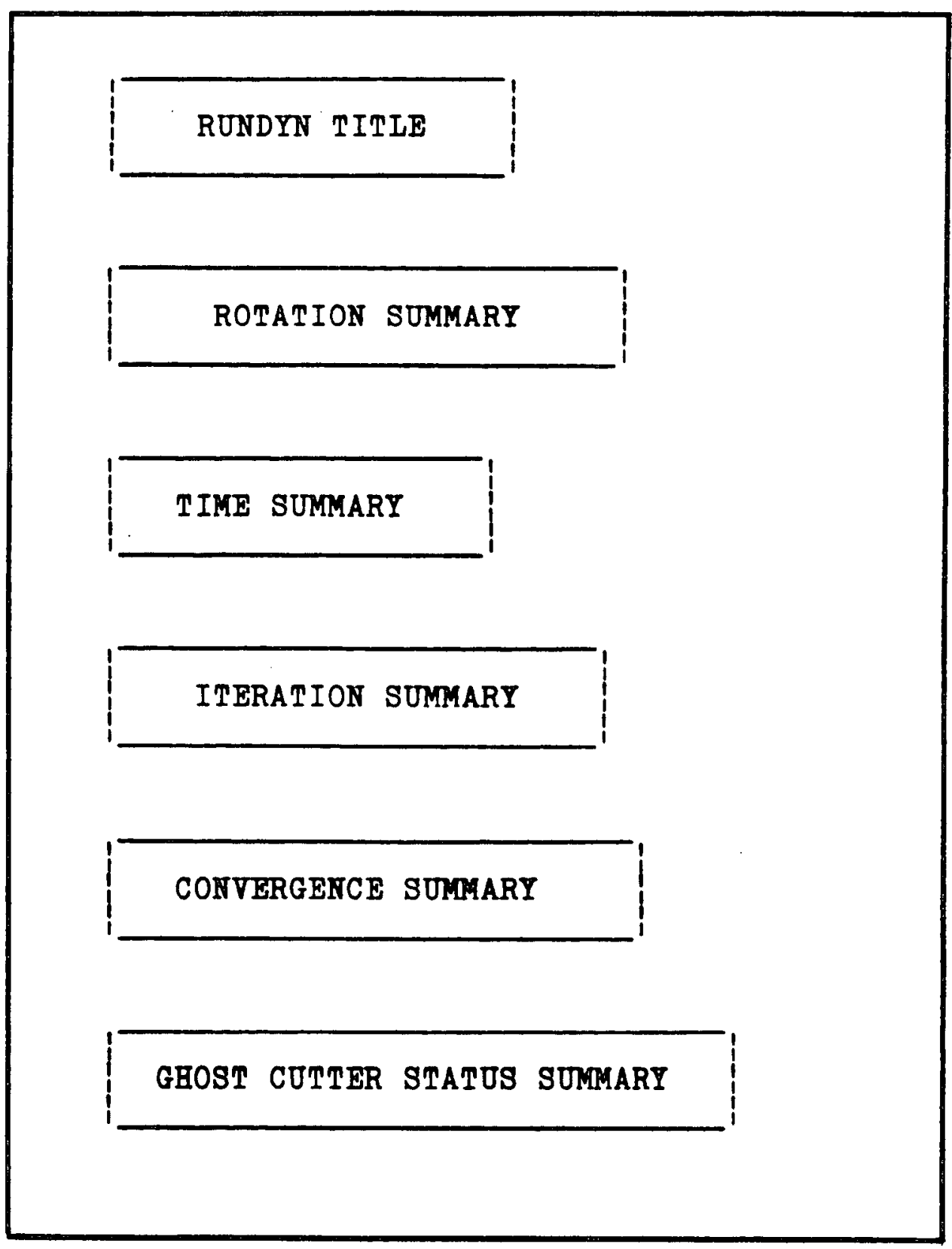




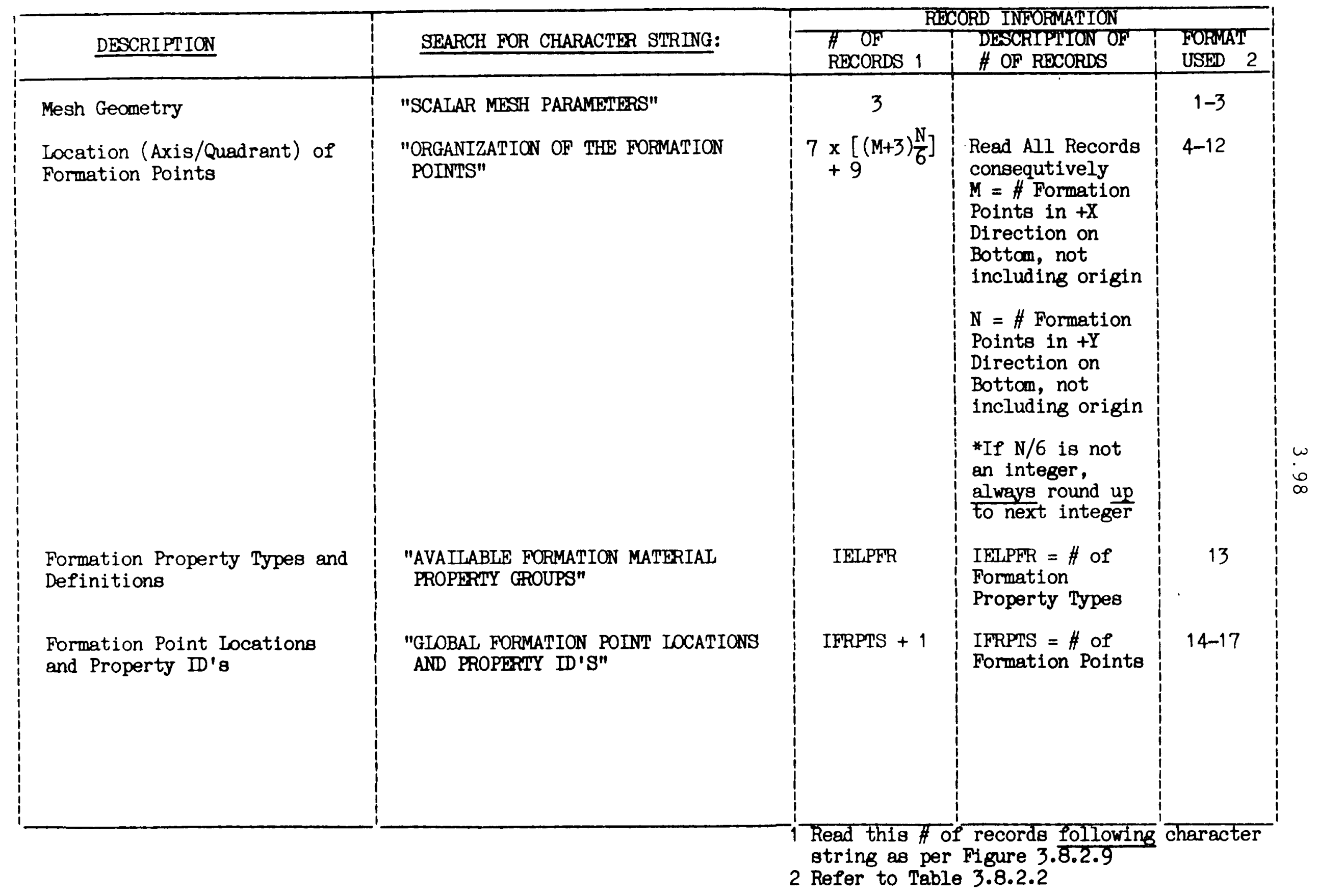

TABLE 3.8.2.1: FORMATION MODEL OUTPUT SUMMARY 
3.99

TABLE 3.8.2.2.: FRMOUT Formats Corresponding to Table 3.8.2.1

1.

2.

3.

4.

5.
87

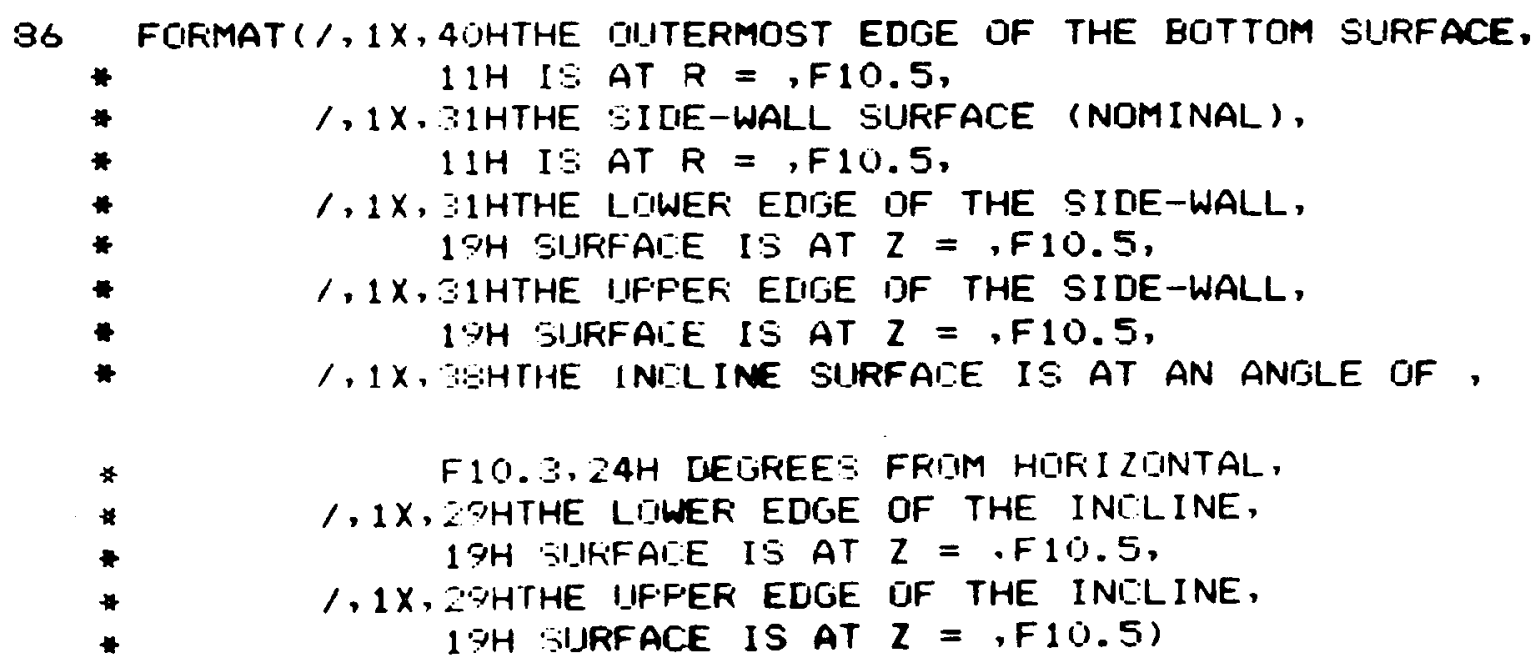

85 FIRMAT $(/, 1 X, 30$ HNIIMBER OF POINTS IN THE + $X$ UIR, 4OHECTTION ON THE BOTTOM (EXCLUDINIS AXIS) =, IS, $1,1 \times, 30 H N I M B E R$ UF POINTS IN THE +Y UIR, 4OHELTION ON THE BUTTOM (EXCLUDINIJ AXIS) =, I5, $1,1 \times, 29 H N L I M E E R$ OF POINTS IN THE THETA, 3OH DIRECTION ON THE SIDE-WALL $=$, I5, $1,1 \times, 25 H N U M E E R$ OF FDINTS IN THE $Z$, 3OH DIFECTION ON THE SIDE-WALL $=, 15$, $1,1 X, 27 H N L I M B E R$ OF POINTS IN THE " $S "$, $28 H$ DIRECTION ON THE INCLINE $=, 15$, $1.1 \times, 29 H N U M B E R$ OF POINTS IN THE THETA, 28H DIRECTION ON THE INCLINE $=.15$ ) .

201

84

FORMAT $/ / /, 45 H$ THE NUMBER OF THE POINT AT THE GRIGIN OF THE, 13H X-Y GRID IS , 15) 
6.

7.

8.

9.

10.

11.

12.

13.

14.

15.

16.

17

SO FORMAT $(/, 1 \times, 6112)$

75 FORMATS $77(1 \mathrm{H}=)$ )

1000 FORMAT $(1 x, 12,1 x, 1 H /, 6(3 x, 16,3 x))$

401 FORMAT $(/ /, 5 X, 3 O H F O ̈ R M A T I O N$ POINT NUMBERS UN THE, * 27H AXES OF THE BOTTOM SURFACE, (, 5X, $57(1 \mathrm{H}-)$ )

910 FORMAT $/ / /, 5 X, 30 H F O R M A T I O N$ POINT NIJMBERS ON THE, $18 H$ SIDE-WALL SURFACE,

$1,5 X, 48(1 H-))$

920 FORMAT $/ /, 5 x, 3 O H F$ ORMATION POINT NUMBERS ON THE, $16 \mathrm{H}$ INCLINE SURFACE, $1,5 X, 46(1 H-))$

33 FORMAT $/ /, 5 X, 29 H N U M B E R$ OF FORMATION POINTS ON, 2.5H THE BOTTOM SURFACE = . I 10 . $1,5 X, 2 \%$ HNIIMEER OF FORMATION POINTS ON, ZSH THE SIDE-WALL SURFACE = , I 10 , $1,5 x, 2$ HNIIMEER OF FORMATION FOINTS ON, 2 SH THE INCLINE SIIRFACE = IIO. $1,5 x, 7 H T H E$ TUTAL NIJMEER OF FORMATIDN, $\because$ SH FOINTS USED IN MOLEL $=, 110$,

302 FORMAT $(1 x, 6 x, 15,8 x, 3(E 12,6,3 x))$

1701 FORMAT $/ / / /, 5 X, 5 H F O I N T, 4 X, 7 H S U R F A C E, 6 X, 7 H X-C O O R D, 6 X$, $7 H Y-C O O R D, 6 X, 7 H Z$-COORD, 4X, 7HFROF ID, 1 , $5 \mathrm{X}, 5 \mathrm{H}-\cdots, 4 \mathrm{X}, 7 \mathrm{H}-\cdots, \cdots,-\cdots, 7 \mathrm{H} \cdots \cdots$,

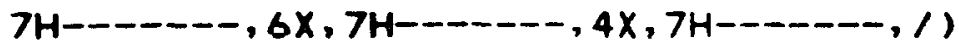

1702 FIRMAT $(5 x, 15,3 x, 84$ BOTTOM, $3(3 x, F 10,4), 3 x, 16)$ c 1703 FORMAT $(5 x, 15,3 x$, SHSIDEWALL, $3(3 x, F 10,4), 3 x, 16)$ C 1704 FORMAT $(5 x, 15,3 x, 8 H$ INCLINE, $3(3 x, F 10,4), 3 x, 16)$ 
FIGURE 3.8.2.9: FORMAT USAGE FOR FORMATION MODEL OUTPUT MESH GEOMETRY
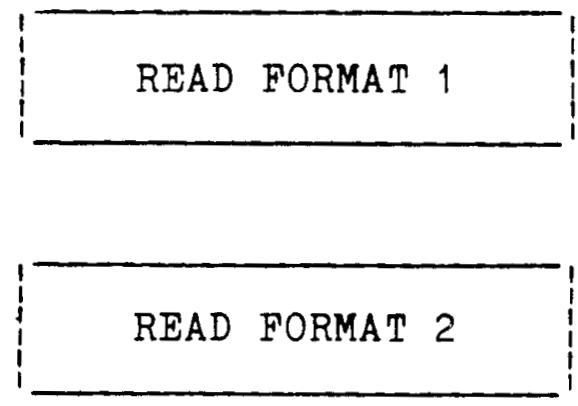

\section{READ FORMAT 3}

\section{IOCATION (AXIS/QUADRANT) OF FORMATION POINTS}

READ FORMAT 4

DO $I=1,4$

READ FORMAT 5

DO $\mathrm{J}=1, \mathrm{~N} / 6^{(1)}$

READ FORMAT 6

Column Headings

READ FORMAT 7 
FIGURE 3.8.2.9: FORMAT USAGE FOR FORMATION MODEL OUTPUT (CONT INUED)

DO $K=1, M^{(2)}$

\section{READ FORMAT 8}

CONTINUE $\mathrm{K}$

\section{READ FORMAT 7}

CONTINUE J

CONTINUE I

READ FORMAT 9

DO $I=1, N / 6^{(1)}$

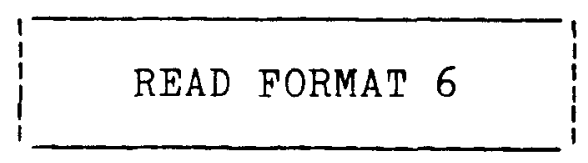

Table Headings
Column Headings

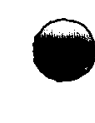

READ FORMAT 7

DO $J=1, M^{(2)}$ 
FIGURE 3.8.2.9: FORMAT USAGE FOR FORMATION MODEL OUTPUT (CONTINUED)

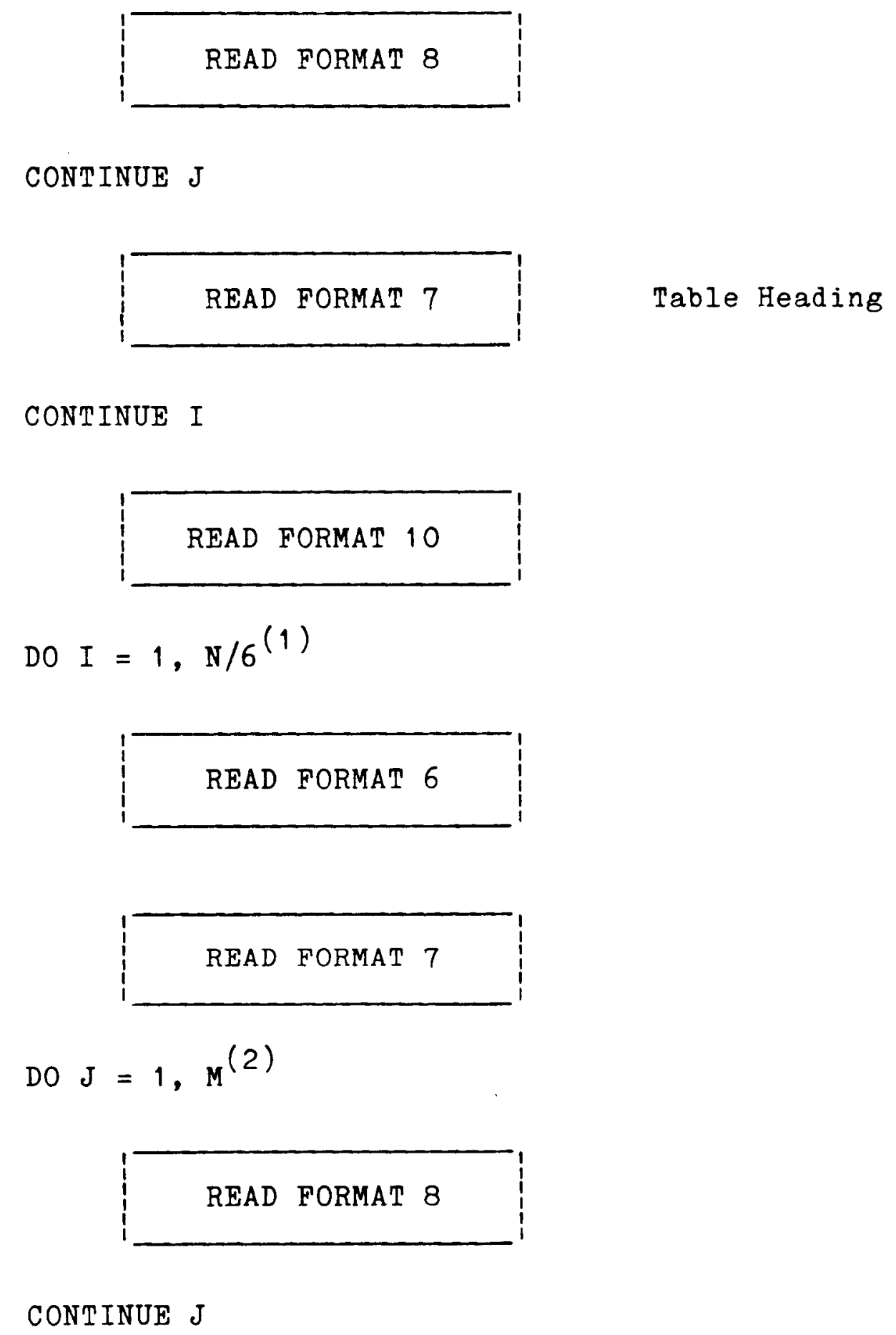


FIGURE 3.8.2.9: FORMAT USAGE FOR FORMATION MODEL OUTPUT (CONTINUED)

\section{READ FORMAT 7}

CONTINUE I

\section{READ FORMAT 11}

DO $I=N / 6^{(1)}$

READ FORMAT 6

READ FORMAT 7

DO $J=1, M^{(2)}$

READ FORMAT 8

CONTINUE $\mathrm{J}$

READ FORMAT 7

CONTINUE I 
FIGURE 3.8.2.9: FORMAT USAGE FOR FORMATION MODEL OUTPUT (CONT INUED)

\section{READ FORMAT 12}

FORMATION PROPERTY TYPES AND DEFINITIONS

DO $I=1, \#$ OF FORMATION POINTS

READ FORMAT 13

CONTINUE I

FORMATION POINT LOCATIONS AND PROPERTY ID'S

READ FORMAT 14

DO $I=1$, \# OF FORMATION POINTS ON BOTTOM

READ FORMAT 15

CONTINUE I

DO I, 1, \# OF FORMATION POINTS ON SIDEWALL

READ FORMAT 16

CONTINUE I 
FIGURE 3.8.2.9: FORMAT USAGE FOR FORMATION MODEL OUTPUT ( CONTINUED)

DO $I=1$, \# OF FORMATION POINTS ON INCLINE

READ FORMAT 17

CONTINUE I

(1) $-N=\#$ of formation points in $+Y$ direction on bottom, not including origin.

If $N / 6$ is not an integer, always round up to the next integer: for $N=4, N / 6=1$

$$
\begin{aligned}
& \text { for } N=8, N / 6=2 \\
& \text { for } N=6, N / 6=1
\end{aligned}
$$

(2) $-M=\#$ of formation points in $+X$ direction on bottom, not including origin. 


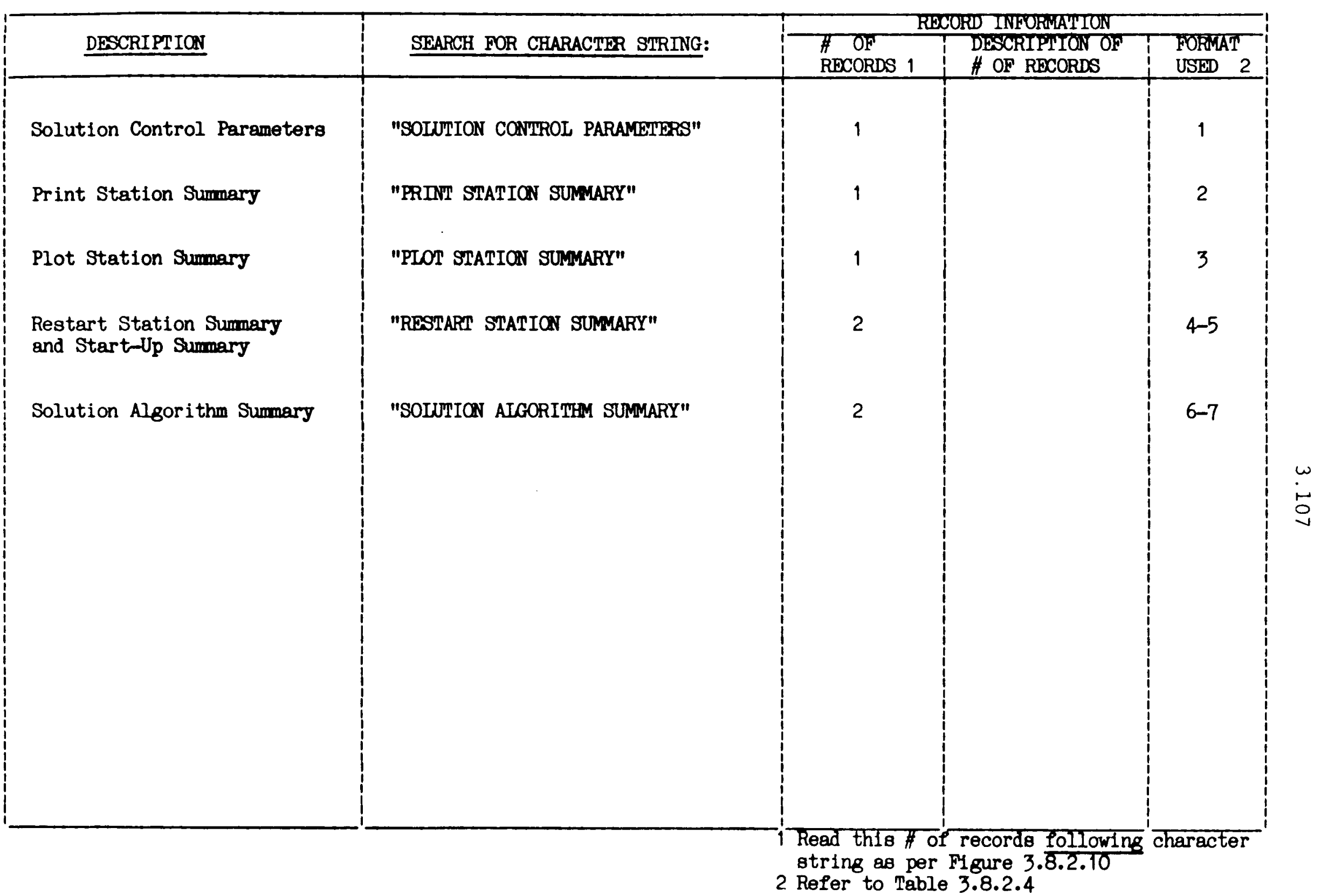

TABLE 3.8.2.3: SOLUTION CONTROL PARAMETERS OUTPUT SUMMARY 
TABLE 3.8.2.4: CNTOUT Formats Corresponding to Table 3.8.2.3

1. 110 FORMAT $/, 5 X, 37 H T O T A L$ OF REVOLUTIONS FOR ANALYSIS : , 13X,E12.7,

$1 / 1,5 X, 41 H T O T A L$ \# OF DEGREES ROTATED FOR ANALYSIS $: 9 X, E 12.7,1 /$.

$25 X, 44 H A N G U L A R$ VELOCITY OF DRILL STRING (DEG/SEC) $:, 6 X, E 12.7,1 /$,

$35 X, 35 H T I M E$ STEP USED FOR ANALYSIS (SEC) $:, 15 X, E 12.7,1 /, 5 X$,

4 44HTOTAL \# OF TIME STEPS TO COMFLETE ANALYSIS : $6 x, 16,1 /, 5 X$,

5 4OHTOTAL TIME SIMULATED IN ANALYSIS (SEC) :, 10X,E12.7)

2.

120 FORMAT $(/, 5 X, 47 H T O T A L$ OF PRINT STATIONS FOR ANALYSIS OUTPUT $:$ $13 X, 16,1 /, 5 X, 40 H D E G R E E S$ ROTATED BETWEEN PRINT STATIONS : , $10 X$,

2 E12.7, $1,5 X, 45 H S I M U L A T E D$ TIME BETWEEN PRINT STATIONS (SEC) $:, 5 X$,

3 E12.7, $/ 1,5 x, 46 H T O T A L$ \#F TIME STEPS BETWEEN PRINT STATIONS :

$44 x, I 6)$

3. 130 FORMAT $(/, 5 X, 46 H T O T A L$ OF PLOT STATIONS FOR ANALYSIS OGFPUT:, $2 X$, $116,1 /, 5 x, 39 H D E G R E E S$ ROTATED BETWEEN PLOT STATIONS $:, 11 x, E 12,7,1 /$, 2 5X, 44HSIMILATED TIME BETWEEN PLOT STATIONS (SEC) :,6X,E12.7,1/,

3 5X,45HTOTAL \# OF TIME STEPS BETWEEN PLOT STATIONS : ,5X, I6)

4. 140 FORMAT $(/, 5 X, 42 H T O T A L$ OF RESTART STATIONS FOR ANALYSIS :,8X, I6, $1 / 1,5 X, 42$ HDEGREES ROTATED BETWEEN RESTART STATIONS : $8 X$, E 12.7,1/, $25 x, 47 H S I M L I L A T E D$ TIME BETWEEN RESTART STATIONS (SEC) : , 3X,E12.7,

$3 / 1,5 X, 48 H T O T A L$ \# OF TIME STEPS BETWEEN RESTART STATIONS :,2X, (6)

5. 150 FORMAT $(10(/), 5 X, 16 H S T A R T-U P$ SUMMARY, $/, 4 X, 18(1 H=), / / 1,5 X, 51 H$ TOTAL 1* OF TIME STEPS TAKEN TO RAMP ON EXT. LOADS : $4 X, 161$

6. 160 FORMAT $/, 5 X, 49 H M A X$. OF ITERATIONS PER TIME STEP FOR SOLUTION 1, $16 x, 16,1 /, 5 X, 50 H C O N V E R G E N C E$ CRITERIA $(x)$ FOR ACCEPTABLE SOLUTION: $2,5 X, E 12.7)$

7. 170 FORMAT $(5(/), 5 x, 42$ HNIJMERICAL INTEGRATION CONSTANT

1 E12.7, $1 /, 5 X, 42 H$ HUMERICAL INTEGRATION CONSTANT

2 E12.7, $1 /, 5 X, 39$ HNUMERICAL INTEGRATION CONSTANT

3 E12.7, $11,5 X, 39$ HNUMERICAL INTEGRATION CONSTANT

4 E12.7, $1 /, 5 X, 3$ 9HNLIMERICAL INTEGRATION CONSTANT

5 E12.7,1/,5X,39HNUMERICAL INTEGRATION CONSTANT

6 E12.7, $/ 1,5 x, 39 H N U M E R I C A L$ INTEGRATION CONSTANT

7 E12.7, $1,5 X, 39$ HNUMERICAL INTEGRATION CONSTANT

- ALPHA : , 3X,

- GAMMA : ,3X,

- AO :,6X,

- A1:.6X.

- A2:.6x.

- A3: :6x,

- A4:.6X,

- A5 :,6X,E12.7) 
FIGURE 3.8.2.10: FORMAT USAGE FOR SOLUTION CONTROL PARAMETERS OUTPUT

SOLUTION CONTROL PARAMETERS

READ FORMAT 1

PRINT STATION SUMMARY

READ FORMAT 2

PLOT STATION SUMMARY

READ FORMAT 3

RESTART STATION SUMMARY

READ FORMAT 4

READ FORMAT 5

SOLUTION ALGORITHM SUMMARY

READ FORMAT 6

READ FORMAT 7 


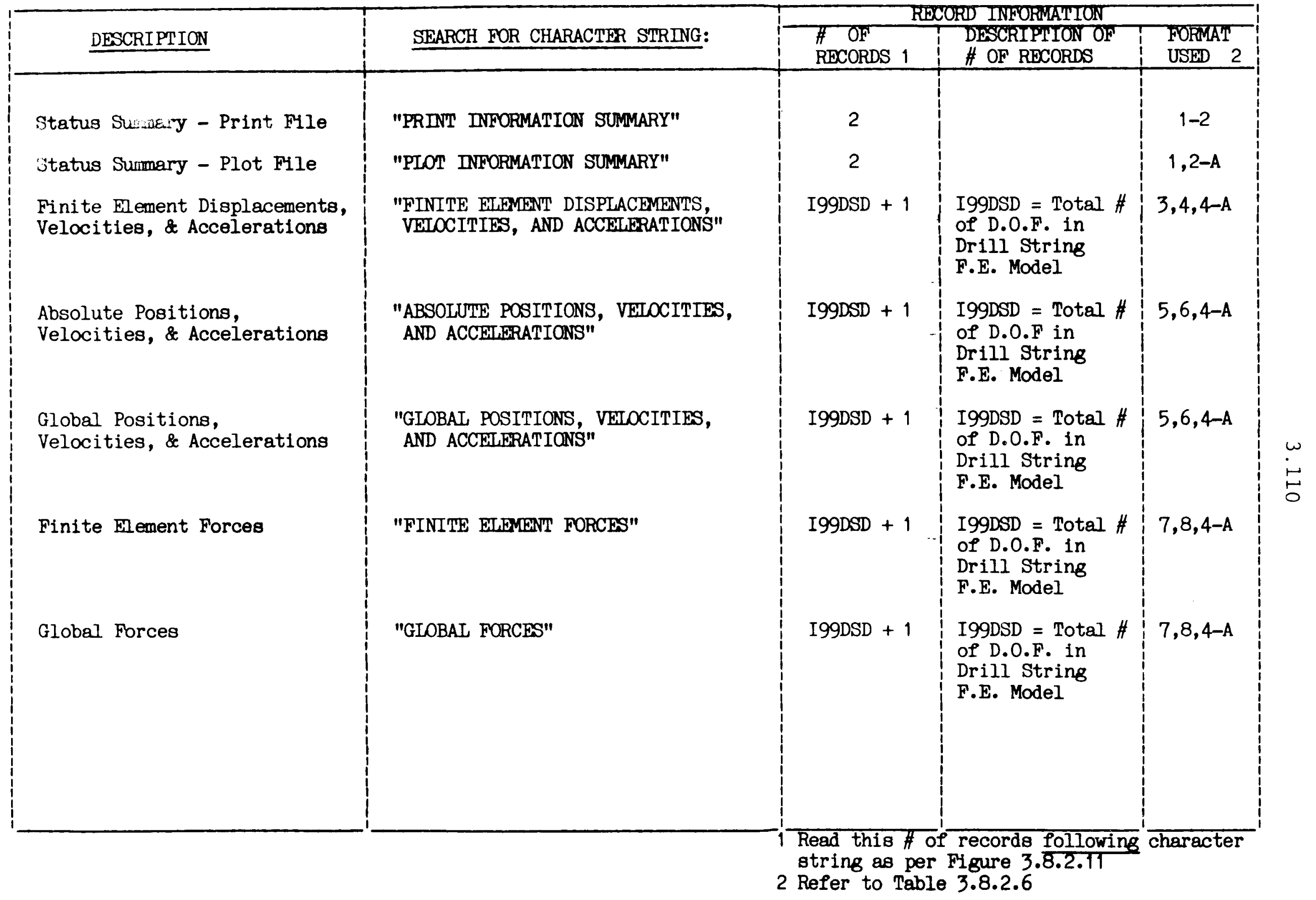

TABLE 3.8.2.5: DYNAMIC SOLUTION OUTPUT SUMMARY

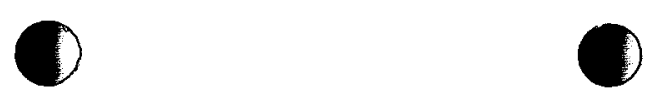




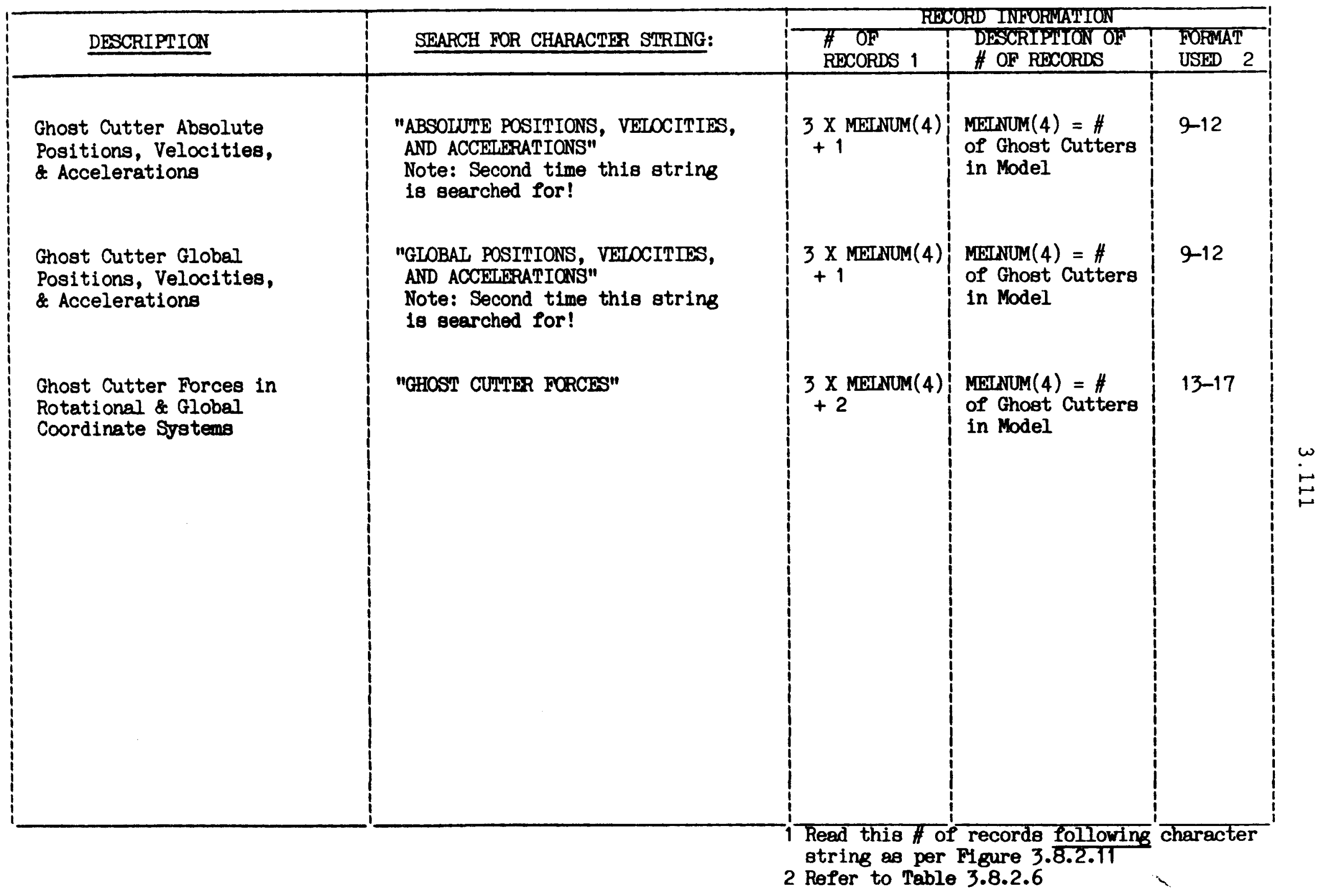

TABLE 3.8.2.5: DYNAMIC SOLUTION OUTPUT SUMMARY (CONTINUED) 
TABLE 3.8.2.6: RUNOUT Formats Corresponding to Table 3.8.2.5

1. 110 FORMAT1/,5X,27HELAPSED TIME SINCE START UP, $2 X, E 13.7,2 X, 19 H S E C O$ INDS (SIMULATED), $1,5 X, 36$ HTOTAL DEGREES ROTATED SINCE START UP, $2 X$, 2 E13.7)

2-A. 120 FORMAT $/ / /, 5 x, 36 H E L A P S E D$ TIME SINCE LAST PLOT STATION, 2X, E13.7, $12 x, 19 H S E C O I N D S$ (SIMLILATED), $1,5 x, 39 H D E$ IREES ROTATED SINCE LAST PLOT 2 STATION, $2 X, E 13.7,1,5 X, 41$ HNUMAER TIME STEPS SINCE LAST PLOT STATIO $3 N, 2 X, 15)$

2. 140 FORMAT $/ /, 5 X, 37 H E L A P S E D T I M E$ SINCE LAST PRINT STATION, 2X, 1 E 13.7, 2X, 1\%HSECONDS (SIMULATED), $/, 5 X, 40 H D E G R E E S$ ROTATED SINCE LAS 2T PRINT STATION, $2 X, E 13.7,1,5 X, 42 H N L M B E R$ TIME STEPS SINCE LAST PRIN 3T STATIUN, 2X, IS)

3. 158 FORMAT (/,5X, 8HD. 0.F. 5X, 17HDISPLACEMENT (IN), 5X, 15HVELOCITY (IN $1 / S), 4 X, 21$ HACCELERATION (IN/S-2), $/, 4 X, 10(1 H-), 3 X, 19(1 H-), 3 X$,

$217(1 H-), 2 X, 22(1 H-), /)$

4. 160 FORMAT $(1,7 X, 14,9 X, E 13.7,8 X, E 13.7,8 X, E 13.7)$

4-A. 170 FORMAT $(1,7 X, 14,9 X, 41 H T I E D$ D.O.F. - NOT EXPLICITLY SOLVED FOR)

5. 183 FORMAT (/,5X, SHD. 0.F. $, 5 X, 13$ POSITION (IN), 5X,15HVELOCITY (IN/S), $15 X, 21 H A C I E L E R A T I O N(I N / S-2), 1,4 X, 10(1 H-), 3 X, 15(1 H-), 3 X, 17(1 H-)$, $23 X, 23(1 H-), 1)$

\section{1}

6. 187 FORMAT $(1,7 X, 14,7 X, E 13,7,5 x, E 13,7,11 X, E 13.7)$

7. 205 FDRMAT $/, 5 X$, SHD. O.F. , 5X, 13HEXTERNAL (LB), 5X, 1OHBCIEY (LB), 10X, 1 14HFORMATION (LB), $1,4 x, 10(1 H-), 3 X, 15(1 H-), 3 X, 12(1 H-), 3 X$,

$216(1 \mathrm{H}-), 1)$

8. 207 FORAT $(1,7 X, I 4,7 X, E 13.7,5 X, E 13.7,7 X, E 13.7)$

9. 222 FORMAT (5X, SHCUTTER $, 5 x, 4 H D I R, .6 x, 9 H P O S$. (IN),7X, 11HVEL. (IN/S), $16 x, 13 H A C C$. (IN/S-2), $/ 4 x, 10(1 H-), 3 X, 6(1 H-), 2 X, 11(1 H-), 5 X$,

$213(1 H-), 5 x, 15(1 H-), / 1)$

।

10. 230 FORMAT $(1,7 X,[4,8 X, 1 H X, 5 X, E 13,7,5 X, E 13,7,5 X, E 13.7)$

11. 240 FORMAT $(1,7 X, 14,8 X, 1 H Y, 3(5 X, E 13.7)$ )

12. 250 FORMAT $(1,7 X, 14,8 X, 1 H Z, 3(5 X, E 13.7)$ )

13. 995 FORMAT $(1 X, 1 H *, 77 x, 1 H *, 1,1 X, 1 H *, 77 x, 1 H *, 1,1 X, 79(1 H *), 10(1))$ 
3.113

TABLE 3.8.2.6: Continued

14. 275. FORMAT ( $5 x$, BHCUTTER , 5X, 4HDIR., 8X, 15HROT. FORCE (LB), $8 X$, 1 17HGLOBAL FORCE (LB), $1,4 X, 10(1 \mathrm{H}-), 3 \mathrm{X}, 6(1 \mathrm{H}-), 6 \mathrm{X}, 17(1 \mathrm{H}-)$,

15. 280 FORMAT $(1,7 X, 14,8 X, 1 H X, 11 X, E 13.7,11 X, E 13.7)$

16. 290 FORMAT $(1,7 X, 14,8 X, 1 H Y, 2(11 X, E 13.7)$ )

17. 300 FORMAT $(/, 7 X, 14,8 X, 1 H Z, 2(11 X, E 13.7)$ ) 
FIGURE 3.8.2.11: FORMAT USAGE FOR DYNAMIC SOLUTION OUTPUT

PRINT INFORMATION SUMMARY - PRINT FILE

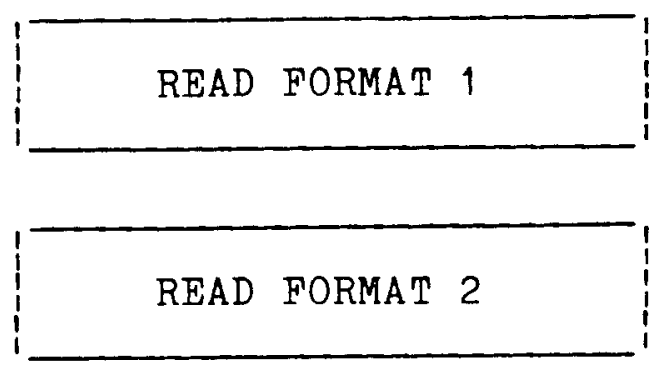

PLOT INFORMATION SUMMARY - PLOM FILE

READ FORMAT 1

READ FORMAT 2-A

FINITE ELEMENT DISPIACEMENTS, VELOCITIES, AND ACCELERATIONS

READ FORMAT 3

DO I $=1$, \# D.O.F. IN DRIL STRING (I99DSD)

IF I IS NOT A TIED D.O.F.

READ FORMAT 4

IF I IS A TIED D.O.F. 
FIGURE 3.8.2.11: FORMAT USAGE FOR DYNAMIC SOLUTION OUTPUT (CONT INUED)

\section{READ FORMAT 4-A}

CONTINUE I

ABSOLUTE POSITIONS, VELOCITIES, AND ACCELERATIONS - Drill String

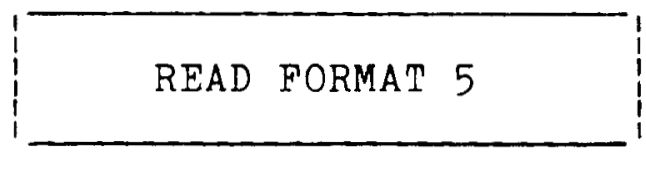

DO I $=1$, \# D.O.F IN DRILL STRING (I99DSD)

IF I IS NOT A TIED D.O.F

READ FORMAT 6

IF I IS A TIED D.O.F.

READ FORMAT 4-A

CONTINUE I

GLOBAL POSITIONS, VELOCITIES, AND ACCELERATIONS - DriII String

READ FORMAT 5 
FIGURE 3.8.2.11: FORMAT USAGE FOR DYNAMIC SOLUTION OUTPUT (CONTINUED)

DO I $=1$, \# D.O.F. IN DRILL STRING (I99DSD)

IF I IS NOT A TIED D.O.F.

\section{READ FORMAT 6}

IF I IS A TIED D.O.F

READ FORMAT 4-A

CONTINUE I

FINITE ELEMENT FORCES

READ FORMAT 7

DO I = 1, \#D.O.F. IN DRILI STRING (I99DSD)

IF I IS NOT A TIED D.O.F.

READ FORMAT 8

IF I IS A TIED D.O.F. 
FIGURE 3.8.2.11: FORMAT USAGE FOR DYNAMIC SOLUTION OUTPUT (CONTINUED)

$$
\text { READ FORMAT 4-A }
$$

CONTINUE I

GLOBAI FORCES

\section{READ FORMAT 7}

DO I $=1$, \#D.O.F IN DRILL STRING (I99DSD)

IF I IS NOT A TIED D.O.F.

\section{READ FORMAT 8}

IF I IS A TIED D.O.F.

$$
\text { READ FORMAT 4-A }
$$

CONTINUE I 
FIGURE 3.8.2.11: FORMAT USAGE FOR DYNAMIC SOLUTION OUTPUT

ABSOLUTE AND GLOBAL POSITIONS, VELOCITIES, AND ACCELERATIONS - Ghost Cutters

\section{READ FORMAT 9}

DO I $=1$, \# OF GHOST CUTTERS (MELNUM (4))

$$
\text { READ FORMAT } 10
$$

READ FORMAT 11

READ FORMAT 12

CONTINUE I

GHOST CUTTER FORCES

READ FORMAT 13

READ FORMAT 14 
FIGURE 3.8.2.11: FORMAT USAGE FOR DYNAMIC SOLUTION OUTPUT (CONT INUED)

DO $I=1$, \# OF GHOST CUTTERS (MELNUM (4))
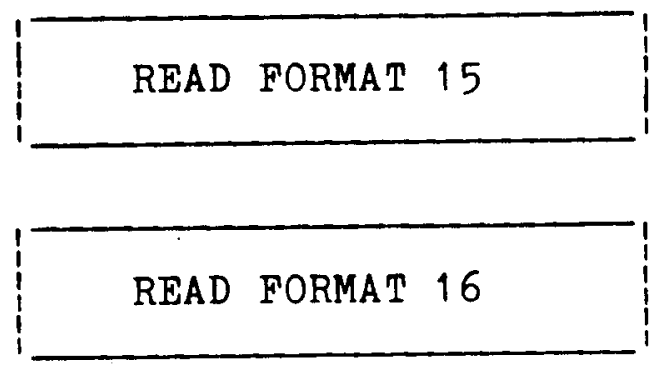

READ FORMAT 17

CONTINUE I 


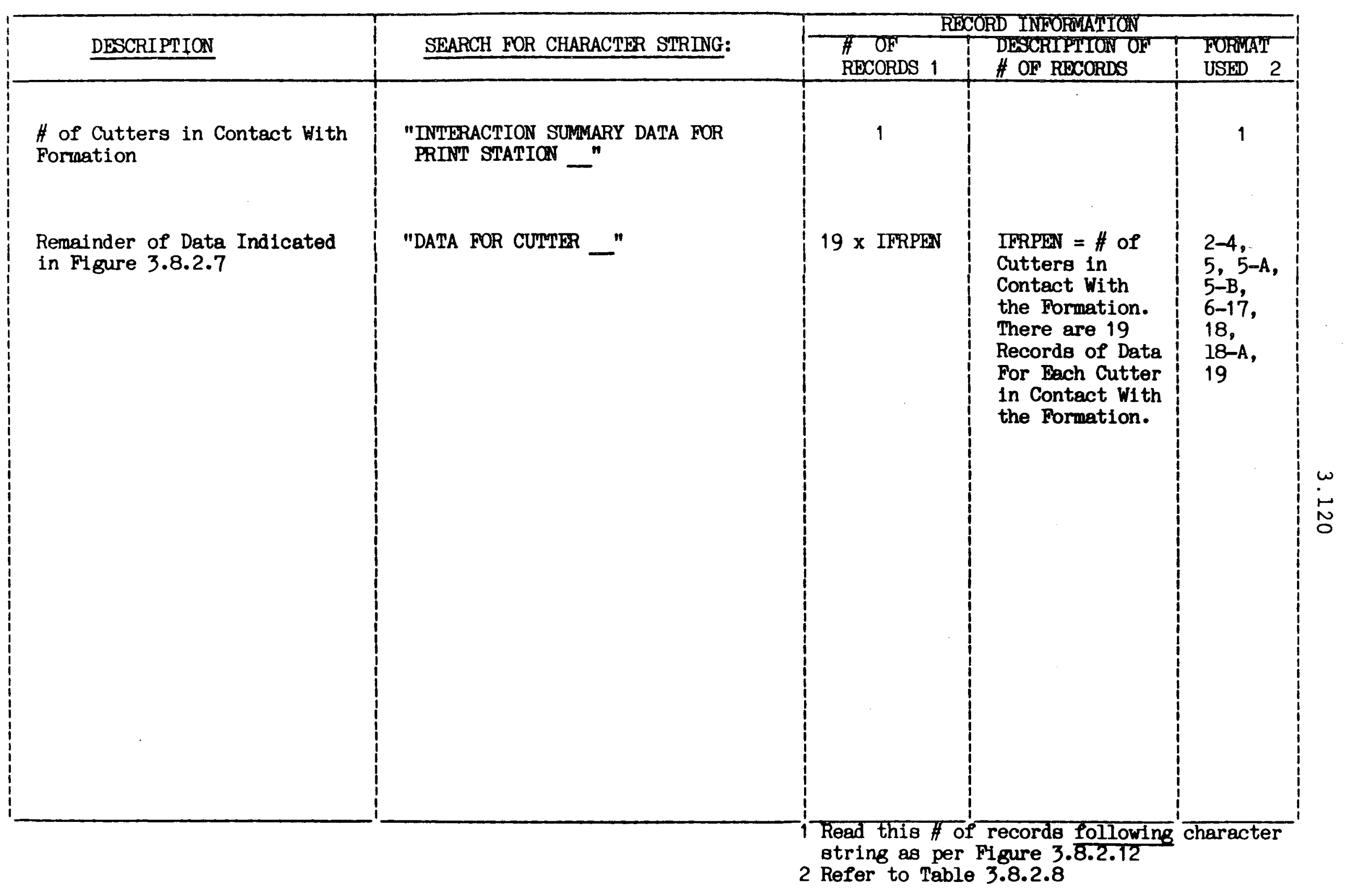

TABLE 3.8.2.7: GHOST CUTTER INTERACTION OUTPUT SUMMARY 
1.

2.

3.

4.

5.

5-A.

5-B.

4007

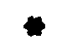

6.

4000

$+$

7.

8.

9.

10.

11.

12.

13.

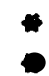

4009

4010

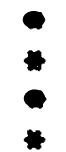

4011

4012

4013

4014

4015
3001 FORMAT $(/ .5 X, 1$ SHTHERE ARE CURRENTLY, $1 X, I 5$, 38H CUTTERS IN CONTACT WITH THE FORMATION)

4002 FORMAT $(1,5 x, 174 T H I S$ CUTTER HAS A ,
26H PENETRATION DISTANCE OF , F10.5)

4003 FORPAT $/, 5 \%$, 25HTHE GLOBAL COORDINATES OF, 27H THE CUTTER $\left(X_{0}, Y_{0}, Z \%\right)$ AREE, $1,5 x, 3(10 x, 510,4)$ )

FORMAT $/, 5 \times, 35 H T H E$ MMER OF THE NEAREST FORMATION, 1OH POINT IS:, I10I

FORMAT $5 \%, 22 H$ (MICH IS PART OF THE, 26H BOTTOM FORMATION SURFACE) ,

FORMAT $15 X, 22 H$ ILHICH IS PART OF THE, ZOH SIDE-WLL FORMATION SURFACE) I

FORMAT 15X.22H (WHICH IS PART OF THE, ZTM INCL INE FOPMATION SURFACE) ,

FOFMAT/ $/, 5 X, 2$ OHTHIS FORMATION POINT'S GLOBAL. 2EH COORDINATES $(X \boxplus, Y \%, Z \otimes)$ ARE\& . $(.5 x, 3(10 x, F 10.4)$ )

FORMAT $1,5 X, 324 I T S$ INTERAA " COORDINATES ARE: , $1.5 x, 3(10 x, F 10.4)$ )

FORMAT $/, 5 X, 20 H T H E$ FORMATION PROPERTIES AT . 2ZH POINT OF CONTACT ARE:

$1,10 X, 33$ MPATERIAL PROPERTY GROUP NMMBER $=.110$. 1.10X,7HKPen $=, F 10.4,12 \mathrm{H}$ Mzero $=$,F10.4, 104 Vhex $=, F 10.4$ )

FORMAT (/,5X,37HCUTTER VELOCITY IN GLOBAL COMPONENTS8,

FORMAT $\left(7 X, 204^{\circ} U\right.$-DOT'

(RELATIVE) $=, 3(2 X, E 13.7)$.

$1,7 \times, 204$

(ABSQLUTE) $=.3(2 X, E 13.7)$ )

FORMAT $(1,7 X, 3$ OHABSOLUTE VELOCITY MAGNITUDE =.E13.7)

FORMAT $(/, 5 X, 32 H I N T E R A C T I O N$ FORCES ON THE CUTTER, $21 \mathrm{H}$ (GLOBAL COMPONENTS): )

FORMAT $(9 X$, THFPO : $3(E 11.5,2 X)$,

BHMAGN. $=, E(1.5)$ 
TABLE 3.8.2.8: Continued

14.

4016 is

15.

16.

4018

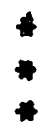

17.

4019

4

18 .

4020

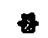

18-A.

$\$ 021$

\section{is}

19.
FORMAT $(8 x$, OHFFric $=, 3(E 11.5,2 X)$,
GHACN. $=, E 11.5)$

$\begin{aligned} \text { FORMAT }(7 x, 9 H F \text { tota } 1 & =, 3(E 11.5,2 x), \\ \text { SHMAGN. } & =, E 11.5)\end{aligned}$

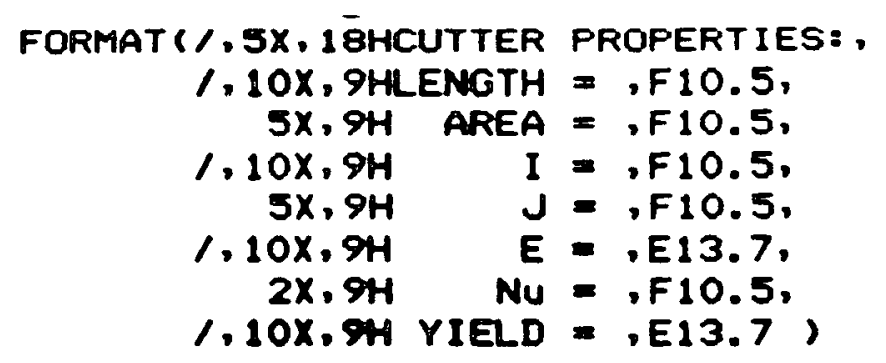

FORMAT $/, 5 X, 1$ HHCUTTER NUMBER , I5, 33H HAS FAILED DURING THIS INCREMENT ,

FORMAT $1 / .5 X, 13 H$ KUTTER NUMBER , I5, 15H HAS NOT FAILED ) 
FIGURE 3.8.2.12: FORMAT USAGE FOR GHOST CUTTER INTERACTION SUMMARY OUTPUT

INTERACTION SUMMARY DATA FOR PRINT STATION

\section{READ FORMAT 1}

DATA FOR CUTTER

DO $I=1$, \# OF CUTTERS IN CONTACT WITH FORMATION (IFRPEN)

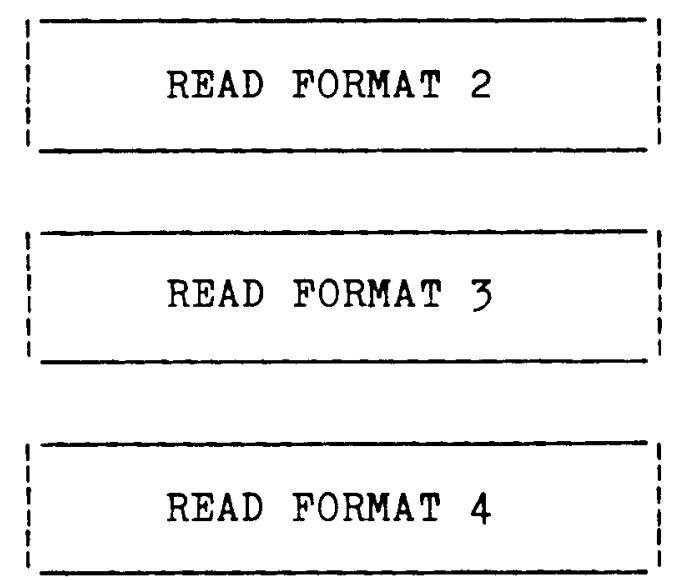

IF THE FORMATION POINT IS ON THE BOTTOM SURFACE

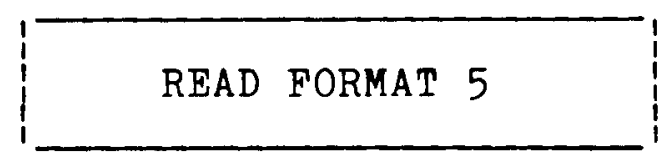

IF THE FORMATION PART IS ON THE SIDE-WALL SURFACE

$$
\text { READ FORMAT 5-A }
$$

IF THE FORMATION POINT IS ON THE INCLINE SURFACE 
FIGURE 3.8.2.12: FORMAT USAGE FOR GHOST CUTTER INTERACTION SUMMARY OUTPUT (CONTINUED)

READ FORMAT 5-B

READ FORMAT 6

READ FORMAT 7

READ FORMAT 8

READ FORMAT 9

READ FORMAT 10

READ FORMAT 11

READ FORMAT 12

READ FORMAT 13 
FIGURE 3.8.2.12: FORMAT USAGE FOR GHOST CUTTER INTERACTION SUMMARY OUTPUT (CONTINUED)

\section{READ FORMAT 14}

READ FORMAT 15

IF THE CUTTER IN CONTACT IS A GAUGE CUTTER, OR IT HAS ALREADY FAIIED -

\section{READ FORMAT 19}

IF THE CUTTER IS A REGULAR COTTER AND HAS NOT PREVIOUSLY FAILED -

READ FORMAT 16

READ FORMAT 17

IF THE CUTTER BROKE AT THE CURRENT TIME STEP:

$$
\text { READ FORMAT } 18
$$

IF THE CUTTER STILL HAS NOT FAILBD:

READ FORMAT 18-A 


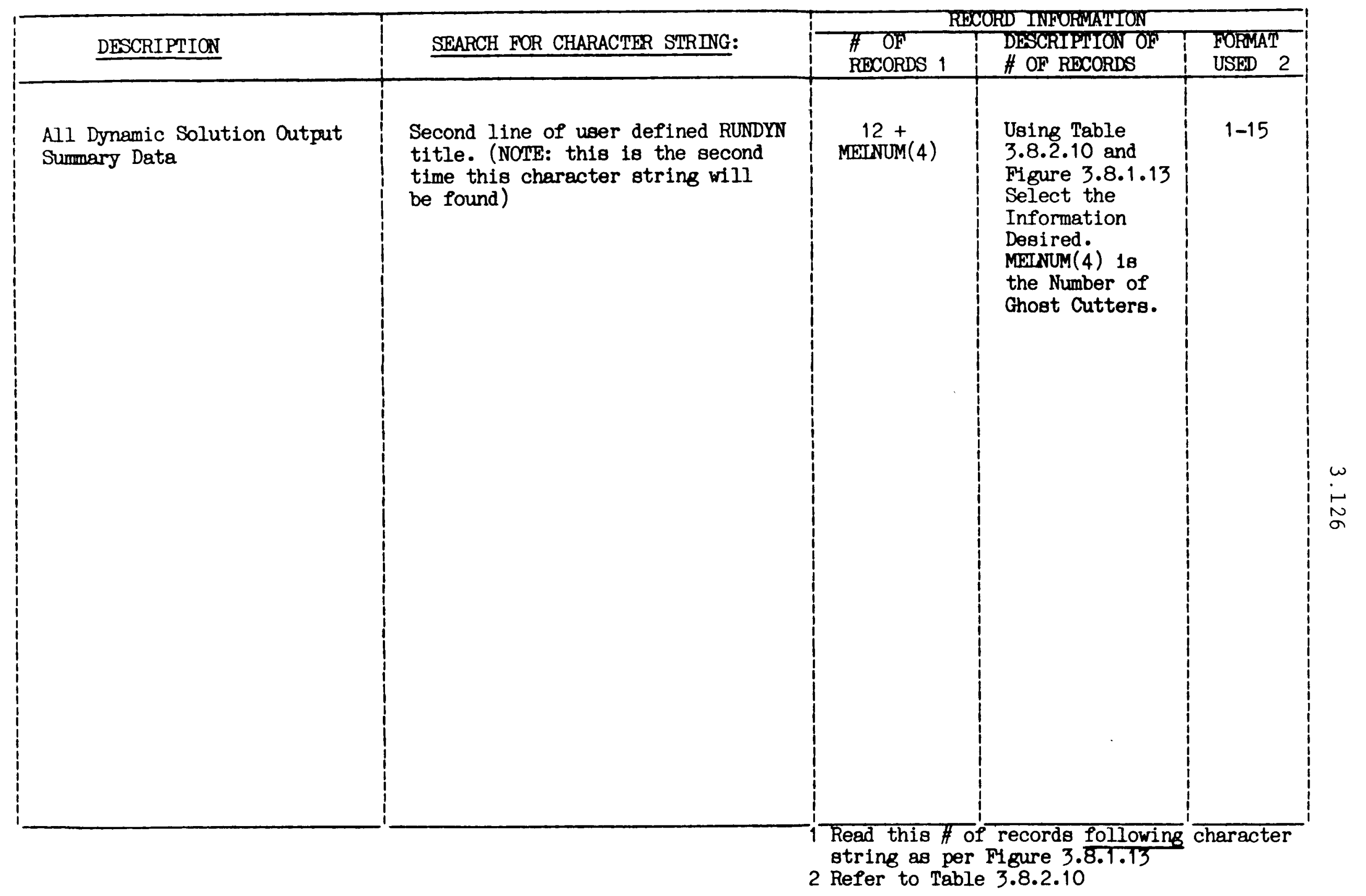

TABLE 3.8.2.9: RUNDYN OUTPUT SUMMARY 
TABLE 3.8.2.10: Summary Formats Corresponding to Table 3.8.2.9

1. 40 FIFMAT $(/ /, 10 \times, 60(1 H *), / /)$

2. 110 FIRMAT $(/ /, 10 x, 28 H T H E$ DRILL STRING HAS FITTATE[1,2X,E13.7, $2 x$,

1 THDEGREES, $1,10 X, 4 H($ OR, $2 x, E 13.7,2 x, 29 H F E V G L U T I U N S)$ DLIRING THE $R$ 2UN)

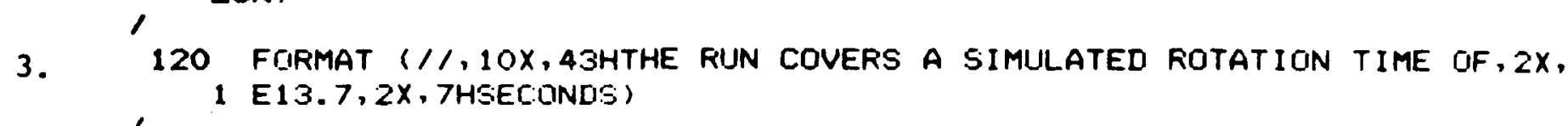

4. 130 FURMAT $(/ /, 10 X, 27 H T H E$ IRILL STRING ROTATED AT, $2 X, E 13.7,2 X$,

1 I8HDEGREES FER SEL:UND, $/, 2 X, 76 H$ K NOTE $\%$ SIGN CONSISTENT WITH $Z$-AXI

$2 S$ ORIENTED UP-STRING IN RIGHT-HAND SYSTEM)

1

5. 140 FORMAT $(/ /, 10 X, 15,2 X, 13 H T I M E$ STEPS OF, $1 X, E 13.7,1 X$,

1 34HSECONDS EAC:H WERE (ISED IN ANALYSIS)

6. 150 FDFMAT $(/ /, 10 X, 15,2 X, 53 H T I M E$ STEPS WERE USED TO FIAMF ON LOADS DUR 1 ING START-UP)

$\gamma$

7. 160 FDRMAT $(/ /, 10 x, 15,2 x, 45 H M O D A L$ DOF WERE USED IN THE SOLIJTION ALGOR 1 I THM, $/, 5 X, 54 H W I T H$ THE HIGHEST NATURAL FREQLIENCY CHARAC:TERIZED BEIN $2 G, 2 X, E 13.7,2 X, 2 H H Z)$

8. '170 FOFMAT $(/ /, 10 X, 15,2 x, 54 H I T E R A T I O N S$ WERE ALLOWED TO OBTAIN EQUILIB IRIUM SOLUTION)

9. 180 FLIRMAT $(/ /, 10 X, 25 H A$ CONVERGENCE CRITEFIA OF, $2 X, E 13.7,2 X, 12 H W A S$ UT 1 ILI IED)

10. 190 FOIMAT $(/ /, 10 X, 15,2 X, 63 H T I M E$ STEPS FAILEI TO CONVERIJE WITHIN SFEC IIFIED ITERATIVE LIMITS)

11. 200 FORMAT $1 / 1,10 X, 60 H T H E$ DYNAMIC INTEGRATION CONSTANTS USED IN THE A INALYSIS ARE $:, 1 /, 20 \mathrm{X}$, BHALPHA $=$, E13.7,10X,8HGAMMA $=$, E13.7)

12. '210 FURMAT $(/ /, 20 X, 25 H G H O S T$ CIJTTER STATUS TABLE,

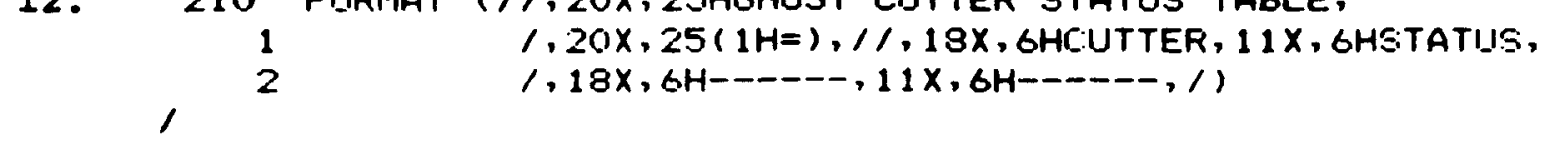

13. 220 FIRMAT (18X,I5, 12X, E.HINTAC:T)

14. 230 FORMAT $(1 \Xi x, 15,9 x, 12$ HIJALILE CUTTER $)$

15. 240 FORMAT $(18 x, 15,5 x, 2$ OHFAILED AT INCFEMENT, I5) 
3.128

FIGURE 3.8.2.13: FORMAT USAGE FOR DYNAMIC SOLUTION OUTPUT SUMMARY

ALI DYNAMIC SOLUTION OUTPUT SUMMARY DATA
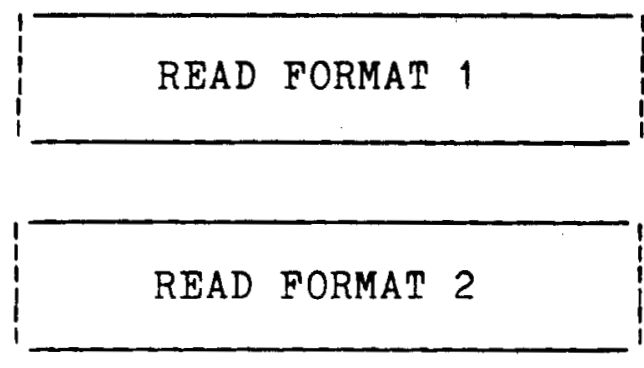

READ FORMAT 3

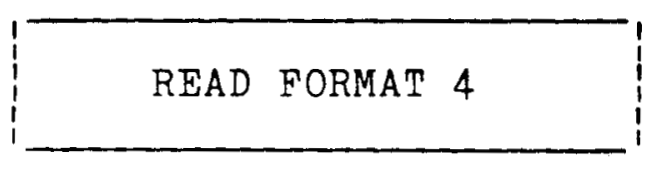

READ FORMAT 5

IF LOADS RAMPED ON (START-UP)

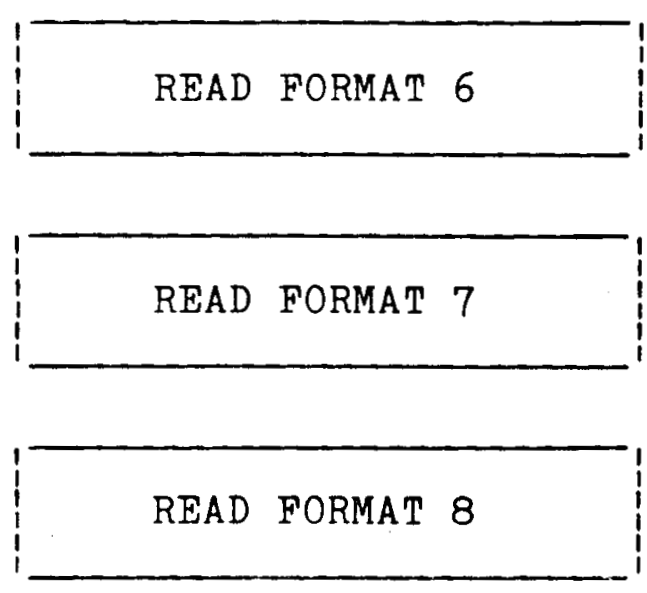


FIGURE 3.8.2.13: FORMAT USAGE FOR DYNAMIC SOIUIION OUTPUT SUMMARY (CONTINUED)
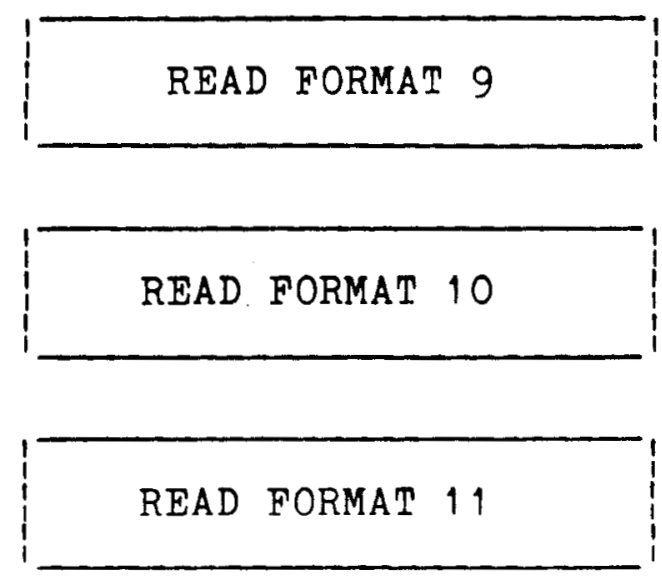

\section{READ FORMAT 12}

DO $I=1$, \# OF GHOST CUTTERS (MELNUM (4))

IF CUTTER I HAS NEVER FAILED

READ FORMAT 13

IF CUTTER I IS A GAUGE CUTTER AND CANNOT FAIL:

$$
\text { READ FORMAT } 14
$$

IF CUTTER I HAS FAILED

$$
\text { READ FORMAT } 15
$$


4.0 EXAMPLE OF A TRANSIENT DYNAMIC ANALYSIS WITH FORMATION INTERACTION

To clarify many of the topics dealt with in preceding sections, examples of actual interactive input sessions required to generate input files are presented in this section. These examples allow the user to see the actual questions asked by the program, and the correct format of the users' responses. The program called GEOIN, discussed in Sections 7.1 and 7.1 .1 , was run to produce these input examples. Following the input example, selected output is presented which was generated by running GEODYN with the input data presented in the input example. All of the results that follow were obtained by running the program on a VAX $11 / 780$ computer.

4.1 INPUT FOR RUNNING THE GENDYN SUB-PROGRAM

This section contains all of the interactive input needed to run GENDYN (model generation) for the model shown in Figures 4.1.1 and 4.1.2. The following is the actual interactive input session: 


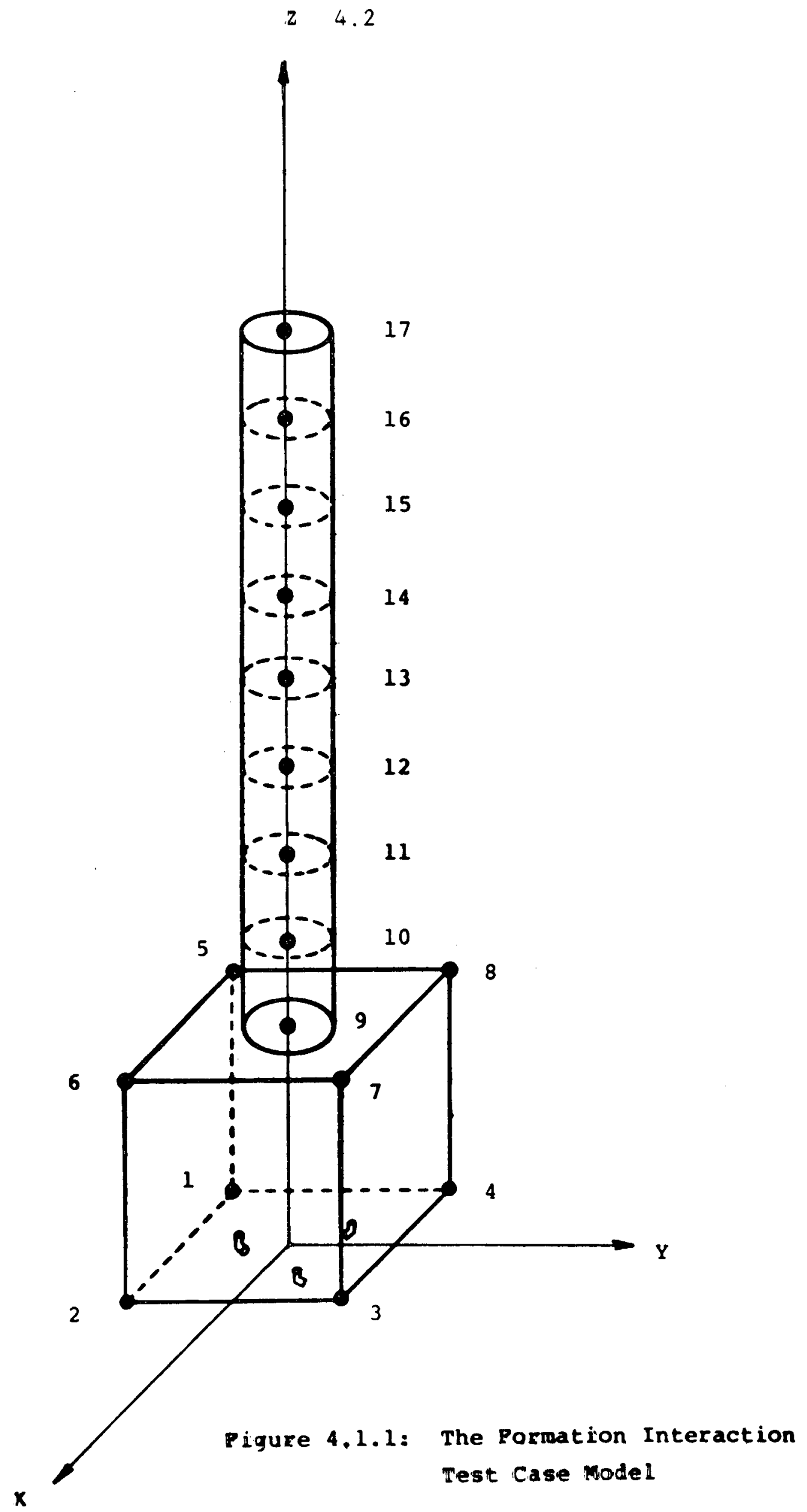



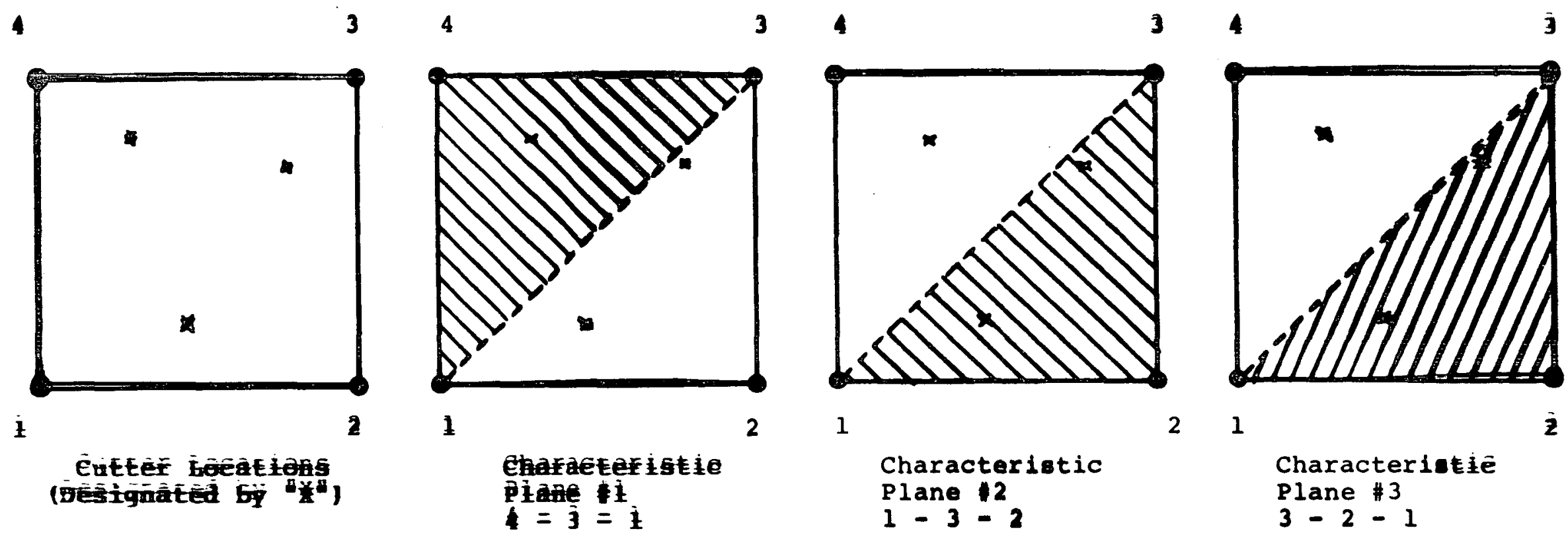

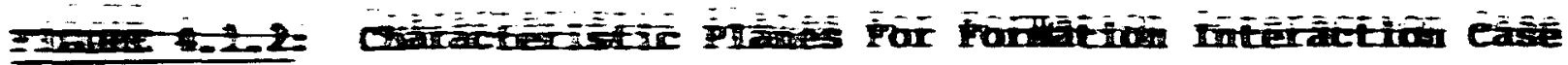


RUN GEOIN

FILE NAME FOR INPUT DATA?

INGFR

FILE NAME FOR OUTPUT DATA?

OUTGFR

THE GEODYN PROGRAM CURRENTLY ALLOWS THE USER TO EXERCISE TWO FUNCTIONS :

1 - THE GENERATION OR MODIFICATION OF A DRILL STRING MODEL ( GENDYN ) ( FINITE ELEMENTS, BOUNDARY SPRINGS, OR GHOST CUTTERS ,

2 - THE EXECUTION OF A SOLUTION FOR THE DRILL STRING MODEL. ( RUNDYN ) LOADS, TIME STEPS, NUMBER OF MODES CONSIDERED, AND FORMATION PROPERTIES MAY ALL BE MODIFIED WITH THIS OPTION.

$==>$ CHOOSE FUNCTION 1 OR 2 :

DO YOU WISH TO PERFORM FUNCTION 2 ? (YES/NO - NO EXECUTES (1) )

$?$

No

IS THIS THE INITIAL EXECUTION OF GENDYN ? ( RESPOND YES OR NO )

$?$

YES

THIS PROGRAM CAN GENERATE BOTH A LUMPED AND CONSISTANT MASS MATRIX. DO YOU WISH TO USE A LUMPED MASS REPRESENTATION ? (YES/NO)

$?$ YES

ENTER THE TITLE FOR THIS RUN -

$?$

UP TO 80 CHARACTERS OF INPUT WILL BE ACCEPTED.

EXAMPLE OF GENDYN INPUT FOR CASE WITH A FORMATION - 12/1/83

ENTER THE TOTAL NUMBER OF ELEMENTS IN THE MODEL

INCLUDE 8-NODE BRICKS, FORMATION BRICKS (IF USED), BEAMS, AND GHOST CUTTERS DO NOT INCLUDE DISCRETE POINTS

12

ENTER THE NUMBER OF ELEMENT TYPES WHICH WILL BE USED IN MODEL : 
TYFES INCLUDE AN 8-NODE BRICK, A FORMATION DISCRETE POINT OR ZO-NOUE BRICK

$?$

4

IF 2O-NODE BRICKS ARE TO BE USED FOR THE FORMATION : $==\Rightarrow$ ENTER A NEGATIVE $1(-1)$

IF DISCRETE POINTS ARE TO BE USED FOR THE FORMATION : $==\Rightarrow$ ENTER A POSITIVE 1 (1)

?

?

?

2

$?$

3

?

1

$?$

8

$?$

3

$?$

$?$

$==\Rightarrow$ IF THERE IS NO FORMATION, ENTER A ZERO. ENTER 1 FOR AN 8-NODE 3-D BRICK

ENTER 2 FOR FORMATION 20-NODE BRICK OR DISCRETE POINT

ENTER 3 FOR A LINEAR 3-D BEAM

ENTER 4 FOR A GHOST CUTTER GEOM SUB-ELEMENT

ENTER APPROPRIATE ID CODE FOR ELEMENT TYPE

ENTER APPROPRIATE ID CODE FOR ELEMENT TYPE

ENTER APPROPRIATE ID CODE FOR ELEMENT TYPE

ENTER APPROPRIATE ID CODE FOR ELEMENT TYPE

ENTER THE NUMBER OF 8-NODE 3-D BRICKS USED IN THE MODEL

ENTER THE NUMBER OF 3-D LINEAR BEAMS USED IN THE MODEL

ENTER THE NUMBER OF GHOST CUTTERS USED IN THE MODEL

ENTER THE NUMBER OF NOUES CONTAINED IN THE FORMATION SIJB-MODEL

IF DISCRETE POINTS ARE USED ENTER ZERO

ENTER THE ELEMENT IDENTIFICATION CODE FOR ELEMENTS CONTAINED IN MODEL :

ENTER THE NUMBER OF BRICK NODES CONTAINED IN THE DRILL STRING SUB-MODEL 
$?$

$?$

9

$?$

8

$?$

ENTER A POSITIVE 1 IF 3-D BRICKS ARE USED IN BIT: A - 1 IF NOT

$?$

$?$

$-2$

$?$

3

$?$

$?$

$-5$

$?$

ENTER THE NUMBER OF DIFFERENT MATERIAL TYPES USED IN FORMATION EITHER FOR DISCRETE POINTS OR 2O-NODE BRICK

$?$

$?$

ENTER THE NUMBER OF DIFFERENT TYPES OF GHOST CUTTERS UTILIZED

NOTE DIFFERENT LENGTHS DO NOT CONSTITUTE DIFFERENT TYPES

$?$

LENGTHS HANDLED SEPARATELY

FOLLOWING INPUT WILL BE UTILIZED TO FERFORM CONSTRAINT TYING

NDTE - THE BEAM NODE TO WHICH THE BIT IS TIED SHOULD BE CONSIDERED EXTERNAL 


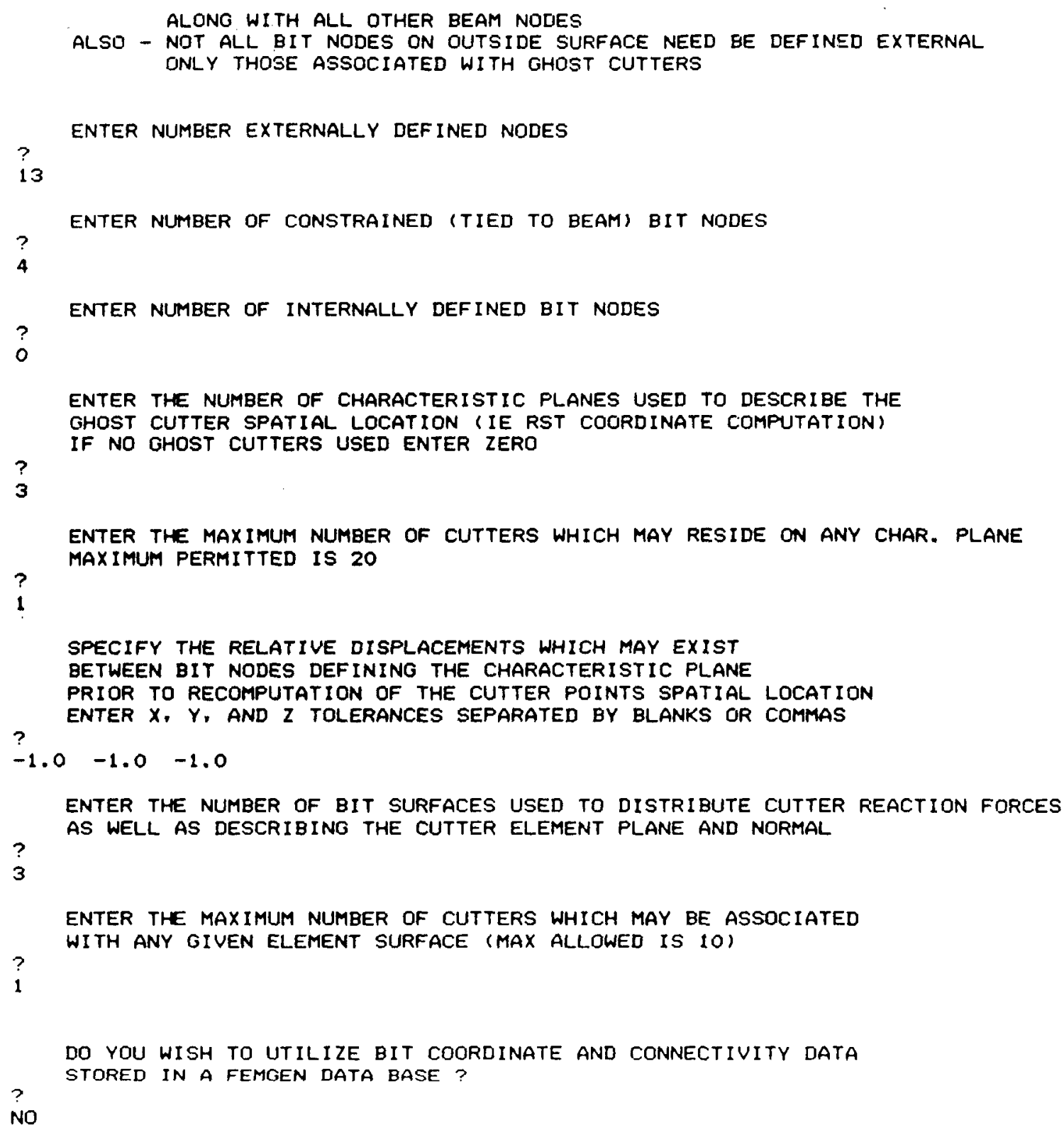


CHANGES IN GHOST CUTTER IESCRIPTIONS DON T CHANGE THE FINITE ELEMENT MOEEL REPLY YES IF FINITE ELEMENT MODEL WILL BE EFFECTED

$?$

YES

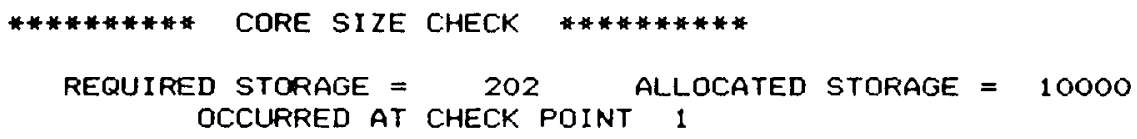

$==x=\Rightarrow$ ENTER ELEMENT CHARACTERIZATION DATA FOR PROPOSED SUB-MODELS : DATA TO INCLUDE ELEMENT NUMBER, TYPE OF ELEMENT, SUB-MODEL ID, AND MAT. ID.

ENTER DATA IN THE FOLLOWING ORDER, USING THE DESIGNATED CODE BELOW :

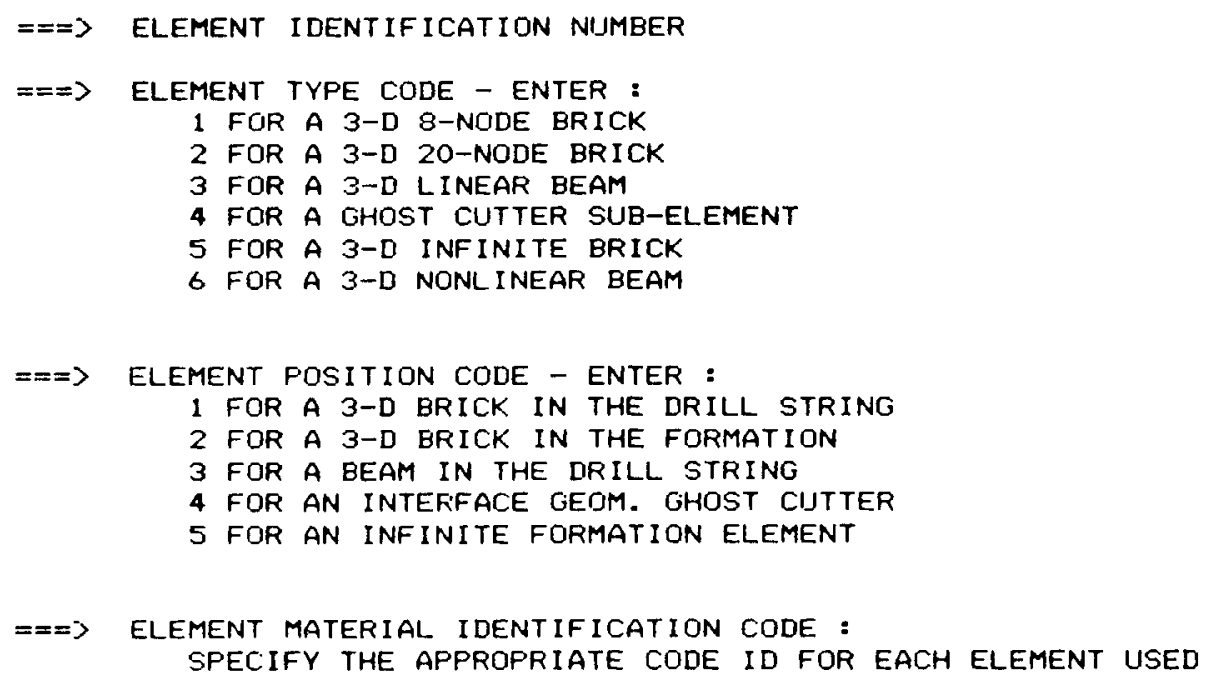




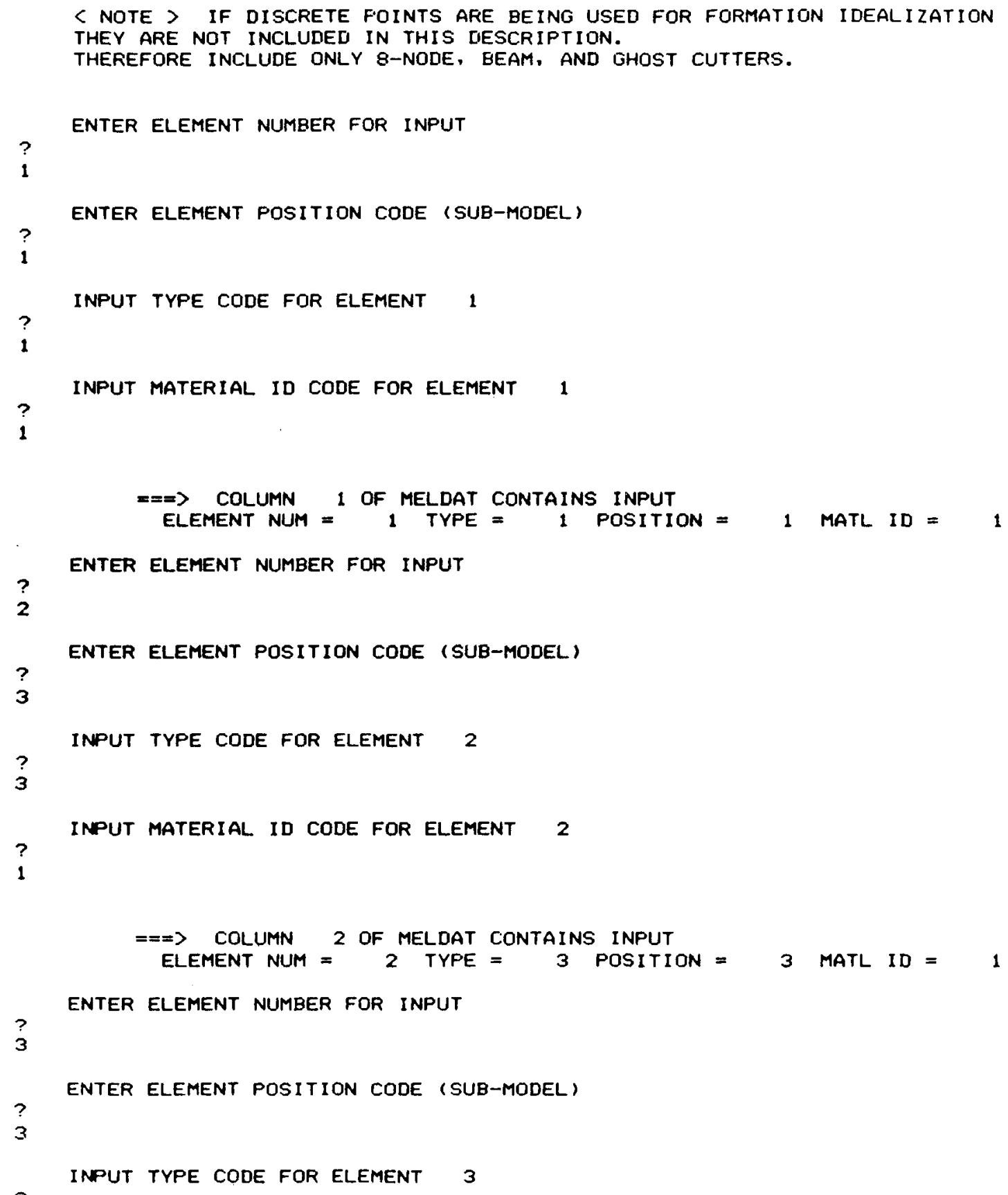


INPUT MATERIAL ID CODE FOR ELEMENT 3

$?$

$==\Rightarrow$ COLUMN 3 OF MELDAT CONTAINS INPUT

ELEMENT NUM $=3$ TYPE $=3$ POSITION $=3$ MATL ID $=2$

ENTER ELEMENT NUMBER FOR INPUT

4

ENTER ELEMENT POSITION CODE (SUB-MODEL)

$?$

INPUT TYPE CODE FOR ELEMENT 4

$?$

INPUT MATERIAL ID CODE FOR ELEMENT 4

$\stackrel{?}{2}$

ELEMENT NUM $=4$ TYPE $=3$ POSITION $=3$ MATL ID $=2$

$?$

5

$?$

3

$?$

3

$?$

$==\Rightarrow$ COLUMN 5 OF MELDAT CONTAINS INPUT ELEMENT NUM $=5$ TYPE $=3$ POSITION $=3$ MATL ID $=2$ ENTER ELEMENT NUMBER FOR INPUT

6

$?$

ENTER ELEMENT POSITION CODE (SUB-MODEL) 
INPUT TYPE CODE FOR ELEMENT 6

3

INPUT MATERIAL ID CODE FOR ELEMENT 6

$?$

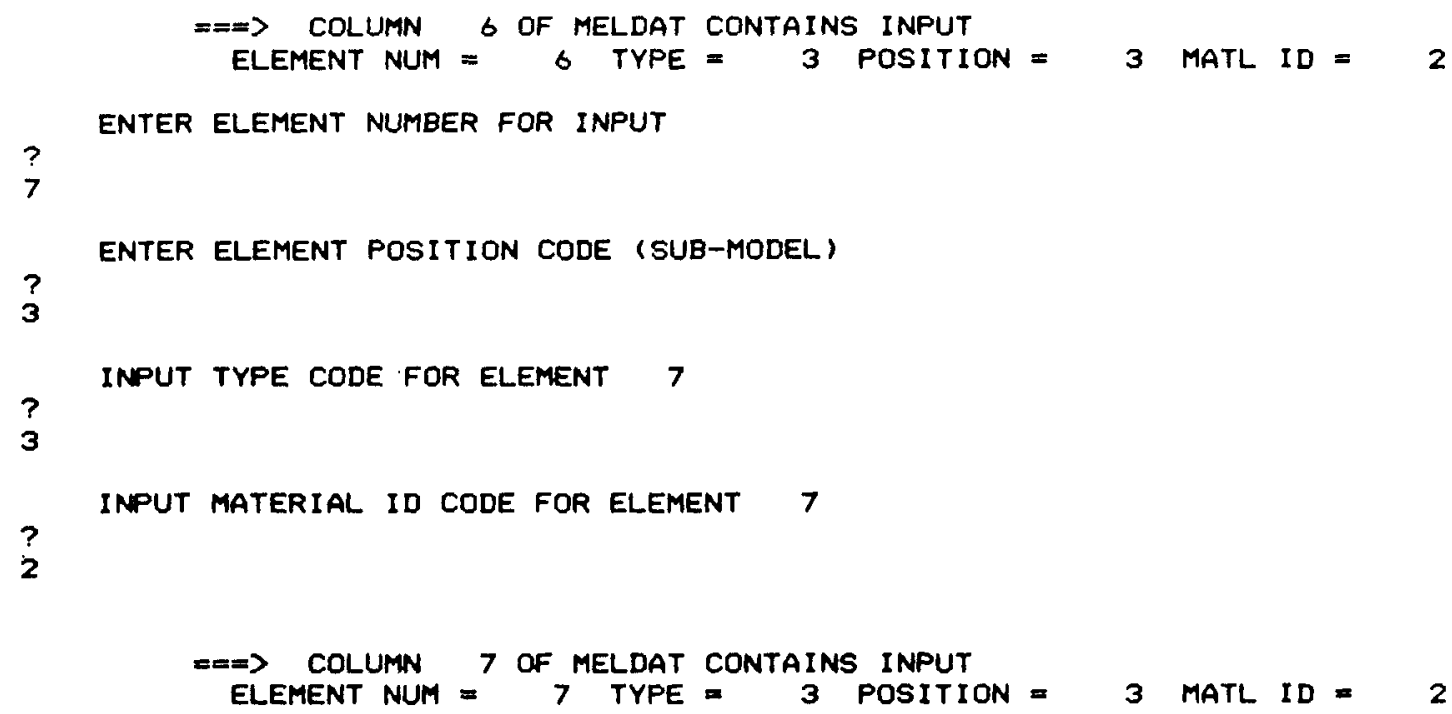


$?$

3

$?$

4

$?$

4

$?$

1

$==\Rightarrow$ COLUMN 12 OF MELDAT CONTAINS INPUT
ELEMENT NUM $=3$ TYPE $=4$ POSITION

ENTER ELEMENT POSITION CODE (SUB-MODEL)

INPUT TYPE CODE FOR ELEMENT 3

INPUT MATERIAL ID CODE FOR ELEMENT 3

HAVE YOU CHANGED ANY INPUT CONCERNING EITHER THE 8-NODE BRICKS OR BEAMS ? IF SO THEY WILL EFFECT THE FINITE ELEMENT MODEL AND MODAL IDEALIZATION CHANGES IN GHOST CUTTER DESCRIPTIONS DON'T CHANGE THE FINITE ELEMENT MODEL REPLY YES IF FINITE ELEMENT MODEL WILL BE EFFECTED

$?$ YES

NEW FINITE ELEMENT MODEL MASS, STIFFNESS, AND EIGENSYSTEM MATRICES WILL BE GENERATED AND SAVED AS FILES MAKE SURE FILE SPACE IS AVAILABLE

********** CORE SIZE CHECK **********

REQUIRED STORAGE $=422$ ALLOCATED STORAGE $=10000$ OCCURRED AT CHECK POINT 3

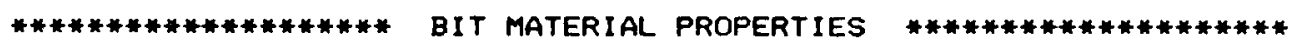

***** INPUT FOLLOWING MATERIAL PROPERTIES FOR MATL ID CODE $=1$ ***** YOUNG'S MODULUS IN (PSI)

POISSON RATIO (NO UNITS)

MATERIAL UNIT WEIGHT (LBS/CUBIC FOOT)

$?$

ENTER YOUNG'S MODULUS

3. OE7

ENTER POISSON RATIO

$?$ 
0.3

ENTER MATERIAL UNIT WEIGHT

$?$

261.636

YOUNG'S MODULUS INPUT $=0.3000000 E+08$

POISSON RATIO INPUT $=0.3000000 E+00$

UNIT WEIGHT INPUT $=0.2616360 E+03$

YES

ARE ALL OF THESE ELEMENT PROPERTIES CORRECT (YES OR NO)?

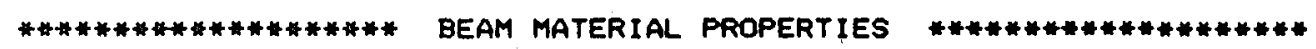

**** INPUT FOLLOWING MATERIAL PROPERTIES FOR MATL ID CODE = 1 **** LENGTH IN (FT.)

OUTSIDE DIAMETER IN (IN.)

INSIDE DIAMETER IN (IN.)

YOUNG'S MODULUS IN (PSI)

POISSON RATIO (NO UNITS)

MATERIAL UNIT WEIGHT (LBS/CUBIC FOOT)

$?$

ENTER LENGTH

0.6121

ENTER OUTSIDE DIAMETER

$?$

5.5

ENTER INSIDE DIAMETER

$?$

2.6

ENTER YOUNG'S MODLLUS

$?$

3. OE7

$?$

ENTER POISSON RATIO

0.3

ENTER MATERIAL UNIT WEIGHT

489.0

LENGTH INPUT (FT.) $=0.6121000 E+00$

OUTSIDE DIAMETER (IN.) $=0.5500000 E+01$

INSIDE DIAMETER (IN.) $=0.2600000 E+01$ 
YOUNG'S MODULUS INPUT $=0.3000000 E+08$

POISSON RATIO INPUT $=0.3000000 E+00$

UNIT WEIGHT INPUT $=0.4890000 E+03$

YES

ARE ALL OF THESE ELEMENT PROPERTIES CORRECT (YES OR NO)?

****************** BEAM MATERIAL PROPERTIES

**** INPUT FOLlOWING MATERIAL PROPERTIES fOR MATL ID CODE = $2 * * * * *$ LENGTH IN (FT.)

DUTSIDE DIAMETER IN (IN.)

INSIDE DIAMETER IN (IN.)

YOUNG'S MODULUS IN (PSI)

POISSON RATIO (NO UNITS)

MATERIAL UNIT WEIGHT (LBS/CUBIC FOOT)

.

$?$

ENTER LENGTH

0.61905

ENTER OUTSIDE DIAMETER

4.25

ENTER INSIDE DIAMETER

$?$

ENTER YOUNG'S MODULUS

3. OE7

$?$

ENTER POISSON RATIO

0.3

ENTER MATERIAL UNIT WEIGHT

$?$

489.0

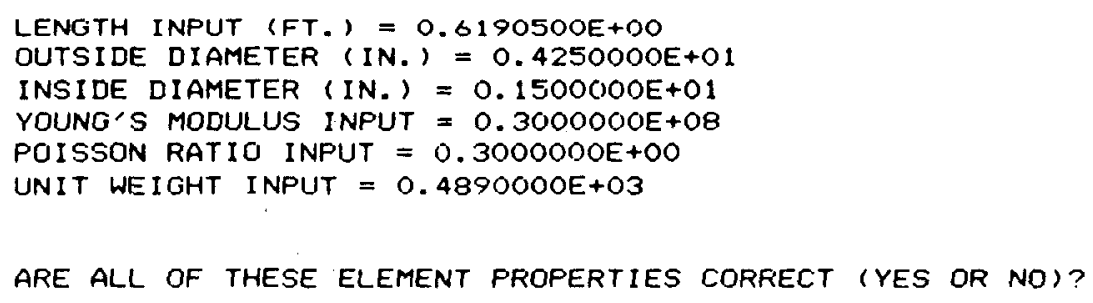


*** INPUT FOLLOWING MATERIAL PROPERTIES FOR MATL ID CODE CROSS SECTION IN (IN.**2)

MOMENT OF INERTIA IN (IN.**4)

POLAR MOMENT OF INERTIA IN (IN.**4)

YOUNG'S MODULUS IN (PSI)

POISSON RATIO (NO UNITS)

YIELD STRENGTH IN (PSI)

$?$

ENTER CROSS-SECTIONAL AREA

0.4418

$?$

ENTER MOMENT OF INERTIA

1.0

$?$

ENTER PQLAR MOMENT OF INERTIA

1. 0

ENTER YOUNG'S MODULUS

?

3. OE7

$?$

ENTER POISSON RATIO

0.3

$?$

ENTER YIELD STRENGTH

36000.0

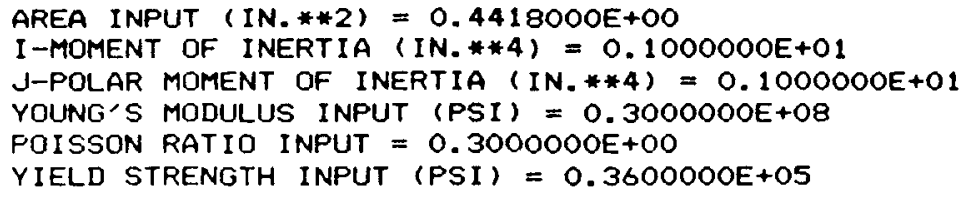

$====\Rightarrow$ DISCRETE POINTS WILL BE USED TO REPRESENT THE FORMATION.

2 DIFFERENT MATERIAL TYPES HAVE BEEN SPECIFIED FOR USE. ENTER AN APPROPRIATE MATERIAL ID CODE NUMBER FOLLOWED BY : $K-P E n$, MU-zero, AND Vmax (SEE USERS MANUAL) 


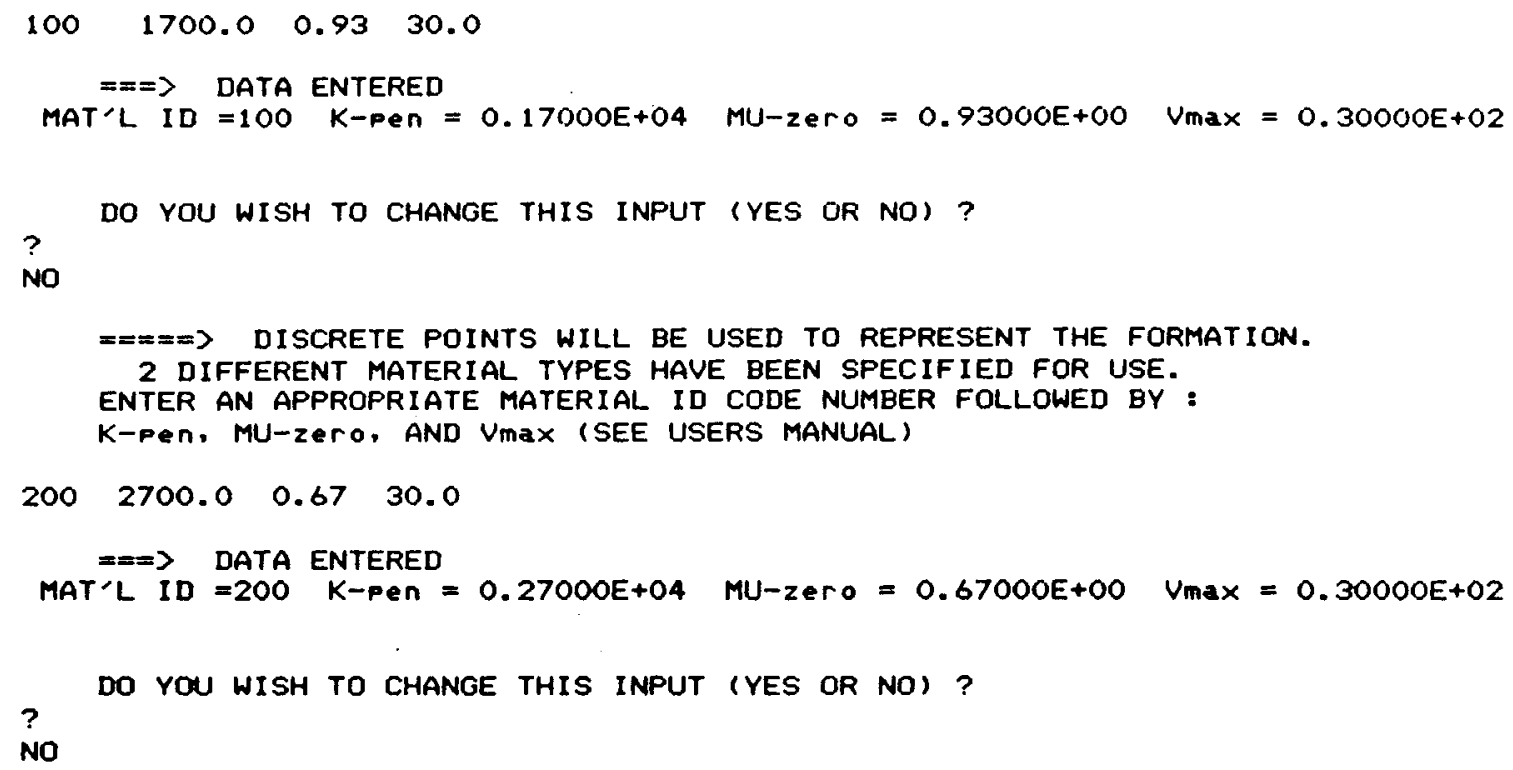

NEW FINITE ELEMENT MODEL MASS, STIFFNESS, AND EIGENSYSTEM MATRICES WILL BE GENERATED AND SAVED AS FILES MAKE SIJRE FILE SPACE IS AVAILABLE 


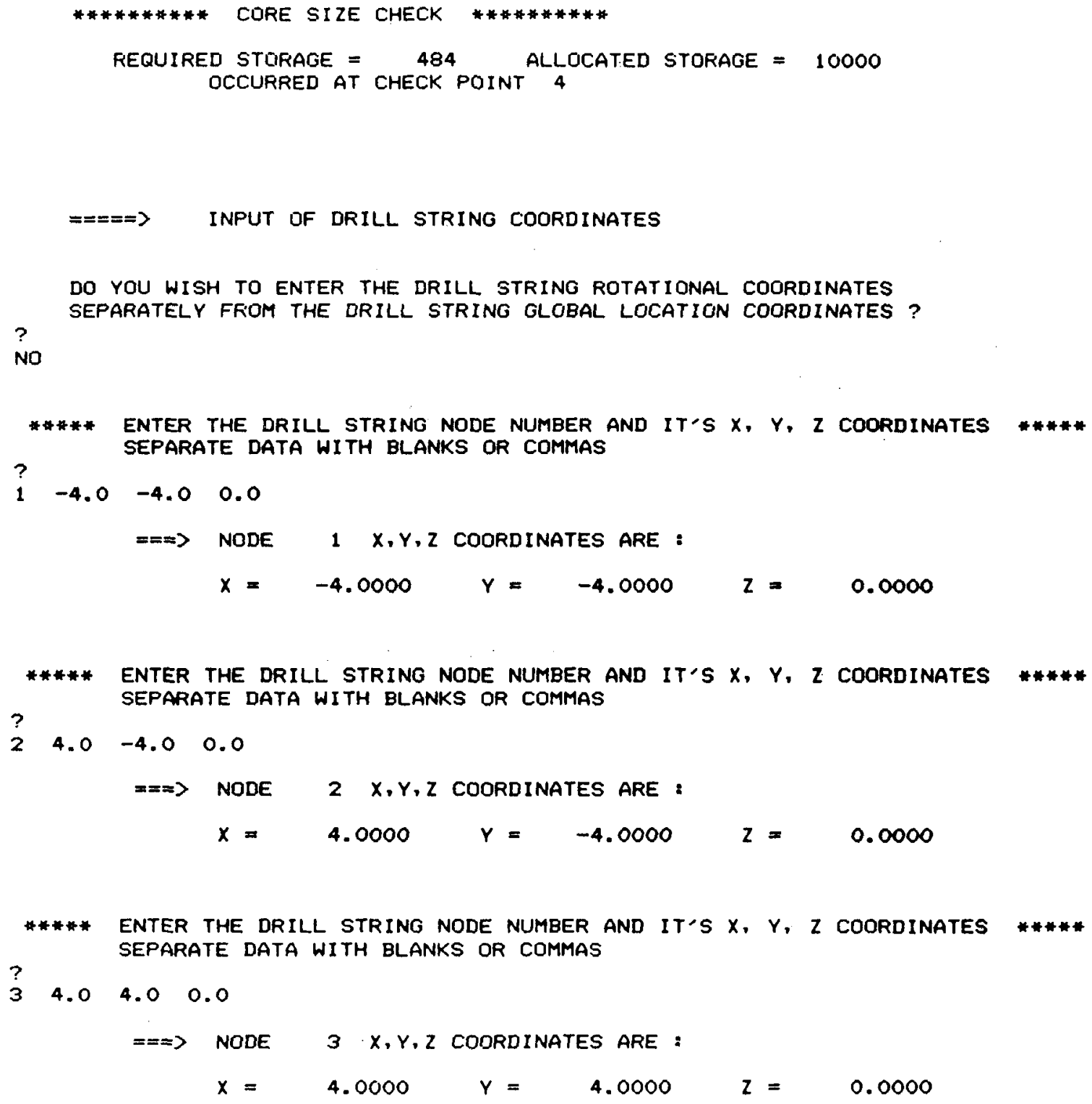




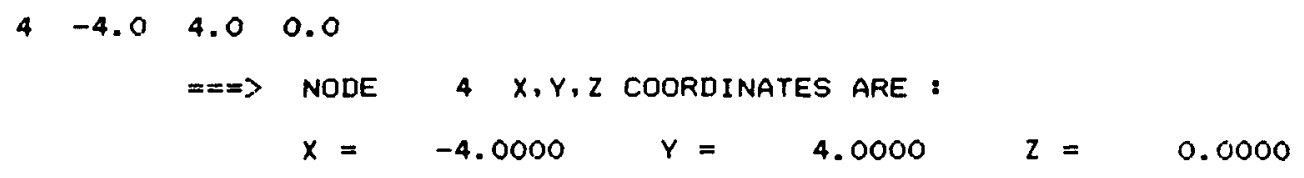
$x=$
4.0000
$Y=$
4.0000
$\mathrm{Z}=$
9.7250

**** ENTER THE DRILL STRING NODE NUMBER AND IT'S $x, Y, z$ COORDINATES **** SEPARATE DATA WITH BLANKS OR COMMAS

$?$

$8 \quad-4.0 \quad 4.0 \quad 9.725$

$==\Rightarrow$ NODE $8 \quad X, Y, Z$ COORDINATES ARE :
$x=$
$-4.0000$
$\checkmark=$
4.0000
$z=$
9.7250

\footnotetext{
**** ENTER THE DRILL STRING NODE NUMBER AND IT'S $x, Y, z$ COORDINATES ***** SEPARATE DATA WITH BLANKS OR COMMAS

$0.0 \quad 0.0 \quad 9.725$
}

$?$ 


\subsection{0}

$===$ NODE $9 \quad X, Y, Z$ COORDINATES ARE :
$x=$
0.0000
$Y=$
0.0000
$Z=$
9.7250

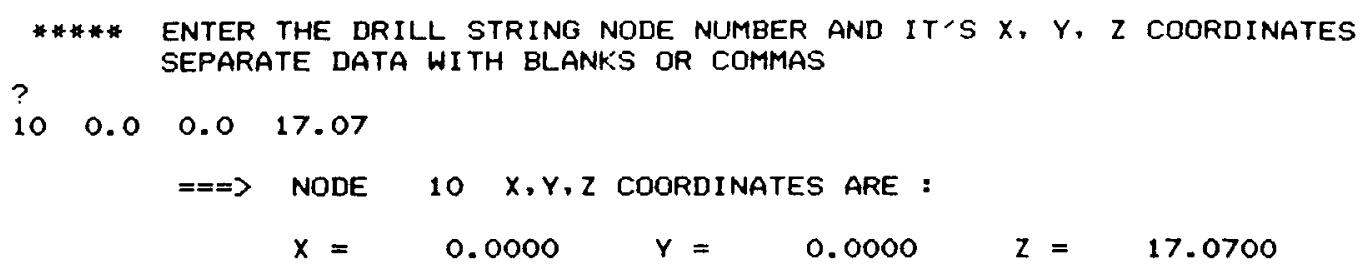




$$
X=0.0000 \quad Y=0.0000 \quad Z=46.7840
$$

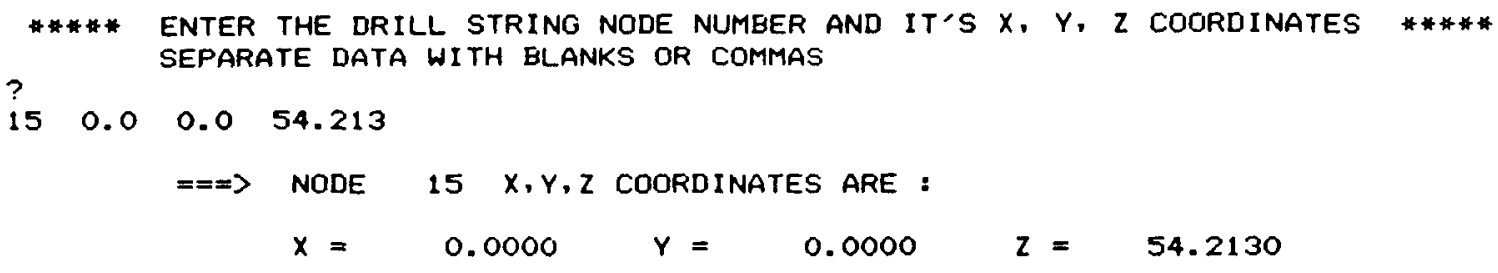


**** ENTER THE GHOST TOOTH NODE NUMBER AND IT'S X, Y, $z$ COORDINATES *****

$?$ SEPARATE DATA WITH BLANKS OR COMMAS

$2 \quad-1.52665 \quad 2.40151 \quad-0.7694$

$===$ NODE $2 \quad X, Y, Z$ COORDINATES ARE :

$X=-1.5266 \quad Y=\quad 2.4015 \quad Z=-0.7694$

*** ENTER THE GHOST TOOTH NODE NUMBER AND IT'S $X, Y, Z$ COORDINATES **** SEPARATE DATA WITH BLANKS OR COMMAS

$?$

$3 \quad-1.36837 \quad 2.49474 \quad-0.2774$

$==\Rightarrow$ NODE $3 x, y, z$ COORDINATES ARE :

$$
X=-1.3684 \quad Y=\quad 2.4947 \quad Z=\quad-0.2774
$$

\footnotetext{
**** ENTER THE GHOST TOOTH NODE NUMBER AND IT'S $X, Y, Z$ COORDINATES SEPARATE DATA WITH BLANKS OR COMMAS

$\begin{array}{llll}? & -0.332 & -2.361 & 0.0\end{array}$

$==2$ NODE $4 \quad X, Y, Z$ COORDINATES ARE :

$$
X=-0.3320 \quad Y=-2.3610 \quad Z=0.0000
$$
}

**** ENTER THE GHOST TOOTH NODE NUMBER AND I $T$ 'S $x, y, z$ COORDINATES ***** SEPARATE DATA WITH BLANKS OR COMMAS

$\stackrel{?}{5}$

$\begin{array}{llll}5 & -0.50616 & -2.31433 & -0.7294\end{array}$

$==2 \quad$ NODE $\quad x, Y, Z$ COORDINATES ARE :

$$
X=-0.5062 \quad Y=-2.3143 \quad Z=-0.7294
$$

**** ENTER THE GHOST TOOTH NODE NUMBER AND IT'S $X, Y, Z$ COORDINATES **** SEPARATE DATA WITH BLANKS OR COMMAS

$?$

$6 \quad-0.6836 \quad-2.26679-0.2374$

$==\mp$ NODE $\& \quad X, Y, Z$ COORDINATES ARE :

$x=-0.6836 \quad Y=-2.2668 \quad z=-0.2374$ 


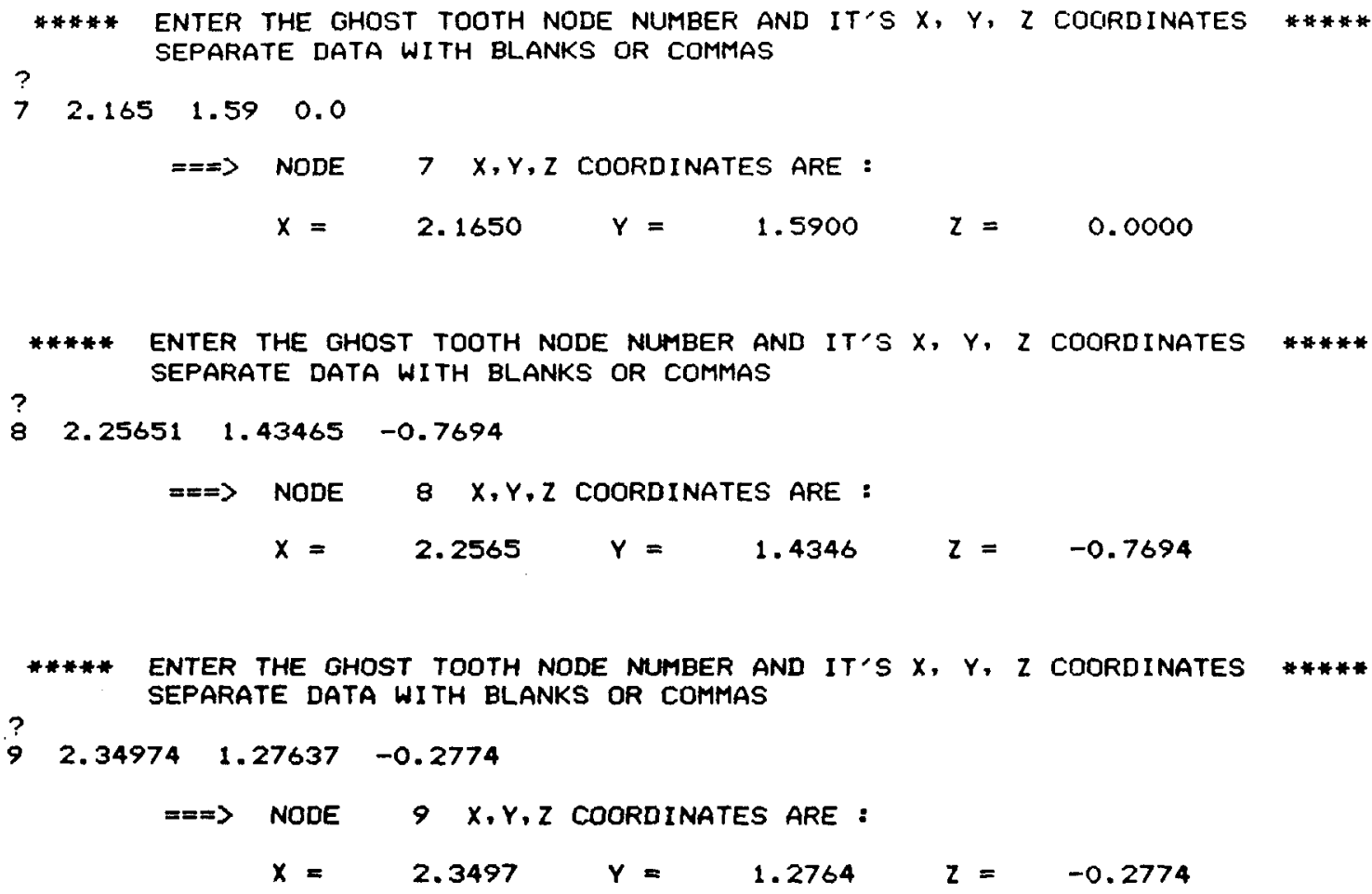

HAVE YOU CHANGED ANY INPUT CONCERNING EITHER THE 8-NODE BRICKS OR BEAMS? IF SO THEY WILL EFFECT THE FINITE ELEMENT MODEL AND MODAL IDEALIZATION CHANGES IN GHOST CUTTER DESCRIPTIONS DON'T CHANGE THE FINITE ELEMENT MODEL ? REPLY YES IF FINITE ELEMENT MODEL WILL BE EFFECTED YES

NEW FINITE ELEMENT MODEL MASS, STIFFNESS, AND EIGENSYSTEM MATRICES WILL BE GENERATED AND SAVED AS FILES

MAKE SURE FILE SPACE IS AVAILABLE

**** ENTER ELEMENT CONNECTIVITY INFORMATION FOR ALL 8-NODE BRICKS ****

DATA ENTERED WILL CONSIST OF THE ELEMENT NUMBER

FOLLOWED BY THE NODE NUMBERS CONSISTENT WITH LDCAL NUMBERING SCHEME

**** please refer to users manual for correct oRLER ***** 
$?$

ENTER ELEMENT NUMBER FOR INPUTT

i

INPUT CONNECTIVITY DATA （ 8-NODES ) FOR ELEMENT SEPARATE DATA BY BLANKS OR COMMAS

$?$

$\begin{array}{llllllll}? & 2 & 3 & 4 & 5 & 6 & 7 & 8\end{array}$

$===>$ ELEMENT

1

2

1 CONNECTIVITY IS :
1 IN PRESCRIBED ORDER

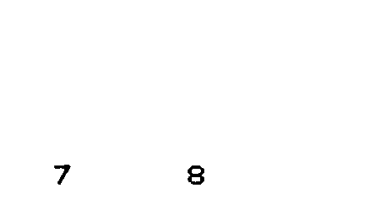

***** ENTER ELEMENT CONNECTIVITY INFORMATION FOR ALL 3-D, LINEAR BEAMS *****

DATA ENTERED WILL CONSIST OF :

$==\Rightarrow$ ELEMENT NUMBER

$==\Rightarrow$ NODE NUMBERS DEFINING BEAM ELEMENT.

PLEASE REFER TO USERS MANUAL FOR CORRECT ORDER.

ENTER ELEMENT NUMBER FOR INPUT

$?$

INPUT CONNECTIUITY DATA (BEAM) FOR ELEMENT 2 IN PRESCRIBED ORDER $?$ SEPARATE DATA BY BLANKS OR COMMAS

$=\Rightarrow$ ELEMENT 2 CONNECTIVITY IS :

910

ENTER ELEMENT NUMBER FOR INPUT

INPUT CONNECTIVITY DATA (BEAM) FOR ELEMENT 3 IN PRESCRIBED ORDER $?$ SEPARATE DATA BY BLANKS OR COMMAS

1011

$==\Rightarrow$ ELEMENT 3 CONNECTIVITY IS : 


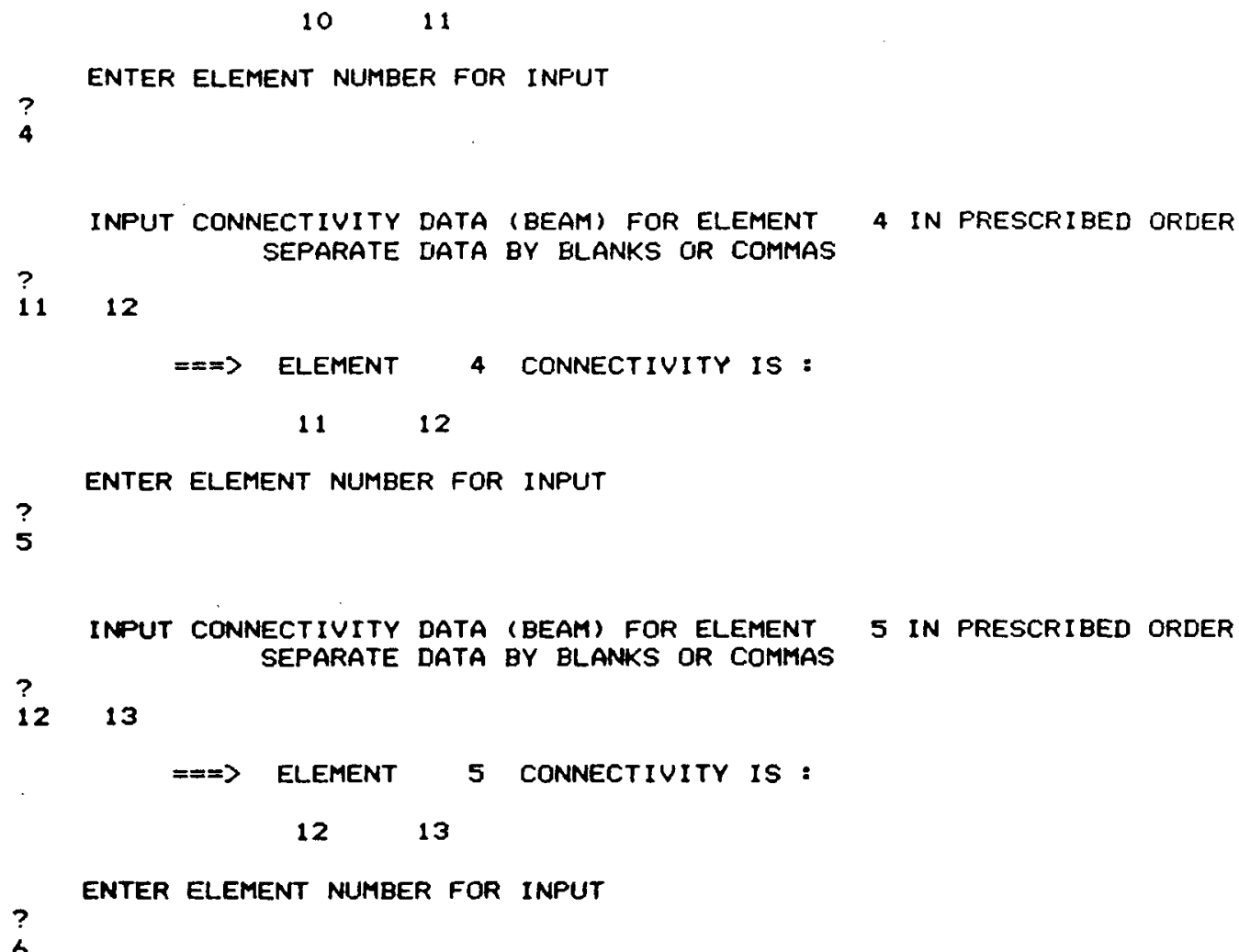


ENTER ELEMENT NUMBER FOR INPUT

INPUT CONNECTIVITY DATA (BEAM) FOR ELEMENT 8 IN PFESCRIBED ORDER SEPARATE DATA BY BLANKS OR COMMAS

ENTER ELEMENT NUMBER FOR INPUT

INPUT CONNECTIUITY DATA (BEAM) FOR ELEMENT SEPARATE DATA BY BLANKS OR COMMAS

$?$

16 17

$==\Rightarrow$ ELEMENT 9 CONNECTIVITY IS :

$16 \quad 17$

*** * ENTER GHOST CUTTER DEFINITION INFORMATION *****

DATA ENTERED WILL CONSIST OF :

$==\equiv$ CUTTER NUMBER.

$===>$ THE PRIMARY BIT F.E. NODE NUMBER

$=2 \Rightarrow$ THE CUTTER SUB-NODE AT INTERSECTION BIT SURFACE

$==>$ THE CUTTER SUB-NODE AT TOP OF BLANK

$==\Rightarrow$ THE CUTTER SUB-NODE AT BOTTOM OF BLANK

(SEE USER MANUAL FOR BETTER DEFINITION)

ENTER GHOST CUTTER SUB-ELEMENT NUMBER

?

INPUT DEFINITION ARRAY DATA FOR CUTTER 1 IN FRESCRIGED ORDER SEPARATE DATA BY BLANKS OR COMMAS

4123 
$==\Rightarrow$ CUTTER 1 DEFINITION DATA IS :

$4 \quad 1 \quad 2 \quad 3$

ENTER GHOST CUTTER SIJB-ELEMENT NUMBER

$?$

INPUT DEFINITION ARRAY DATA FOR CUTTER 2 IN PRESCRIBED ORDER $?$ SEPARATE DATA BY BLANKS OR COMMAS

1456 $==\Rightarrow$ CUTTER 2 DEFINITION DATA IS :

1456

?

3

$?$

3. 789

3 IN PRESCRIBED ORDER

INPUT DEFINITION ARRAY DATA FOR CUTTER SEPARATE DATA BY BLANKS OR COMMAS

ENTER GHOST CUTTER SUB-ELEMENT NUMBER

89

$===>$ CUTTER 3 DEFINITION DATA IS :

$\begin{array}{llll}3 & 7 & 8 & 9\end{array}$

**** ENTER GHOST CUTTER CHARACTERISTIC PLANE INFO. \#*\#*

DATA ENTERED WILL CONSIST OF :

$= \pm=>$ CHARACTERISTIC PLANE NUMBER

$=\equiv \Rightarrow$ THE THREE BIT F.E. NODES DESCRIBING THE PLANE

$==\Rightarrow$ THE GHOST CUTTER NUMBERS LOCATED ON THE PLANE

AFTER IDENTIFYING ALL CUTTERS ON A PLANE, ENTER A ZERO OR A NEGATIVE NUMBER TO SIGNIFY COMPLETION OF INPUT DATA FOR THAT FLANE.

ENTER CHARACTERISTIC PLANE NUMBER

$?$

INPUT THE BIT F.E. NODE NUMBERS DEFINING CHARACTERISTIC PLANE NUMBER 1 SEPARATE DATA BY BLANKS OR COMMAS 
INPUT THE GHOST CUTTER NUMBERS WHICH OCCUR ON THIS FLANE.

TO EXIT INPUT MODE ENTER ZERO OR NEGATIVE NUMBER.

CUTTER ENTRY 1 IS CUTTER NUMBER:

1

$==>$ CHARACTERISTIC PLANE 1 DATA IS

$\begin{array}{llll}4 & 3 & 1 & 1\end{array}$

ENTER CHARACTERISTIC PLANE NUMBER

$?$

INPUT THE BIT F.E. NODE NUMBERS DEFINING CHARACTERISTIC PLANE NUMBER SEPARATE DATA BY BLANKS OR COMMAS

$?$

132

INPUT THE GHOST CUTTER NUMBERS WHICH OCCUR ON THIS PLANE. TO EXIT INPUT MODE ENTER ZERO OR NEGATIVE NUMBER.

CUTTER ENTRY 1 IS CUTTER NUMBER:

$?$

$==\Rightarrow \quad$ CHARACTERISTIC PLANE 2 DATA IS

1232

ENTER CHARACTERISTIC PLANE NUMBER

$?$

INPUT THE BIT F.E. NODE NUMBERS DEFINING CHARACTERISTIC PLANE NUMBER SEPARATE DATA BY BLANKS OR COMMAS

21

INPUT THE GHOST CUTTER NUMBERS WHICH OCCUR ON THIS PLANE. TO EXIT INPUT MODE ENTER ZERO OR NEGATIVE NUMBER.

CUTTER ENTRY 1 IS CUTTER NUMBER: 
DATA ENTERED WILL CONSIST OF : $==>$ FOUR BIT NODE NUMBERS DEFINING SURFACE ( ENTER A ZERO FOR 4-TH IF ON SURFACE OF WEDGE) $=\Rightarrow$ THE GHOST CUTTER NUMBERS LOCATED ON THE SURFACE ( MAXIMUM OF 1 CUTTERS ON SURFACE PERMITTED)

AFTER IDENTIFYING ALL CUTTERS ON A SURFACE. ENTER A ZERO OR A NEGATIVE NUMBER TO SIGNIFY COMPLETION OF INPUT DATA FOR THAT SURFACE.

ENTER THE BIT F.E. NODE MUMBERS DEFINING THE SURFACE SEPARATE BY BLANKS OR COMMAS

ENTER A ZERO FOR NON-EXISTENT NODE

$?$

321

CUTTER ENTRY 1 IS CUTTER MUMBER\&

?

GHOST CUTTER NUMBERS JUST ENTERED ARE LISTED BELOW : 1

DO YOU WISH TO RE-ENTER THIS DATA? ( YES OR NO )

ENTER THE BIT F.E. NODE MUMERS DEFINING THE SURFACE SEPARATE BY BLANKS OR COMMAS

ENTER A ZERO FOR NON-EXISTENT NODE

$?$

1432

$?$

CUTTER ENTRY 1 IS CUTTER NUMBER:

GHOST CUTTER NUMBERS JUST ENTERED ARE LISTED BELOW : 2

DO YOU WISH TO RE-ENTER THIS DATA? ( YES OR NO ) 
NO

ENTER THE BIT F.E. NODE NUMBERS DEF INING THE SURFACE

SEFARATE BY BLANKS OR COMMAS

$?$

ENTER A ZERO FOR NON-EXISTENT NODE

$\begin{array}{llll}3 & 2 & 1 & 4\end{array}$

$?$

CUTTER ENTRY 1 IS CUTTER NUMBER:

3

GHDST CUTTER NUMBERS JUST ENTERED ARE LISTED BELOW :

3

DO YOU WISH TO RE-ENTER THIS DATA? ( YES OR NO )

$?$

HAVE YOU CHANGED ANY INPUT CONCERNING EITHER THE 8-NODE BRICKS OR BEAMS ? IF SO THEY WILL EFFECT THE FINITE ELEMENT MODEL AND MODAL IDEALIZATION CHANGES IN GHOST CUTTER DESCRIPTIONS DON'T CHANGE THE FINITE ELEMENT MODEL

$?$ REPLY YES IF FINITE ELEMENT MODEL WILL BE EFFECTED

YES

NEW FINITE ELEMENT MODEL MASS, STIFFNESS, AND EIGENSYSTEM MATRICES

WILL BE GENERATED AND SAVED AS FILES

MAKE SURE FILE SPACE IS AVAILABLE

$?$

IS THIS THE FIRST TIME THE PROGRAM HAS BEEN RUN FOR THIS MODEL ?

YES

DO YOU WISH TO ENTER NEW SPRING CONSTANTS ?

(YES/NO)

$?$

YES

$==>$ INPUT THE BOUNDARY $X, Y, Z$ TRANSLATION SPRING CONSTANTS FOR NODE 17 SEPARATE INPUT WITH BLANKS OR COMMAS

$?$

$2769.2 \quad 2769.2 \quad 10031.0$

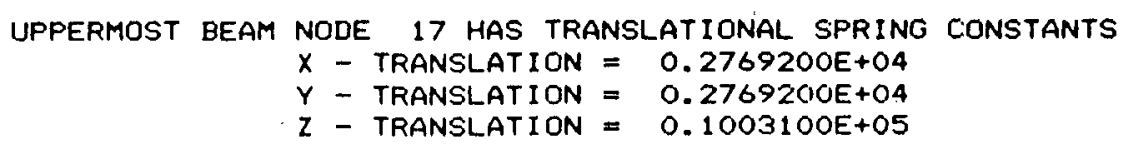

$==3$ INPUT THE BOUNDARY $X, Y, Z$ ROTATIONAL SFRING CONSTANTS FOR NODE 17 SEPARATE INPUT WITH BLANKS OR COMMAS 
$?$

$50938.0 \quad 50938.0 \quad 9795.6$

UPPERMOST BEAM NODE 17 HAS ROTATIONAL SPRING CONSTANTS

$X-$ ROTATIONAL $=0.5093800 E+05$

$Y$ - ROTATIONAL $=0.5093800 E+05$

$Z$ - ROTATIONAL $=0.9795600 E+04$

DO YOU WISH TO RE-ENTER ANY OF THIS DATA ? (YES/NO)

?

NO

HAVE YOU CHANGED ANY INPUT CONCERNING EITHER THE 8-NODE BRICKS OR BEAMS ? IF SO THEY WILL EFFECT THE FINITE ELEMENT MODEL AND MODAL IDEALI ZATION CHANGES IN GHOST CUTTER DESCRIPTIONS DON'T CHANGE THE FINITE ELEMENT MODEL $?$ REPLY YES IF FINITE ELEMENT MODEL WILL BE EFFECTED

YES

NEW FINITE ELEMENT MODEL MASS, STIFFNESS, AND EIGENSYSTEM MATRICES WILL BE GENERATED AND SAVED AS FILES

MAKE SURE FILE SPACE IS AVAILABLE

********** CORE SIZE CHECK **********

REQUIRED STORAGE $=442$ ALLOCATED STORAGE $=10000$ OCCURRED AT CHECK POINT 5

$===x=>$ DEFINE THE EXTERNAL NODES :

$=\approx$ USER HAS SPECIFIED THAT 13 NODES ARE EXTERNAL.

A NODE NMMBER MUST BE ENTERED EACH TIME ONE IS REQUESTED BELOW. REMEMBER THAT ALL BEAM NODES ARE EXTERNAL !

\section{$?$}

1

$?$

ENTER AN EXTERNAL DRILL STRING NODE NUMBER (ENTRY * 2 )

ENTER AN EXTERNAL DRILL STRING NODE NUMBER (ENTRY \# 3 ) 
3 $?$

ENTER AN EXTERNAL DRILL STRING NODE NLMBER (ENTRY * 4 )

4

$?$

ENTER AN EXTERNAL DRILL STRING NODE NUMBER (ENTRY \# 5 )

$?$

ENTER AN EXTERNAL DRILL STRING NODE NUMBER (ENTRY * 6 )

10

?

ENTER AN EXTERNAL DRILL STRING NODE NUMBER (ENTRY * 7 ,

11

$?$

ENTER AN EXTERNAL DRILL STRING NODE NUMBER (ENTRY * 8 ) 12

$?$

ENTER AN EXTERNAL DRILL STRING NODE NUMBER (ENTRY * 13

$?$

ENTER AN EXTERNAL DRILL STRING NODE NUMBER (ENTRY * 10 )

14

ENTER AN EXTERNAL DRILL STRING NODE NUMBER (ENTRY * 11 ) $?$

15

ENTER AN EXTERNAL DRILL STRING NODE NUMBER (ENTRY *12) $?$

16

$?$

ENTER AN EXTERNAL DRILL STRING NODE NUMBER (ENTRY * 13 )

17

$=\varepsilon=\approx \Rightarrow$ DEFINE THE TIED BIT NODES :

$=2$ USER HAS SPECIFIED THAT 4 NODES ARE TIED TO BEAM.

A NODE NUMBER MUST BE ENTERED EACH TIME ONE IS REQUESTED BELOW.

ENTER A TIED BIT NODE NUMBER (ENTRY * 1 )

$?$ 


\subsection{3}

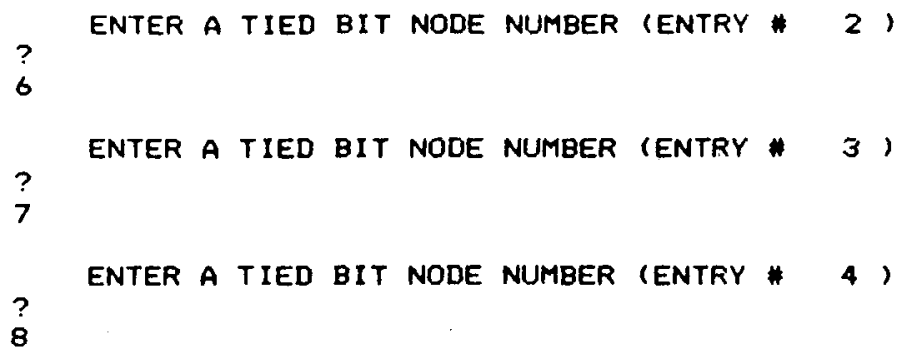

$====\Rightarrow$ DEFINE THE INTERNAL NODES :

$==\Rightarrow$ USER HAS SPECIFIED THAT O NODES ARE INTERNAL. A NODE NUMBER MUST BE ENTERED EACH TIME ONE IS REQUESTED BELOW.

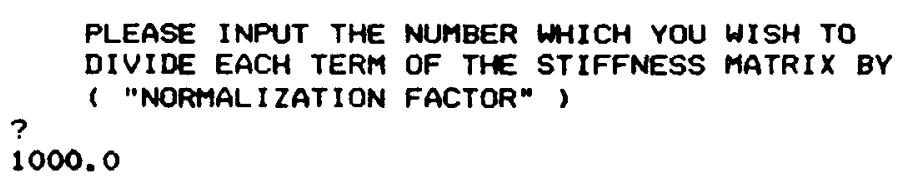

HAVE YOU CHANGED ANY INTERNAL/EXTERNAL, NODE DEFINITIONS OR ? 
The actual input file generated by the preceding interactive input session is listed below. Note that because this data file was generated and listed on a VAX computer, the first column of data does not get printed. Consequently, a line which says "O" is really "NO", and a line that says "ES" is really "YES". 
TYPE INGFR. DAT

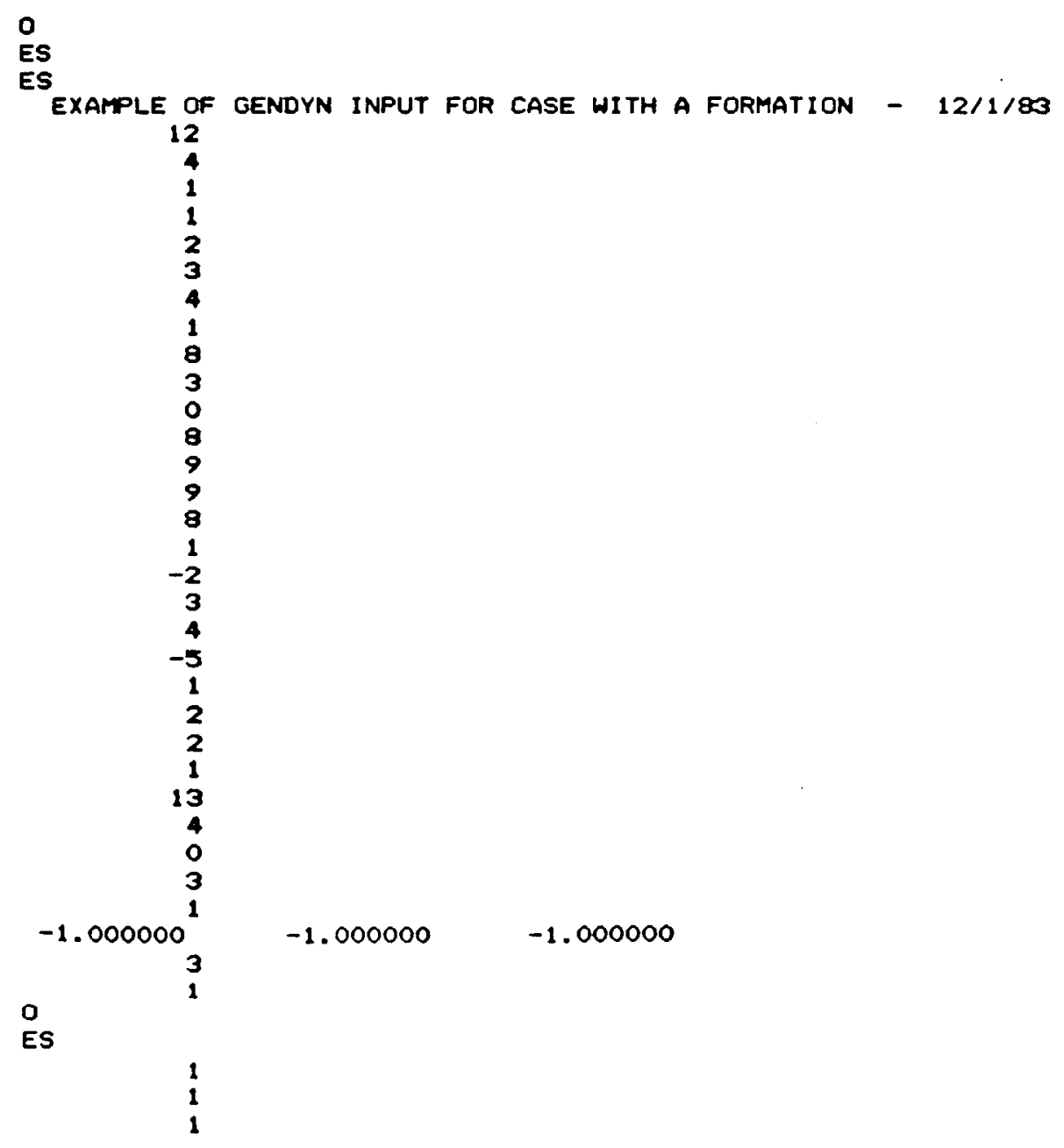


3. $0000000 E+07$

0.3000000

261.6360

ES

0.6121000

5.500000

2.800000

3. $0000000 E+07$

0.3000000

489.0000

ES 


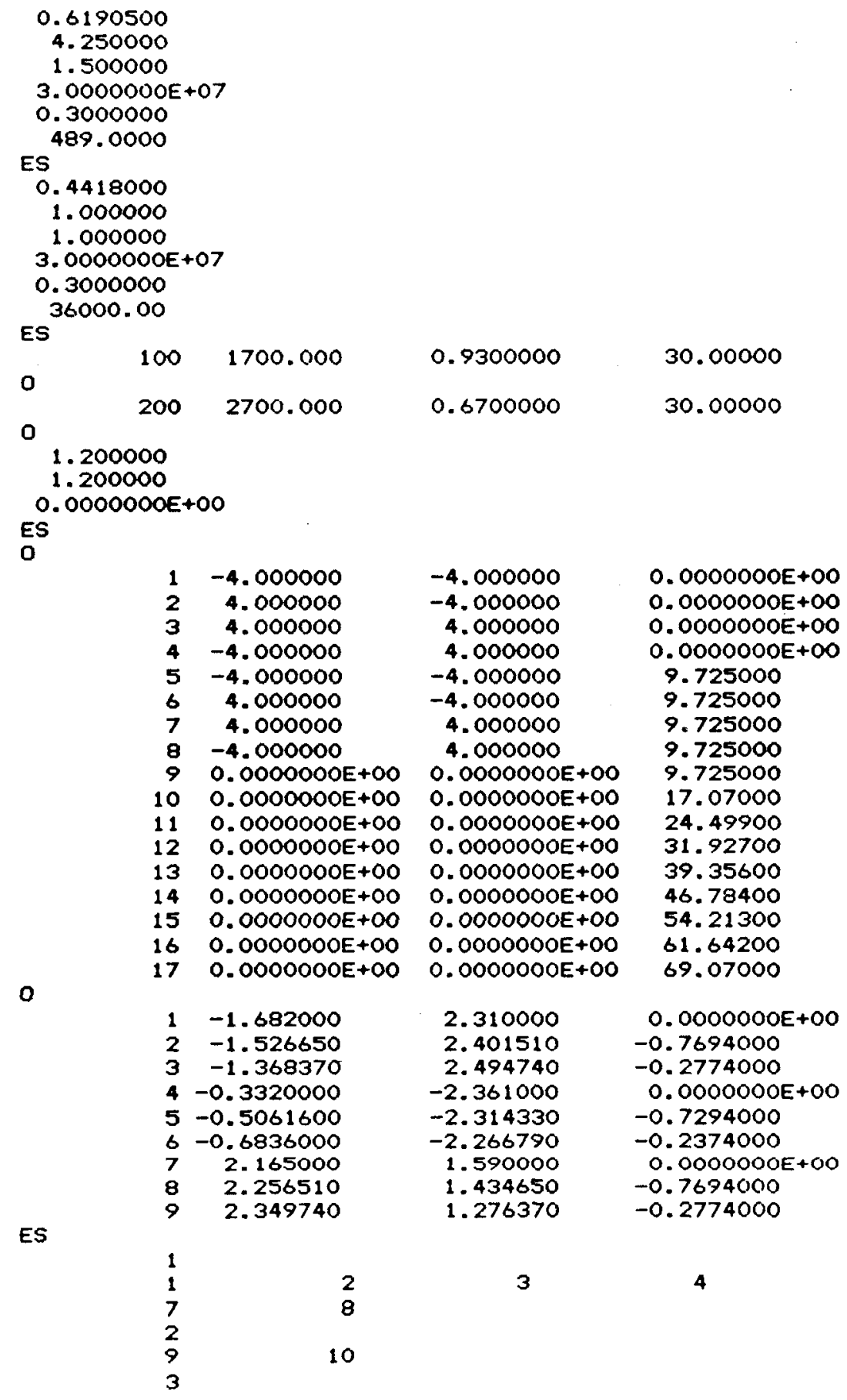




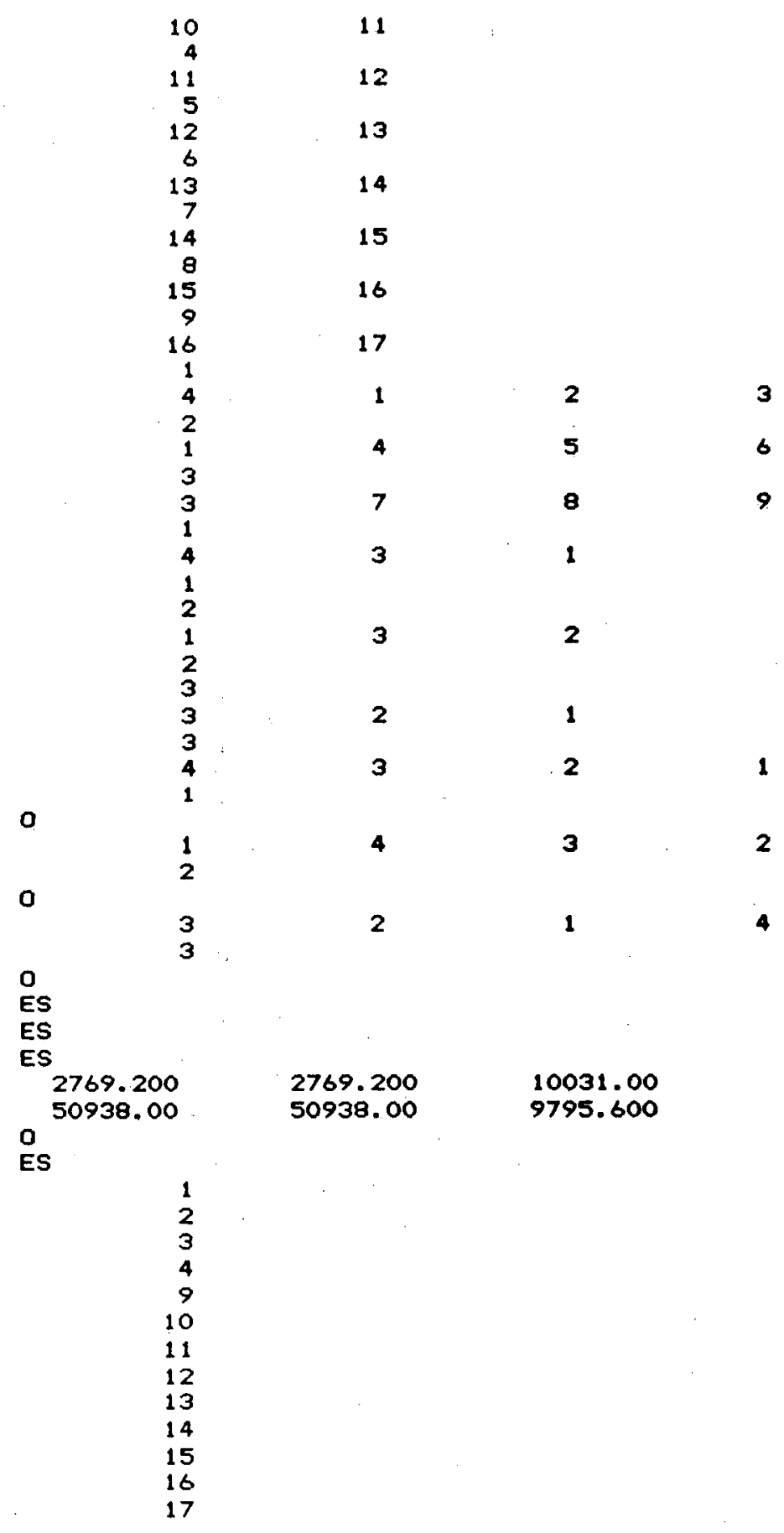


4.39

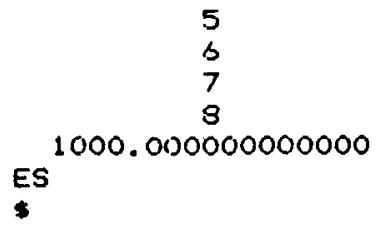

0

$\theta$

6

$\theta$ 
4.1.1 OUTPUT FROM RUNNING THE GENDYN SUB-PROGRAM

GEODYN was run using the input file just generated. The resulting GENDYN summary file, discussed in Section 3.8 .1 and illustrated in Figure 3.8.2.3, is shown here: 
GENDYN OUTPUT

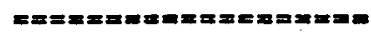
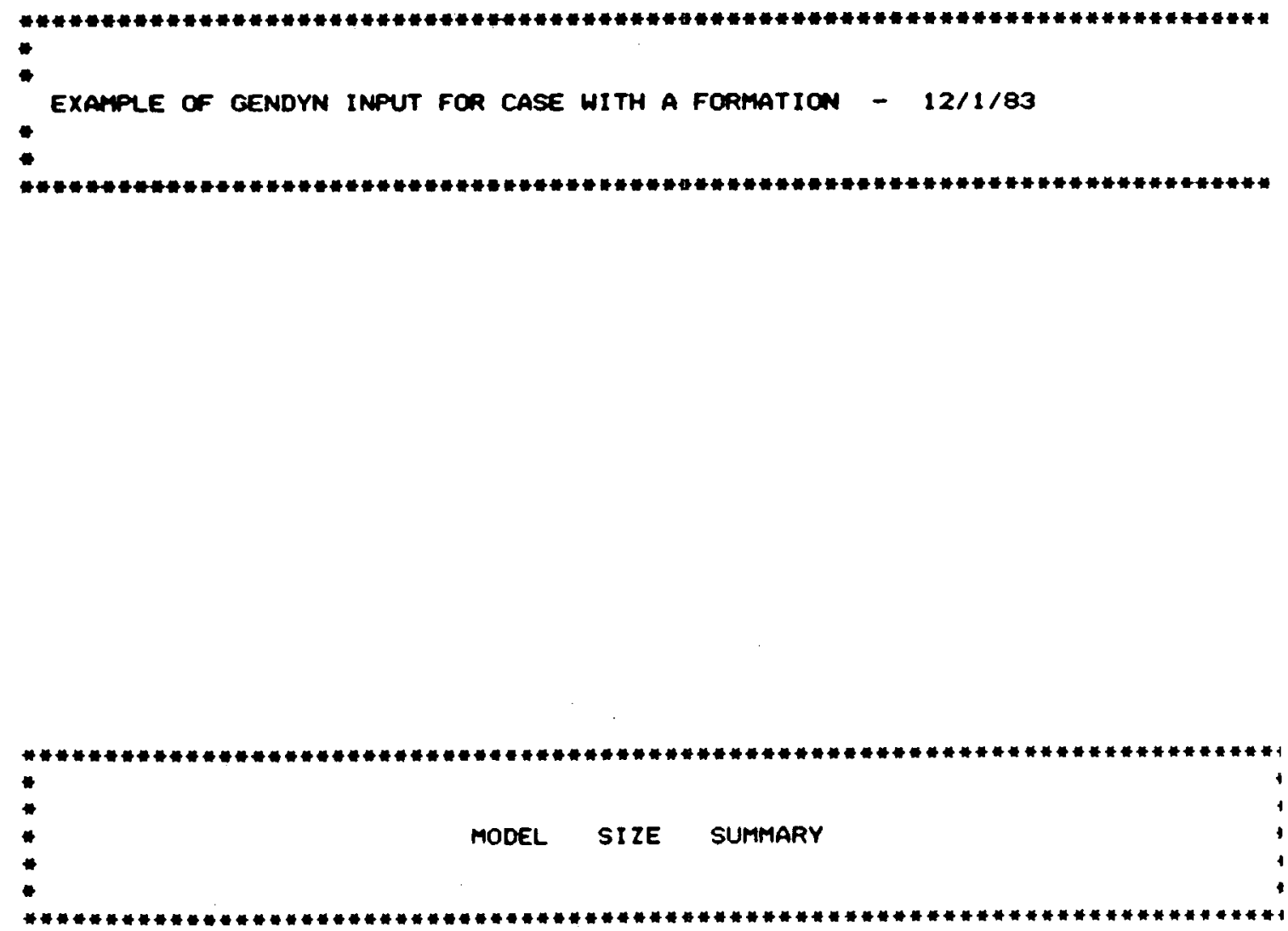


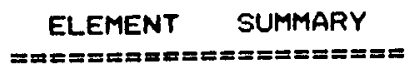

TOTAL NUMBER OF 8-NODE BRICK ELEMENTS :

TOTAL NUMBER OF 2O-NODE BRICK ELEMENTS :

TOTAL NUMBER OF LINEAR BEAM ELEMENTS : 8

TOTAL NUMBER OF GHOST CUTTER GEOMETRIC SUB-ELEMENTS : 3

TOTAL NUMBER OF INFINITE CONTINUUM BRICK ELEMENTS :

TOTAL NUMBER OF NON-LINEAR BEAM ELEMENTS :

NODE SUMMARY

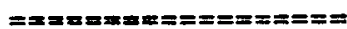

TOTAL NUMBER OF BIT NODES (8-NODE BRICKS): 8

TOTAL NUMBER OF LINEAR BEAM NODES ! 9

TOTAL NUMBER OF GHOST CUTTER SUB-NODES : 9

OEGREE - OF - FREEDOM SUMMARY

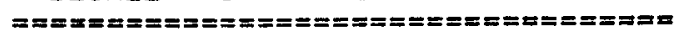

TOTAL NUMBER OF BIT D.O.F. (3-NODE BRICKS) : 24

TOTAL NUMBER OF LINEAR BEAM D.O.F. : 54

TITAL NUMBER OF IIRILL STRING D,O.F. PRIOR TO TYING : 78 
TOTAL NUMBER OF DRILL STRING D.O.F. AFTER TYING !

TYING CONSTRAINTS SUMMARY

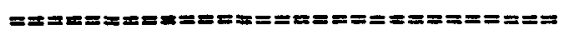

TOTAL NUMBER OF TIED BIT NODES :

4

LIST OF TIED BIT NODE NUMBERS :

$\begin{array}{llll}5 & 6 & 7 & 8\end{array}$

ELEMENT DEFINITION (CONNECTIUITY) SUMMARY

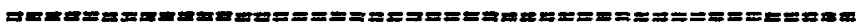

Q-NODE BRICKS ,

ELEMENT CONSISTS OF NODES :

1

123

$\begin{array}{lllll}4 & 5 & 6 & 7 & 8\end{array}$

LINEAR BEAMS :

$\begin{array}{ccc}\text { ELEMENT * } & \text { CONSISTS OF NODES : } \\ 2 & 9 & 10 \\ 3 & 10 & 11 \\ 4 & 11 & 12 \\ 5 & 12 & 13\end{array}$




$\begin{array}{lll}6 & 13 & 14 \\ 7 & 14 & 15 \\ 9 & 15 & 16 \\ 9 & 16 & 17\end{array}$

MATERIAL TYPE AND PROPERTIES SUMMARY

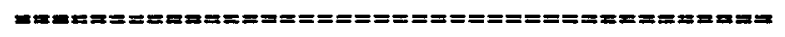

8-NODE BRICK MATERIAL PROPERTIES

$\begin{array}{cccc}\text { MATERIAL TYPE * YOUNG'S MOD. (PSI) } & \text { POISSON RATIO UNIT WT. (PCF) } \\ 1 & 0.3000000 E+08 & 0.3000000 E+00 & 0.2616360 E+03\end{array}$

8-NODE BRICK MATERIAL TYPES

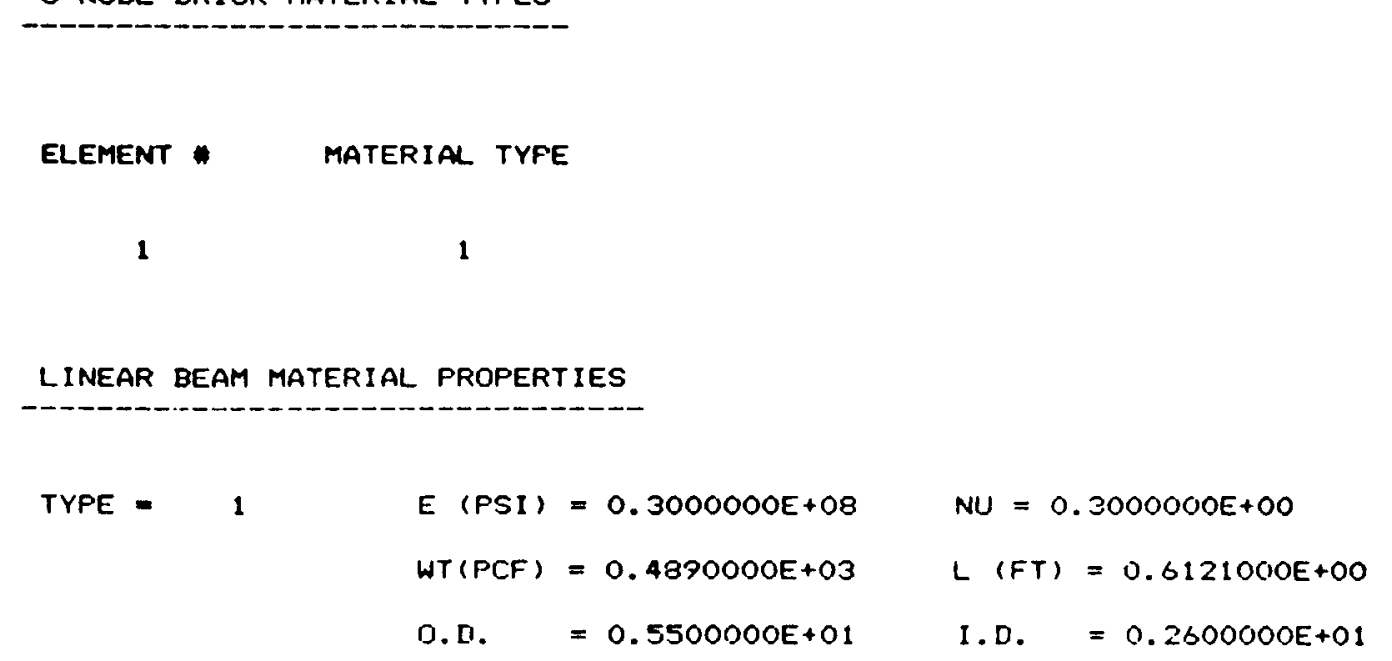




$\begin{array}{rlrl}\text { TYPE }=2(P S I)=0.3000000 E+03 & N U=0.3000000 E+00 \\ \text { WT }(P C F)=0.4990000 E+03 & L(F T)=0.8190500 E+00 \\ \text { o.D. }=0.4250000 E+01 & \text { I.D. }=0.1500000 E+01\end{array}$

LINEAR BEAM MATERIAL TYPES

ELEMENT - MATERIAL TYPE

\begin{tabular}{|c|c|c|c|}
\hline & 2 & 1 & \\
\hline & 3 & 2 & . \\
\hline & 4 & 2 & . \\
\hline & 5 & 2 & \\
\hline & 6 & 2 & \\
\hline & 7 & 2 & \\
\hline & 8 & 2 & \\
\hline & 9 & 2 & \\
\hline GHOST & CUTTER & MATERIAL & PROPERTIES \\
\hline TYPE - & $=1$ & $A(1 N-2)$ & $=0.4418000 E+00$ \\
\hline & & $I(I N-4)$ & $=0.1000000 E+01$ \\
\hline & & NU & $=0.3000000 E+00$ \\
\hline
\end{tabular}

$E(P S I)=0.3000000 E+08$ $J(I N-4)=0.1000000 E+01$ SY(PSI) $=0.3600000 E+05$ 
GHOST CUTTER MATERIAL TYPES

GHOST CUTTER MATERIAL TYPES

CUTTER * MATERIAL TYPE

$\begin{array}{ll}1 & 1 \\ 2 & 1 \\ 3 & 1\end{array}$

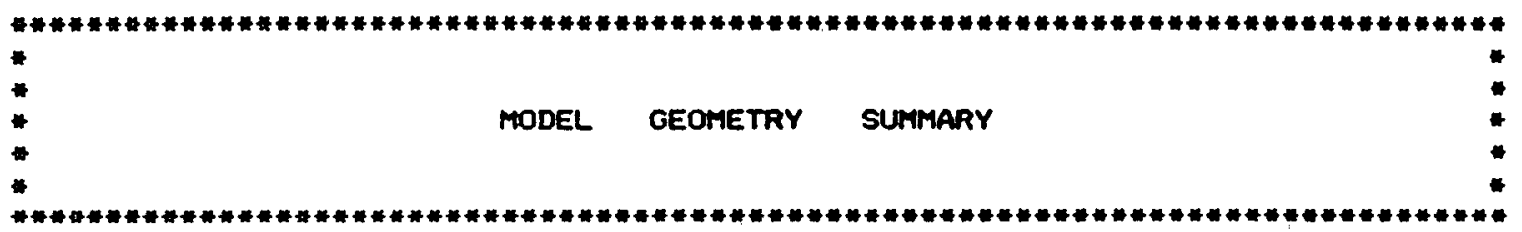

DRILL STRING NODAL COORDINATE SUMMARY

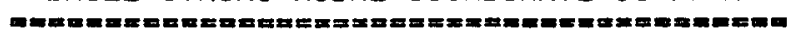

$\begin{array}{crrr}\text { NODE } & X \text {-COORD. } & Y \text {-COORD. } & z \text {-COORD. } \\ 1 & -4.00000 & -4.00000 & 0.00000 \\ 2 & 4.00000 & -4.00000 & 0.00000\end{array}$




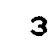

4

5

6

7

$\mathbf{8}$

9

10

11

12

13

14

15

16

17
4.00000

$-4.00000$

$-4.00000$

4. 00000

4.00000

$-4.00000$

0.00000

0.00000

0.00000

0.00000

0.00000

0.00000

0.00000

0.00000

0.00000
4.00000

4.00000

$-4.00000$

$-4.00000$

4. 00000

4. 00000

0.00000

0.00000

0.00000

0.00000

0.00000

0.00000

0.00000

0.00000

0.00000
0.00000

0.00000

9.72500

9.72500

9.72500

9.72500

9.72500

17.07000

24.49700

31.92700

39.35600

46.78400

54.21300

61.64200

69.07000

GHOST CUTTER SUMMARY

GHOST CUTTER SUB-NODE COORDINATE SUMMARY

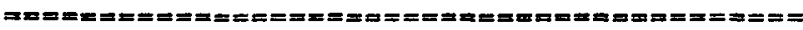

SUB-NODE

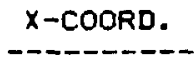

$-1.63200$
Y-COORD.

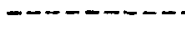

2.31000
Z-COORD.

$-\cdots-\cdots-\infty$

0.00000 
2

3

4

5

6

7

8

9
$-1.52665$

$-1.36837$

$-0.33200$

$-0.50616$

$-0.68360$

2.16500

2.25651

2.34974
2.40151

2.43474

$-2.36100$

$-2.31433$

$-2.26679$

1.59000

1.43465

1.27637
$-0.76940$

$-0.27740$

0.00000

$-0.72940$

$-0.23740$

0.00000

$-0.76940$

$-0.27740$

GHOST CUTTER SUB-NODE LOCAL COORDINATE SUMMARY

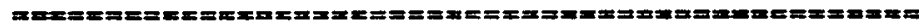

\begin{tabular}{cccc} 
SUB-NODE & R-COORD. & S-COORD. & T-COORD. \\
\hline 1 & 2.31800 & 1.69000 & 0.00000 \\
2 & 2.47335 & 1.59849 & 0.76940 \\
3 & 2.63163 & 1.50526 & 0.27740 \\
4 & 3.75262 & 1.43472 & 0.00000 \\
5 & 3.66247 & 1.27857 & 0.72940 \\
6 & 3.57061 & 1.11948 & 0.23740 \\
7 & 2.41000 & 1.83500 & 0.00000 \\
8 & 2.56535 & 1.74349 & 0.76940 \\
9 & 2.72363 & 1.65026 & 0.27740
\end{tabular}




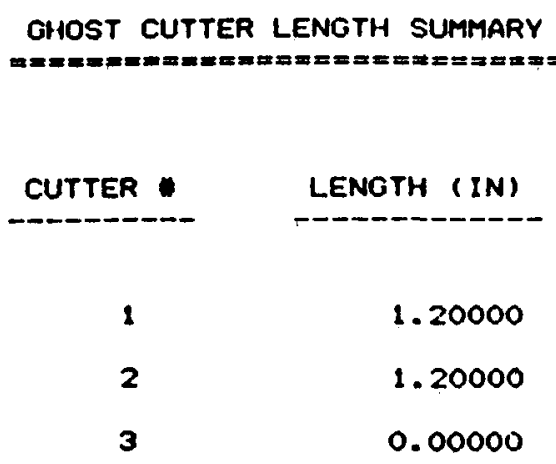

CUTTER DEFINITIONS

CUTTER - PRIMARY NODE SUB-NODEs : BIT SURF. TOP BLANK BOT. BLANK

$\begin{array}{ll}1 & 4 \\ 2 & 1 \\ 3 & 3\end{array}$

1

4

2

3

1

3

7

5

6

8

9

CHARACTERISTIC PLANE DEFINITIONS

PLANE NODE 1 NODE 2 NODE 3

1

4

3

1 
2

3
1

3
3

2
2

1

Plane 1 contaINS cutters :

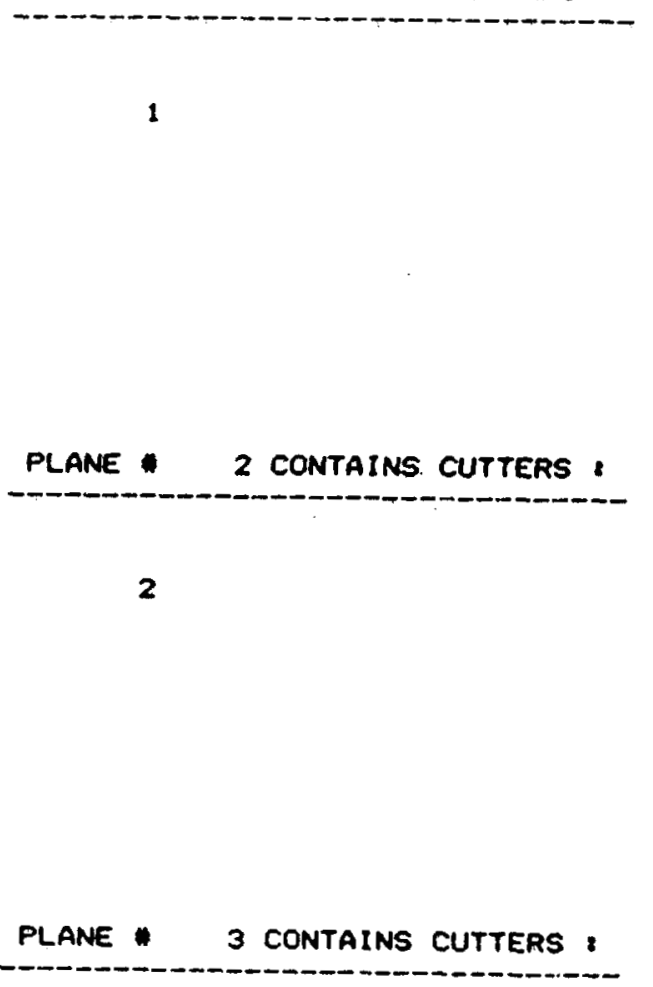

3 
BIT SURFACE DEFINITIONS

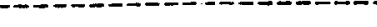

$\begin{array}{rrrrr}\text { SURFACE NODE } 1 & \text { NODE } 2 & \text { NODE } 3 & \text { NODE } 4 \\ 1 & 4 & 3 & 2 & 1 \\ 2 & 1 & 4 & 3 & 2 \\ 3 & 3 & 2 & 1 & 4\end{array}$

SURFACE 1 CONTAINS CUTTERS :

1

SURFACE * 2 CONTAINS CUTTERS :

2

SURFACE * 3 CONTAINS CUTTERS : 
EIGENUALUE NUMBER

1

2

3

4

5

6

7

8

9

10

11 value

$0.29002 D+02$

$0.290570+02$

$0.103370+04$

$0.12282 \mathrm{D}+05$

o. $15324 D+05$

$0.153250+05$

$0.806310+06$

$0.806310+06$

$0.642590+07$

$0.642590+07$

$0.144970+08$
FREQUENCY

$0.857100+00$

$0.857920+00$

$0.511700+01$

$0.176380+02$

$0.19702 \mathrm{D}+02$

$0.19702 \mathrm{D}+02$

$0.142710+03$

$0.142910+03$

$0.403450+03$

$0.40345 D+03$

$0.605780+0.3$ 
$0.26858 D+08$

$0.26858 D+08$

$0.62981 D+08$

$0.772100+08$

$0.772100+08$

$0.112880+09$

$0.17290 \mathrm{D}+09$

$0.172900+09$

$0.279970+09$

$0.310460+09$

$0.330420+09$

$0.330420+09$

$0.39298 D+09$

$0.50678 D+09$

$0.56035 D+09$

$0.560350+09$

$0.68106 \mathrm{D}+09$

$0.732700+09$

$0.793110+09$

$0.793110+09$

$0.864480+09$

$0.98420 D+09$

$0.10318 D+10$

$0.11292 D+10$

$0.124020+10$

$0.149830+10$

$0.149830+10$

$0.175630+10$
$0.82481 D+03$

$0.324810+03$

$0.126310+04$

$0.139350+04$

$0.13985 D+04$

$0.169100+04$

$0.20827 D+04$

$0.20927 D+04$

$0.26630 D+04$

$0.28043 D+04$

$0.28930 D+04$

$0.289300+04$

$0.315500+04$

$0.358290+04$

$0.37675 D+04$

$0.37675 D+04$

$0.415350+04$

$0.43081 D+04$

$0.44822 \mathrm{D}+04$

$0.44822 \mathrm{D}+04$

$0.46795 D+04$

$0.499300+04$

$0.51123 D+04$

$0.53482 \mathrm{D}+04$

$0.560490+04$

$0.618 .050+04$

$0.61605 D+04$

$0.667000+04$ 


$\begin{array}{lll}40 & 0.22514 \mathrm{D}+10 & 0.75517 \mathrm{D}+04 \\ 41 & 0.25549 \mathrm{D}+10 & 0.80446 \mathrm{D}+04 \\ 42 & 0.25549 \mathrm{D}+10 & 0.80446 \mathrm{D}+04 \\ 43 & 0.26597 \mathrm{D}+10 & 0.82079 \mathrm{D}+04 \\ 44 & 0.26614 \mathrm{D}+10 & 0.82107 \mathrm{D}+04 \\ 45 & 0.27373 \mathrm{D}+10 & 0.83269 \mathrm{D}+04 \\ 46 & 0.28787 \mathrm{D}+10 & 0.85392 \mathrm{D}+04 \\ 47 & 0.28932 \mathrm{D}+10 & 0.85607 \mathrm{D}+04 \\ 48 & 0.28932 \mathrm{D}+10 & 0.85607 \mathrm{D}+04 \\ 49 & 0.29524 \mathrm{D}+10 & 0.86478 \mathrm{D}+04 \\ 50 & 0.30760 \mathrm{D}+10 & 0.88270 \mathrm{D}+04 \\ 51 & 0.30760 \mathrm{D}+10 & 0.88270 \mathrm{D}+04 \\ 52 & 0.37842 \mathrm{D}+10 & 0.97905 \mathrm{D}+04 \\ 53 & 0.37842 \mathrm{D}+10 & 0.97905 \mathrm{D}+04 \\ 54 & 0.48331 \mathrm{D}+10 & 0.11065 \mathrm{D}+05 \\ 55 & 0.48331 \mathrm{D}+10 & 0.11065 \mathrm{D}+05 \\ 56 & 0.59058 \mathrm{D}+10 & 0.12231 \mathrm{D}+05 \\ 57 & 0.59058 \mathrm{D}+10 & 0.12231 \mathrm{D}+05 \\ 58 & 0.67843 \mathrm{D}+10 & 0.13109 \mathrm{D}+05 \\ 59 & 0.67843 \mathrm{D}+10 & 0.13109 \mathrm{D}+05 \\ 60 & 0.75624 \mathrm{D}+10 & 0.13840 \mathrm{D}+05 \\ 61 & 0.76719 \mathrm{D}+10 & 0.13940 \mathrm{D}+05 \\ 62 & 0.76719 \mathrm{D}+10 & 0.13940 \mathrm{D}+05 \\ 63 & 0.84788 \mathrm{D}+10 & 0.14655 \mathrm{D}+05 \\ 64 & 0.84788 \mathrm{D}+10 & 0.14655 \mathrm{D}+05 \\ 65 & 0.89950 \mathrm{D}+10 & 0.15095 \mathrm{D}+05 \\ 66 & 0.83950 \mathrm{D}+10 & 0.15095 \mathrm{D}+05\end{array}$


4.2 INPUT FOR RUNNING THE RUNDYN SUB-PROGRAM

This section contains all of the interactive input needed to run RUNDYN for the model shown in Figures 4.1 .1 and 4.1.2. This example includes a formation model. The following is the actual interactive input session: 
RUN GEOIN

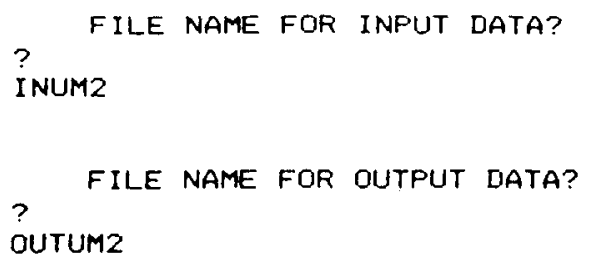




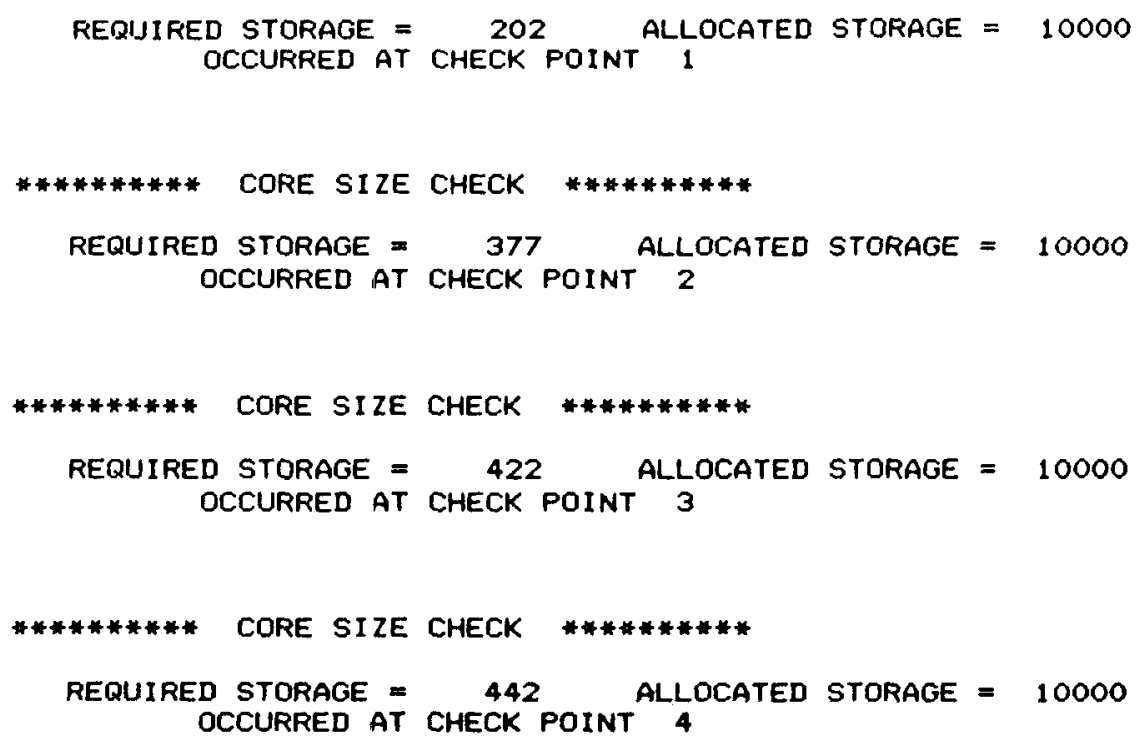

\begin{tabular}{|c|c|c|c|}
\hline & & & \\
\hline 1 & & 0 & $\begin{array}{l}0.85725 D+00 \\
0.85756 D+00\end{array}$ \\
\hline 3 & , & & $0.51170 D+O 1$ \\
\hline 4 & , & & $0.17638 \mathrm{D}+02$ \\
\hline 5 & 1 & & $0.19702 \mathrm{D}+02$ \\
\hline 6 & 1 & 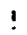 & $0.19702[1+02$ \\
\hline 7 & , & & $0.14291 \mathrm{D}+03$ \\
\hline 8 & 1 & & $0.14 .291 \mathrm{D}+03$ \\
\hline 9 & 1 & : & $0.40345 \mathrm{D}+03$ \\
\hline 10 & 1 & & $0.40345 \mathrm{D}+03$ \\
\hline 11 & I & & $0.605980+03$ \\
\hline 12 & 1 & & $0.82481 D+03$ \\
\hline 13 & 1 & & $0.82481 \mathrm{D}+03$ \\
\hline 14 & 1 & & $0.12631[1+04$ \\
\hline 15 & 1 & & $0.13985 D+04$ \\
\hline 16 & 1 & & $0.13985[1+04$ \\
\hline 17 & 1 & & $0.169100+04$ \\
\hline 18 & & $!$ & $0.20927 D+04$ \\
\hline
\end{tabular}




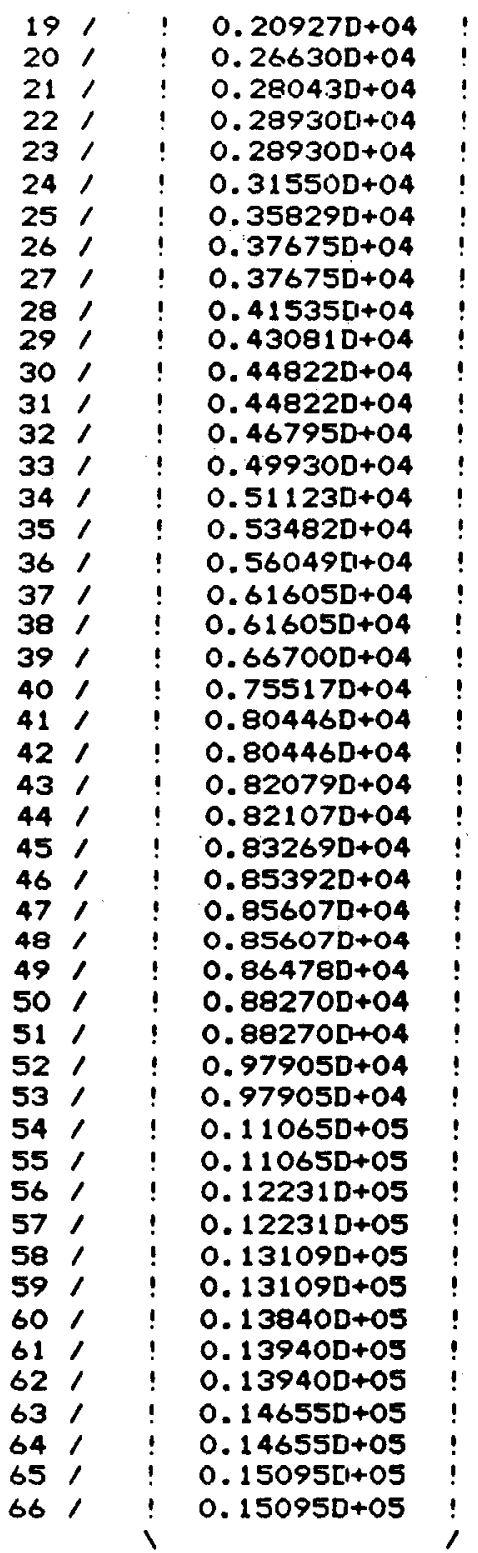

PLEASE INPUT THE NUMBER OF MODES TO BE CONSIDERED IN THIS ANALYSIS. 
ANALYSIS WILL BE BASED ON 24 MODES / FREQUENCIES.

NEW [Kmodal] AND [Mmodal] WILL BE GENERATED.

HOW MANY TIMES GREATER MUST A DIAGONAL TERM BE THAN AN OFF-DIAGONAL TERM IN ORDER FOR A MODAL MATRIX TO BE CONSIDERED TO BE DIAGONAL ?

$?$

50.0

$===\Rightarrow$ INPUT OF FORMATION POINT DATA :

IF A PREVIOUS FORMATION MESH DOES NOT EXIST, OR IF ONE DOES EXIST BUT IT IS NOW UNSATISFACTORY, THEN INPUT OF FORMATION DISCRETE POINT IDEALIZATION PARAMETERS IS REQUIRED.

DO YOU WISH TO USE THE EXISTING DISCRETE POINT PARAMETERS ? RESPOND YES OR NO (ANSWER NO IF PARAMETERS DON'T EXIST)

$?$

NO

FOLLOWING INPUT INFORMATION WILL BE UTILIZED IN THE DESCRIPTION OF THE FORMATION DISCRETE POINT IDEALIZATION. (REFER TO USERS MANUAL)

< NOTE > ALL PARAMETERS WITH THE EXCEPTION OF Z-COORDINATES MUST BE POSITIVE

INPUT THE FORMATION PARAMETERS FOR THE BOTTOM SURFACE OF THE FORMATION THESE INCLUDE THE DELTA-X AND DELTA-Y OF POINTS ON BOTTOM AND THE RADIUS AND Z-COORD OF THE START OF THE INCLINED SURFACE

< NOTE > IF NO INCLINE EXISTS INPUT RADIUS FOR SIDE WALL SURFACE

INPUT IN ORDER SEPARATED BY BLANKS OR COMMAS

2.0

2.0

6.0

$-0.7694$

DATA INPUT FOR FORMATION BOTTOM SURFACE DEFINITION IS : DISCRETE POINT DELTA-X SPACING $=2.0000$ DISCRETE POINT LELTA-Y SPACING $=2.0000$ RAUIUS TO THE START OF THE SIDE INCLINE SURFACE $=0.0000$

THE Z-COORD OF THE LOWER EXTENT OF SIDE INCLINE SURFACE $=-0.7694$

DO YOU WISH TO MODIFY ANY OF THIS INPUT ? (RESPOND YES OR NO) 
No

INPUT THE FORMATION PARAMETERS FOR THE SIDE WALL SURFACE OF THE FORMATION THESE INCLLIDE THE DELTA-THETA AND THE DELTA-Z OF POINTS ON WALL

THE Z-COORD DEF INING THE LOWER EXTENT OF SIDE WALL SURFACE

AND THE Z-COORD OF THE UPPERMOST ROCK WALL LOCATION

INPUT IN ORDER SEPARATED BY BLANKS OR COMMAS

$?$

$90.0 \quad 0.25 \quad 0.25 \quad 0.5$

DATA INPUT FOR FORMATION SIDE WALL SURFACE DEFINITION IS : DISCRETE POINT DELTA-THETA SPACING = 90.0000

DISCRETE POINT DELTA-Z SPACING $=0.2500$

THE Z-COORD OF THE LOWER EXTENT OF SIDE WALL SURFACE $=0.2500$

THE $Z$-COORD OF THE UPPERMOST SIDE WALL LOCATION $=0.5000$

DO YOU WISH TO MODIFY ANY OF THIS INPUT ? (RESPOND YES OR NO)

?

NO

INPUT THE FORMATION PARAMETERS FOR SIDE INCLINE SURFACE OF THE FORMATION THESE INCLUDE THE DELTA-THETA AND DELTA-S OF POINTS ON INCLINE

THE RADIUS DEFINING OUTER EXTENT OF INCLINE SURFACE

AND THE ANGLE FROM HORIZONTAL TO INCLINE SURFACE

INPUT IN ORDER SEPARATED BY BLANKS OR COMMAS

$?$

$90.0 \quad 0.7 \quad 7.0 \quad 40.0$

DATA INPUT FOR FORMATION SIDE INCLINE SURFACE DEFINITION IS : DISCRETE POINT DELTA-THETA SPACING $=90.0000$

DISCRETE POINT DELTA-S SPACING = 0.7000

THE RADIUS TO THE OUTER EXTENT OF INCLINE SURFACE = 7.0000

THE ANGLE FROM HORIZONTAL TO INCLINE SURFACE $=40.0000$

DO YOU WISH TO MODIFY ANY OF THIS INPUT ? (RESPOND YES OR NO)

$?$

No

CHECK OF INCLINE ANGLE AND CONSISTENT SURFACE DESCRIPTION DATA INCL INE INTERSECTION WITH SIDE WALL BASED ON INCLINE ANGLE $=0.0697$ Z-COORD OF SIDE WALL MESH STARTS AT 0.2500

IF INITIAL > LATTER HAVE INCONSISTENT INPUT DATA !

ARE THESE RESULTS CONSISTENT ?

IF SO RESPAND YES AND CONTINUE

$?$

IF NOT RESPOND NO AND RE-ENTER DATA

YES

IFRNMX -----> 
$\begin{array}{ll}\text { IFRNMY -- } & 3 \\ \text { IFRNXY --- } & 3 \\ \text { IFRNTW }----> & 3 \\ \text { IFRNZW }----> & 5 \\ \text { IFRNSI --- } & 2 \\ \text { IFRNTI }----> & 3\end{array}$

********* CORE SIIE CHECK **********
REQUIRED STORAGE $=707$ ALLOCATED STORAGE = 10000
OCCURRED AT CHECK POINT 8

$===>$ GENERATION OF FORMATION DISCRETE POINT MODEL WILL FOLLOW $<====$

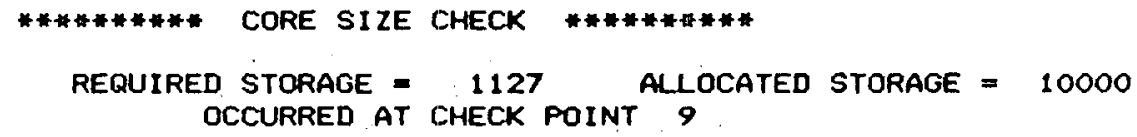

BY DEFAULT, THE PENETRATION COORDINATES OF ALL THE BOTTOM SURFACE FORMATION POINTS ARE SUCH THAT ALL POINTS WILL LIE ON A UNIFORM SLOPE BETWEEN THE ORIGIN AND THE OUTER RADIUS OF THE BOTTOM SURFACE.

INPUT THE $Z$ COORDINATE OF THE FORMATION

AT THE ORIGIN OF THE $X-Y$ GRID:

$-0.7294$

$X-Y$ ORIGIN IS AT $Z=-0.7294$

DO YOU WISH TO MODIFY ANY OF THE DEFAULT PENETRATION COORDINATES 
FOR THE BOTTOM SURFACE ? (Y OR N)

NO

BY DEFAULT, THE PENETRATION COORDINATE FOR ALL SIDE-WALL FORMATION POINTS ARE SET EQUAL TO THE NOMINAL WALL RADIUS AS PREVIOUSLY INPUT (RFRRWL)

DO YOU WISH TO MODIFY ANY OF THE DEFALLT PENETRATION COORDINATES FOR THE SIDE-WALL SURFACE ? (Y OR N) NO

BY DEFAULT, THE PENETRATION COORDINATE FOR ALL INCLINE SURFACE FORMATION POINTS ARE SET TO ZERO (THE INCLINE SURFACE WILL BE SMOOTH)

DO YOU WISH TO MODIFY ANY OF THE DEFALLT PENETRATION COORDINATES FOR THE INCLINE SURFACE ? ( $Y$ OR $N$ ) NO

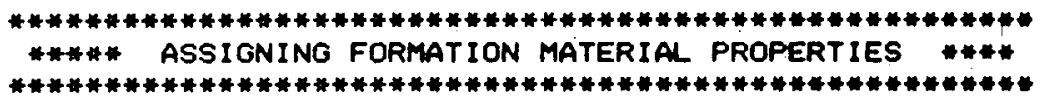

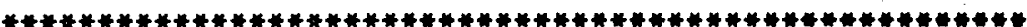

$========$ FOR THE "BOTTOM" FORMATION SURFACEI

TWO METHODS ARE AVAILABLE FOR ASSIGNING MATERIAL PROPERTY ID'S TO THE FORMATION POINTS ON THE BOTTOM SURFACE:

$1 \rightarrow-\rightarrow$ THE USER SPECIFIES A MATERIAL ID. AND THE $X$ AND $Y$ RANGES FOR WHICH IT APPLIES.

THIS MATERIAL ID WILL BE USED FOR ALL OF THE BOTTOM SURFACE F.POINTS WITHIN THE SPECIFIED RANGE.

$2 \rightarrow-\rightarrow$ THE USER ENTERS AN X COORDINATE, A $Y$ COORDINATE, A RADIUS, AND A MATERIAL ID. THE MATERIAL ID WILL BE ASSIGNED TO EVERY BOTTOM SURFACE F.POINT WITHIN THE SPECIFIED RADIUS FROM THE GIVEN $X-Y$ LOCATION.

SELECT A MATERIAL ASSIGNMENT METHOD :

1 ---D RANGE METHOD

$2--->$ RADIUS METHOD 


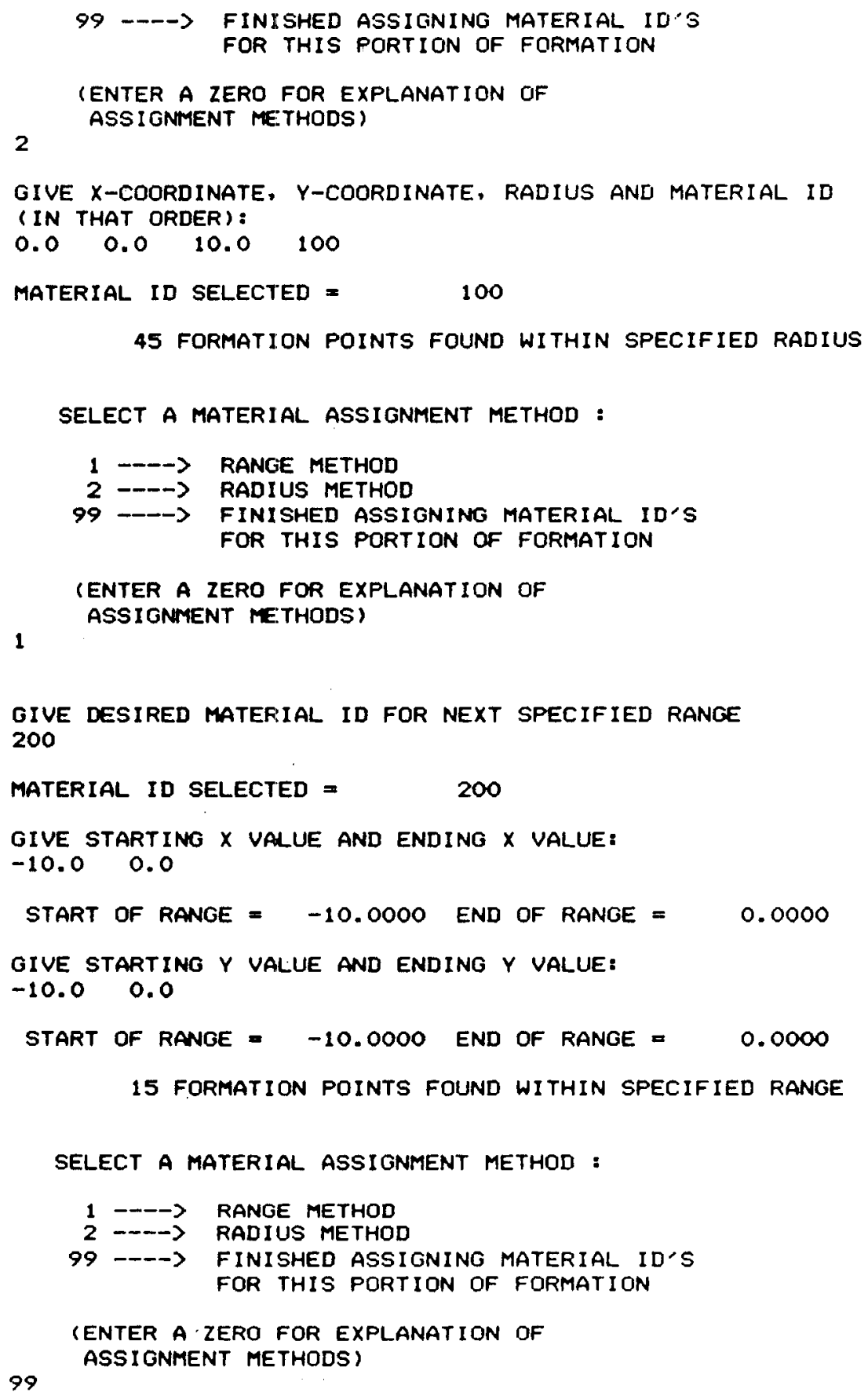


$=======$ FOR THE "SIDE-WALL" FORMATION SURFACE:

SELECT A MATERIAL ASSIGNMENT METHOD :

1 - - $>$ RANGE METHOD

2 - - $>$ RADIUS METHOD

$99--\rightarrow$ FINISHED ASSIGNING MATERIAL ID'S

FOR THIS PORTION OF FORMATION

(ENTER A ZERO FOR EXPLANATION OF

1 ASSIGNMENT METHODS)

GIVE DESIRED MATERIAL ID FOR NEXT SPECIFIED RANGE: 100

MATERIAL ID SELECTED $=\quad 100$

GIVE STARTING THETA VALUE AND ENDING THETA VALUE:

$0.0 \quad 360.0$

START OF RANGE $=0.0000$ END OF RANGE $\approx 360.0000$

GIVE STARTING $Z$ VALUE AND ENDING $Z$ VALUE:

0.01 .0

START OF RANGE $=0.0000$ END OF RANGE $=1.0000$

10 FORMATION POINTS FOUND WITHIN SPECIFIED RANGE

SELECT A MATERIAL ASSIGNMENT METHOD:

$1--\rightarrow$ RANGE METHOD

2 - - $>$ RADIUS METHOD

$99--\infty$ FINISHED ASSIGNING MATERIAL ID'S

FOR THIS PORTION OF FORMATION

(ENTER A ZERO FOR EXPLANATION OF

99 ASSIGNMENT METHODS)

$========$ FOR THE "INCLINE" FORMATION SURFACE:

SELECT A MATERIAL ASSIGNMENT METHOD :

1 -- $\rightarrow$ RANGE METHOD

$2--\rightarrow$ RADIUS METHOD

$99--\infty$ FINISHED ASSIGNING MATERIAL ID'S

FOR THIS PORTION OF FORMATION

(ENTER A ZERO FOR EXPLANATION OF 
IS UTILIZED. BE SURE ROTARY SFEED IS ENTERED WITH APFROFRIATE SIGN. 120.0

IS A ROTARY SPEED OF 120.0000 RPM SATISFACTORY? (RESPOND YES OR NO) ? YES

SPECIFY THE INUMEER OF REVOLUTIONS (OR FRACTION OF) TO BE USED IN ANALYSIS < NOTE > DIRECTION DEFINED BY ROTATIONAL DIRECTION

$?$ 1.0

IS A NUMBER OF REVOLUTIONS =1.00000 SATISFACTORY ? (RESPOND YES OR M) Y YES

SPECIFY THE SIZE OF THE TIME STEPS TO BE USED IN THE ANALYSIS. VALUE SHOULD BE ON THE ORDER OF $1 / 6$ RECIPROCAL OF HIGHEST NAT. FREQ. USED TO CHARACTERIZE THE GENERALI ZED MODAL DISPLACEMENTS.

THE HIGHEST NATURAL FREQUENCY SPECIFIED $=0.3155040 E+04$

< NOTE > THE TIME STEP SIZE WILL BE CONSTANT FOR THE ANALVSIS.

A TIMESTEP SIZE OF $0.5282553 E-04$ HAS BEEN SET AS THE DEFALLT VALUE. DO YOU WISH TO MODIFY THIS VALUE ? (RESPOND YES OR NO)

$?$ YES 


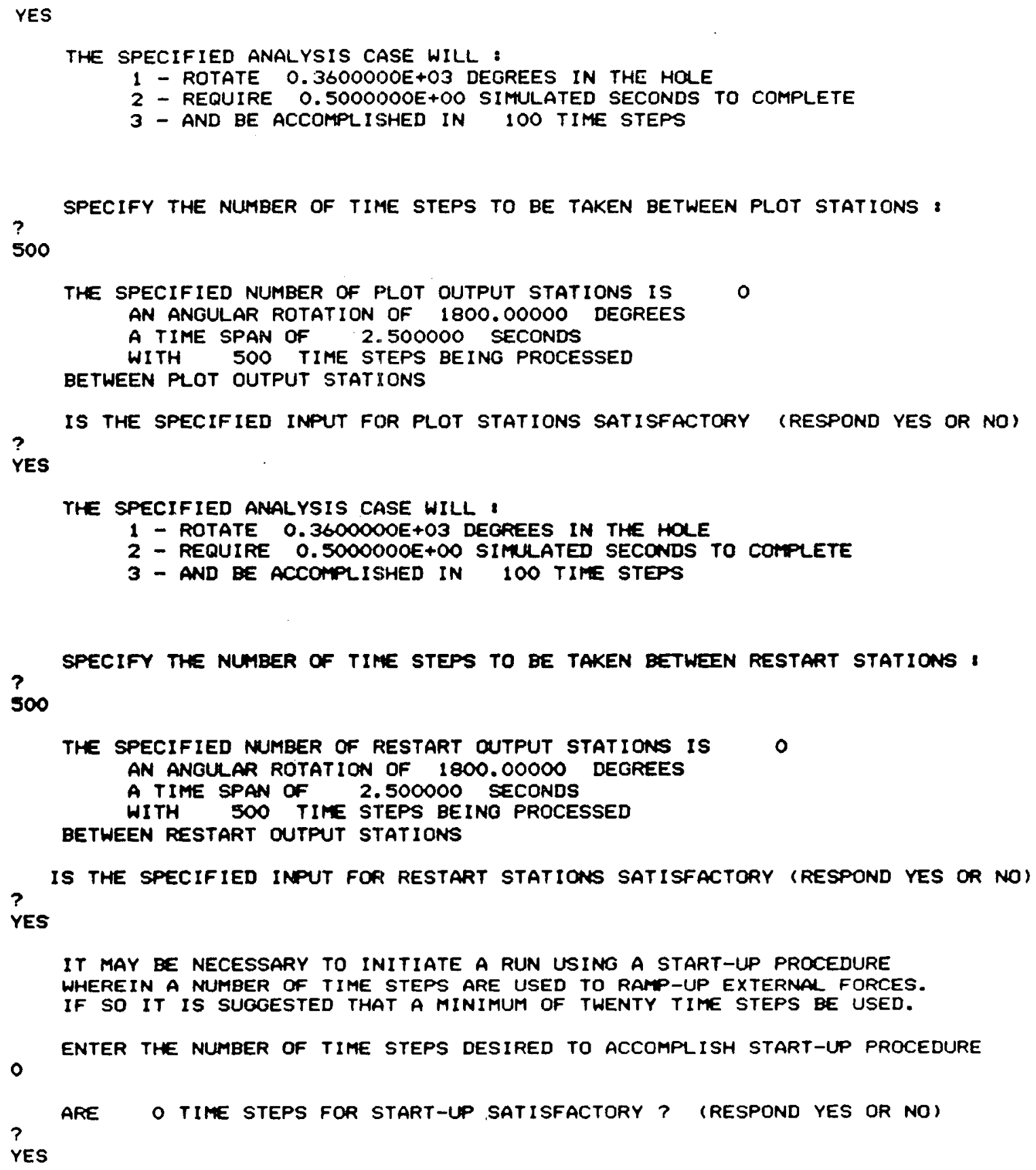


TME NEWMARK METHOD OF NUMERICAL INTEGRATION WILL BE EMPLOYED

IN THE SOLUTION ALGORITHM. THIS METHOD USES INTEGRATION CONSTANTS OF : ALPHA $=0.25$ GATHA $=0.50$

THE SOLUTION SCHEME EMPLOYED BY THIS PROGRAM PERMITS SOLUTION ITERATION WITHIN A TIME STEP TO OBTAIN A CONVERGED SOLUTION.

PLEASE SPECIFY THE MAXIMUM MUMBER OF ITERATIONS ALLOWED TO OBTAIN CONVERGENCI $?$

A SUGGESTED LIMIT IS 5

15

IS THE SPECIFIED ITERATION NUMBER LIMIT 15 SATISFACTORY (RESPOND YES OR NO $?$ YES

SPECIFY THE CONVERGENCE CRITERIA TO BE EMPLOYED IN THE ITERATIVE SOLUTION. THIS VALUE SHOLLD BE ENTERED AS A PERCENTILE TOLERANCE

TO BE APPLIED TO CONSECUTIVE PSI APPROXIMATIONS

OF MODAL DISPLACEMENT INCREMENTS $(n(t+d e)$ te $t))-(n(t))$

A TOLERANCE OF BETHEen I I AND .S PERCENT IS SUGCESTED

PLEASE ENTER THE CONVERGENE CRITERIA TOLERANCE

$?$

0.5

A COMVERGENCE CRITERIA TOLERANCE OF 0.500 HAS BEEN SPECIFIED

$?$

IS THIS VALLE SATISFACTORY (RESPOND YES OR NO)

YES

0001

- 
The actual input file generated by the preceding interactive input session is listed below. Note that because this data file was generated and listed on a VAX computer, the first column of data does not get printed. Consequently, a line which says "O" is really "NO", and a line that says "ES" is really "YES". 


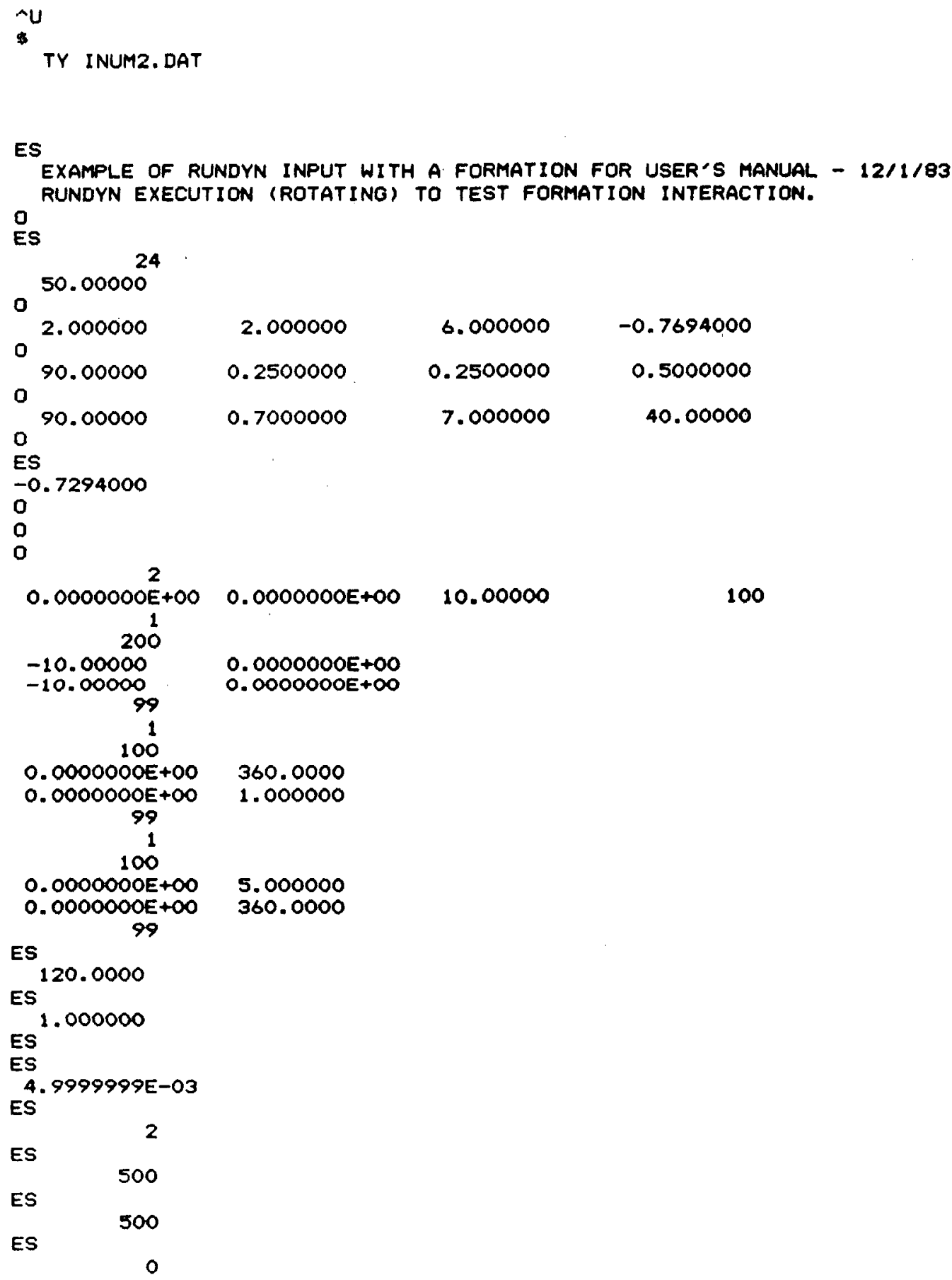


4.71

ES

ES 15

0.5000000

ES

$\bullet$

$\varphi$

$\Theta$

$\ominus$ 
4.2.1 FORCE FILES FOR RUNNING THE RUNDYN SUB-PROGRAM

The actual external force file used to perform this run is shown below. The external force file is discussed in Sections $3.5 .11,7.2$ and 7.2 .1 . 
$0.0000000 E+00 \quad 0.0000000 E+00$

$20.0000000 E+00 \quad 0.0000000 E+00$

$0.0000000 E+00 \quad 0.0000000 E+00$

$30.0000000 E+00 \quad 0.0000000 E+00$

$0.0000000 E+\infty 0 \quad 0.0000000 E+\infty 0$

$40.0000000 E+00 \quad 0.0000000 E+00$

$0.0000000 E+\infty 0 \quad 0.0000000 E+00$

$50.0000000 E+00 \quad 0.0000000 E+00$

$0.0000000 E+00 \quad 0.0000000 E+00$

$60.0000000 E+00 \quad 0.0000000 E+00$

$0.0000000 E+\infty 00.0000000 E+00$

$7 \quad 0.0000000 E+00 \quad 0.0000000 E+00$

$0.0000000 E+00 \quad 0.0000000 E+00$

$8 \quad 0.0000000 E+00 \quad 0.0000000 E+00$

$0.0000000 E+\infty 00.0000000 E+00$

S $0.0000000 E+00 \quad 0.0000000 E+00$

$0.0000000 E+00 \quad 0.0000000 E+00$

$10 \quad 0.0000000 E+00 \quad 0.0000000 E+00$

$0.0000000 E+00 \quad 0.0000000 E+00$

$10.0000000 E+00 \quad 0.0000000 E+00$

$0.0000000 E+00 \quad 0.0000000 E+\infty 0$

$20.0000000 E+00 \quad 0.0000000 E+\infty$

$0.0000000 E+\infty 00.0000000 E+\infty 0$

$30.0000000 E+00 \quad 0.0000000 E+\infty 0$

$0.0000000 E+\infty 00.0000000 E+\infty 0$

$40.0000000 E+00 \quad 0.0000000 E+00$

$0.0000000 E+\infty 0$ O.0000000E+0O

$50.0000000 E+00 \quad 0.0000000 E+\infty 0$

$0.0000000 E+\infty 00.0000000 E+\infty 0$

$6 \quad 0.0000000 E+00 \quad 0.0000000 E+00$

$0.0000000 E+00 \quad 0.0000000 E+00$

$7 \quad 0.0000000 E+00 \quad 0.0000000 E+\infty$

$0.0000000 E+\infty 00.0000000 E+00$

$80.0000000 E+00 \quad 0.0000000 E+00$

$0.0000000 E+00 \quad 0.0000000 E+\infty 0$

$9 \quad 0.0000000 E+00 \quad 0.0000000 E+00$

$0.0000000 E+\infty 00.0000000 E+\infty 0$.

$10 \quad 0.0000000 E+00 \quad 0.0000000 E+\infty 0$

$0.0000000 E+\infty 00.0000000 E+\infty 0$

$10.0000000 E+00 \quad 0.0000000 E+00$

$0.0000000 E+00 \quad 0.0000000 E+00$

$20.0000000 E+00 \quad 0.0000000 E+00$

$0.0000000 E+\infty 00.0000000 E+00$

$30.0000000 E+00 \quad 0.0000000 E+00$

$0.0000000 E+00 \quad 0.0000000 E+00$

$40.0000000 E+00 \quad 0.0000000 E+00$

$0.0000000 E+00 \quad 0.0000000 E+00$

$50.0000000 E+00 \quad 0.0000000 E+00$

$0.0000000 E+\infty 0.0000000 E+00$

$6 \quad 0.0000000 E+00 \quad 0.0000000 E+00$

$0.0000000 E+00 \quad 0.0000000 E+00$

$70.0000000 E+00 \quad 0.0000000 E+00$
$0.0000000 E+00$

$-127.16000$

$-254.32000$

$-381.48000$

$-508.64000$

$-635.80000$

$-762.96000$

$-890.12000$

$-1017.2800$

$-1144.4400$

$-1271.6000$

$-1271.6000$

$-1271.6000$

$-1271.6000$

$-1271.6000$

$-1271.6000$

$-1271.6000$

$-1271.6000$

$-1271.6000$

$-1271.6000$

$-1271.6000$

$-1271.6000$

$-1271.6000$

$-1271.6000$

$-1271.6000$

$-1271.6000$

$-1271.6000$
$0.0000000 E+00$

$0.0000000 E+00$

$0.0000000 E+00$

$0.0000000 E+00$

$0.0000000 E+00$

$0.0000000 E+00$

$0.0000000 E+00$

$0.0000000 E+00$

$0.0000000 E+\infty 0$

$0.0000000 E+00$

$0.0000000 E+00$

$0.0000000 E+\infty 0$

$0.0000000 E+00$

$0.0000000 E+00$

$0.0000000 E+\infty$

$0.0000000 E+\infty 0$

$0.0000000 E+00$

$0.0000000 E+\infty 0$

$0.0000000 E+\infty 0$

$0.0000000 E+\infty 0$

$0.0000000 E+\infty 0$

$0.0000000 E+00$

$0.0000000 E+00$

$0.0000000 E+00$

$0.0000000 E+00$

$0.0000000 E+00$

$0.0000000 E+00$ 


$$
\begin{aligned}
& 0.0000000 E+00 \quad 0.0000000 E+00 \\
& 80.0000000 E+00 \quad 0.0000000 E+00 \quad-1271.6000 \\
& 0.0000000 E+00 \quad 0.0000000 E+00 \\
& 90.0000000 E+00 \quad 0.0000000 E+00 \quad-1271.6000 \\
& 0.0000000 E+00 \quad 0.0000000 E+00 \\
& 10 \quad 0.0000000 E+00 \quad 0.0000000 E+00 \quad-1271.6000 \\
& 0.0000000 E+00 \quad 0.0000000 E+00 \\
& 10.0000000 E+00 \quad 0.0000000 E+00 \quad-1271.6000 \\
& 0.0000000 E+00 \quad 0.0000000 E+00 \\
& 20.0000000 E+00 \quad 0.0000000 E+00 \quad-1271.6000 \\
& 0.0000000 E+00 \quad 0.0000000 E+00 \\
& 3 \quad 0.0000000 E+00 \quad 0.0000000 E+00 \quad-1271.6000 \\
& 0.0000000 E+00 \quad 0.0000000 E+00 \\
& 40.0000000 E+00 \quad 0.0000000 E+00 \quad-1271.6000 \\
& 0.0000000 E+00 \quad 0.0000000 E+00 \\
& 5 \quad 0.0000000 E+00 \quad 0.0000000 E+00 \quad-1271.6000 \\
& 0.0000000 E+00 \quad 0.0000000 E+00 \\
& 6 \quad 0.0000000 E+00 \quad 0.0000000 E+00 \quad-1271.6000 \\
& 0.0000000 E+00 \quad 0.0000000 E+00 \\
& 70.0000000 E+00 \quad 0.0000000 E+00 \quad-1271.6000 \\
& 0.0000000 E+00 \quad 0.0000000 E+00 \\
& 80.0000000 E+00 \quad 0.0000000 E+00 \\
& 0.0000000 E+00 \quad 0.0000000 E+00 \\
& 90.0000000 E+00 \quad 0.0000000 E+00 \\
& 0.0000000 E+00 \quad 0.0000000 E+00 \\
& 10 \quad 0.0000000 E+\infty 0 \quad 0.0000000 E+00 \\
& 0.0000000 E+00 \quad 0.0000000 E+00 \\
& 10.0000000 E+00 \quad 0.0000000 E+00 \\
& 0.0000000 E+00 \quad 0.0000000 E+00 \\
& 20.0000000 E+00 \quad 0.0000000 E+00 \\
& 0.0000000 E+00 \quad 0.0000000 E+00 \\
& 30.0000000 E+00 \quad 0.0000000 E+00 \quad-1271.6000 \\
& 0.0000000 E+00 \quad 0.0000000 E+00 \\
& 4 \quad 0.0000000 E+00 \quad 0.0000000 E+00 \quad-1271.6000 \\
& 0.0000000 E+00 \quad 0.0000000 E+00 \\
& 5 \quad 0.0000000 E+00 \quad 0.0000000 E+00 \quad-1271.6000 \\
& 0.0000000 E+00 \quad 0.0000000 E+00 \\
& 6 \quad 0.0000000 E+00 \quad 0.0000000 E+00 \quad-1271.6000 \\
& 0.0000000 E+00 \quad 0.0000000 E+00 \\
& 70.0000000 E+00 \quad 0.0000000 E+00 \quad-1271.6000 \\
& \begin{array}{cccc}
0.0000000 E+00 & 0.0000000 E+00 & \\
8 & 0.0000000 E+00 & 0.0000000 E+00 & -1271.6000
\end{array} \\
& 0.0000000 E+00 \quad 0.0000000 E+00 \\
& 90.0000000 E+00 \quad 0.0000000 E+\infty 0 \quad-1271.6000 \\
& 0.0000000 E+00 \quad 0.0000000 E+00
\end{aligned}
$$

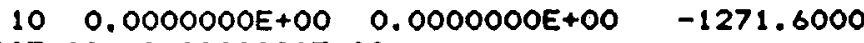

$$
\begin{aligned}
& 0.0000000 E+00 \quad 0.0000000 E+00 \\
& 10.0000000 E+00 \quad 0.0000000 E+00 \quad-1271.6000 \\
& 0.0000000 E+00 \quad 0.0000000 E+00 \\
& 20.0000000 E+00 \quad 0.0000000 E+00 \quad-1271.6000 \\
& 0.0000000 E+00 \quad 0.0000000 E+00 \\
& 30.0000000 E+00 \quad 0.0000000 E+00 \quad-1271.6000 \\
& 0.0000000 E+00 \quad 0.0000000 E+00 \\
& 4 \quad 0.0000000 E+00 \quad 0.0000000 E+00 \quad-1271.6000 \\
& 0.0000000 E+00 \quad 0.0000000 E+00 \\
& 5 \quad 0.0000000 E+00 \quad 0.0000000 E+00 \quad-1271.6000 \\
& 0.0000000 E+00 \quad 0.0000000 E+00
\end{aligned}
$$


6 O. OOOOOOIOE+OO $0.0000000 E+00$

$0.0000000 E+00 \quad 0.0000000 E+00$

$7 \quad 0.0000000 E+00 \quad 0.0000000 E+00$

$0.0000000 E+00 \quad 0.0000000 E+00$

$8 \quad 0.0000000 E+00 \quad 0.0000000 E+00$

$0.0000000 E+00 \quad 0.0000000 E+00$

$90.0000000 E+00 \quad 0.0000000 E+00$

$0.0000000 E+\infty 0 \quad 0.0000000 E+00$

$10 \quad 0.0000000 E+00 \quad 0.0000000 E+00$

$0.0000000 E+00 \quad 0.0000000 E+00$

$10.0000000 E+00 \quad 0.0000000 E+00$

$0.0000000 E+00 \quad 0.0000000 E+00$

$20.0000000 E+00 \quad 0.0000000 E+00$

$0.0000000 E+00 \quad 0.0000000 E+00$

$30.0000000 E+00 \quad 0.0000000 E+00$

$0.0000000 E+00 \quad 0.0000000 E+00$

$40.0000000 E+00 \quad 0.0000000 E+00$

$0.0000000 E+00 \quad 0.0000000 E+00$

$50.0000000 E+00 \cdot 0.0000000 E+00$

$0.0000000 E+00 \quad 0.0000000 E+00$

$6 \quad 0.0000000 E+00 \quad 0.0000000 E+00$

$0.0000000 E+\infty 0 \quad 0.0000000 E+C O$

$7 \quad 0.0000000 E+00 \quad 0.0000000 E+\infty 0$

$0.0000000 E+00 \quad 0.0000000 E+00$

$80.0000000 E+00 \quad 0.0000000 E+00$

$0.0000000 E+00 \quad 0.0000000 E+00$

- $0.0000000 E+00 \quad 0.0000000 E+00$

$0.0000000 E+\infty 00.0000000 E+C O$

$10 \quad 0.0000000 E+00 \quad 0.0000000 E+00$

$0.0000000 E+00 \quad 0.0000000 E+00$

$10.0000000 E+00 \quad 0.0000000 E+00$

$0.0000000 E+\infty 00.0000000 E+C D$

$2 \quad 0.0000000 E+00 \quad 0.0000000 E+\infty 0$

$0.0000000 E+00 \quad 0.0000000 E+00$

$30.0000000 E+00 \quad 0.0000000 E+\infty$

$0.0000000 E+00 \quad 0.0000000 E+C D$

$40.0000000 E+00 \quad 0.0000000 E+00$

$0.0000000 E+00 \quad 0.0000000 E+C H$

$5 \quad 0.0000000 E+00 \quad 0.0000000 E+00$

$0.0000000 E+00 \quad 0.0000000 E+00$

$6 \quad 0.0000000 E+00 \quad 0.0000000 E+00$

$0.0000000 E+00 \quad 0.0000000 E+C D$

$7 \quad 0.0000000 E+00 \quad 0.0000000 E+\infty 0$

$0.0000000 E+00 \quad 0.0000000 E+00$

$8 \quad 0.0000000 E+00 \quad 0.0000000 E+00$

$0.0000000 E+00 \quad 0.0000000 E+00$

Q $0.0000000 E+00 \quad 0.0000000 E+00$

$0.0000000 E+00 \quad 0.0000000 E+00$

$10 \quad 0.0000000 E+00 \quad 0.0000000 E+00$

$0.0000000 E+00 \quad 0.0000000 E+00$

$10.0000000 E+00 \quad 0.0000000 E+00$

$0.0000000 E+00 \quad 0.0000000 E+00$

$20.0000000 E+00 \quad 0.0000000 E+00$

$0.0000000 E+00 \quad 0.0000000 E+00$

$3 \quad 0.0000000 E+00 \quad 0.0000000 E+\infty 0$

$0.0000000 E+00 \quad 0.0000000 E+00$

$40.0000000 E+00 \quad 0.0000000 E+00$
$-1271.6000$

$-1271.6000$

$-1271.6000$

$-1271.6000$

$-1271.6000$

$-1271.6000$

$-1271.6000$

$-1271.6000$

$-1271.6000$

$-1271.6000$

$-1271.6000$

$-1271.6000$

$-1271.6000$

$-1271.6000$

$-1271.6000$

$-1271.6000$

$-1271.6000$

$-1271.6000$

$-1271.6000$

$-1271.6000$

$-1271.6000$

$-1271.6000$

$-1271.6000$

$-1271.6000$

$-1271.6000$

$-1271.6000$

$-1271.6000$

$-1271.6000$

$-1271.6000$
$0.0000000 E+00$

$0.0000000 E+00$

$0.0000000 E+00$

$0.0000000 E+00$

$0.0000000 E+00$

$0.0000000 E+00$

$0.0000000 E+00$

$0.0000000 E+00$

$0.0000000 E+00$

$0.0000000 E+00$

$0.0000000 E+00$

$0.0000000 E+00$

$0.0000000 E+00$

$0.0000000 E+00$

$0.0000000 E+00$

$0.0000000 E+00$

$0.0000000 E+00$

$0.0000000 E+00$

$0.0000000 E+00$

$0.0000000 E+00$

$0.0000000 E+00$

$0.0000000 E+00$

$0.0000000 E+00$

$0.0000000 E+00$

$0.0000000 E+00$

$0.0000000 E+00$

$0.0000000 E+00$

$0.0000000 E+00$

$0.0000000 E+00$ 
$0.0000000 E+00 \quad 0.0000000 E+00$

$5 \quad 0.0000000 E+00$
$0.0000000 E+00 \quad 0.0000000 E+00$

$S$ O. OOOOOOOE+OO O.

$0.0000000 E+00 \quad 0.0000000 E+00$

$70.0000000 E+00 \quad 0.0000000 E+00$

$0.0000000 E+00 \quad 0.0000000 E+00$

$80.0000000 E+00 \quad 0.0000000 E+00$

$0.0000000 E+00 \quad 0.0000000 E+00$

$90.0000000 E+00 \quad 0.0000000 E+00$

$0.0000000 E+00 \quad 0.0000000 E+00$

$10 \quad 0.0000000 E+00 \quad 0.0000000 E+00$

$0.0000000 E+00 \quad 0.0000000 E+O 0$

$10.0000000 E+00 \quad 0.0000000 E+00$

$0.0000000 E+00 \quad 0.0000000 E+00$

$20.0000000 E+00 \quad 0.0000000 E+00$

$0.0000000 E+00 \quad 0.0000000 E+00$

$30.0000000 E+00 \quad 0.0000000 E+00 \quad-1271.6000 \quad 0.0000000 E+00$

$0.0000000 E+00 \quad 0.0000000 E+00$

$40.0000000 E+00 \quad 0.0000000 E+00 \quad-1271.6000 \quad 0.0000000 E+00$

$0.0000000 E+00 \quad 0.0000000 E+00$

$50.0000000 E+00 \quad 0.0000000 E+00 \quad-1271.6000$

$0.0000000 E+00$

$0.0000000 E+00 \quad 0.0000000 E+00$

$6 \quad 0.0000000 E+\infty 0 \quad 0.0000000 E+00 \quad-1271.6000$

$0.0000000 E+00$

$0.0000000 E+00 \quad 0.0000000 E+00$

$70.0000000 E+00 \quad 0.0000000 E+00$

$-1271.6000$

$0.0000000 E+00$

$0.0000000 E+00 \quad 0.0000000 E+00$

$80.0000000 E+00 \quad 0.0000000 E+00$

$-1271.6000$

$0.0000000 E+00$

$0.0000000 E+00 \quad 0.0000000 E+00$

$90.0000000 E+00 \quad 0.0000000 E+00 \quad-1271.6000$

$0.0000000 E+00$

$0.0000000 E+\infty 0$ 0.0000000E+OO

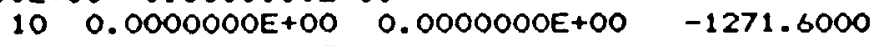

$0.0000000 E+00 \quad 0.0000000 E+00$

$0.0000000 E+00$

TY OUTGEN. GEN 
4.2.2 OUTPUT FROM RUNNING THE RUNDYN SUB-PROGRAM

GEODYN was run using the input file just generated. The information reported next is representative of the data obtained from this run: 
FIGURE 4.2.2.1: Selected RUNDYN Output -

Formation Interaction

\begin{tabular}{|c|c|c|c|c|}
\hline $\begin{array}{l}\text { Print } \\
\text { Station\# }\end{array}$ & D.O.F.\# & $\begin{array}{l}\text { Displ. } \\
\text { (in) }\end{array}$ & $\begin{array}{l}\text { Velocity } \\
(\text { in } / \mathrm{s})\end{array}$ & $\begin{array}{c}\text { Acceleration } \\
\left(\text { in } / s^{2}\right)\end{array}$ \\
\hline 1 & $\begin{array}{r}1 \\
25\end{array}$ & $\begin{array}{l}.2661 \mathrm{E}-2 \\
.2886 \mathrm{E}-2\end{array}$ & $\begin{array}{l}.5899 \mathrm{EO} \\
.6817 \mathrm{EO}\end{array}$ & $\begin{array}{l}.4609 \mathrm{E} 2 \\
.8364 \mathrm{E} 2\end{array}$ \\
\hline 5 & $\begin{array}{r}1 \\
25\end{array}$ & $\begin{array}{l}.7169 \mathrm{E}-1 \\
.1151 \mathrm{EO}\end{array}$ & $\begin{array}{l}.2133 \mathrm{E} 1 \\
.5079 \mathrm{E} 1\end{array}$ & $\begin{array}{l}.2824 \mathrm{E} 2 \\
.1297 \mathrm{E} 3\end{array}$ \\
\hline 10 & $\begin{array}{r}1 \\
25\end{array}$ & $\begin{array}{l}.2967 \mathrm{EO} \\
.5032 \mathrm{EO}\end{array}$ & $\begin{array}{l}.8360 \mathrm{E} 1 \\
.9991 \mathrm{E} 1\end{array}$ & $\begin{array}{l}.2292 \mathrm{E} 3 \\
.7801 \mathrm{E} 2\end{array}$ \\
\hline 15 & $\begin{array}{r}1 \\
25\end{array}$ & $\begin{array}{l}.1041 \mathrm{E1} \\
.1128 \mathrm{E} 1\end{array}$ & $\begin{array}{l}.2191 \mathrm{E} 2 \\
.1561 \mathrm{E} 2\end{array}$ & $\begin{array}{l}.2629 \mathrm{E} 3 \\
.1477 \mathrm{E} 3\end{array}$ \\
\hline 20 & $\begin{array}{r}1 \\
25\end{array}$ & $\begin{array}{l}.2424 \mathrm{E} 1 \\
.2093 \mathrm{E} 1\end{array}$ & $\begin{array}{l}.3167 \mathrm{E} 2 \\
.2256 \mathrm{E} 2\end{array}$ & $\begin{array}{l}.1814 \mathrm{E} 2 \\
.7745 \mathrm{E} 2\end{array}$ \\
\hline 25 & $\begin{array}{r}1 \\
25\end{array}$ & $\begin{array}{l}.4012 \mathrm{E} 1 \\
.3288 \mathrm{E} 1\end{array}$ & $\begin{array}{l}.3000 E 2 \\
.2394 E 2\end{array}$ & $\begin{array}{l}-.1846 \mathrm{E3} \\
-.9408 \mathrm{E} 2\end{array}$ \\
\hline 30 & $\begin{array}{r}1 \\
25\end{array}$ & $\begin{array}{l}.4179 \mathrm{E} 1 \\
.3523 \mathrm{E} 1\end{array}$ & $\begin{array}{l}-.4228 \mathrm{E} 2 \\
-.2794 \mathrm{E} 2\end{array}$ & $\begin{array}{l}-.2125 E 4 \\
-.1484 E 4\end{array}$ \\
\hline 35 & $\begin{array}{r}1 \\
25\end{array}$ & $\begin{array}{l}.5841 \mathrm{EO} \\
.1088 \mathrm{E} 1\end{array}$ & $\begin{array}{l}-.8399 \mathrm{E} 2 \\
-.5872 \mathrm{E} 2\end{array}$ & $\begin{array}{l}-.3801 \mathrm{E2} \\
-.2099 \mathrm{E} 3\end{array}$ \\
\hline 40 & $\begin{array}{r}1 \\
25\end{array}$ & $\begin{array}{l}-.3361 \mathrm{E1} \\
-.2085 \mathrm{E} 1\end{array}$ & $\begin{array}{l}-.6938 \mathrm{E} 2 \\
-.6522 \mathrm{E} 2\end{array}$ & $\begin{array}{l}.6327 \mathrm{E3} \\
.1140 \mathrm{E3}\end{array}$ \\
\hline 45 & $\begin{array}{r}1 \\
25\end{array}$ & $\begin{array}{l}-.5672 \mathrm{E} 1 \\
-.4755 \mathrm{E} 1\end{array}$ & $\begin{array}{l}-.3424 \mathrm{E} 1 \\
-.1467 \mathrm{E} 2\end{array}$ & $\begin{array}{l}.2983 E 4 \\
.3355 E 4\end{array}$ \\
\hline 50 & $\begin{array}{r}1 \\
25\end{array}$ & $\begin{array}{l}-.3876 \mathrm{E} 1 \\
-.3069 \mathrm{E} 1\end{array}$ & $\begin{array}{l}.6258 \mathrm{E} 2 \\
.5590 \mathrm{E} 2\end{array}$ & $\begin{array}{l}.5989 \mathrm{E3} \\
.2605 \mathrm{E3}\end{array}$ \\
\hline
\end{tabular}


5.0 EXAMPIE OF A QUALIFICATION - TYPE ANALYSIS (NO FORMATION)

To clarify many of the topics dealt with in preceding sections, this section presents examples of actual interactive input sessions required to generate input files for a qualification-type analysis (an analysis with no formation). These examples allow the user to see the actual questions asked by the program, and the correct format of the users' responses. The program called GEOIN, discussed in Sections 7.1 and 7.1 .1 , was run to produce these input examples. Following the input example, selected output is presented which was generated by running GEODYN with the input data presented in the input example. All of the results that follow were obtained by running the program on an VAX $11 / 780$ computer.

5.1 INPUT FOR RUNNING THE GENDYN SUB-PROGRAM

This section contains all of the interactive input needed to run GENDYN (model generation) for the model shown in Figures 5.1 .1 and 5.1.2. The following is the actual interactive input session: 


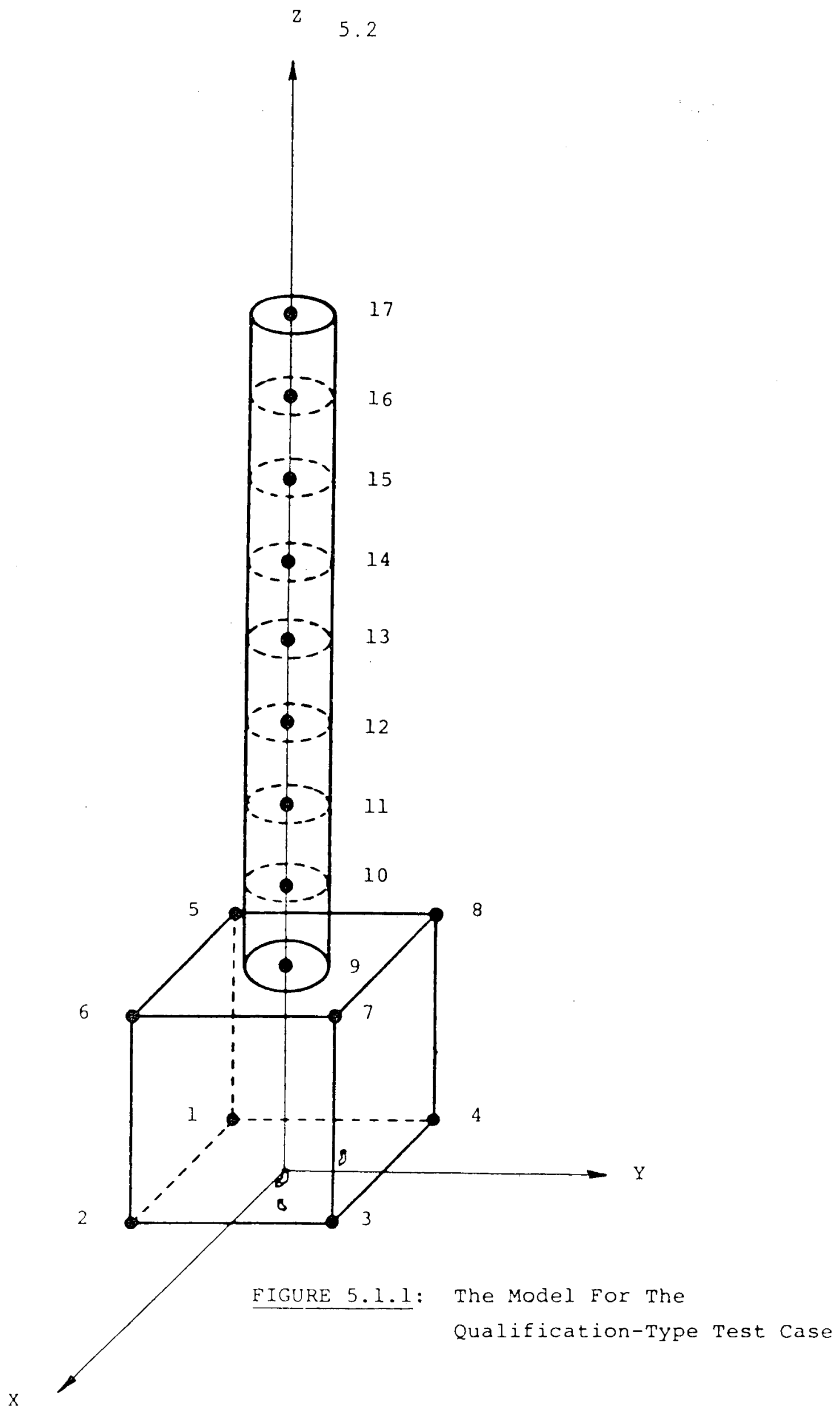



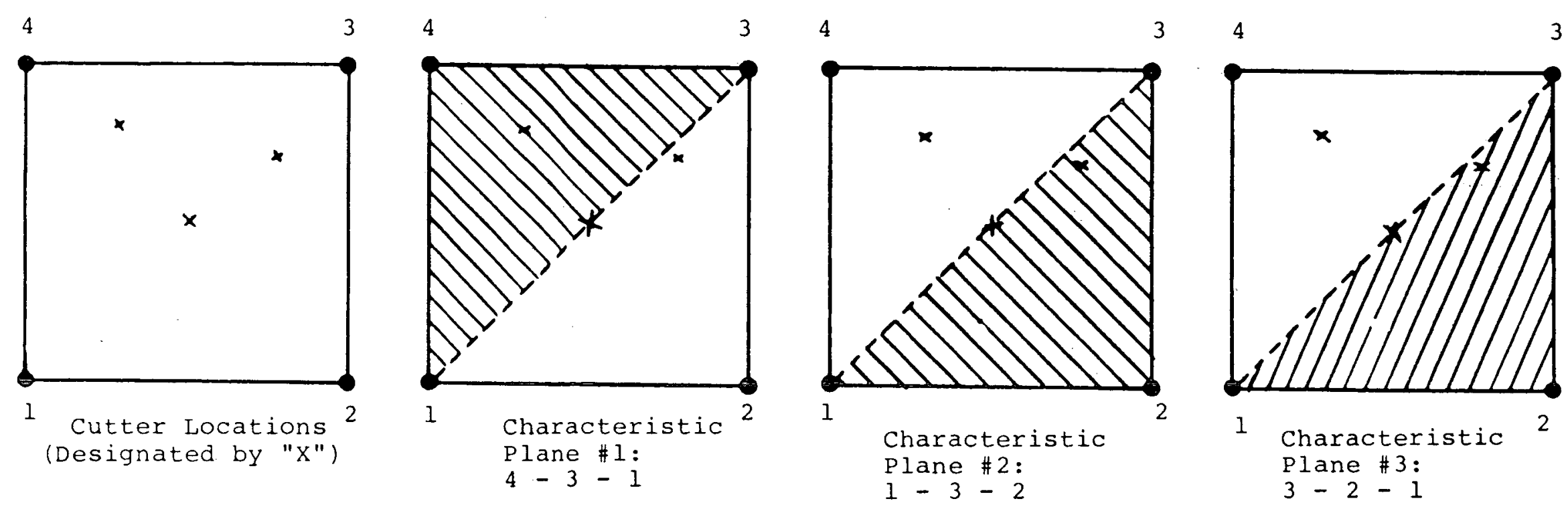

FIGURE 5.1.2: Characteristic Planes for Qualification-Type Test Case 
RUN GEOIN

FILE NAME FQF INFUT DATA?

INGEN

FILE NAME FQR DUTFUT DATA?

QUTGEN

THE GEODYN PROGRAM CURFENTLY ALLOWS THE USER TO EXERCISE TWO FUNCTIONS :

1 - THE GENERATION OR MODIFICATION OF A DRILL STRING MODEL ( GENDYN) ( FINITE ELEMENTS, BOUNDARY SPRINGS, OR GHOST CUTTERS )

2 - THE EXECUTION OF A SOLUTION FOR THE DRILL STRING MODEL. ( RUNUYN ) LOADS, TIME STEPS, NUMBER OF MODES CONSILERED, AND FORMATION PROPERTIES MAY ALL BE MOIIFIED WITH THIS OPTION.

$==\Rightarrow$ CHOOSE FLINCTION 1 OR 2 :

DO. YOU WISH TO PERFORM FUNCTION 2 ? (YES/NO - NO EXECUTES (1) )

$?$

No

$?$

IS THIS THE INITIAL EXECUTION OF GENDYN? ( RESFOND YES OR NO )

YES

THIS PROGRAM CAN GENERATE BOTH A LUMPED AND CONSISTANT MASS MATRIX.

$?$

DO YOU WISH TO LISE A LUMFED MASS REPRESENTATION? (YES/NO)

YES

ENTER THE TITLE FOR THIS RIJN -

$?$

UP TO SO CHARACTERS OF INFIT WILL BE ACCEPTED.

EXAMFLE OF GENDYN INPUT FOR DRILL STRING WITH 3 CUTTERS - 11/30183

ENTER THE TOTAL NIMMER DF ELEMENTS IN THE MOLIEL

INCLUDE 8-NODE ERICKS, FORMATIDN BRICKS (IF IJEEU), EEAMS, AND GHIIST CIJTTERS

$?$

DO NOT INCLUDE DISIERETE FOINTS

12 
ENTER THE NIMMBER OF ELEMENT TYFES WHICH WILL EE LISED IN MOUEL :

TYFES INILUDE AN S-NOLE BRICK, A FORMATION IISCRETE FUINT OR ZO-NOIE BRIICK

$?$

3

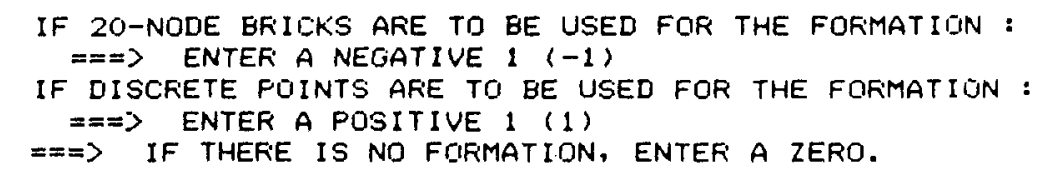

IF 20-NODE BFIICKS ARE TO BE USED FOR THE FORMATION : $==\Rightarrow$ ENTEF A NEGATIVE $1(-1)$

IF DISCRETE FOINTS ARE TO BE USED FOR THE FORMATION : $==\Rightarrow$ ENTER A POSITIVE 1 (1) $==\Rightarrow$ IF THERE IS NO FGIRMATION, ENTEF A ZERO. $?$

ENTER THE ELEMENT IDENTIFICATION CODE FOR ELEMENTS CONTAINED IN MODEL : ENTER 1 FQR AN 8-NODE 3-D BRICK

ENTER 2 FUR FORMATION 2O-NODE BFICK OR DISCFETE POINT

ENTER 3 FUR A LINEAR 3-D EEAM

$?$

ENTER 4 FOR A GHOST CUTTER GEOM SUB-ELEMENT

ENTER APPROPRIATE ID CODE FOR ELEMENT TYFE

1

ENTER APFROFRIATE ID CODE FOR ELEMENT TYPE

3

$?$

$?$

1

$?$

ENTER THE NUMBER OF FORMATION 20-NODE BRICKS IN MODEL

0

ENTER THE NUMBER OF GHOST CUTTERS USED IN THE MODEL

3

ENTER THE NIMMER OF NDUES CONTAINED IN THE FGRMATION SUB-MUDEL

IF IISCFETE FOINTS AFE USED ENTER ZERO

$?$

ENTER THE NUMBER OF BRICK NODES CONTAINEII IN THE DRILL STFING SUB-MOUEL 


\section{6}

2

9

$?$

$?$

8

$?$

$?$

1

$?$

$?$

3

$?$

4

$?$

$-5$

?

I

?

0

$?$

2

ENTER THE NIJMBER IJF DIFFERENT TYFES OF GHOST CUTTERS UTILIZED

NOTE DIFFEFENT LENGTHS UD NDT CIONSTITUTE IIFFERENT TYFES

LENGTHS HANILED SEFARATELY

FOLLOWING INPUT WILL BE IITILIZED TO FEFFRIFM EONSTRAINT TYING

ENTER THE NUMBER OF GHOST TOUTH GEIMMETRY SIIB-NOLES IISELI ON THE EIT

ENTER THE MAXIMUM NUMBER OF NODES ANY ELEMENT MAY CONTAIN

ENTER FOSITIONAL CODE IDENTIFICATION FOR MODEL IDEALIZATION

ENTER A FOSITIVE 1 IF $3-D$ BRICKS ARE USED IN EIT: A - 1 IF NOT

ENTER A 2 IF 3-D BRICKS ARE USED IN FORMATION CHARACTERIZATION; A -2 IF NOT

ENTER A 3 IF 3-D BEAMS ARE USED IN DRILL STRING; A -3 IF NOT,

ENTER A 4 IF A GHOST TOOTH IDEALIZATION IS INCLUDED; A -4 IF NOT

ENTER A 5 IF INFINITE ELEMENTS ARE UTILIZED; A -5 IF NOT

ENTER THE NUMBER OF DIFFERENT MATERIALS USED TO DEFINE BIT ELEMENTS

ENTER THE NUMBER OF DIFFERENT MATERIAL TYPES USED IN FORMATION EITHER FOR DISCRETE POINTS OR 2O-NODE BRICK

ENTER THE NIJMBER OF DIFFERENT BEAM SECTIONS IN THE LRILL STRINIS

ENTEF THE NUMBEF OF BEAM NDDES CONTAINEI IN THE DFILL STRING SULB-MODEL 


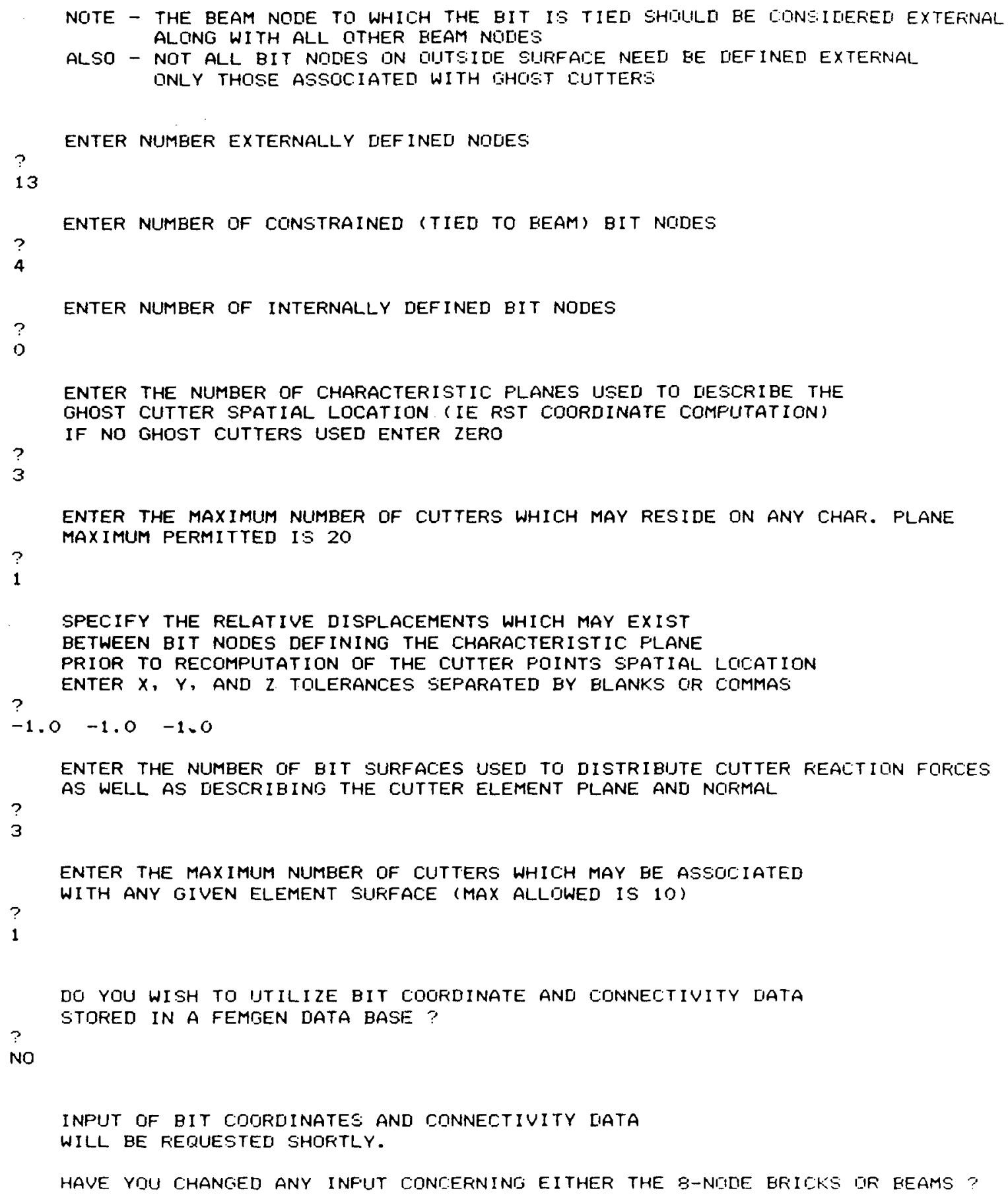


IF SO THEY WILL EFFECT THE FINITE ELEMENT MOUEL AND MOLAL ILIEALIZATION CHANGES IN GHOST CLITTER DESCRIPTILINS LIUN T LHANGE THE FINITE ELEMENT MODEL $?$ REFLY YES IF FINITE ELEMENT MIDDEL WILL EE EFFECTED

YES

NEW FINITE ELEMENT MODEL MASS, STIFFNESS, AND EIGENSYSTEM MATRICES WILL BE GENERATED AND SAVED AS FILES MAKE SUIRE FILE SPACE IS AVAILABLE

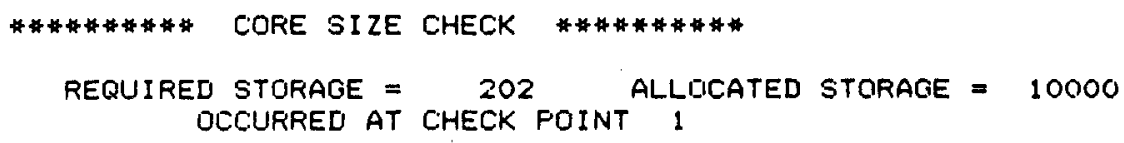

$====\Rightarrow$ ENTER ELEMENT CHARACTERIZATION DATA FOR PROPOSED SUB-MODELS : DATA TO INCLUDE ELEMENT NUMBER, TYPE OF ELEMENT, SUB-MODEL ID, AND MAT. ID.

ENTER DATA IN THE FOLLOWING ORDER, USING THE DESIGNATED CDDE BELOW:

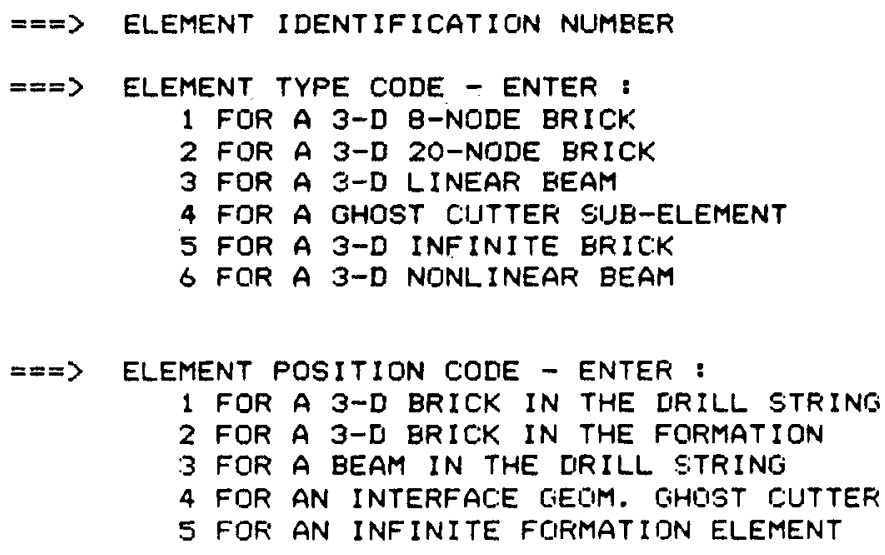


C NOTE $>$ IF DISCRETE POINTS ARE BEING UISED FOR FORMATIIIN ILIEALIZATIUN THEY ARE NOT INCLLIDED IN THIS DESCRIPTION.

THEREFCIRE INCLUDE GINLY 8-NODE, BEAM, AND GHUST CUTTEFS.

ENTER ELEMENT NUIMBER FOR INPUT

$?$

1

$?$

1

?

?

1

$=\Rightarrow$ COLUMN 1 OF MELDAT CONTAINS INFUT ELEMENT NUM $=1$ TYPE $=1$ POSITION $=1$ MATL ID $=1$

ENTER ELEMENT NUMBER FOR INPUT

?

2

$?$

3

$?$

1

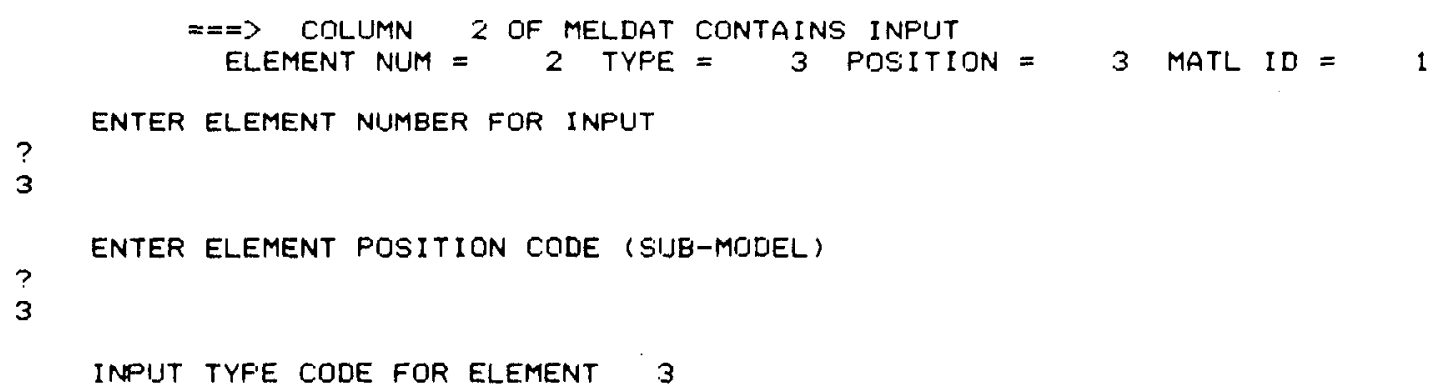


$?$

3

?

2

$$
==\Rightarrow \text { COLUMN } 3 \text { OF MELDAT CONTAINS INPUT }
$$

ELEMENT NUM $=3$ TYPE $=3$ FOSITION $=3$ MATL ID $=2$

?

$?$

$?$

$?$

2

$===>\quad$ COLUMN ELEMENT NUM $=$

OF MELLAT CONTAINS INFUT 4 TYPE $=3$ POSITION $=$

ENTER ELEMENT NUMBER FOR INPUT

ENTER ELEMENT POSITION CODE (SUB-MODEL)

$?$

3

$?$

3

INPUT MATERIAL ID CODE FOR ELEMENT 5

$?$

$$
===>\text { COLUMN } 5 \text { OF MELDAT CONTAINS INPUT }
$$$$
\text { ELEMENT NUM }=5 \text { TYFE }=3 \text { PGIITION }
$$

ENTER ELEMENT NUMEER FCIR INFUT

$?$

ENTER ELEMENT POSITION CODE (SUB-MODEL) 
INPUT TYFE DODE FOR ELEMENT 6

INPUT MATERIAL ID CODE FOR ELEMENT 6

$===>$ COLUMN 6 OF MELDAT CONTAINS INFIJT

ELEMENT NUM $=3$ TYFE $=3$ FOSITION $=3$ MATL ID $=2$

ENTER ELEMENT NUMBER FGR INPUT

$?$

$?$

ENTER ELEMENT POSITION CODE (SUB-MODEL)

3

$?$

INPUT TYPE CODE FOR ELEMENT 7

3

INPUT MATERIAL ID CODE FOR ELEMENT 7

$?$

$===>$ COLUMN 7 OF MELDAT CONTAINS INFIUT ELEMENT NUM $=7$ TYPE $=3$ POSITION $=3$ MATL $1 D=2$

ENTER ELEMENT NUMBER FOR INPUT.

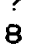

ENTER ELEMENT POSITION CODE (SUB-MODEL)

3

$?$

INPUT TYPE CODE FOR ELEMENT 8

3

INPUT MATERIAL ID CODE FOR ELEMENT 8

2

$==\Rightarrow$ COLUMN $\&$ OF MELDAT LONTAINS INFUT

ELEMENT NIJM $=8$ TYFE $=3$ FDSITION $=3$ MATL ID $=2$

ENTER ELEMENT NUMEER FOR INPUT

$?$ 
$?$

3

$?$

$?$

2

ENTER ELEMENT NUMBER FGR INPUT

i

$?$

ENTER ELEMENT POSITION CODE (SUB-MODEL)

4

?

$?$

1

$==\Rightarrow$ COLUMN 10 OF MELDAT CONTAINS INFUT

ELEMENT NUM $=1$ TYPE $=4$ POSITION $=4$ MATL $I D=1$

ENTER ELEMENT NUMBER FOR INPUT

$\dot{2}$

ENTER ELEMENT POSITION CODE (SUB-MODEL)

$?$

$?$

4

$?$

INPUT MATERIAL ID CODE FOR ELEMENT 2

$==\Rightarrow$ COLUMN 11 OF MELDAT CONTAINS INPUT

ELEMENT NUM $=2$ TYPE $=4$ POSITION

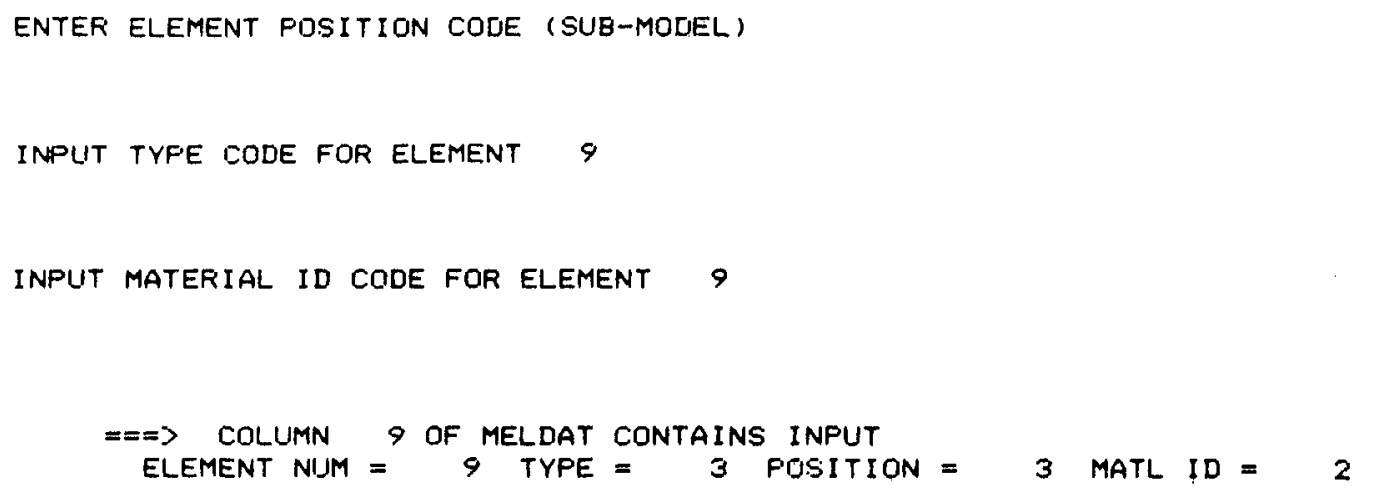

$==\Rightarrow$ COLUMN 9 OF MELDAT CONTAINS INPUT

ELEMENT NIMM $=9$ TYPE $=3$ POSITION $=3$ MATL ID $=2$ 
ENTER ELEMENT NUMBER FGR INPUT

$?$

ENTER ELEMENT POSITION CODE (SUE-MODEL)

4

INPUT TYPE CODE FOR ELEMENT 3

4

INPUT MATERIAL ID CODE FOR ELEMENT 3

$?$

$==>$ COLUMN 12 OF MELDAT CONTAINS INPUT

ELEMENT NUM $=3$ TYPE $=4$ POSITION $=4$ MATL ID $=1$

HAVE YOU CHANGED ANY INPUT CONCERNING EITHER THE 8-NODE BRICKS OR BEAMS ? IF SO THEY WILL EFFECT THE FINITE ELEMENT MODEL AND MODAL IDEALIZATION

CHANGES IN GHOST CUTTER DESCRIPTIONS DON'T CHANGE THE FINITE ELEMENT MODEL $?$ REPLY YES IF FINITE ELEMENT MODEL WILL BE EFFECTED

YES

NEW FINITE ELEMENT MODEL MASS, STIFFNESS, AND EIGENSYSTEM MATRICES WILL BE GENERATED AND SAVED AS FILES

MAKE SURE FILE SPACE IS AVAILABLE

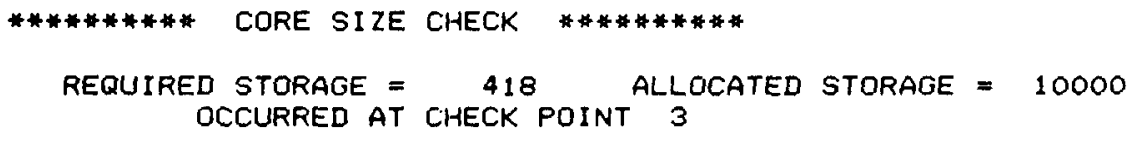

****************** BIT MATERIAL PRDPERTIES

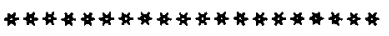

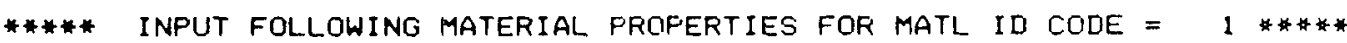 YOUNG'S MODULUS IN (FSI) POISSCN RATIO (NO UNITS) MATERIAL UNIT WEIGHT (LBS/CUBIC FODT)

$?$

ENTER YOUNG'S MODULUS

3. OE7

ENTER POISSON RATIO 
$?$

0.3

ENTER MATERIAL UNIT WEIGHT

$?$

26.1 .636

YES

YOUNG'S MODULUS INPUT $=0.3000000 E+08$

POISSON RATIO INPUT $=0.3000000 E+00$

UNIT WEIGHT INPUT $=0.2616360 E+03$

ARE ALL OF THESE ELEMENT PROPERTIES CORRECT (YES OR NO)?

***************** BEAM MATERIAL PROPERTIES

**** INPUT FOLLOWING MATERIAL PROPERTIES FOR MATL ID CODE

LENGTH IN (FT.)

OUTSIDE DIAMETER IN (IN.)

INSIDE DIAMETER IN (IN.)

YOUNG'S MODULUS IN (PSI)

POISSON RATIO (NO UNITS)

MATERIAL UNIT WEIGHT (LBS/CUBIC FOOT)

$?$

ENTER LENGTH

0.6121

$?$

ENTER OUTSIDE DIAMETER

5.5

$?$

ENTER INSIDE DIAMETER

2.6

ENTER YOUNG'S MODULUS

3. OE7

ENTER POISSON RATIO

$?$

0.3

$?$

ENTER MATERIAL UNIT WEIGHT

489.0

LENGTH INPUT (FT.) $=0.6121000 E+00$

OUTSIDE DIAMETER (IN.) $=0.5500000 E+01$ 


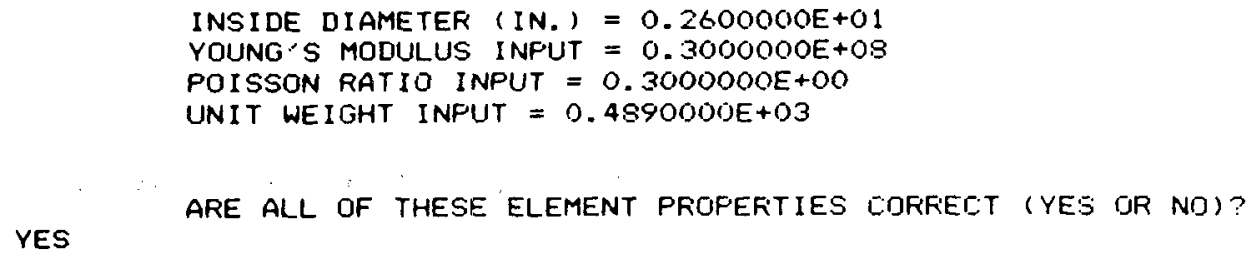

******************** BEAM MATERIAL PROPERTIES

**** INPUT FOLLOWING MATERIAL PROPERTIES FOR MATL ID LDDE = $2 * * * *$ LENGTH IN (FT.) OUTSIDE DIAMETER IN (IN.)

INSIDE DIAMETER IN (IN.)

YOUNG'S MODULUS IN (PSI)

POISSON RATIO (NO UNITS)

MATERIAL UNIT WEIGHT (LBS/CUBIC FOOT)

\section{$?$ \\ 0.61905}

ENTER LENGTH

$?$

ENTER OUTSIDE DIAMETER

4.25

$?$

ENTER INSIDE DIAMETER

1.5

ENTER YOUNG'S MODURUS

3. OE7

$?$

ENTER POISSON RATIO

0.3

$?$

ENTER MATERIAL UNIT WEIGHT

489.0

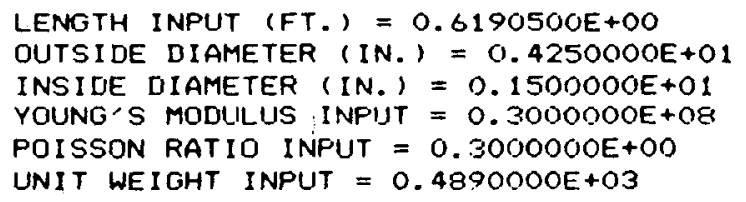




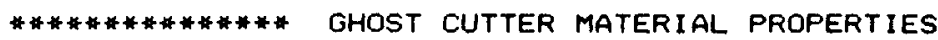

**** INPUT FOLLOWING MATERIAL PROPERTIES FOR MATL ID CODE = CROSS SECTION IN (IN.**2)

MOMENT DF INERTIA IN (IN. *\#4)

POLAR MOMENT OF INERTIA IN (IN. \#4)

YOUNG'S MODULUS IN (PSI)

POISSON RATIO (NO UNITS)

YIELD STRENGTH IN (PSI)

\section{$?$}

ENTER CROSS-SECTIONAL AREA

0.4418

$?$

ENTER MOMENT OF INERTIA

1.0

$?$

ENTER PQLAR MOMENT OF INERTIA

1.0

$?$

ENTER YOUNG'S MODULUS

3. OE7

$?$

ENTER POISSON RATIO

0.3

?

ENTER YIELD STRENGTH

36000.0

AREA INPUT (IN.**2) $=0.4418000 E+00$

I-MOMENT OF INERTIA $($ IN. $\# * 4)=0.1000000 E+01$

$J$-POLAR MOMENT OF INERTIA (IN.**4) $=0.1000000 E+01$

YOUNG'S MODULUS INFUT (PSI) $=0.3000000 E+08$

POISSON RATIO INPUT $=0.3000000 E+00$

YIELD STRENGTH INPUT $(P S I)=0.3600000 E+05$

YES

ARE ALL OF THESE ELEMENT PROPERTIES CORFECT (YES OR NO)? 
THE GHOST CUTTER BREAK-OFF MECHANISM REQUIRES INFUT

OF A LENGTH OF EACH CUTTER.

INFUT THE LENGTH FOR GHOST DUTTER, 1

$?$

1.2

INPUT THE LENGTH FOR GHOST CUTTER, 2

$?$

1.2

INPUT THE LENGTH FOR GHOST CUTTER, 3

$?$

0.0

HAVE YOU CHANGED ANY INPUT CONCERNING EITHER THE 8-NODE BRICKS OR BEAMS? IF SO THEY WILL EFFECT THE FINITE ELEMENT MODEL AND MODAL IDEALIZATION CHANGES IN GHOST CUTTER DESCRIPTIONS DON'T CHANGE THE FINITE ELEMENT MODEL REPLY YES IF FINITE ELEMENT MODEL WILL BE EFFECTED

$?$ YES

NEW FINITE ELEMENT MODEL MASS, STIFFNESS, AND EIGENSYSTEM MATRICES WILL BE GENERATED AND SAVED AS FILES

MAKE SURE FILE SPACE IS AVAILABLE

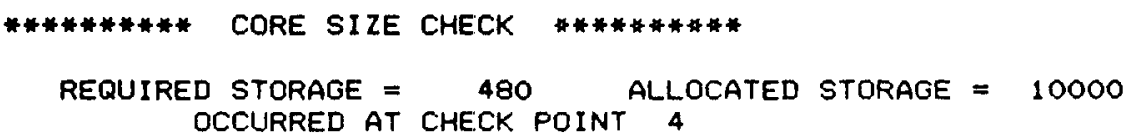

$===\Rightarrow \quad$ INPUT OF DRILL STRING COORDINATES

DO YOU WISH TO ENTER THE DRILL STRING ROTATIONAL COORDINATES SEPARATELY FROM THE DRILL STRING GLOBAL LOCATION COORDINATES ?

NO

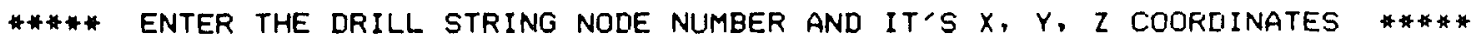
SEPARATE DIATA WITH BLANKS OR COMMAS

$?$

$\begin{array}{llll}1 & -4.0 & -4.0 & 0.0\end{array}$

$==\Rightarrow$ NODE $1 \quad x, \gamma, Z$ COORDINATES ARE :
$x$
$-4.0000$
$Y=$
$-4.0000$
$z=$
0.0000 
***** ENTER THE DRILL STRING NODE NUMBER AND IT'S X, Y, $z$ COORDINATES **** SEPARATE DATA WITH BLANKS OR COMMAS

$?$

$7 \quad 4.0 \quad 4.0 \quad 9.725$

$==\Rightarrow$ NODE $7 \quad X, Y, Z$ COORDINATES ARE :
$x=$
4. 0000
$Y=$
4. 0000
$z=$
9.7250

*** ENTER THE DRILl STRING NODE NUMBER AND IT'S $x, y, z$ COORDINATES ***** SEPARATE DATA WITH ELANKS OR COMMAS

$\stackrel{?}{8}$

$-4.0 \quad 4.0 \quad 9.725$

$==\Rightarrow$ NODE $8 \quad X, Y, Z$ COORDINATES ARE :
$x=$
$-4.0000$
$Y=$
4.0000
$z=$
9.7250
**** ENTER THE DRILL STRING NODE NUMBER AND IT'S $x, Y, z$ COORDINATES ***** SEPARATE DATA WITH BLANKS OR COMMAS
$?$
$90.0 \quad 0.0 \quad 9.725$
$==>$ NODE
$9 \quad X, Y, Z$ COORDINATES ARE :
$x=$
0.0000
$Y=$
0.0000
$z=$
9.7250

**** ENTER THE DRILL STRING NODE NUMBER AND IT'S $x, Y, Z$ CLORDINATES SEPARATE DATA WITH BLANKS OR COMMAS

$?$

$10 \quad 0.0 \quad 0.0 \quad 17.07$

$==2$ NODE $10 \quad X, Y, Z$ COORDINATES ARE :
$x=$
0.0000
$Y=$
0.0000
$\mathrm{Z}=$
17.0700

**** ENTER THE DRILL STRING NODE NUMBER AND IT'S $x, y, z$ COORDINATES SEPARATE DATA WITH BLANKS OR COMMAS

$?$ 0.0

$==\Rightarrow$ NODE $11 \quad X, Y, Z$ COORDINATES ARE :
$x=$
0.0000
$Y=$
0.0000
$z=$
24.4990 


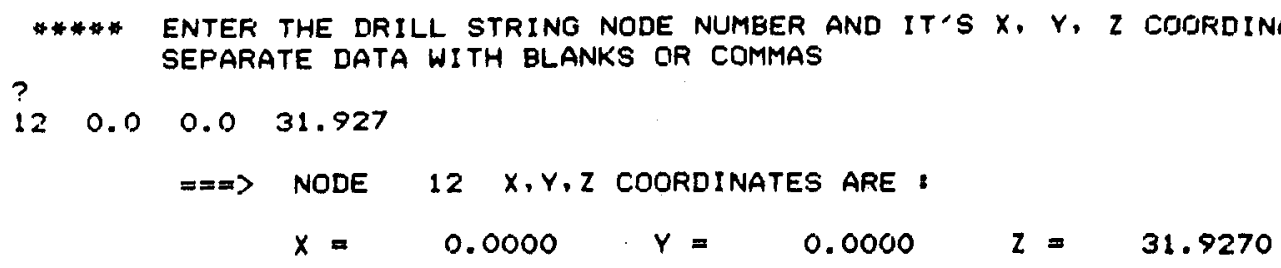

*** ENTER THE DRILL STRING NOdE NUMBER AND IT'S $x, y, z$ CDORDINATES $?$ SEPARATE DATA WITH BLANKS OR COMMAS

$\begin{array}{llll}13 & 0.0 & 0.0 & 39.356\end{array}$

$\Rightarrow \quad$ NODE $13 \quad x, Y, Z$ CODRDINATES ARE:
$x=$
0.0000
$Y=$
0.0000
$z=$
39.3560

** * ENTER THE DRILL STRING NODE NUMBER AND IT'S $X, Y, z$ COORDINATES SEPARATE DATA WITH BLANKS OR COMMAS

$?$

$14 \quad 0.0 \quad 0.0 \quad 46.784$

$==\Rightarrow$ NODE

$14 X, Y, Z$ COORDINATES ARE :
$x=$
0.0000
$Y=$
0.0000
$z=$
46.7840

**** ENTER THE DRILL STRING NODE NUMBER AND IT'S $x, Y, z$ COORDINATES SEPARATE DATA WITH BLANKS OR COMMAS

150.0
$0.0 \quad 54.213$
$==\Rightarrow \quad$ NODE
$15 X, Y, Z$ COORDINATES ARE :
$x=$
$0.0000 \quad Y=$
0.0000
$z=$
54.2130

*** ENTER THE DRILl STRING NODE NUMBER AND IT's $x, y, z$ COCRDINATES SEPARATE DATA WITH BLANKS OR COMMAS
$0.0 \quad 61.642$
$==\Rightarrow$ NODE $16 \quad X, Y, Z$ CODRDINATES ARE :

$$
X=0.0000, Y=0.0000 \quad Z=61.6420
$$

**** ENTER the DRILL STRING NODE NUMBER AND IT'S $x, y, z$ COORDinates SEPARATE DATA WITH BLANKS OR COMMAS 
$?$

$17 \quad 0.0 \quad 0.0 \quad \$ 9.07$

$===>$ NODE

$x=$

$17 X, Y, Z$ COORDINATES ARE :
0.0000

$z=$

69.0700

$==3==>$ INPUT OF GHOST CUTTER SUB-NODE COORDINATES

DO YOU WISH TO ENTER THE SUB-NODE ROTATIONAL COORDINATES SEPARATELY FROM THE SUB-NODE GLOBAL LOCATION COORDINATES ?

$?$

NO

* * ENTER the ghost tooth nOde nUmber and IT'S $x, y, z$ coordinates SEPARATE DATA WITH BLANKS OR COMMAS

$?$

$1-1.682 \quad 2.310 \quad 0.0$

$==\Rightarrow$ NODE $1 \quad X, Y, Z$ COORDINATES ARE :
$x=$
$-1.6820$
$Y=$
2.3100
$z=$
0.0000

**** ENTER THE GHOST TOOTH NODE NUMBER AND IT'S $x, y, z$ COORDINATES SEPARATE DATA WITH BLANKS OR COMMAS

?

$\begin{array}{llll}2 & -1.52685 & 2.40151 & -0.7694\end{array}$

$==\Rightarrow$ NODE $2 \quad X, Y, Z$ COORDINATES ARE :

$$
X=-1.5266 \quad Y=2.4015 \quad Z=-0.7694
$$

**** enter the ghost tooth nOde nUmber and It's $x, y, z$ CoORdinates *\#** SEPARATE DATA WITH BLANKS OR COMMAS

$?$

$\begin{array}{llll}3 & -1.36837 & 2.49474 & -0.2774\end{array}$

$===>$ NODE $3 \quad x, Y, Z$ COORDINATES ARE :

$$
X=-1.3684 \quad Y=\quad 2.4947 \quad Z=\quad-0.2774
$$

* * ENTER the ghost tooth nOde number and it's $x, y, z$ coordinates SEPARATE DATA WITH BLANKS OR COMMAS 
$0.0 \quad 0.0 \quad 0.0$

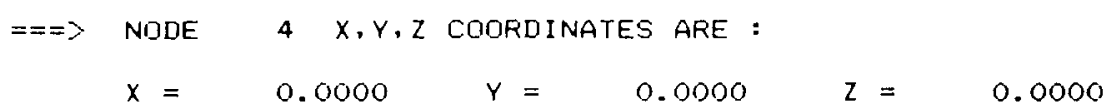

\footnotetext{
* * * ENTER THE ghOST TOOTH NODE NUMBER AND IT'S $x, y, Z$ COORDINATES *\#* * SEPARATE DATA WITH BLANK'S OR COMMAS

$\begin{array}{llll}? & 0.0 & 0.0 & -0.7294\end{array}$

$===>$ NODE $5 \quad X, Y, Z$ COORDINATES ARE :
$x=$
$0.0000 \quad Y=$
0.0000
$z=$
$-0.7294$

* ** ENTER THE GHOST TOOTH NODE NUMBER AND IT'S $X, Y, Z$ COORDINATES SEPARATE DATA WITH BLANKS OR COMMAS

$?$

$60.0 \quad 0.0 \quad-0.2374$

$==\Rightarrow \quad$ NODE

$6 \quad X, Y, Z$ COORDINATES ARE :

$X=0.0000 \quad Y=0.0000 \quad Z=-0.2374$

\footnotetext{
*** ENTER THE GHOST TOOTH NOdE NUMBER AND IT'S $X, Y, Z$ COORDINATES SEPARATE DATA WITH BLANKS OR COMMAS

$72.165 \quad 1.590 \quad 0.0$

$==\Rightarrow$ NODE $7 \quad X, Y, Z$ COORDINATES ARE :

$X=2.1650 \quad Y=1.5900 \quad Z=0.0000$
}

*** ENTER THE GHOST TGOTH NODE NUMBER AND IT'S $X, Y, Z$ COORDINATES **** SEPARATE DATA WITH BLANKS OR COMMAS

$?$

$\begin{array}{llll}8 & 2.25651 & 1.43465 & -0.7694\end{array}$

$==>$ NODE $8 \quad X, Y, Z$ COORDINATES ARE :

$X=2.2565 \quad Y=1.4346 \quad Z=-0.7694$

*** ENTER THE GHOST TOOTH NODE NUMEER AND IT'S $x, Y, z$ COORDINATES **\# * SEPARATE DATA WITH BLANKS OR COMMAS

$?$

$9 \quad 2.34974 \quad 1.27637 \quad-0.2774$ 


$$
\begin{array}{rlrrr}
=\Rightarrow & \text { NODE } & 9 & X, Y, Z \text { COORDINATES AFE : } & \\
& x= & 2.3497 \quad Y=\quad 1.2764 & Z=-0.2774
\end{array}
$$

HAVE YOU CHANGED ANY INPUT CONCERNING EITHER THE 8-NODE BRICKS OR EEAMS ? IF SO THEY WILL EFFECT THE FINITE ELEMENT MODEL AND MODAL IDEALIZATION CHANGES IN GHOST CUTTER DESCRIPTIONS DON'T CHANGE THE FINITE ELEMENT MODEL REPLY YES IF FINITE ELEMENT MODEL WILL BE EFFECTED YES

NEW FINITE ELEMENT MODEL MASS, STIFFNESS, AND EIGENSYSTEM MATRICES WILL BE GENERATED AND SAVED AS FILES

MAKE SURE FILE SPACE IS AVAILABLE

**** ENTER ELEMENT CONNECTIVITY INFORMATION FOR ALL 8-NODE BRICKS

DATA ENTERED WILL CONSIST OF THE ELEMENT NUMBER

FOLLOWED BY THE NODE NUMBERS CONSISTENT WITH LOCAL NUMBERING SCHEME

***** PLEASE REFER TO USERS MANUAL FOR CORRECT ORDER *****

ENTER ELEMENT NUMBER FOR INPUT

$?$

INPUT CONNECTIVITY DATA ( 8-NODES ) FOR ELEMENT SEPARATE DATA BY BLANKS OR COMMAS

$?$

$\begin{array}{llllllll}1 & 2 & 3 & 4 & 5 & 6 & 7 & 8\end{array}$

$==>$ ELEMENT

1

CONNECTIVITY IS :

1

2

3

4

5

6

7

8

**** ENTER ELEMENT CONNECTIVITY INFORMATION FOR ALL 3-D, LINEAR BEAMS *****

DATA ENTERED WILL CONSIST OF :

$==\Rightarrow$ ELEMENT NUMBER

$==\Rightarrow$ NODE NUMBERS DEF INING BEAM ELEMENT.

PLEASE REFER TO USERS MANUAL FOR CORRECT ORDER. 
ENTER ELEMENT NUMBER FGR INFUT

$?$

INPUT CONNECTIVITY DATA (BEAM) FOR ELEMENT SEPARATE DATA BY BLANKS OR COMMAS

2 IN PRESCRIBED ORDER

$?$

10

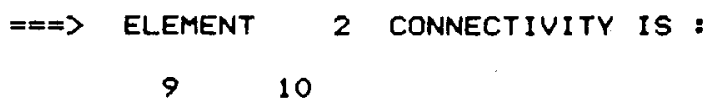

ENTER ELEMENT NUMBER FOR INPUT

3

INPUT CONNECTIVITY DATA (BEAM) FOR ELEMENT

3 IN PRESCRI BED ORDER $?$ SEPARATE DATA BY BLANKS OR COMMAS

1011

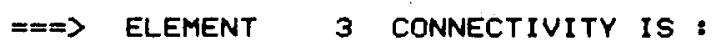

4 IN PRESCRIBED ORDER $?$

$11 \quad 12$

$===>$ ELEMENT 4 CONNECTIVITY IS :

$11 \quad 12$

ENTER ELEMENT NUMBER FOR INPUT

$\stackrel{?}{5}$

INPUT CONNECTIVITY DATA (BEAM) FOR ELEMENT

$?$ SEPARATE DATA BY ELANKS OR COMMAS

13

$==\Rightarrow$ ELEMENT 5 CONNECTIVITY IS :

$12 \quad 13$ 
$?$

s

INPUT CONNECTIVITY DATA (BEAM) FOR ELEMENT $?$

13

14

$==\Rightarrow$ ELEMENT 6 CONNECTIVITY IS :

$13 \quad 14$

ENTER ELEMENT NUMBER FOR INPUT

$?$

INPUT CONNECTIVITY DATA (BEAM) FOR ELEMENT SEPARATE DATA BY BLANKS OR COMMAS

7 IN PRESCRIEED ORDER

$?$

1415

$==\Rightarrow$ ELEMENT 7 CONNECTIVITY IS :

14

15

ENTER ELEMENT NUMBER FOR INPUT

$\stackrel{?}{8}$

INPUT CONNECTIVITY DATA (BEAM) FOR ELEMENT SEPARATE DATA BY BLANKS OR COMMAS

$?$

1516

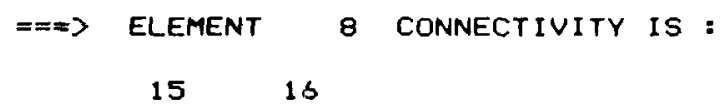

ENTER ELEMENT NUMBER FOR INPUT

?

INPUT CONNECTIVITY DATA (BEAM) FOR ELEMENT SEPARATE DATA BY BLANKS OR COMMAS

$?$

$16 \quad 17$

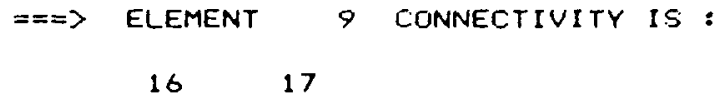


*** * ENTER GHOST CUTTER DEFINITION INFORMATION ****

DATA ENTERED WILL CONSIST OF :

$==\Rightarrow$ CUTTER NUMBER

$==\Rightarrow$ THE PRIMARY BIT F.E. NODE NUMBER

$==\Rightarrow$ THE CUTTER SUB-NODE AT INTERSECTION BIT SURFACE

$==\Rightarrow$ THE CUTTER SUB-NODE AT TOP OF BLANK

$===>$ THE CUTTER SUB-NODE AT BOTTUM OF BLANK

¿SEE USER MANUAL FOR BETTER DEFINITION>

$?$

ENTER GHOST CUTTER SUB-ELEMENT NUMEER

INPUT DEFINITION ARRAY DATA FOR CUTTER

1 IN PRESCRIBED ORDER SEPARATE DATA BY BLANKS OR COMMAS

$?$

4123

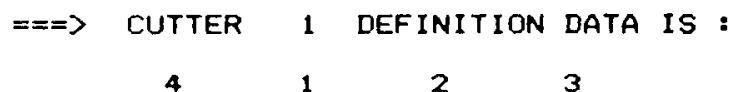

ENTER GHOST CUTTER SUB-ELEMENT NUMBER

$?$

INPIJT DEFINITION ARRAY DATA FOR CUTTER 2 IN PRESCRIBED ORDER SEPARATE DATA BY BLANKS OR COMMAS

$?$

456

$===>$

CUTTER

1

2

DEFINITION DATA IS:

5

6

ENTER GHOST CUTTER SUB-ELEMENT NUMBER

$?$

3

INPUT DEFINITION ARRAY DATA FOR CUTTER 3 IN FRESCRIBED ORDER SEPARATE DATA BY BLANKS OR COMMAS

$?$

$\begin{array}{llll}3 & 7 & 8 & 9\end{array}$

$===$ CUTTER 3 DEFINITION DATA IS : 
DATA ENTERED WILL CONSIST OF :

$==\Rightarrow$ CHARACTERIST IC PLANE NUMBER

$==\Rightarrow$ THE THREE BIT F.E. NODES DESCRIBING THE PLANE

$==\Rightarrow$ THE GHOST CUTTER NUMBERS LOCATED ON THE PLANE

AFTER IDENTIFYING ALL CUTTERS ON A PLANE, ENTER A ZERO OR A NEGATIVE NUMBER TO SIGNIFY COMPLETION OF INPUT DATA FOR THAT PLANE.

?

1

INPUT THE BIT F.E. NODE NUMBERS DEFINING CHARACTERISTIC PLANE NUMBER 1 SEPARATE DATA BY BLANKS OR COMMAS

?

431

INPUT THE GHOST CUTTER NUMBERS WHICH DCCUR ON THIS PLANE. TO EXIT INPUT MODE ENTER ZERO OR NEGATIVE NUMBER.

CUTTER ENTRY 1 IS CUTTER NUMBER:

1

$===>$ CHARACTERISTIC PLANE 1 DATA IS

4

3

1

1

ENTER CHARACTERISTIC PLANE NUMBER

$?$

INPUT THE BIT F.E. NODE NUMBERS DEFINING CHARACTERISTIC PLANE NUMBER SEPARATE DATA BY BLANKS OR COMMAS

2

INPUT THE GHOST CUTTER NUMBERS WHICH OCCUR ON THIS PLANE. TO EXIT INPUT MODE ENTER ZERO OR NEGATIVE NUMBER. 
CUTTER ENTRY 1 IS CUTTER NUMBER:

2

$==\Rightarrow$ CHARACTERISTIC PLANE 2 DATA IS

$12 \quad 2 \quad 2$

ENTER CHARACTERISTIC PLANE NUMBER

INPUT THE BIT F.E. NODE NUMBERS DEFINING CHARACTERISTIC PLANE NUMBER $?$

321

INPUT THE GHOST CUTTER NUMBERS WHICH OCCUR ON THIS PLANE. TO EXIT INPUT MODE ENTER ZERO OR NEGATIVE NUMBER.

$?$

CUTTER ENTRY 1 IS CUTTER NUMBER:

3

$==\Rightarrow$ CHARACTERISTIC PLANE 3 DATA IS

$\begin{array}{llll}3 & 2 & 1 & 3\end{array}$

*** ENTER bit hOUSING surface definition aRRAY INFo. ****

DATA ENTERED WILL CONSIST OF :

$==\Rightarrow$ FOUR BIT NODE NUMBERS DEFINING SURFACE

( ENTER A ZERO FOR 4-TH IF ON SURFACE OF WEDGE)

$==>$ THE GHOST CUTTER NUMBERS LOCATED ON THE SURFACE

( MAXIMUM OF 1 CUTTERS ON SURFACE PERMITTED)

AFTER IDENTIFYING ALL CUTTERS ON A SURFACE, ENTER A ZERO OR A

NEGATIVE NUMBER TO SIGNIFY COMPLETION OIF INPUT IIATA FOR THAT SLIRFACE.

ENTER THE BIT F.E. NODE NUMBERS DEF INING THE SURFACE

SEPARATE BY BLANKS OR COMMAS

ENTER A ZERO FOR NON-EXISTENT NODE

4321 


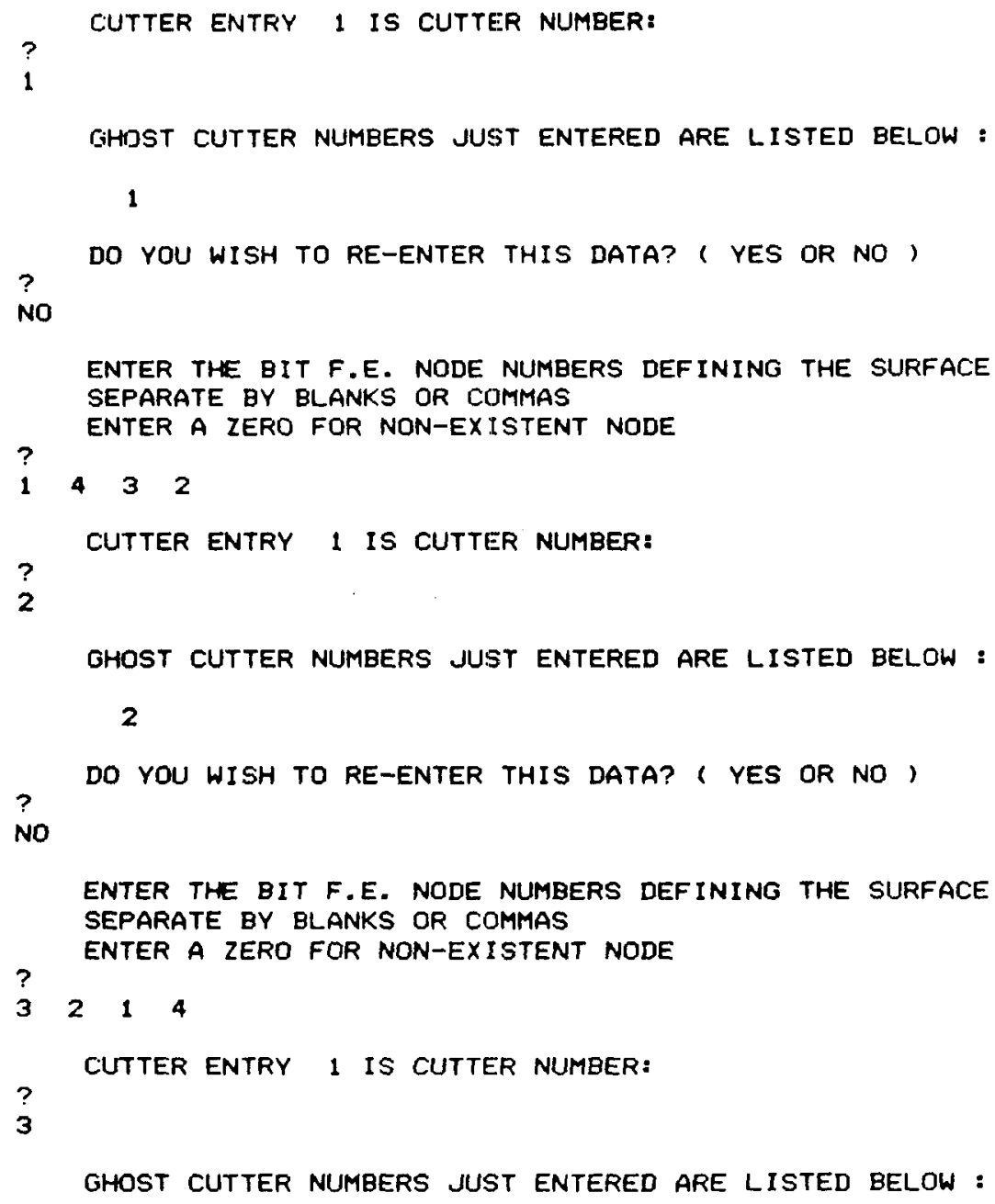


WILL BE GENERATED AND SAVED AS FILES

MAKE SURE FILE SPACE IS AVAILAELE

$==\Rightarrow$ INPUT THE BOUNDARY $X, Y, Z$ TRANSLATION SFRING CONSTANTS FOR NODE 17 SEPARATE INPUT WITH BLANKS OR COMMAS

$?$

$2769.2 \quad 2769.2 \quad 10031.0$

UPPERMOST BEAM NODE 17 HAS TRANSLATIONAL SPRING CONSTANTS

$X$ - TRANSLATION $=0.2769200 E+04$

$Y$ - TRANSLATION $=0.2769200 E+04$

$Z$ - TRANSLATION $=0.1003100 E+05$

$==\Rightarrow$ INPUT THE BOUNDARY $X, Y, Z$ ROTATIONAL SPRING CONSTANTS FOR NODE SEPARATE INPUT WITH BLANKS OR COMMAS

$?$

$50934.0 \quad 50934.09795 .6$

UPPERMOST BEAM NODE 17 HAS ROTATIONAL SPRING CONSTANTS

$X$ - ROTATIONAL $=0.5093400 E+05$

$Y-$ ROTATIONAL $=0.5093400 E+05$

$Z$ - ROTATIONAL $=0.9795600 E+04$

DO YOU WISH TO RE-ENTER ANY OF THIS DATA? (YES/NO)

$?$

NO

HAVE YOU CHANGED ANY INPUT CONCERNING EITHER THE 8-NODE BRICKS OR BEAMS? IF SO THEY WILL EFFECT THE FINITE ELEMENT MODEL AND MODAL IDEAL IZATION CHANGES IN CHOST CUTTER DESCRIPTIONS DON'T CHANGE THE FINITE ELEMENT MODEI REPLY YES IF FINITE ELEMENT MGDEL WILL BE EFFECTED

YES

NEW FINITE ELEMENT MODEL MASS, STIFFNESS, AND EIGENSYSTEM MATRICES

WILL BE GENERATED AND SAVED AS FILES

MAKE SURE FILE SPACE IS AVAILABLE

******** CORE SIZE CHECK \#*\#****** 
REQUIRED STORAGE $=438$ ALLOCATED STORAGE $=10000$ OCCURRED AT CHECK POINT 5

$=====>$ DEFINE THE EXTERNAL NODES :

$==\Rightarrow$ USER HAS SPECIFIED THAT 13 NODES ARE EXTERNAL. A NODE NUMBER MUST BE ENTERED EACH TIME ONE IS REQUESTED BELOW. REMEMBER THAT ALL BEAM NODES ARE EXTERNAL ! 
$?$

15

$?$

16

$?$

17

$====\Rightarrow$ DEFINE THE TIED BIT NODES :

$m=\$$ USER HAS SPECIFIED THAT 4 NODES ARE TIED TO BEAM. A NODE NUMBER MUST BE ENTERED EACH TIME ONE IS REQUESTED BELOW.

ENTER A TIED BIT NODE NUMBER (ENTRY * 1 )

$\stackrel{?}{\mathbf{s}}$

ENTER A TIED BIT NODE NUMBER (ENTRY 2 ,

$?$

ENTER A TIED BIT NODE NUMBER (ENTRY *3 )

$?$

$\stackrel{?}{8}$

ENTER A TIED BIT NODE NUMBER (ENTRY * 4 )

$==m==>$ DEF INE THE INTERNAL NODES :

$==\Rightarrow$ USER HAS SPECIFIED THAT O NODES ARE INTERNAL.

A NODE NUMBER MUST BE ENTERED EACH TIME ONE IS REQUESTED BELOW.

PLEASE INPUT THE NUMBER WHICH YOU WISH TO DIVIDE EACH TERM OF THE STIFFNESS MATRIX BY ( "NORMALI ZATION FACTOR",

?

1000.0 
HAVE YOU CHANGED ANY INTERNAL/EXTERNAL NODE DEFINITIONS OR THE LIST OF TIED NODES ? (YES/NO)

$?$ YES

NEW FINITE ELEMENT MODEL WILL BE MADE FOR NEW [K] AND [M].

********* CORE SIZE CHECK

REQUIRED STORAGE := 630 OCCURRED AT CHECK POINT 6
2468

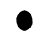


The actual input file generated by the preceding interactive input session is listed below. Note that because this data file was generated and listed on a VAX computer, the first column of data does not get printed. Consequently, a line which says "O" is really "NO", and a line that says "ES" is really "YES". 
TYPE INGEN. DAT

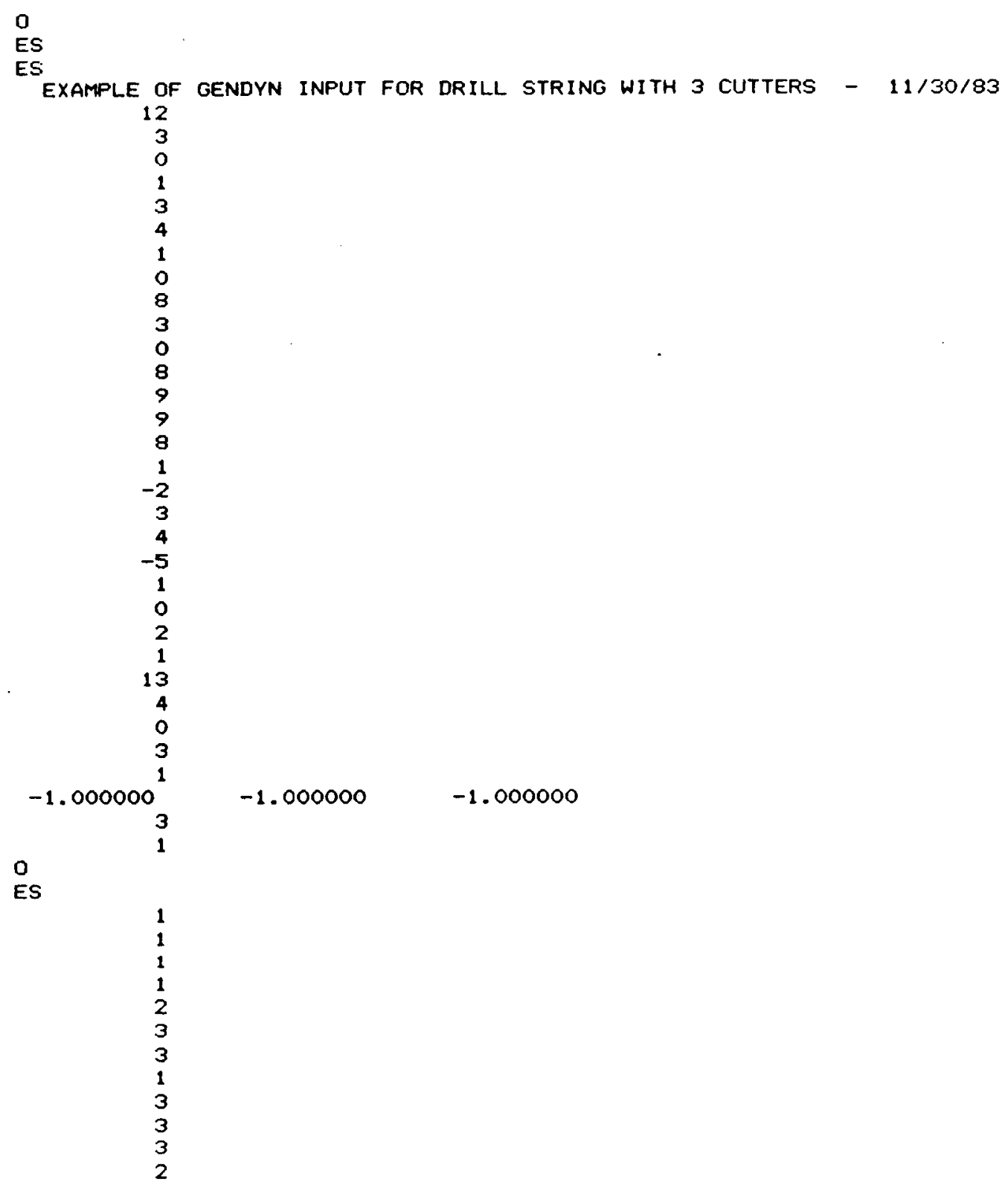


1.000000

3. $0000000 E+07$

0.3000000

ES

36000.00

1. 200000

1.200000

$0.0000000 E+00$

ES

0

o

$\begin{array}{cc}1 & -4.000000 \\ 2 & 4.000000 \\ 3 & 4.000000 \\ 4 & -4.000000 \\ 5 & -4.000000 \\ 6 & 4.000000 \\ 7 & 4.000000 \\ 8 & -4.000000 \\ 9 & 0.0000000 E+00 \\ 0.0000000 E+00 \\ 1 & 0.0000000 E+00 \\ 2 & 0.0000000 E+00 \\ 3 & 0.0000000 E+00 \\ 4 & 0.0000000 E+00 \\ 5 & 0.0000000 E+00 \\ 6 & 0.0000000 E+00 \\ 7 & 0.0000000 E+00\end{array}$

$-4.000000$

$-4.000000$

4. 000000

4.000000

$-4.000000$

$-4.000000$

4.000000

4. 000000

$0.0000000 E+00$

$0.0000000 E+00$

$0.0000000 E+00$

$0.0000000 E+00$

$0.0000000 E+00$

$0.0000000 E+00$

$0.0000000 E+00$

$0.0000000 E+00$

$0.0000000 E+00$

$0.0000000 E+00$

$0.0000000 E+00$

$0.0000000 E+00$

9.725000

9.725000

9.725000

9.725000

9.725000

17.07000

24.49900

31.92700

39.35600

46.78400

54.21300

61.64200

$0.0000000 E+00 \quad 69.07000$

$1-1.682000$

$-1.526650$

$-1.368370$

$0.0000000 E+C 0$

2. 310000

2.401510

$0.0000000 E+00$

2.494740

$-0.7694000$

$0.0000000 E+00$

$-0.2774000$

$0.0000000 E+C O$

$0.0000000 E+C 10$

$0.0000000 E+00$

$0.0000000 E+00$

2.165000

2. 256510

$0.0000000 E+00$

$-0.7294000$

1.590000

1.434650

$0.0000000 E+00$

ES

2. 349740

1.276370

$-0.7694000$

$-0.2774000$

3

4

5

6

10

11

12

13

14

15

16

17 


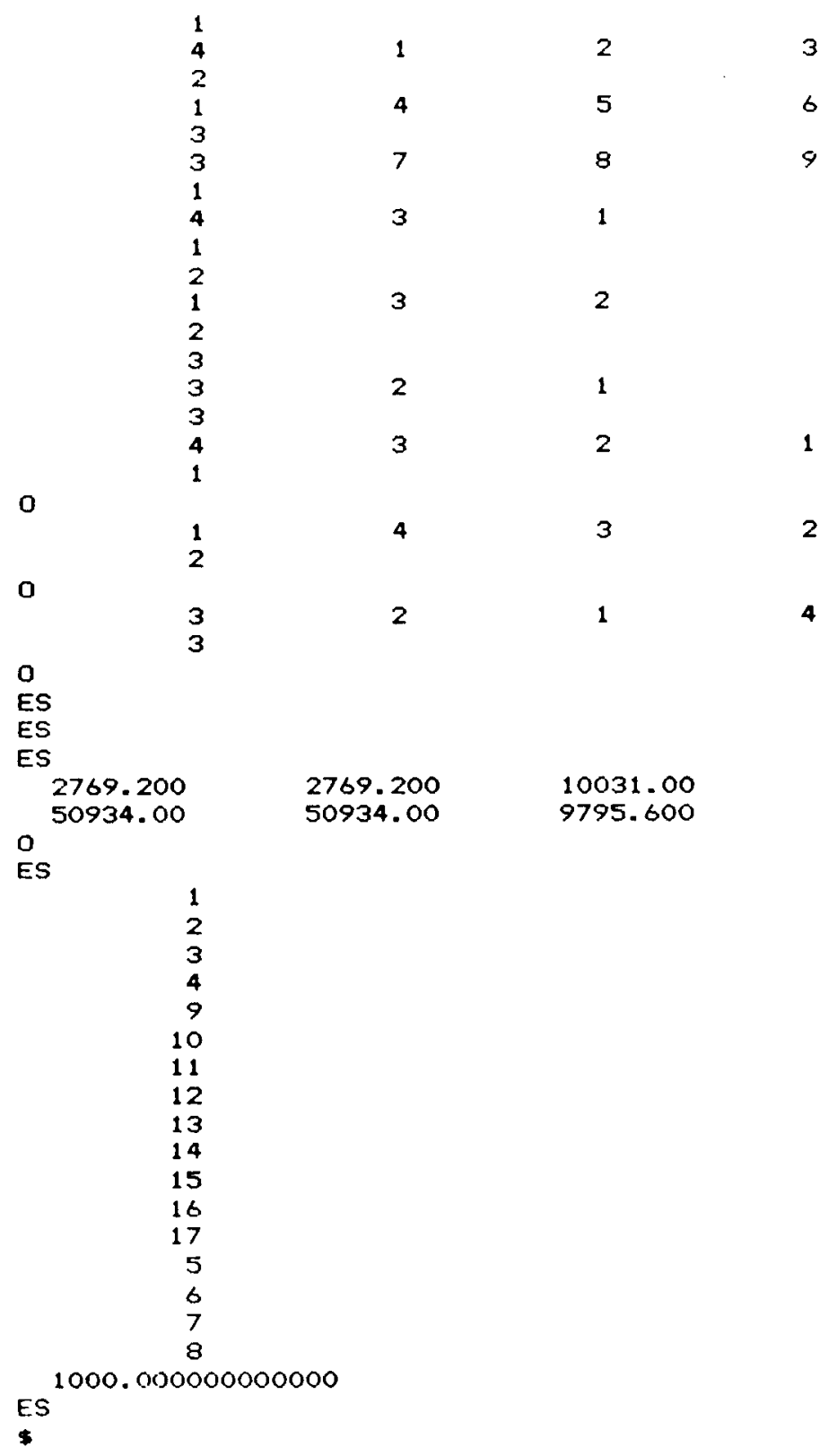


5.1.1 OUTPUT FROM RUNNING THE GENDYN SUB-PROGRAM

GEODYN was run using the input file just generated. The resulting GENDYN summary file, discussed in Section 3.8 .1 and illustrated in Figure $3 \cdot 8 \cdot 2 \cdot 3$, is shown here: 


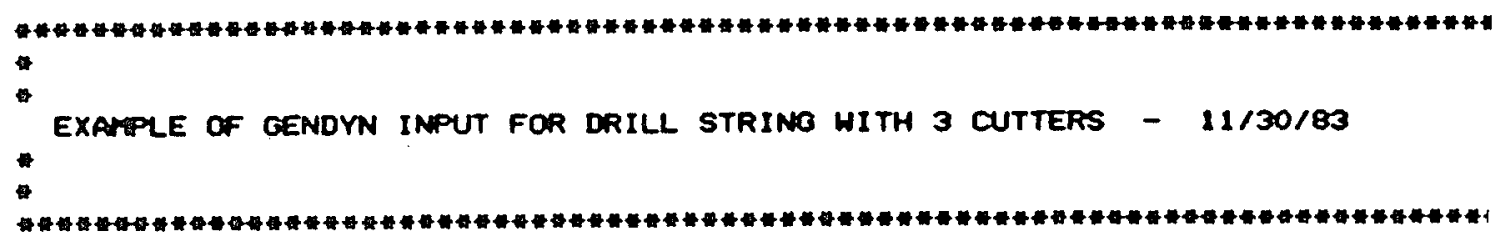




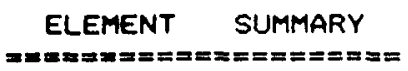

TOTAL NUMBER OF 8-NODE BRICK ELEMENTS :

TOTAL NUMBER OF 20-NODE BRICK ELEMENTS :

TOTAL NUMBER OF LINEAR BEAM ELEMENTS :

TOTAL NUMBER OF GHOST CUTTER GEOMETRIC SUB-ELEMENTS :

TOTAL NUMBER OF INFINITE CONTINUUM BRICK ELEMENTS :

0

TOTAL NUMBER OF NON-LINEAR BEAM ELEMENTS:

NODE SUMMARY

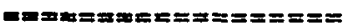

TOTAL NUMBER OF BIT NODES (8-NODE BRICKS) : 8

TOTAL NUMBER OF LINEAR BEAM NODES : ?

TOTAL NUMBER OF GHOST CUTTER SUB-NODES : 9

DEGREE - OF - FREEDOM SUMMARY

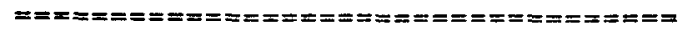

TOTAL NUMBER OF BIT D.D.F. (B-NODE BRICKS) : 24

TOTAL NUMBER OF LINEAR BEAM D.O.F. : 54

TOTAL NIMMBER OF DRILL STRING D.O.F. PRIOR TO TYING : $7: 3$ 
TOTAL NUMBER OF DRILL STRING D.D.F. AFTER TYING :

TYING CONSTRAINTS SUMMARY

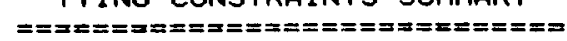

TOTAL NUMBER OF TIED BIT NODES :

LIST OF TIED BIT NODE NUMBERS :

5

6

7

ELEMENT DEFINITION (CONNECTIVITY) SUMMARY

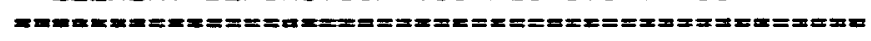

8-NODE BRICKS :

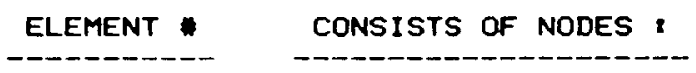

1

12345

LIMEAR BEAMS :

$\begin{array}{ccc}\text { ELEMENT } & \text { CONSISTS OF NODES : } \\ 2 & 9 & 10 \\ 3 & 10 & 11 \\ 4 & 11 & 12 \\ 5 & 12 & 13\end{array}$




$\begin{array}{lll}6 & 13 & 14 \\ 7 & 14 & 15 \\ 8 & 15 & 16 \\ 9 & 16 & 17\end{array}$

MATERIAL TYPE AND PROPERTIES SUMMARY

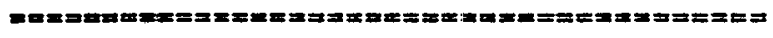

8-NODE BRICK MATERIAL PROPERTIES

MATERIAL TYPE " YOUNG'S MOD. (PSI) POISSON RATIO

UNIT HT. (PCF)

1

$0.3000000 E+08$

$0.3000000 E+00$

$0.2616360 E+03$

8-NODE BRICK MATERIAL TYPES

ELEMENT - MATERIAL TYPE

1

1

LINEAR BEAM MATERIAL PROPERTIES

-

TYPE =
$E(P S I)=0.3000000 E+08$
$N U=0.3000000 E+00$
$W T(P C F)=0.4870000 E+03$
$L(F T)=0.6121000 E+00$
o. D.
$=0.5500000 E+01$
I.D. $=0.2600000 E+01$ 


$\begin{array}{rll}\text { TYPE }=2 \text { E } & \text { NUSI }=0.3000000 E+00 \\ \text { WT }(P C F)=0.3000000 E+08 & & \text { L }(F T)=0.6190500 E+00 \\ \text { O.D. }=0.4250000 E+01 & \text { I.D. }=0.1500000 E+01\end{array}$

LINEAR BEAM MATERIAL TYPES

ELETENT * MATERIAL TYPE

$\begin{array}{ll}2 & 1 \\ 3 & 2 \\ 4 & 2 \\ 5 & 2 \\ 6 & 2 \\ 7 & 2 \\ 8 & 2 \\ 9 & 2\end{array}$

GHOST CUTTER MATERIAL PROPERTIES

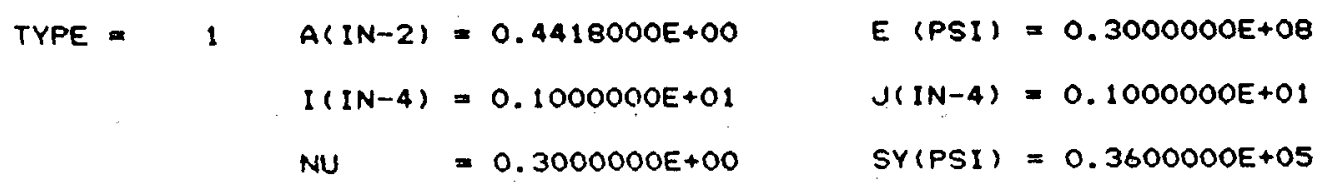


GHOST CUTTER MATERIAL TYPES

CUTTER * MATERIAL TYPE

1

2

3
1

1

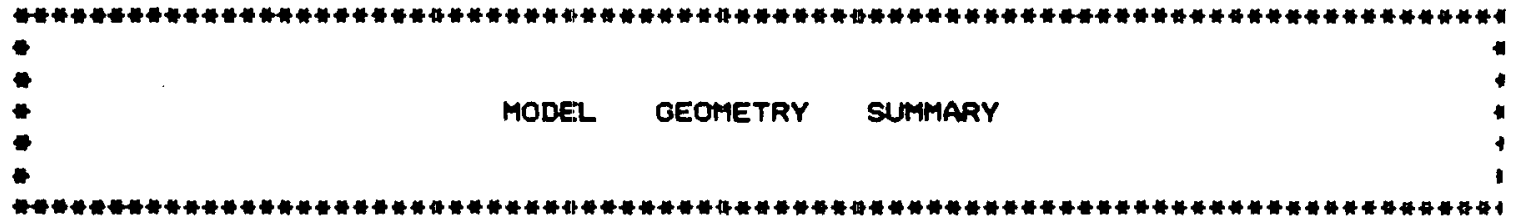

DRILL STRING NODAL COORDINATE SUMMARY

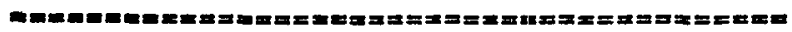

$\begin{array}{crrr}\text { NODE } & X \text { COORD. } & \text { Y-COORD. } & z-\text { COORD. } \\ 1 & -4.00000 & -4.00000 & 0.00000 \\ 2 & 4.00000 & -4.00000 & 0.00000\end{array}$




$\begin{array}{llll}3 & 4.00000 & 4.00000 & 0.00000 \\ 4 & -4.00000 & 4.00000 & 0.00000 \\ 5 & -4.00000 & -4.00000 & 9.72500 \\ 6 & 4.00000 & -4.00000 & 9.72500 \\ 7 & 4.00000 & 4.00000 & 9.72500 \\ 8 & -4.00000 & 4.00000 & 9.72500 \\ 9 & 0.00000 & 0.00000 & 9.72500 \\ 10 & 0.00000 & 0.00000 & 17.07000 \\ 11 & 0.00000 & 0.00000 & 24.49900 \\ 12 & 0.00000 & 0.00000 & 31.92700 \\ 13 & 0.00000 & 0.00000 & 39.35600 \\ 14 & 0.00000 & 0.00000 & 46.78400 \\ 15 & 0.00000 & 0.00000 & 54.21300 \\ 16 & 0.00000 & 0.00000 & 61.64200 \\ 17 & 0.00000 & 0.00000 & 69.07000\end{array}$

GMOST CUTTER SUMMARY

GHOST CUTTER SUB-NODE COORDINATE SUMMARY

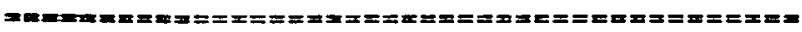

SUB-NODE

1
$X-\operatorname{COORD}$.

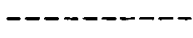

$-1.63200$
$Y-$ COORD.

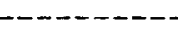

2.31000
z-COORD.

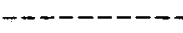

0.00000 


$\begin{array}{lrll}2 & -1.52665 & 2.40151 & -0.76940 \\ 3 & -1.36837 & 2.49474 & -0.27740 \\ 4 & 0.00000 & 0.00000 & 0.00000 \\ 5 & 0.00000 & 0.00000 & -0.72940 \\ 6 & 0.00000 & 0.00000 & -0.23740 \\ 7 & 2.16500 & 1.59000 & 0.00000 \\ 8 & 2.25651 & 1.43465 & -0.76940 \\ 9 & 2.34974 & 1.27637 & -0.27740\end{array}$

GHOST CUTTER SUB-NODE LOCAL COORDINATE SUMMARY

-

\begin{tabular}{cccc} 
SUANNODE & R-COORD & S-COORD & T-COORD. \\
\hline 1 & 2.31800 & 1.69000 & 0.00000 \\
2 & 2.47335 & 1.59849 & 0.76940 \\
3 & 2.63163 & 1.50526 & 0.27740 \\
4 & 5.65685 & 0.00000 & 0.00000 \\
5 & 5.65685 & 0.00000 & 0.72940 \\
6 & 5.65685 & 0.00000 & 0.23740 \\
7 & 2.41000 & 1.83500 & 0.00000 \\
8 & 2.56535 & 1.74349 & 0.76940 \\
9 & 2.72363 & 1.65026 & 0.27740
\end{tabular}


GHOST CUTTER LENGTH SUMMARY

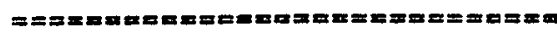

CUTTER * LENGTH (IN)

$\begin{array}{ll}1 & 1.20000 \\ 2 & 1.20000 \\ 3 & 0.00000\end{array}$

CUTTER DEFINITIONS

CUTTER PRIMARY NODE SUB-NODES BIT SUAF. TOP BLANK BOT. BLANK

$\begin{array}{ll}1 & 4 \\ 2 & 1 \\ 3 & 3\end{array}$

1

2

3

4

6

5

$\mathbf{8}$

9

CHARACTERISTIC PLANE DEFINITIONS

Plane NODE 2 NODE 2 NODE 3 
5.49

2

3

1

3
3

2
1

plane 1 contaINS cutters:

1

Plañ. 2 CONTAINS CUTtERS

2

plane 3 contains cutters :

PLANE " 
BIT SURFACE DEFINITIONS

\section{BIT SURFACE DEFINITIONS}

$\begin{array}{ccccc}\text { SURFACE NODE } & 1 & \text { NODE } 2 & \text { NODE } 3 & 4 \\ 1 & 4 & 3 & 2 & 1 \\ 2 & 1 & 4 & 3 & 2 \\ 3 & 3 & 2 & 1 & 4\end{array}$

SURFACE * 1 CONTAINS CUTTERS :

1

SURFACE 2 CONTAINS CUTTERS

2

SURFACE 3 CONTAINS CUTTERS : 


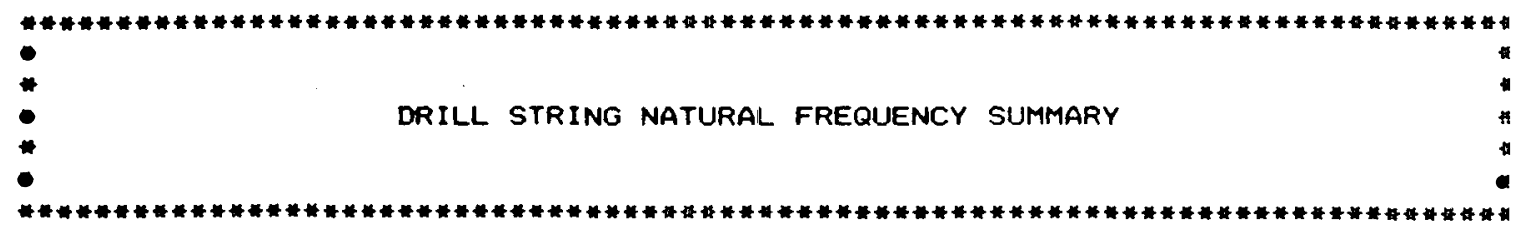

EIGENUALUES AND fREQUENCIES

eIgenvalue Number

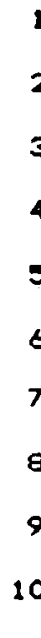

value

$0.290130+02$

$0.290250+02$

$0.103370+0.4$

$0.12282 D+05$

$0.15324 D+0.5$

$0.15324 D+05$

$0.806310+0.5$

$0.806310+06$

$0.642590+07$

$0.642590+07$

$0.14497 D+08$
FREQUENCY

$0.85727 D+00$

$0.85745 \mathrm{D}+00$

$0.511700+01$

$0.176380+02$

$0.197020+02$

$0.19702 \mathrm{D}+02$

$0.142910+03$

$0.14291 \mathrm{D}+03$

$0.403450+03$

$0.40345 D+03$

$0.605930+03$ 


\begin{tabular}{|c|c|c|}
\hline 12 & $0.268580+08$ & $0.824810+03$ \\
\hline 13 & $0.26858 D+08$ & $0.824810+03$ \\
\hline 14 & $0.62981 D+08$ & $0.126310+04$ \\
\hline 15 & $0.772100+08$ & $0.13985 D+04$ \\
\hline 16 & $0.772100+08$ & $0.13985 D+04$ \\
\hline 17 & $0.112880+09$ & $0.169100+04$ \\
\hline 18 & $0.172900+09$ & $0.20927 D+04$ \\
\hline 19 & $0.172900+09$ & $0.209270+04$ \\
\hline 20 & $0.27997 D+09$ & $0.266300+04$ \\
\hline 21 & $0.310460+09$ & $0.28043 D+04$ \\
\hline 22 & $0.33042 D+09$ & $0.289300+04$ \\
\hline 23 & $0.330420+09$ & $0.289300+04$ \\
\hline 24 & $0.392980+09$ & $0.315500+04$ \\
\hline 25 & $0.506780+09$ & $0.358290+04$ \\
\hline 26 & $0.560350+09$ & $0.376750+04$ \\
\hline 27 & $0.560350+09$ & $0.376750+04$ \\
\hline 28 & $0.68106 D+\infty$ & $0.415350+04$ \\
\hline 29 & $0.732700+09$ & $0.430810+04$ \\
\hline 30 & $0.793110+\infty 9$ & $0.44822 \mathrm{D}+04$ \\
\hline 31 & $0.79311 \mathrm{D}+09$ & $0.448220+04$ \\
\hline 32 & $0.864480+09$ & $0.46795 D+04$ \\
\hline 33 & $0.984200+09$ & $0.499300+04$ \\
\hline 34 & $0.10318 D+10$ & $0.51123 D+04$ \\
\hline 35 & $0.112920+10$ & $0.53482 D+04$ \\
\hline 36 & $0.124020+10$ & $0.560490+04$ \\
\hline 37 & $0.14983 D+10$ & $0.61605 D+04$ \\
\hline 38 & $0.149830+10$ & $0.616050+04$ \\
\hline 39 & $0.17563 D+10$ & $0.66700 D+04$ \\
\hline
\end{tabular}


40

41

42

43

44

45

46

47

48

49

50

51

52

53

54

55

56

57

58

59

60

61

62

63

6.4

65

66
$0.225140+10$

$0.2554901+10$

0. $255490+10$

$0.265970+10$

$0.26614 D+10$

$0.27373 D+10$

$0.287870+10$

$0.289320+10$

$0.29932 \square+10$

$0.29524 D+10$

$0.307600+10$

$0.30760 D+10$

$0.37842 D+10$

$0.37842 D+10$

$0.48331 D+10$

$0.48331 D+10$

$0.590580+10$

$0.590580+10$

$0.67843 D+10$

$0.67843 D+10$

$0.75624 D+10$

$0.767170+10$

$0.76719 D+10$

$0.84788 D+10$

$0.84788 D+10$

$0.879500+10$

$0.897500+10$
$0.7551701+04$

$0.30446[+104$

$0.80446[1+04$

$0.820770+04$

$0.82107 D+04$

$0.832690+04$

$0.85392 \mathrm{D}+04$

$0.856070+04$

$0.856070+04$

$0.864780+04$

$0.882700+04$

$0.8827 O D+04$

$0.97905 D+04$

$0.979050+04$

$0.11065 \mathrm{D}+05$

$0.110650+05$

0. $12231 \mathrm{D}+05$

$0.122310+05$

$0.13109[1+05$

$0.131090+05$

$0.138400+05$

o. $139400+05$

$0.13940 D+05$

$0.146550+05$

$0.146550+05$

$0.150950+05$

$0.15095 \mathrm{D}+0.5$ 
5.2 INPUT FOR RUNNING THE RUNDYN SUB-PROGRAM

This section contains all of the interactive input needed to run RUNDYN for the model shown in Figure 5.1.1 and 5.1.2. This example does not include a formation model. The following is the actual interactive input session: 
FUN GEOIN

FILE NAME FOR INPUT LIATA?

INLIMX

FILE NAME FOR OUTFUT DATA?

?

DUTUMX

THE GEODYN PROGRAM CURRENTLY ALLOWS THE USER TO EXERCISE TWO FIUNCTIONS :

1 - THE GENERATION OR MODIFICATION OF A DRILL STRING MODEL ( GENDYN) ( FINITE ELEMENTS, BOUNDARY SPRINGS, GR GHOST CUTTERS )

2 - THE EXECUTION OF A SOLUTION FOR THE DRILL STRING MODEL. ( RLINDYN ) LOADS, TIME STEPS. NUMBER OF MODES CONSIDERED, AND FORMATION PROPERTIES MAY ALL BE MODIFIED WITH THIS OPTION.

$==\Rightarrow$ CHOOSE FUNCTION 1 OR 2 :

DO YOU WISH TO PERFORM FUNCTION 2 ? (YES/NO - NO EXECUTES (1))

$?$

YES

PLEASE INPUT TWO LINES OF UP TO 80 CHARACTERS EACH

FOR A TITLE OF THIS RUN.

12 ELEMENT MODEL WITH 3 CUTTERS - USER'S MANUAL EXAMPLE.

RUNDYN EXECUTION FOR AXIAL MODE QUALIFICATION - 12/1/83

DO YOU DESIRE TO SEE SOLUTION ALGORITHM DEBUG FRINT OUT ?

$$
?
$$$$
\text { RESPOND YES OR NO }
$$

NO

$?$

IS THIS THE FIRST TIME RUNDYN HAS BEEN EXECUTED ( RESFOND YES OR NO) YES

********* CORE SIZE CHECK *\#******* 
REQUIRED STORAGE $=202$ ALLOCATED STORAGE = 20000 OCCURRED AT CHECK POINT 1

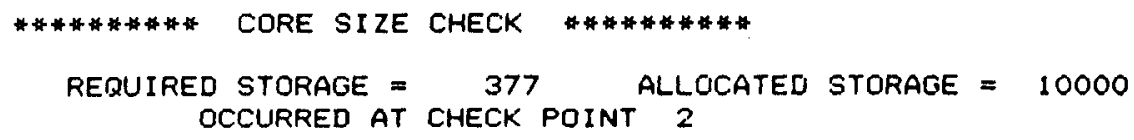

THE NATURAL FREQUENCIES (HERTZ) OF THE TIED DRILL STRING SYSTEM ARE :

\begin{tabular}{|c|c|c|c|c|}
\hline & & & & 1 \\
\hline 1 & 1 & ! & $0.85728 D+00$ & 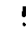 \\
\hline 2 & 1 & $?$ & $0.85812 \mathrm{D}+00$ & \\
\hline 3 & 1 & ! & $0.51170 D+01$ & \\
\hline 4 & 1 & ! & $0.176380+02$ & \\
\hline 5 & 1 & $!$ & $0.19702 D+02$ & \\
\hline 6 & 1 & ! & $0.19702 \mathrm{D}+02$ & \\
\hline 7 & 1 & ! & $0.14291 \mathrm{D}+03$ & \\
\hline 8 & 1 & ! & $0.14291 \mathrm{D}+03$ & \\
\hline 9 & 1 & ! & $0.40345 D+03$ & \\
\hline 10 & / & ! & $0.40345 D+03$ & \\
\hline 11 & 1 & $!$ & $0.60598[1+03$ & \\
\hline 12 & / & I & $0.82481 D+03$ & \\
\hline 13 & / & ! & $0.324810+03$ & \\
\hline 14 & 1 & 1 & $0.12631 \mathrm{D}+04$ & \\
\hline 15 & / & ! & $0.13985 D+04$ & \\
\hline 16 & / & ! & $0.13985 D+04$ & \\
\hline 17 & / & ? & $0.16710[1+04$ & \\
\hline 18 & / & $!$ & $0.20927 D+04$ & \\
\hline
\end{tabular}




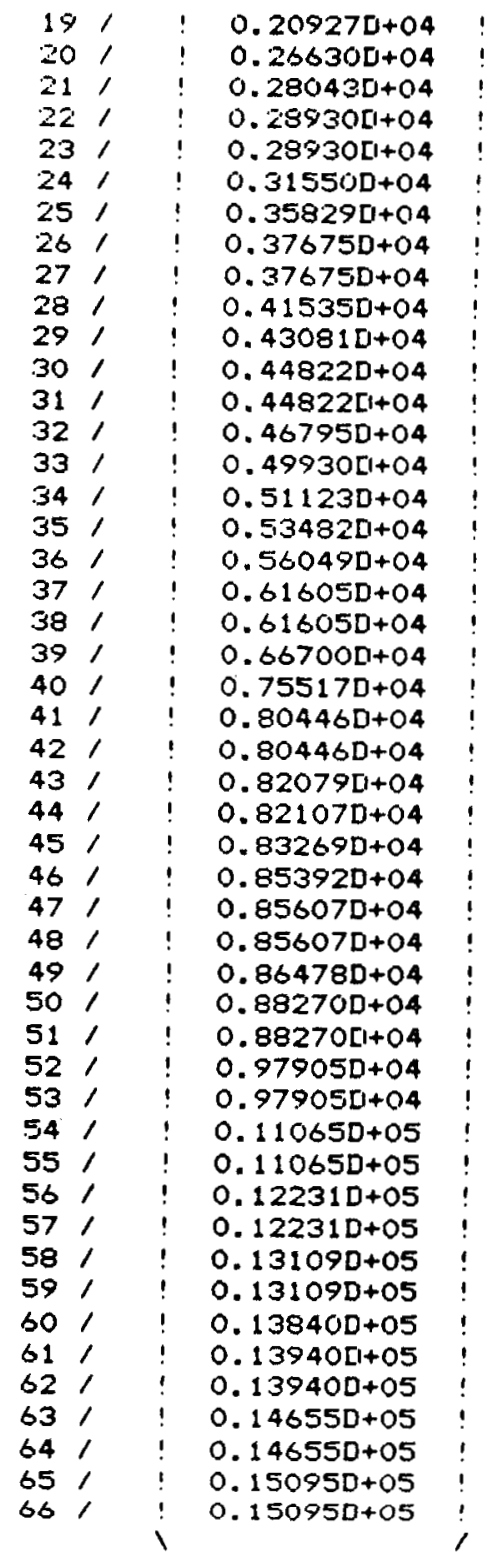

PLEASE INFIUT THE NUMBER OF MODES TO EE CONSIDERED $?$ IN THIS ANALYSIS. 
ANALYSIS WILL BE BASED ON 24 MODES / FREDUENCIES.

NEW [Kmodal] AND [Mmodal] WILL BE GENERATED.

HOW MANY TIMES GREATER MUST A DIAGONAL TERM BE THAN AN DFF-DIAGONAL TERM IN ORDER FOR A MODAL MATRIX TO BE CONSIDERED TO BE DIAGONAL ?

$?$

1000.0

IS THIS THE FIRST TIME RUNDYN WILL BE EXECUTED ( RESPOND YES OR NO) YES

* * INPUT OF SOlution algorithm PaRAmeters * *

THE USER MUST SPECIFY CERTAIN PARAMETERS USED TO DEFINE AN ANALYSIS SITUATION. PARAMETERS OF ROTARY SPEED, INTEGRATION CONSTANTS, ETC. MUST BE INPUT. WHERE APPROPRIATE, DEFAULT VALUES WILL BE SUGGESTED.

SPECIFY THE ROTARY SPEED OF THE DRILL STRING TO BE USED IN THIS ANALYSIS. THIS VALUE WILL BE TFEATED AS A CONSTANT APPLIED TO THE UPFERMOST NODE FOINT (BEAM) OF THE MUDEL.

UNITS FOR INPUT ARE REVOLUTIONS PER MINUTE.

( NOTE > A RIGHT-HANDED COORDINATE SYSTEM WITH THE Z-AXIS POINTED UP-STRINC IS UTILIZED. BE SURE ROTARY SPEED IS ENTERED WITH APPROFRIATE SIGN.

$?$

0.0

IS A ROTARY SPEED OF 0.0000 FPM SATISFACTORY? (RESPONI YES OR NO) YES

SPECIFY THE SIZE OF THE TIME STEPS TO BE USED IN THE ANALYSIS. VALUE SHOULD BE ON THE ORDER OF $1 / 6$ RECIPROCAL OF HIGHEST NAT. FREQ. USED TO DHARACTERIZE THE GENERALIZED MODAL DISPLACEMENTS. THE HIGHEST NATURAL FREQLIENCY SPECIFIED $=0.3155040 E+04$

$\therefore$ NOTE > THE TIME STEF SIZE WILL BE CONSTANT FOR THE ANALYSIS.

A TIMESTEP GIZE OIF $0.5282553 E-04$ HAS BEEN SET AS THE DEFAULT VALUE. 


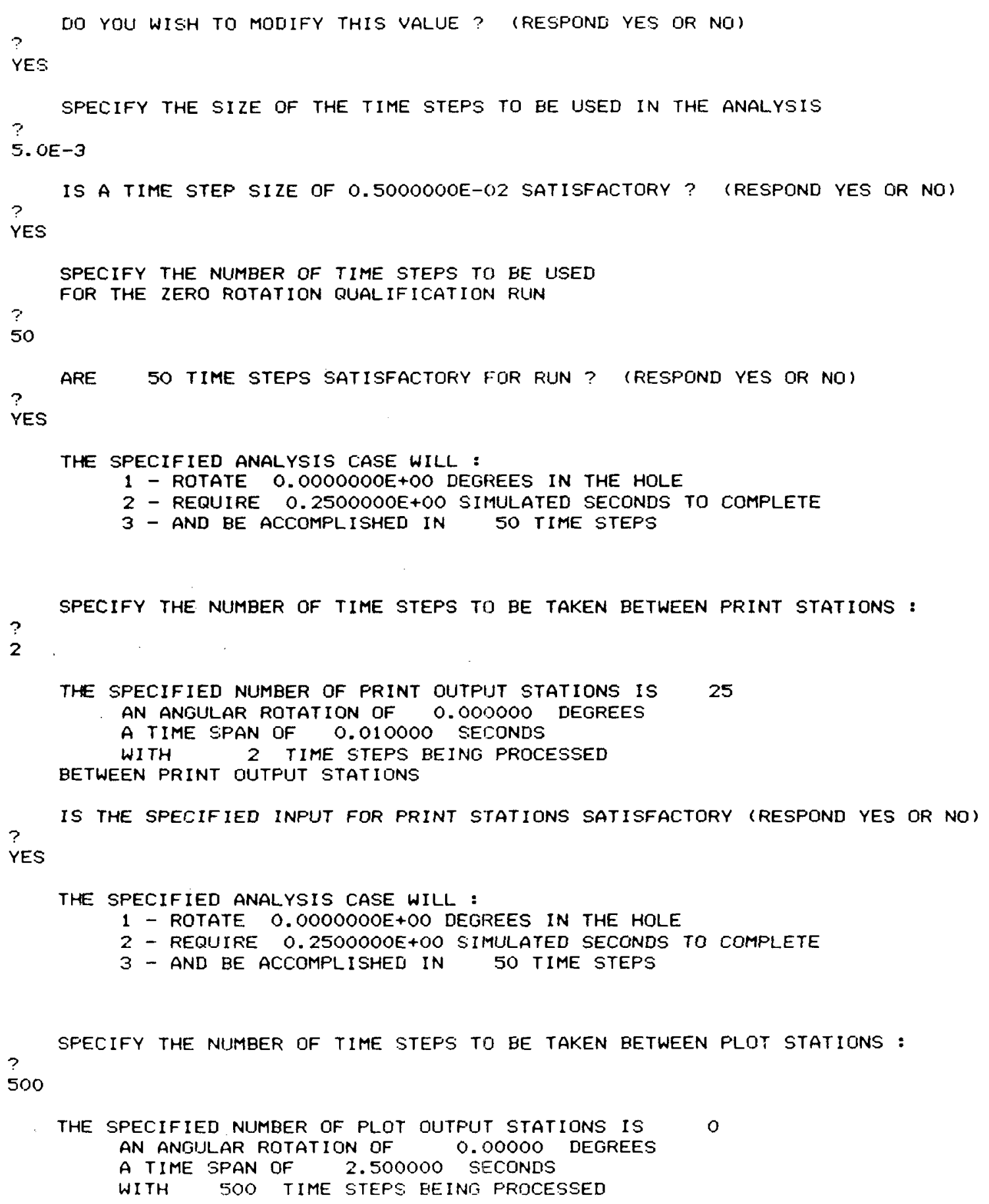


BETWEEN PLOT OUTPUT STATIONS

IS THE SPECIFIED INPUT FOR PLOT STATIONS SATISFACTORY (RESPOND YES OR NO)

YES

THE SPECIFIED ANALYSIS CASE HILL :

1 - ROTATE 0.0000000 + 00 DEGREES IN THE HOLE

2 - REQUIRE $0.2500000 E+00$ SIMULATED SECONDS TO COMPLETE

3 - AND BE ACCOMPLISHED IN 50 TIME STEPS

SPECIFY THE NUMBER OF TIME STEPS TO BE TAKEN BETWEEN RESTART STATIONS ,

500

THE SPECIFIED NUMBER OF RESTART OUTPUT STATIONS IS O AN ANGULAR ROTATION OF 0.00000 DEGREES

A TIME SPAN OF 2.500000 SECONDS

WITH SOO TIME STEPS BEINO PROCESSED

BETLEEN RESTART OUTPUT STATIOAS

IS THE SPECIFIED INPUT FOR RESTART STATIONS SATISFACTORY (RESPOND YES OR NO) YES

IT MAY BE NECESSARY TO INITIATE A RUN USING A START UP PROCEDURE WHEREIN A NUMBER OF TIME STEPS ARE USED TO RAMP-UP EXTERNAL FORCES. IF SO IT IS SUGGESTED THAT A MINIMU OF THENTY TIME STEPS BE USED.

ENTER THE NUMEER OF TIME STEPS DESIRED TO ACCOMPLISH START-UP PROCEDURE

o

ARE O TIME STEPS FOR START-UP SATISFACTORY ? (RESPOND YES OR NO)

$?$

YES

THE NEWHARX RETHOD OF NUMERICAL INTEGRATION WILL BE EMPLOYED

IN THE SOLUTION ALGORITHM. THIS METHOD USES INTEGRATION CONSTANTS O .

ALPYA $=0.25$

GANA $=0.50$

THE SOLUTION SCHEME EMPLOYED BY THIS PROGRAM PERMITS SOLUTION ITERATION WITHIN A TIME STEP TO OBTAIN A CONUERGED SOLUTION.

PLEASE SPECIFY THE MAXIMUM NUMBER OF ITERATIONS ALLOWED TO OBTAIN CONVERGENCE 
$?$

A SUGGESTED LIMIT IS 5

$?$

IS THE SPECIFIED ITERATION NUMBER LIMIT 5 SATISFACTORY (RESPOND YES OR NO) YES

SPECIFY THE CONVERGENCE CRITERIA TO BE EMPLOYED IN THE ITERATIVE SOLUTION. THIS VALUE SHOULD BE ENTERED AS A PERCENTILE TOLERANCE

TO BE APPLIED TO CONSECUTIVE PSI APPROXIMATIONS

OF MODAL DISPLACEMENT INCREMENTS $(n(t+d e l t a t))-(n(t))$

A TOLERANCE OF BETWEEN I I AND .5 PERCENT IS SUGGESTED

PLEASE ENTER tHE CONUERGENCE CRITERIA TOLERANCE

0.10

A CONVERGENCE CRITERIA TOLERANCE OF 0.100 HAS BEEN SPECIFIED

IS THIS VALUE SATISFACTORY (RESPOND YES OR NO)

?

YES

0001

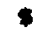


The actual input file generated by the preceding interactive input session is listed below. Note that because this data file was generated and Iisted on a VAX computer, the first column of data does not get printed. Consequently, a line which says "O" is really "NO", and a line that says "ES" is really "YES". 
TYPE INUMX.DAT

ES

12 ELEMENT MODEL WITH 3 CUTTERS - USER'S MANUAL EXAMPLE. o RUNDYN EXECUTION FOR AXIAL MODE QUALIFICATION - 12/1/83

ES

1000.000

ES

$0.0000000 E+00$

ES

ES

4. $9999999 E-03$

ES

ES

50

ES

ES $\quad 500$

ES 500

ES

ES

0.1000000

ES

TYPE FNAME.DAT

NumX

UTUMX

* 
5.2.1 FORCE FILES FOR RUNNING THE RUNDYN SUB-PROGRAM

The actual external force file (discussed in Sections 3.5.11, 7.2 and 7.2 .1 ) and cutter force file (discussed in Section 3.5.12) used to perform this run are shown below: 
TY EXTFRC. DAT

$$
\begin{aligned}
& 10.0000000 E+00 \quad 0.0000000 E+C O \quad 0.0000000 E+00 \quad 0.0000000 E+00 \\
& 0.0000000 E+00 \quad 0.0000000 E+00 \\
& 20.0000000 E+00 \quad 0.0000000 E+00 \quad 0.0000000 E+00 \quad 0.0000000 E+00 \\
& 0.0000000 E+00 \quad 0.0000000 E+00 \\
& 30.0000000 E+00 \quad 0.0000000 E+00 \quad 0.0000000 E+00 \quad 0.0000000 E+00 \\
& 0.0000000 E+00 \quad 0.0000000 E+00 \\
& 40.0000000 E+O O \quad 0.0000000 E+C 10 \quad 0.0000000 E+00 \quad 0.0000000 E+00 \\
& 0.0000000 E+00 \quad 0.0000000 E+00 \\
& 5 \quad 0.0000000 E+00 \quad 0.0000000 E+C 10 \quad 0.0000000 E+00 \quad 0.0000000 E+00 \\
& 0.0000000 E+00 \quad 0.0000000 E+00 \\
& 6 \quad 0.0000000 E+00 \quad 0.0000000 E+(10 \quad 0.0000000 E+00 \quad 0.0000000 E+00 \\
& 0.0000000 E+00 \quad 0.0000000 E+00 \\
& 7 \quad 0.0000000 E+00 \quad 0.0000000 E+00 \quad 0.0000000 E+00 \quad 0.0000000 E+00 \\
& 0.0000000 E+00 \quad 0.0000000 E+00 \\
& 8 \quad 0.0000000 E+00 \quad 0.0000000 E+\infty 0 \quad 0.0000000 E+00 \quad 0.0000000 E+00 \\
& 0.0000000 E+00 \quad 0.0000000 E+00 \\
& 90.0000000 E+00 \quad 0.0000000 E+\infty 0 \quad 0.0000000 E+00 \quad 0.0000000 E+00 \\
& 0.0000000 E+\infty 0.0000000 E+\infty \\
& 10 \quad 0.0000000 E+\infty 00.0000000 E+\infty 0 \\
& 0.0000000 E+C 0 \quad 0.0000000 E+\infty 0 \\
& 10.0000000 E+00 \quad 0.0000000 E+00 \\
& 0.0000000 E+00 \quad 0.0000000 E+00 \\
& 20.0000000 E+\infty 0 \quad 0.0000000 E+00 \\
& 0.0000000 E+00 \quad 0.0000000 E+00 \\
& 30.0000000 E+00 \quad 0.0000000 E+\infty \\
& 0.0000000 E+\infty 00.0000000 E+00 \\
& 40.0000000 E+00 \quad 0.0000000 E+00 \\
& 0.0000000 E+\infty 0 \quad 0.0000000 E+00 \\
& 50.0000000 E+00 \quad 0.0000000 E+100 \\
& 0.0000000 E+00 \quad 0.0000000 E+00 \\
& 6 \text { O. } 0.000000 E+00 \quad 0.0000000 E+00 \quad 0.0000000 E+00 \quad 0.0000000 E+\infty 0 \\
& 0.0000000 E+00 \quad 0.0000000 E+00 \\
& 7 \quad 0.0000000 E+00 \quad 0.0000000 E+\infty 0 \\
& 0.0000000 E+00 \quad 0.0000000 E+00 \\
& 80.0000000 E+00 \quad 0.0000000 E+100 \\
& 0.0000000 E+00 \quad 0.0000000 E+\infty 0 \\
& 90.0000000 E+00 \quad 0.0000000 E+\infty 0 \\
& 0.0000000 E+\infty \quad 0.0000000 E+00 \\
& 20 \quad 0.0000000 E+00 \quad 0.0000000 E+100 \\
& 0.0000000 E+00 \quad 0.0000000 E+00 \\
& 10.0000000 E+00 \quad 0.0000000 E+100 \\
& 0.0000000 E+00 \quad 0.0000000 E+00 \\
& 20.0000000 E+00 \quad 0.0000000 E+100 \\
& 0.0000000 E+00 \quad 0.0000000 E+00 \\
& 30.0000000 E+00 \quad 0.0000000 E+\infty 0 \quad 0.0000000 E+00 \quad 0.0000000 E+00 \\
& 0.0000000 E+00 \quad 0.0000000 E+00 \\
& 4 \text { O. OOOOOOOE + OO } 0.0000000 E+00 \\
& 0.0000000 E+00 \quad 0.0000000 E+00 \\
& 50.0000000 E+00 \quad 0.0000000 E+00 \\
& 0.0000000 E+00 \quad 0.0000000 E+00 \\
& \text { S } 0.0000000 E+00 \quad 0.0000000 E+00 \\
& 0.0000000 E+00 \quad 0.0000000 E+00 \\
& 70.0000000 E+00 \quad 0.0000000 E+00 \\
& 0.0000000 E+00 \quad 0.0000000 E+00 \\
& 0.0000000 E+00 \quad 0.0000000 E+00 \\
& 0.0000000 E+00 \quad 0.0000000 E+00 \\
& 0.0000000 E+00 \quad 0.0000000 E+00 \\
& 0.0000000 E+00 \quad 0.0000000 E+\infty 0 \\
& 0.0000000 E+00 \quad 0.0000000 E+00 \\
& 0.0000000 E+00 \quad 0.0000000 E+\infty 0 \\
& 0.0000000 E+00 \quad 0.0000000 E+00 \\
& 0.0000000 E+00 \quad 0.0000000 E+00 \\
& 0.0000000 E+00 \quad 0.0000000 E+00 \\
& 0.0000000 E+\infty 00.0000000 E+00 \\
& 0.0000000 E+00 \quad 0.0000000 E+\infty 0 \\
& 0.0000000 E+00 \quad 0.0000000 E+00 \\
& 0.0000000 E+00 \quad 0.0000000 E+00 \\
& 0.0000000 E+00 \quad 0.0000000 E+00 \\
& 0.0000000 E+00 \quad 0.0000000 E+00
\end{aligned}
$$


$0.0000000 E+00 \quad 0.0000000 E+00$

\& $0.0000000 E+00 \quad 0.0000000 E+00$

$0.0000000 E+00$ 0.0000000E+00

$90.0000000 E+00 \quad 0.0000000 E+00$

$0.0000000 E+00 \quad 0.0000000 E+00$

$30 \quad 0.0000000 E+00 \quad 0.0000000 E+00$

$0.0000000 E+00 \quad 0.0000000 E+00$

$10.0000000 E+00 \quad 0.0000000 E+00$

$0.0000000 E+00 \quad 0.0000000 E+00$

$20.0000000 E+00 \quad 0.0000000 E+00$

$0.0000000 E+00 \quad 0.0000000 E+00$

$3 \quad 0.0000000 E+00 \quad 0.0000000 E+00$

$0.0000000 E+00 \quad 0.0000000 E+00$

$40.0000000 E+00 \quad 0.0000000 E+00$

$0.0000000 E+00 \quad 0.0000000 E+00$

$5 \quad 0.0000000 E+00 \quad 0.0000000 E+00$

$0.0000000 E+00 \quad 0.0000000 E+00$

$\checkmark \quad 0.0000000 E+00 \quad 0.0000000 E+00$

$0.0000000 E+00 \quad 0.0000000 E+00$

$7 \quad 0.0000000 E+00 \quad 0.0000000 E+00$

$0.0000000 E+00 \quad 0.0000000 E+00$

$80.0000000 E+00 \quad 0.0000000 E+00$

$0.0000000 E+00 \quad 0.0000000 E+00$

$90.0000000 E+00 \quad 0.0000000 E+00$

$0.0000000 E+00 \quad 0.0000000 E+00$

$40 \quad 0.0000000 E+00 \quad 0.0000000 E+00$

$0.0000000 E+00 \quad 0.0000000 E+00$

$10.0000000 E+00 \quad 0.0000000 E+00$

$0.0000000 E+00 \quad 0.0000000 E+00$

$20.0000000 E+00 \quad 0.0000000 E+00$

$0.0000000 E+00 \quad 0.0000000 E+00$

$30.0000000 E+00 \quad 0.0000000 E+00$

$0.0000000 E+00 \quad 0.0000000 E+00$

$40.0000000 E+00 \quad 0.0000000 E+00$

$0.0000000 E+00 \quad 0.0000000 E+00$

$5 \quad 0.0000000 E+00 \quad 0.0000000 E+00$

$0.0000000 E+00 \quad 0.0000000 E+00$

\& $0.0000000 E+00 \quad 0.0000000 E+00$

$0.0000000 E+00 \quad 0.0000000 E+00$

$7 \quad 0.0000000 E+00 \quad 0.0000000 E+00$

$0.0000000 E+00 \quad 0.0000000 E+00$

$8 \quad 0.0000000 E+00 \quad 0.0000000 E+00$

$0.0000000 E+00 \quad 0.0000000 E+00$

$90.0000000 E+00 \quad 0.0000000 E+00$

$0.0000000 E+00 \quad 0.0000000 E+00$

50 $0.0000000 E+00 \quad 0.0000000 E+00$

$0.0000000 E+00 \quad 0.0000000 E+00$

$10.0000000 E+00 \quad 0.0000000 E+00$

$0.0000000 E+00 \quad 0.0000000 E+00$

$20.0000000 E+00 \quad 0.0000000 E+00$

$0.0000000 E+00 \quad 0.0000000 E+00$

$3 \quad 0.0000000 E+00 \quad 0.0000000 E+00$

$0.0000000 E+00 \quad 0.0000000 E+00$

$40.0000000 E+00 \quad 0.0000000 E+00$

$0.0000000 E+00 \quad 0.0000000 E+00$

$50.0000000 E+00 \quad 0.0000000 E+00$

$0.00001000 E+00 \quad 0.0000000 E+00$
$0.0000000 E+00 \quad 0.0000000 E+00$

$0.0000000 E+00 \quad 0.0000000 E+00$

$0.0000000 E+00 \quad 0.0000000 E+00$

$0.0000000 E+00 \quad 0.0000000 E+00$

$0.0000000 E+00 \quad 0.0000000 E+00$

$0.0000000 E+00 \quad 0.0000000 E+00$

$0.0000000 E+00 \quad 0.0000000 E+00$

$0.0000000 E+00 \quad 0.0000000 E+00$

$0.0000000 E+00 \quad 0.0000000 E+00$

$0.0000000 E+00 \quad 0.0000000 E+00$

$0.0000000 E+00 \quad 0.0000000 E+00$

$0.0000000 E+00 \quad 0.0000000 E+00$

$0.0000000 E+00 \quad 0.0000000 E+00$

$0.0000000 E+00 \quad 0.0000000 E+00$

$0.0000000 E+00 \quad 0.0000000 E+00$

$0.0000000 E+00 \quad 0.0000000 E+00$

$0.0000000 E+00 \quad 0.0000000 E+00$

$0.0000000 E+00 \quad 0.0000000 E+00$

$0.0000000 E+00 \quad 0.0000000 E+00$

$0.0000000 E+00 \quad 0.0000000 E+00$

$0.0000000 E+00 \quad 0.0000000 E+00$

$0.0000000 E+00 \quad 0.0000000 E+00$

$0.0000000 E+00 \quad 0.0000000 E+00$

$0.0000000 E+00 \quad 0.0000000 E+00$

$0.0000000 E+00 \quad 0.0000000 E+00$

$0.0000000 E+00 \quad 0.0000000 E+00$

$0.0000000 E+00 \quad 0.0000000 E+00$

$0.0000000 E+00 \quad 0.0000000 E+00$ 


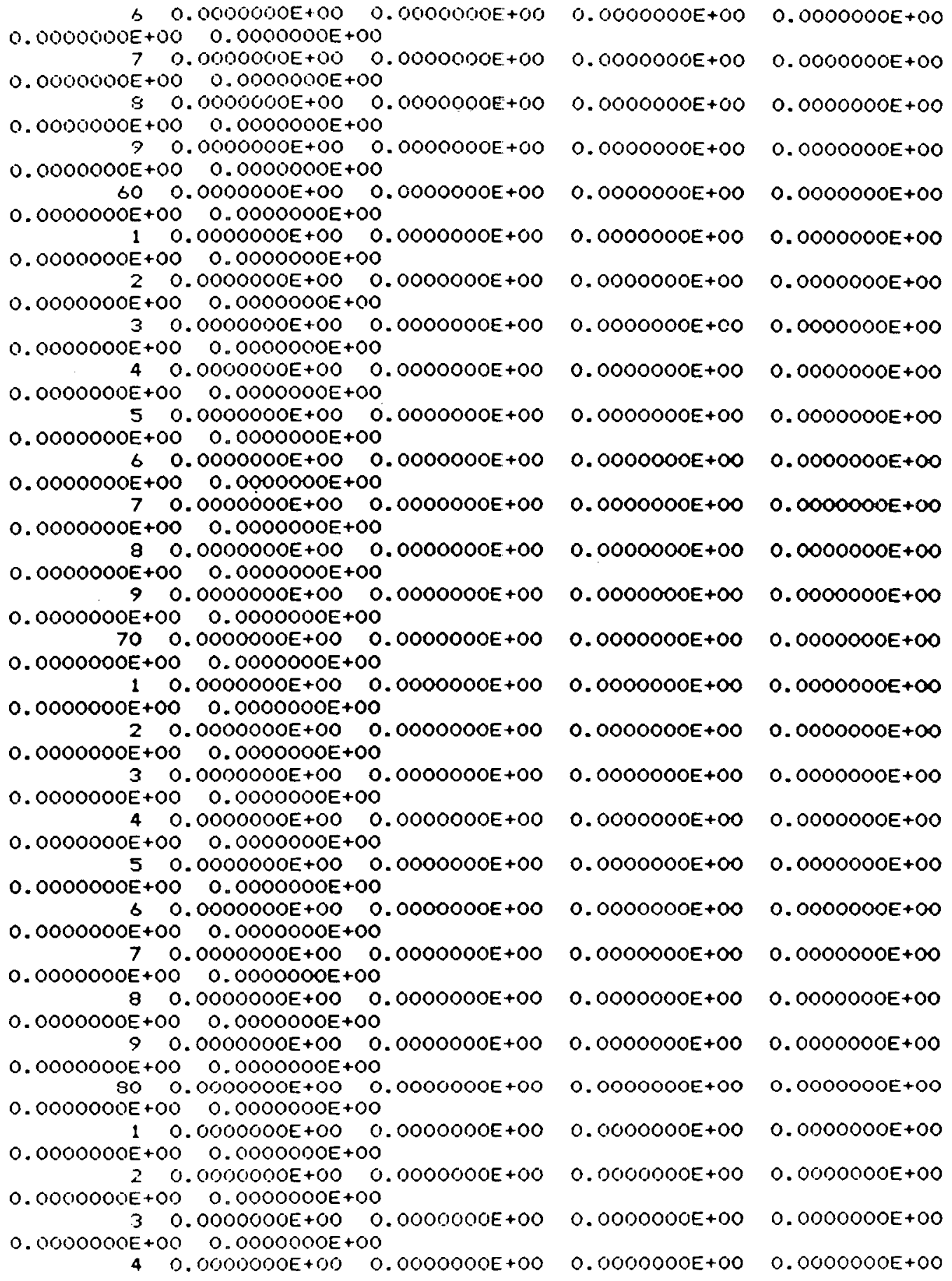




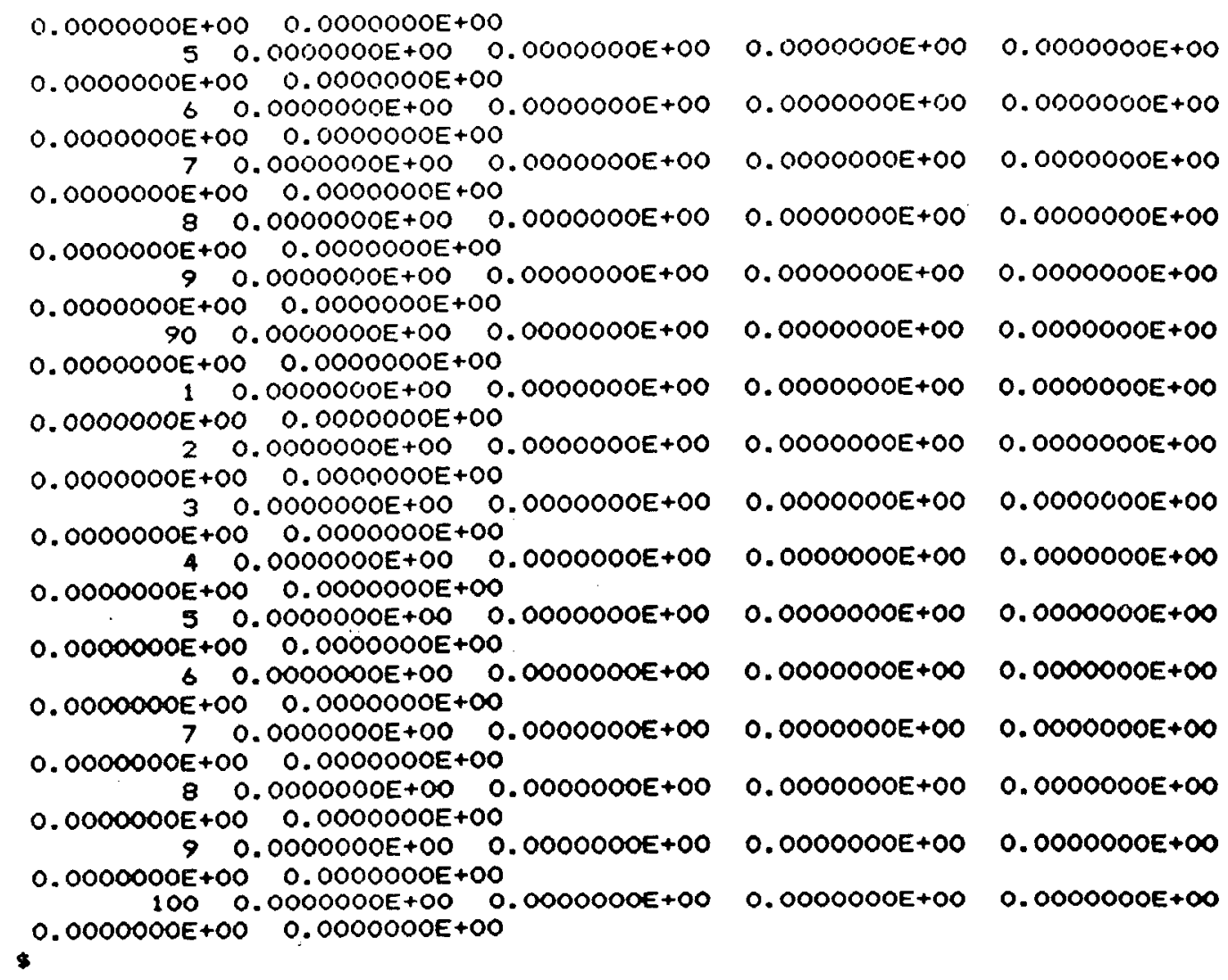


TY EXTCFF.DAT

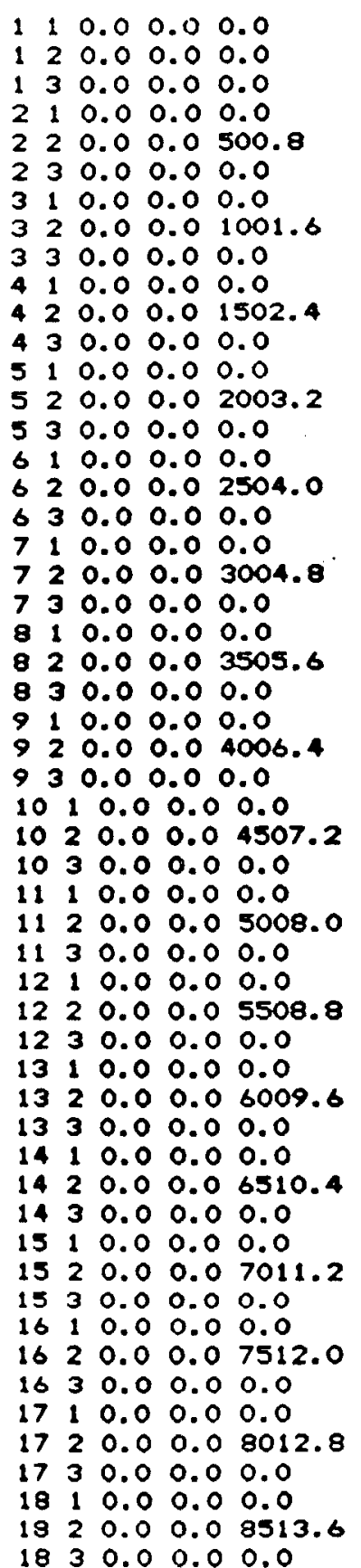




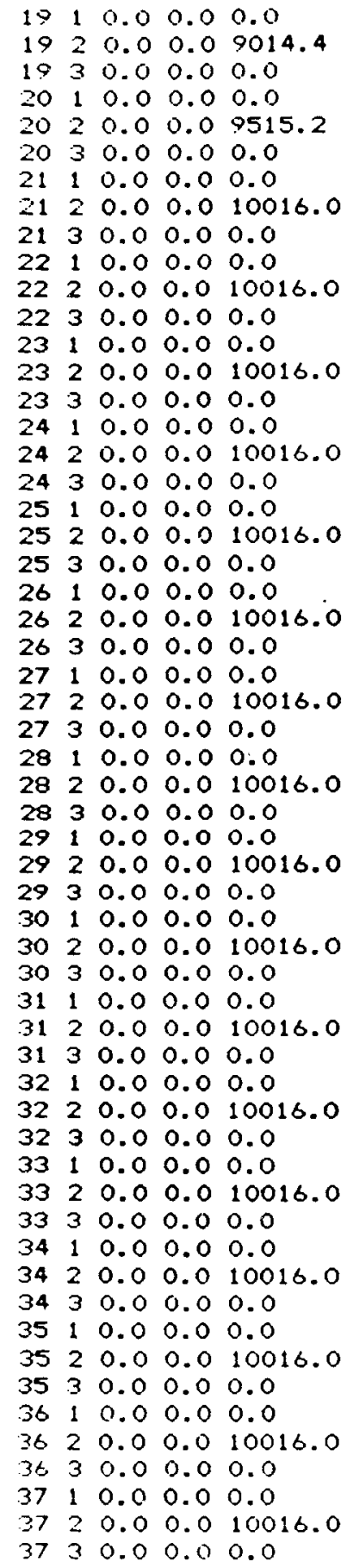


38110.00 .00 .0

$38=0.00 .010016 .0$

$\begin{array}{llllll}33 & 3 & 0.0 & 0.0 & 0.0\end{array}$

$\begin{array}{lllll}39 & 1 & 0.0 & 0.0 & 0.0\end{array}$

$3920.0 \quad 0.010016 .0$

$\begin{array}{lllll}39 & 3 & 0.0 & 0.0 & 0.0\end{array}$

$\begin{array}{llllll}40 & 1 & 0.0 & 0.0 & 0.0\end{array}$

4020.00 .010016 .0

$\begin{array}{lllll}40 & 3 & 0.0 & 0.0 & 0.0\end{array}$

4110.00 .00 .0

$\begin{array}{lllll}41 & 2 & 0.0 & 0.0 & 10016.0\end{array}$

$\begin{array}{lllll}413 & 0.0 & 0.0 & 0.0\end{array}$

$\begin{array}{lllll}421 & 0.0 & 0.0 & 0.0\end{array}$

4220.00 .010016 .0

$\begin{array}{lllll}42 & 3 & 0.0 & 0.0 & 0.0\end{array}$

$\begin{array}{llllll}43 & 1 & 0.0 & 0.0 & 0.0\end{array}$

4320.00 .010016 .0

$\begin{array}{llllll}43 & 3 & 0.0 & 0.0 & 0.0\end{array}$

$\begin{array}{lllll}44 & 1 & 0.0 & 0.0 & 0.0\end{array}$

$4420.0 \quad 0.010016 .0$

$\begin{array}{lllll}443 & 0.0 & 0.0 & 0.0\end{array}$

$\begin{array}{lllll}45 & 1 & 0.0 & 0.0 & 0.0\end{array}$

4520.00 .010016 .0

$\begin{array}{lllll}45 & 3 & 0.0 & 0.0 & 0.0\end{array}$

$\begin{array}{lllll}46 & 1 & 0.0 & 0.0 & 0.0\end{array}$

$\begin{array}{lllll}46 & 2 & 0.0 & 0.0 & 10016.0\end{array}$

$\begin{array}{lllll}46 & 3 & 0.0 & 0.0 & 0.0\end{array}$

$\begin{array}{llllll}47 & 1 & 0.0 & 0.0 & 0.0\end{array}$

4720.00 .010016 .0

$\begin{array}{lllll}47 & 3 & 0.0 & 0.0 & 0.0\end{array}$

4810.00 .00 .0

$4820.0 \quad 0.010016 .0$

$\begin{array}{lllll}48 & 3 & 0.0 & 0.0 & 0.0\end{array}$

$\begin{array}{lllllllll}49 & 1 & 0.0 & 0.0 & 0.0\end{array}$

4920.00 .010016 .0

$\begin{array}{lllll}49 & 3 & 0.0 & 0.0 & 0.0\end{array}$

$\begin{array}{llllllll}50 & 1 & 0.0 & 0.0 & 0.0\end{array}$

50 $20.0 \quad 0.010016 .0$

$\begin{array}{llllll}50 & 3 & 0.0 & 0.0 & 0.0\end{array}$ 


\subsection{2}

5.2.2 OUTPUT FROM RUNNING THE RUNDYN SUB-PROGRAM

GEODYN was run using the input file just generated. The information reported next is representative of the data obtained from this run: 
FIGURE 5.2.2.1: Selected RUNDYN Output Qualification-Type Test Case

\begin{tabular}{|c|c|c|c|c|}
\hline $\begin{array}{c}\text { Print } \\
\text { Station\# }\end{array}$ & D.0.F.\# & $\begin{array}{c}\text { Displ. } \\
\text { (in) }\end{array}$ & $\begin{array}{c}\text { Velocity } \\
(\text { in/s) }\end{array}$ & $\begin{array}{c}\text { Acceleration } \\
(\text { in/s })\end{array}$ \\
\hline 1 & 3 & $.3571 \mathrm{E}-2$ & $.1429 \mathrm{E} 1$ & $.5714 \mathrm{E} 3$ \\
5 & 27 & $.3571 \mathrm{E}-2$ & $.1428 \mathrm{E} 1$ & $.5713 \mathrm{E} 3$ \\
& 3 & $.5381 \mathrm{EO}$ & $.8515 \mathrm{E} 1$ & $-.1071 \mathrm{E} 4$ \\
10 & 27 & $.5381 \mathrm{EO}$ & $.8515 \mathrm{E} 1$ & $-.1072 \mathrm{E} 4$ \\
& 3 & $.1016 \mathrm{E} 1$ & $.1652 \mathrm{E} 2$ & $-.7960 \mathrm{E} 3$ \\
15 & 27 & $.1016 \mathrm{E} 1$ & $.1652 \mathrm{E} 2$ & $-.7969 \mathrm{E} 3$ \\
& 3 & $.9085 \mathrm{EO}$ & $.1118 \mathrm{E} 2$ & $.1112 \mathrm{E} 4$ \\
20 & 27 & $.9085 \mathrm{E} 0$ & $.1118 \mathrm{E} 2$ & $.1112 \mathrm{E} 4$ \\
& 3 & $.8655 \mathrm{EO}$ & $-.6298 \mathrm{EO}$ & $.1628 \mathrm{E} 4$ \\
& 27 & $.8655 \mathrm{EO}$ & $-.6296 \mathrm{EO}$ & $.1628 \mathrm{E} 4$ \\
& 3 & $.9194 \mathrm{EO}$ & $-.1175 \mathrm{E} 2$ & $.9755 \mathrm{E} 3$ \\
& 27 & $.9194 \mathrm{EO}$ & $-.1175 \mathrm{E} 2$ & $.9763 \mathrm{E} 3$ \\
\hline
\end{tabular}


6.0 OVERVIEW OF INPUT DATA

The purpose of the information presented in this section is to alert the user to the types of data that should be available as input to the program prior to commencing a program execution. This data is graphically presented in groups of similar information, and is essentially in the same order as it is requested by the program. In addition, reference is made to sections of this manual which give more detail about the nature of the input data.

\subsection{OVERVIEW OF GENDYN INPUT}

The following is an illustration of the major types of data required to generate a finite element model by running GENDYN:

NUMBER AND TYPES OF ELEMENTS UTILIZED IN MODEL $\longrightarrow$ Refer to Section 2.1

NUMBER OF NODES IN ELEMENTS AND IN TOTAL MODEL $\longrightarrow$ Refer to Sub-Sections in 2.1

NUMBER OF DIFFERENT MATERIAL TYPES AVAILABLE FOR EACH ELEMENT TYPE AND THE FORMATION

NUMBER OF EXTERNAI, INTERNAL, AND TIED (CONSTRAINED) DRILI STRING NODES

$\longrightarrow$ Refer to Sections $2.3 .2,2.3 .3$, and 2.3 .4

NUMBER OF GHOST CUTTERS, CHARACTERISTIC PLANES, AND BIT SURFACES

$\longrightarrow$ Refer to Sections $2.1 .4,2.2 .1$, and 2.2 .2 


\section{2}

SPECIFY TYPE AND POSITION CODES FOR EACH ELEMENT IN THE MODEL

$\longrightarrow$ Refer to Section 2.1

SPECIFY MATERIAI PROPERTIES FOR EACH MATERIAL TYPE

$\longrightarrow$ Refer to Sub-Sections in 2.1

INPUT A IENGTH FOR EACH GHOST CUTTER

$\longrightarrow$ Refer to Section 2.1.4

INPUT DRILI STRING NODAL COORDINATES

$\longrightarrow$ Refer to Sections $3.2,3.2 .1$, and 3.3

INPUT GHOST CUTTER SUB-NODE COORDINATES

$\longrightarrow$ Refer to Sections 2.1.4, 3.2, 3.2.1, and 3.3

INPUT ELEMENT CONNECTIVITY FOR 8-NODE BRICKS

AND IINEAR BEAMS

$\longrightarrow$ Refer to Sections 2.1 .1 and 2.1 .2

INPUT GHOST CUTTER DEFINITIONS (CONNECTIVITY)

$\longrightarrow$ Refer to Section 2.1.4 
DEFINE GHOST CUTTER CHARACTERISTIC PLANES

$\longrightarrow$ Refer to Section 2.2.1

DEFINE BIT SURFACES ASSOCIATED WITH GHOST CUTTERS

$\longrightarrow$ Refer to Section 2.2.2

SPECIFY UP-STRING SPRING CONSTANTS FOR

IMPOSITION OF BOUNDARY CONDITIONS

$\longrightarrow$ Refer to Section 2.4.2

INPUT ALI EXTERNAL DRILI, STRING NODES Refer to Section 2.3.2

INPUT ALL TIED BIT NODES

$\longrightarrow$ Refer to Sections $2.3 .4,2.4$, and 2.4 .1

INPUT ALL INTERNAL DRILI, STRING NODES

$\longrightarrow$ Refer to Section 2.3 .3

INPUT STIFFNESS "NORMALIZATION FACTOR"

$\longrightarrow$ Refer to Section 2.5 
6.2 OVERVIEW OF RUNDYN INPUT

The following is an illustration of the major types of data required to perform a dynamic analysis by running RUNDYN. Note that input data pertaining to a formation mesh is only necessary if a formation is included in the analysis:

SPECIFY THE NUMBER OF MODES TO CONSIDER IN THE CURRENT ANALYSIS

$\longrightarrow$ Refer to Section 2.6

SPECIFY HOW MANY TIMES GREATER A DIAGONAL TERM

OF A MATRIX MUST BE THAN AN OFF-DIAGONAL TERM

IN ORDER THAT A MATRIX MAY BE CONSIDERED

TO BE DIAGONAL

$\longrightarrow$ Refer to Section 2.6

DEFINE THE FORMATION MESH, IF THERE IS A FORMATION. INCLUDES THE BOTTOM, INCLINE AND SIDEWALL PORTIONS

$\longrightarrow$ Refer to Sections 2.7 .0 and 3.6 through 3.6 .2

DEFINE PENETRATION COORDINATES FOR BOTTOM,

INCLINE, AND SIDEWALL PORTIONS OF

THE FORMATION

$\longrightarrow$ Refer to Sections 3.2 .4 and 3.6 .2

through $3 \cdot 6 \cdot 2 \cdot 2$ 
ASSIGN MATERIAL PROPERTIES TO FORMATION POINTS $\longrightarrow$ Refer to Section 3.6.3

SPECIFY THE ROTARY SPEED OF THE DRILL STRING AND THE NUMBER OF REVOLUTIONS (OR FRACTION OF) TO BE USED IN THE ANALYSIS

$\longrightarrow$ Refer to Sections 3.2 .1 and 3.3

SPECIFY SOLUTION ALGORITHM PARAMETERS:

TIME STEP SIZE, NUMBER OF TIME STEPS, NUMBER OF TIME STEPS TO ACCOMPLISH SMART-UP IF APPIICABLE

$\longrightarrow$ Refer to Sections 2.8 and 2.8 .1

SPECIFY MAXIMUM NUMBER OF ITERATIONS ALLOWED

FOR A CONVERGED SOLUTION, AND THE CONVERGENCE TOLERANCE

$\longrightarrow$ Refer to Sections 2.8 .2 and 2.8 .3

SPECIFY NUMBER OF TIME STEPS BETWEEN PRINT

STATIONS, PLOT STATIONS, AND RE-START

STATIONS - IF APPLICABLE

$\longrightarrow$ Refer to Section 2.8.4 
7.0 UTILITY PROGRAMS AND THEIR UTILIZATION

To assist the user in running the GEODYN program, several utility programs exist. Typically, these separate programs help the user create files which are either necessary or helpful for running GEODYN. This section discusses how to use these utility programs, and what they do.

\subsection{INPUT FILE}

Input for the GEODYN program may be completely interactive (user types data in as program executes), or it may come from an interactively generated input file (when the program is run using such a file, it is referred to as a non-interactive run). If several runs are to be made using very similar models, it may be convenient to have the program input stored in a file and read in when needed. This relieves the user from the task of re-typing all of the model geometry, element definitions, etc. for similar models, and allows the user to simply edit appropriate entries in the input file instead.

Generation of an input file is no more difficult than entering input interactively by actually running the GEODYN program. While generating an input file, the user will not even be aware that he or she is not actually running GEODYN. This is 
because the user is asked to input data interactively in the exact same order that GEODYN asks for input. Furthermore, all error checks on input used in GEODYN are also incorporated into the input file generation routine. Each response that the user types in is automatically written to an input file.

\subsubsection{FILES ASSOCIATED WITH INPUT FILE GENERATION}

The user is expected to assign a six character name for both the name of the file which is to contain input data, and the name of the file which is to contain output data. The input file generating routine requests the user to provide these names, which are entirely up to the user's discretion. They are automatically stored in a file called FNAME.DAT. When the non-interactive version of GEODYN is executed, this FNAME.DAT file is automatically opened and read. The program is then instructed to open an input file having the user-specified name, and automatically read all input data from this file. At the same time, it opens an output file having the user-specified name, and writes various output data to this file.

To Create An Input File: RUN GEOIN

User prompted for : Name of input file?

User prompted for : Name of output file?

User prompted for : AII GEODYN program input. 


\begin{abstract}
Files Created: FNAME.DAT - Contains name of input and output files.

INNAME.DAT - Contains all input data to run GEODYN. INNAME is the user specified name.
\end{abstract}

NOTE: When the non-interactive version of GEODYN is executed, the files FNAME.DAT and INNAME.DAT (or whatever the user decides to call it) must be available! If either one is not available, an error will occur and execution will be terminated! Also, if a new input file has been generated since the last run, and it has a different name, then the file FNAME.DAT will contain the names most recently specified for input and output files. So be certain that when you execute GEODYN (non-interactively) the file FNAME.DAT contains the names of the files you want to use for input and output! The file names currently in FNAME.DAT may be verified by simply typing the file. Furthermore, if you try to write output to a file which already exists, the data in this existing output file will be over-written. If you really want the same output file name for a subsequent run, but still want to retain the previous output data, rename the old output file! 


\subsection{EXTERNAL FORCE FILE}

The external forces which are applied to the six degrees-offreedom at the top of the drill string at each time step must be stored in a file. During the execution of a dynamic solution, these forces are read in from this file. For convenience, a small program may be run which creates this file by interactively requesting necessary external force input from the user, and writing the user's responses to the external force file.

\subsubsection{FILES ASSOCIATED WITH EXTERNAI FORCE FILE GENERATION}

The external force file which is automatically generated has the form:

\begin{tabular}{ccccccc}
\hline Time Step \#1 & Fx & Fy & Fz & Mx & $M y$ & $M z$ \\
Time Step \#2 & Fx & Fy & Fz & Mx & My & Mz \\
$:$ & $:$ & $:$ & $:$ & $:$ & $:$ & $:$ \\
Time Step \#n & Fx & $\dot{F y}$ & $\dot{F}_{z}$ & $\dot{M x}$ & $\dot{M y}$ & $\dot{M}_{z}$ \\
\hline
\end{tabular}

The user is requested to input the number of time steps for the current run before this file is created. 
To Create An External Force File: RUN EXTFRC

User prompted for: Number of time steps for the solution

User prompted for: The time step number, followed by the values of the six external

forces at this time step.

Files Created: EXTFRC.DAT - The external force file in the correct format to be read by GEODYN .

NOTE: When GEODYN is executed for a dynamic solution, the external force file EXTFRC.DAT must be available, or an error will occur and execution will be terminated. 
VIII. DISTRIBUTION

TID-4500-R66-UC-66c (507)

Tom Anderson

Drilling Fluid Consultants

17726 S. W. Overlook Ln

Lake Oswego, OR 97034

Ed Bingman

Shell Oil Company

Two Shell Plaza

P.O. Box 2099

Houston, TX 77001

Larry Diamond

Dyna-Drill

P.O. Box C-19576

Irvine, CA 92713

Tom Turner

Phillips Petroleum Company Geothermal Operations

655 East 4500 South

Salt Lake City, UT 84107

Jim Kingsolver

Geothermal Operations

Smith Tool

P.O. Box C-19511

Irvine, CA 92713

John C. Rowley

Los Alamos National Labs

Mail Stop D-461

Los Alamos, NM 87545

Ed Martin (2)

Superior Oil

Eastern Division

P.0. Box 51108 OCS

Lafayette, LA 70505
B.J. Livesay

2616 Angell Avenue

San Diego, CA 92122

Ben Bradford

Dowell

P.O. Box 2710

Tulsa, OK 74102

Gene Polk

NL Baroid

P.O. Box 280

Sandia Park, NM 87047

James W. Langford

Security Division

Dresser Industries, Inc.

P.0. Box 24647

Dallas, TX 75224

John E. Fontenot

NL, MWD

P.O. Box 60070

Houston, TX 77205

Del E. Pyle

Union Geothermal Division

Union Oil Co. of California

Union Oil Center

Los Angeles, CA 90017

William D. Rumbaugh

Research \& Development

ot is

P.O. Box 34380

Dallas, TX 75234

Dwight Smith

Halliburton

Drawer 1431

Duncan, OK 73533 
Tom Warren

Amoco Production Company

Research Center

P.O. Box 591

Tulsa, Ok 74102

H.E. Mallory

P.0. Box 54696

Tulsa, OK 74144

Jim Combs

Geothermal Resources Int'l Inc. 545 Middlefield, Rd., Suite 200 Menlo Park, CA 94025

Dr. Melvin Friedman

Dept. of Geology

Texas A \& M University

Jerry Baird (10)

Jordan, Apostal, Ritter Associates, Inc.

Administration Building 7

Davisville, RI 02854

U.S. Department of Energy

Geothermal \& Hydropower

Technologies Division

Forrestal Bldg., CE 324

1000 Independence Ave. S.W.

Washington, D.C. 20585

ATTN: J. Bresee

R. Toms

D. Allen
W.P. Grace, DOE/ALO

Nuclear \& Geosciences Division

3141

3151

C. Ostrander (5)

6000

W.L. Garner (3)

6200

6240

6241

6241

6246

6247

6250

6330

8424

1521

7542

6241

E.H. Beckner

V.L. Dugan

R.K. Traeger

J.R. Kelsey (10)

B.C. Caskey (10)

B. Granoff

P.J. Hommert

B.W. Marshall

W.D. Weart

M.A. Pound

C.M. Stone

T.G. Carne

J.T. Finger

Umesh Chandra (2)

$\mathrm{NL}$ Industries, MWD

P.O. Box 60070

Houston, TX 77205

A. Aduci

U.S. Department of Energy

San Francisco Operations Office 1333 Broadway

Wells Fargo Building

Oakl and, CA 94612

Dr. Victor A. Dunayevsky

The Standard Oil Co. (Ohio)

4440 Warrensville Ctr. Road

Cleveland, $\mathrm{OH} 44128$

David A. Clark

Conoco, Inc.

P.O. Box 1267

Ponca City, OK 74603 